\title{
COMPARATIVE SURVIVAL STUDY (CSS) of PIT-tagged Spring/Summer Chinook and Summer Steelhead
}

\section{Annual Report}

\author{
Project No. 1996-020-00 \\ BPA Contract No. 37369-CSS \\ BPA Contract No. 35850-FPC
}

Prepared by

Comparative Survival Study Oversight Committee and Fish Passage Center:

Thomas Berggren, Jack Tuomikoski, and Sergei Rassk, Fish Passage Center Howard Schaller, Paul Wilson, and Steve Haeseker, U.S. Fish and Wildlife Service Earl Weber, Columbia River Intertribal Fish Commission Charlie Petrosky, Idaho Department of Fish and Game Eric Tinus and Tim Dalton, Oregon Department of Fish and Wildlife

Robin Ehlke, Washington Department of Fish and Game

Project Leader: Michele DeHart, Fish Passage Center

\section{Final}

11/25/08 



\section{Table of Contents}

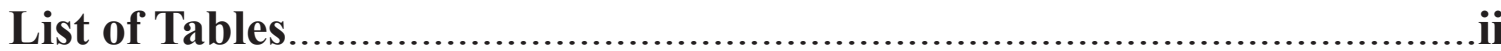

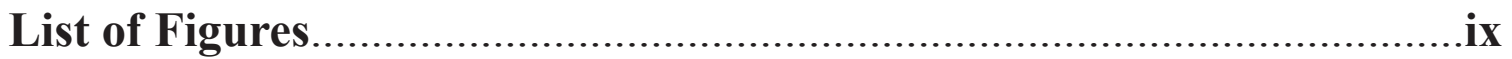

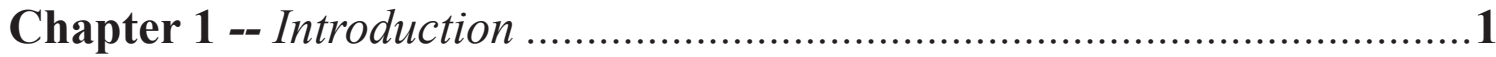

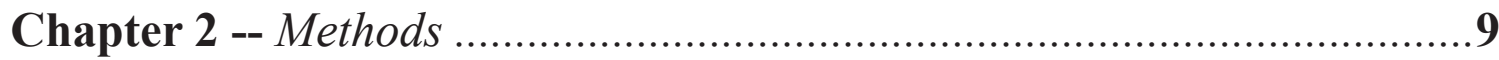

Chapter 3-- Annual SAR by Study Category, TIR, $S_{R}$, and D for Hatchery and Wild Spring/Summer Chinook Salmon and Steelhead: Patterns and Significance

Chapter 4 -- Evaluation of Smolt Size Effects on Collection at Lower Granite and Little Goose Dams

Chapter 5 -- Associations between smolt outmigration experience

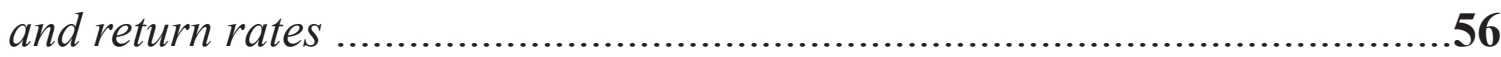

Chapter 6 -- Overall Annual SAR Patterns .............................................63

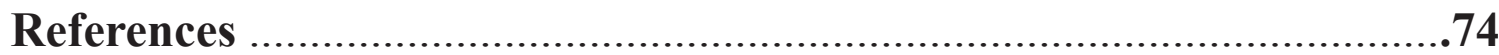

Appendix A -- Supporting Tables of PIT-Tag Marking Data and Estimates of Survival and Major CSS Parameters

Appendix B -- CSS Planned PIT-tagging Activity for 2009 and Assessment of Sample Size Requirements. 


\section{List of Tables}

Table 3.1. Estimated SAR LGR-to-LGR $(\%)$ for PIT-tagged wild Chinook in annual aggregate for each study category from 1994 to 2006 (with 90\% confidence intervals) 21

Table 3.2. PIT-tagged wild Chinook estimated $\theta$ for TIR and D and corresponding lower limit of non-parametric confidence interval, which provides a one-tail $(\alpha=0.05)$ test of $\mathrm{H}_{0}$ : $\theta \leq 1$ versus $\mathrm{H}_{\mathrm{A}}: \theta>1$

Table 3.3. Estimated SAR LGR-to-LGR $(\%)$ for PIT-tagged spring Chinook from Rapid River Hatchery for each study category from 1997 to 2006 (with $90 \%$ confidence intervals) ......

Table 3.4. Estimated SAR LGR-to-LGR $(\%)$ for PIT-tagged spring Chinook from Dworshak Hatchery for each study category from 1997 to 2006 (with 90\% confidence intervals) ......

Table 3.5. Estimated SAR $\mathrm{LGR}_{\text {-to-LGR }}(\%)$ for PIT-tagged spring Chinook from Catherine Creek AP for each study category from 2001 to 2006 (with 90\% confidence intervals) ......

Table 3.6. Estimated SAR LGR-to-LGR $(\%)$ for PIT-tagged summer Chinook from McCall Hatchery for each study category from 1997 to 2006 (with $90 \%$ confidence intervals) ......

Table 3.7. Estimated SAR LGR-to-LGR $(\%)$ for PIT-tagged summer Chinook from Imnaha River AP for each study category from 1997 to 2006 (with 90\% confidence intervals) ......

Table 3.8. Estimated TIR and corresponding lower limit of non-parametric confidence interval, which provides a one-tail $(\alpha=0.05)$ test of H0: TIR $\leq 1$ versus HA: TIR $>1$, of PIT-tagged wild Chinook compared to hatchery spring Chinook

Table 3.9. Estimated TIR and corresponding lower limit of non-parametric confidence interval, which provides a one-tail $(\alpha=0.05)$ test of H0: TIR $\leq 1$ versus HA: TIR $>1$, of PIT-tagged wild Chinook compared to hatchery summer Chinook

Table 3.10. Estimated D and corresponding lower limit of non-parametric confidence interval, which provides a one-tail $(\alpha=0.05)$ test of H0: $\mathrm{D} \leq 1$ versus HA: $\mathrm{D}>1$, of PITtagged wild Chinook compared to hatchery spring Chinook

Table 3.11. Estimated D and corresponding lower limit of non-parametric confidence interval, which provides a one-tail $(\alpha=0.05)$ test of H0: $\mathrm{D} \leq 1$ versus HA: $\mathrm{D}>1$, of PITtagged wild Chinook compared to hatchery summer Chinook

Table 3.12. Estimated SARLGR-to-LGR (\%) for PIT-tagged wild steelhead in annual aggregate for each study category from 1997 to 2005 (with $90 \%$ confidence intervals) .....

Table 3.13. Estimated TIR and corresponding lower limit of non-parametric confidence interval, which provides a one-tail $(\alpha=0.05)$ test of H0: TIR $\leq 1$ versus HA: TIR $>1$, of PIT-tagged wild steelhead compared to wild Chinook. 
Table 3.14. Estimated D and corresponding lower limit of non-parametric confidence interval, which provides a one-tail $(\alpha=0.05)$ test of $\mathrm{H} 0$ : $\mathrm{D} \leq 1$ versus HA: D $>1$, of PITtagged wild steelhead compared to wild Chinook

Table 3.15. Estimated SARLGR-to-LGR (\%) for PIT-tagged hatchery steelhead in annual aggregate for each study category from 1997 to 2005 (with 90\% confidence intervals)

Table 3.16. Estimated TIR and corresponding lower limit of non-parametric confidence interval, which provides a one-tail $(\alpha=0.05)$ test of H0: TIR $\leq 1$ versus HA: TIR $>1$, of PIT-tagged hatchery steelhead compared to wild steelhead 38

Table 3.17. Estimated D and corresponding lower limit of non-parametric confidence interval, which provides a one-tail $(\alpha=0.05)$ test of $\mathrm{H} 0$ : $\mathrm{D} \leq 1$ versus HA: $\mathrm{D}>1$, of PITtagged hatchery steelhead compared to wild steelhead

Table 5.1. Counts of adults at LGR and BON for all CSS groups for the migration years 2003-2005. Counts are shown for fish with two different routes of passage as emigrating juveniles (transported [T0] and in-river groups [CX]). The "adds" column is for any individual adults seen at any upstream facility (MCA, ICH, or LGR) and not seen at BON; BON efficiency is calculated with these counts

Table 5.2. Adult success rates for all CSS groups for the migration years 2003-2005. Adult success rate for the transported(T0) and in-river groups (CX), and the ratio T0/CX are each shown with their $90 \%$ confidence interval

Table 6.1. Study-specific SARs and weights (estimated proportion of run-at-large reflected by each study category) used to estimate the annual SARs for wild Chinook with jacks excluded ....

Table 6.2. Study-specific SARs and weights (estimated proportion of run-at-large reflected by each study category) used to estimate the annual SARs for hatchery Chinook with jacks excluded

Table 6-3. Study-specific SARs and weights (estimated proportion of run-at-large reflected by each study category) used to estimate the annual SARs for wild Chinook with jacks included

Table 6.4. Study-specific SARs and weights (estimated proportion of run-at-large reflected by each study category) used to estimate the annual SARs for hatchery Chinook with jacks included

Table 6.5. Comparison of estimated overall annual SARs between original weighted SARs method and pre-assigned Group TWS method for 2-salt returns from 2006 wild and hatchery juvenile spring/summer Chinook migration

Table 6.6. Study-specific SARs and weights (estimated proportion of run-at-large reflected by each study category) used to estimate the annual SARs for wild steelhead .....

Table 6.7. Study-specific SARs and weights (estimated proportion of run-at-large reflected by each study category) used to estimate the annual SARs for hatchery steelhead

Table A-1. Number of PIT-tagged wild Chinook parr/smolts from the four tributaries above Lower Granite Dam and Snake River trap used in the CSS analyses for migration years 1994 to 2006 
Table A-2. Hatchery spring/summer Chinook PIT-tagged and released in Snake River basin specifically for CSS (long time series), 1997 to 2006

Table A-3. Number of PIT-tagged wild steelhead smolts from four tributaries above Lower Granite Dam (plus Snake River trap) used in the CSS for migration years 1997 to 2005

Table A-4. Number of PIT-tagged hatchery steelhead smolts from four tributaries above Lower Granite Dam (plus mainstem Snake River) used in the CSS for migration years 1997 to 2005

Table A-5. Estimated number of PIT-tagged wild Chinook (aggregate of fish tagged in 10-month period between July 25 and May 20) arriving Lower Granite Dam in each of the three study categories from 1994 to 2006 (with 90\% confidence intervals), with detected adults at Lower Granite (GRA) and Bonneville (BON) adult ladders

Table A-6. Estimated number of PIT-tagged spring Chinook from Rapid River Hatchery arriving Lower Granite Dam in each of the three study categories from 1997 to 2006 (with 90\% confidence intervals), with detected adults at Lower Granite (GRA) and Bonneville (BON) adult ladders

Table A-7. Estimated number of PIT-tagged spring Chinook from Dworshak Hatchery arriving Lower Granite Dam in each of the three study categories from 1997 to 2006 (with 90\% confidence intervals), with detected adults at Lower Granite (GRA) and Bonneville (BON) adult ladders

Table A-8. Estimated number of PIT-tagged spring Chinook from Catherine Creek Acclimation Pond arriving Lower Granite Dam in each of the three study categories from 2001 to 2006 (with 90\% confidence intervals), with detected adults at Lower Granite (GRA) and Bonneville (BON) adult ladders

Table A-9. Estimated number of PIT-tagged summer Chinook from McCall Hatchery arriving Lower Granite Dam in each of the three study categories from 1997 to 2006 (with 90\% confidence intervals), with detected adults at Lower Granite (GRA) and Bonneville (BON) adult ladders

Table A-10. Estimated number of PIT-tagged summer Chinook from Imnaha River Acclimation Pond arriving Lower Granite Dam in each of the three study categories from 1997 to 2006 (with 90\% confidence intervals), with detected adults at Lower Granite (GRA) and Bonneville (BON) adult ladders

Table A-11. Estimated number of PIT-tagged wild steelhead (aggregate of tagged fish $>130 \mathrm{~mm}$ released in 12-month period between July 1 and June 30) arriving Lower Granite Dam in each of the three study categories from 1997 to 2005 (with $90 \%$ confidence intervals), with detected adults at Lower Granite (GRA) adult ladders

Table A-12. Estimated number of PIT-tagged hatchery steelhead (aggregate of tagged fish released in 3-month period between April 1 and June 30) arriving Lower Granite Dam in each of the three study categories from 1997 to 2005 (with 90\% confidence intervals), with detected adults at Lower Granite (GRA) adult ladders 
Table A-13. Estimated in-river survival LGR to BON (SR), TIR, and D of PIT-tagged wild Chinook for migration years 1994 to 2006 (with 90\% confidence intervals)

Table A-14. Estimated in-river survival LGR to BON (SR), TIR, and D of PIT-tagged Rapid River Hatchery spring Chinook for 1997 to 2006 (with 90\% confidence intervals)

Table A-15. Estimated in-river survival LGR to BON (SR), TIR, and D of PIT-tagged Dworshak Hatchery spr+ing Chinook for 1997 to 2006 (with 90\% confidence intervals)

Table A-16. Estimated in-river survival LGR to BON (SR), TIR, and D of PIT-tagged Catherine Creek AP spring Chinook for 2001 to 2006 (with 90\% confidence intervals)

Table A-17. Estimated in-river survival LGR to BON (SR), TIR, and D of PIT-tagged McCall Hatchery summer Chinook for 1997 to 2006 (with 90\% confidence intervals)

Table A-18. Estimated in-river survival LGR to BON (SR), TIR, and D of of PITtagged Imnaha AP summer Chinook for 1997 to 2006 (with 90\% confidence intervals)

Table A-19. Estimated in-river survival LGR to BON (SR), TIR, and D of PIT-tagged wild steelhead for migration years 1997 to 2005 (with 90\% confidence intervals)

Table A-20. Estimated in-river survival LGR to BON (SR), TIR, and D of PIT-tagged hatchery steelhead for migration years 1997 to 2005 (with $90 \%$ confidence intervals)

Table A-21. In-river smolt survival rate estimates through hydrosystem for the PIT-tag aggregate of wild spring/summer Chinook in migration years 1994 to 2006

Table A-22. In-river smolt survival rate estimates from hatchery to LGR and through reaches in the hydrosystem for PIT-tagged Rapid River Hatchery spring Chinook in migration years 1997 to 2006 A-16

Table A-23. In-river smolt survival rate estimates from hatchery to LGR and through reaches in the hydrosystem for PIT-tagged Dworshak Hatchery spring Chinook in migration years 1997 to 2006 A-17

Table A-24. In-river smolt survival rate estimates from hatchery to LGR and through reaches in the hydrosystem for PIT-tagged Catherine Creek Acclimation Pond spring Chinook in migration years 2001 to 2006 .... .A-18

Table A-25. In-river smolt survival rate estimates from hatchery to LGR and through reaches in the hydrosystem for PIT-tagged McCall Hatchery summer Chinook in migration years 1997 to 2006 A-19

Table A-26. In-river smolt survival rate estimates from hatchery to LGR and through reaches in the hydrosystem for PIT-tagged Imnaha Acclimation Pond summer Chinook in migration years 1997 to 2006 A-20 
Table A-27. In-river smolt survival rate estimates through reaches in the hydrosystem for the PIT-tag aggregate of wild summer steelhead in migration years 1997 to 2005

Table A-28. In-river smolt survival rate estimates through reaches in the hydrosystem for the PIT-tag aggregate of hatchery summer steelhead in migration years 1997 to 2005

Table A-29. Age composition of returning PIT-tagged wild Chinook jacks and adults detected at Lower Granite Dam that were PIT-tagged during the 10-month period from July 25 to May 20 for each migration year between 1994 and 2006

Table A-30. Age composition of returning PIT-tagged wild steelhead adults detected at Lower Granite Dam that were PIT-tagged during the 12-month period from July 1 to June 30 for each migration year between 1997 and 2005

Table A-31. Age composition of returning PIT-tagged hatchery steelhead adults detected at Lower Granite Dam that migrated as smolts in 1997 to 2005

Table A-32. Age composition of returning PIT-tagged hatchery Summer Chinook adults and jacks detected at Lower Granite Dam that migrated as smolts in 1997 to 2006

Table A-33. Age composition of returning PIT-tagged hatchery Spring Chinook adults and jacks detected at Lower Granite Dam that migrated as smolts in 1997 to 2006

Table A-34. Number of PIT-tagged wild Chinook actually transported from each dam and estimate (ti) of total PIT-tagged wild Chinook that would have been transported if all tagged fish were transported at same rate as the untagged run-at-large, 1994 to 2006

Table A-35. Estimated dam-specific transportation SARs (\%) of the PIT-tagged wild Chinook aggregate for migration years 1994 to 2006 (with 90\% confidence intervals)

Table A-36. Number of PIT-tagged hatchery Chinook actually transported from each dam and estimate (ti) of total PIT-tagged hatchery Chinook that would have been transported if all PIT-tagged fish had been transported at same rate as the untagged run-atlarge

Table A-37. Estimated dam-specific transportation SAR percentages of PIT-tagged hatchery Spring Chinook that outmigrated in 1997 to 2006 (with 90\% confidence intervals)

Table A-38. Estimated dam-specific transportation SAR percentages of PIT-tagged hatchery Summer Chinook that outmigrated in 1997 to 2006 (with 90\% confidence intervals)

Table A-39. Number of PIT-tagged wild steelhead actually transported from each dam and estimate (ti) of total PIT-tagged wild steelhead that would have been transported if all PIT- tagged fish had been transported at same rate as the untagged run-at-large 
Table A-40. Estimated dam-specific transportation SAR percentages of PIT-tagged wild steelhead in the annual aggregate groups for 1997 to 2005 (with 90\% confidence intervals)

Table A-41. Number of PIT-tagged hatchery steelhead actually transported from each dam and estimate (ti) of total PIT-tagged hatchery steelhead that would have been transported if all PIT- tagged fish had been transported at same rate as the untagged runat-large.

Table A-42. Estimated dam-specific transportation SAR percentages of PIT-tagged hatchery steelhead in the annual aggregate groups for 1997 to 2005 (with 90\% confidence intervals) A-29

Table B-1. Average percent coefficient of variation (CV) in the SR, SARs, and TIR based on logarithmic fits of CV versus the number released over migration years 19942004 analyzed in the CSS

Table B.2. Wild Chinook/steelhead and hatchery Chinook smolts to tag for CSS 2009 program

Table B.3. Hatchery steelhead smolts to tag for CSS 2009 program B-8

Table B.4. Hatchery Chinook with TIR point estimates greater than 1.25 sorted by ascending $\operatorname{SAR}(\mathrm{C} 0)$

Table B.5. Hatchery Chinook PIT tagged smolts summarized from 2006 to 2008. Total smolts tagged, smolts in study categories, and the 25th and 50th percentile of LGR juvenile detects are shown

Table B.6. Numbers of PIT tagged smolts released and estimated at Lower Granite Dam in Groups TWS and BWS for hatchery Chinook (2006-2008), wild Chinook (2006-2007), and wild steelhead (2006) B-12

Table B.7. Coordinated 2008 PIT-tagging of hatchery steelhead by IDFG, USFWS, and CSS to create TWS and BWS groups of production fish released from Dworshak, Clearwater, Magic Valley, and Hagerman hatcheries

Table B.8. Numbers of PIT tagged smolts released estimated T1 and C0 smolts at Lower Granite Dam, percent of release in Group TWS, and estimate number of smolts at Lower Granite Dam in Groups TWS and BWS for wild Chinook (2006-2007) and wild steelhead (2006) by drainage and overall aggregate 


\section{List of Figures}

Figure 1.1. Salmonid life cycle in the Snake River and lower Columbia River basins (Source: Marmorek et al. 2004) 2

Figure 1.2. CSS PIT tag release locations and PIT-tag detection sites in the Columbia River Basin

Figure 1.3. CSS PIT-tag release watersheds and PIT-tag detection sites in the Columbia River Basin

Figure 3.1. Estimated LGR-LGR SAR for PIT-tagged wild Chinook aggregate in transport $\left[\operatorname{SAR}\left(\mathrm{T}_{0}\right)\right]$ and in-river $\left[\mathrm{SAR}\left(\mathrm{C}_{0}\right)\right.$ and $\left.\mathrm{SAR}\left(\mathrm{C}_{1}\right)\right]$ study categories for migration years 1994 to 2006 (incomplete adult returns for 2006)

Figure 3.2. Trend in $\operatorname{SAR}\left(\mathrm{C}_{0}\right)$ (top plot), $\operatorname{SAR}\left(\mathrm{C}_{1}\right)$ (middle plot) and $\operatorname{SAR}\left(\mathrm{T}_{0}\right)$ (bottom plot) for PIT-tagged Snake River wild and hatchery spring/summer Chinook in migration years 1994 to 2006

Figure 3.3. Trend in in-river survival $\left(\mathrm{S}_{\mathrm{R}}\right)$ for PIT-tagged Snake River wild and hatchery spring/summer Chinook in migration years 1994 to 2004 .28

Figure 3.4. Trend in TIR (log-transformed) for PIT-tagged Snake river hatchery and wild Chinook for migration years 1994 to 2006 .29

Figure 3.5. Trend in D (log-transformed) for PIT-tagged Snake River hatchery and wild Chinook in migration years 1994-2006 .31

Figure 3.6. Estimated LGR-LGR SAR for PIT-tagged wild steelhead aggregate in transport $\left[\operatorname{SAR}\left(\mathrm{T}_{0}\right)\right]$ and in-river $\left[\operatorname{SAR}\left(\mathrm{C}_{0}\right)\right.$ and $\left.\operatorname{SAR}\left(\mathrm{C}_{1}\right)\right]$ study categories for migration years 1997 to 2005 (incomplete adult returns for 2005) 33

Figure 3.7. Trend in in-river survival $\left(\mathrm{S}_{\mathrm{R}}\right)$ for PIT-tagged Snake River wild steelhead and wild Chinook for migration years 1997 to 2005

Figure 3.8. Trend in TIR (log transformed) for PIT-tagged wild steelhead and wild Chinook from migration years 1997 to 2005

Figure 3.9. Trend in D (log-transformed) for PIT-tagged Snake River wild steelhead and wild Chinook in migration years 1997-2005 .35

Figure 3.10. Estimated LGR-LGR SAR for PIT-tagged hatchery steelhead aggregate in transport $\left[\operatorname{SAR}\left(\mathrm{T}_{0}\right)\right]$ and in-river $\left[\operatorname{SAR}\left(\mathrm{C}_{0}\right)\right.$ and $\left.\operatorname{SAR}\left(\mathrm{C}_{1}\right)\right]$ study categories for migration years 1997 to 2005 (incomplete adult returns for 2005)

Figure 3.11. Trend in in-river survival $\left(S_{R}\right)$ for PIT-tagged Snake River hatchery and wild steelhead for migration years 1997 to 2005

Figure 3.12. Trend in TIR (log-transformed) for PIT-tagged Snake River hatchery and wild steelhead in migration years 1997 to 2005 .

Figure 3.13. Trend in D (log-transformed) for PIT-tagged Snake River hatchery and wild steelhead in migration years 1997-2005 
Figure 4.1. Comparisons of length for detected and undetected wild Chinook in 2003. Panel A and B display a histogram of $1 \mathrm{~mm}$ length bins for the LGR undetected and for LGR detected fish, respectively; panel $\mathrm{C}$ is the cumulative length frequency plots for LGR. Panels D,E, and F display the same information for LGS

Figure 4.2. Comparisons of length for detected and undetected wild Chinook in 2004. Panel A and B display a histogram of 1mm length bins for the LGR undetected and for LGR detected fish, respectively; panel $\mathrm{C}$ is the cumulative length frequency plots for LGR. Panels D,E, and F display the same information for LGS

Figure 4.3. Comparisons of length for detected and undetected wild Chinook in 2005. Panel A and B display a histogram of $1 \mathrm{~mm}$ length bins for the LGR undetected and for LGR detected fish, respectively; panel $\mathrm{C}$ is the cumulative length frequency plots for LGR. Panels D,E, and F display the same information for LGS .... 46

Figure 4.4. Comparisons of length for detected and undetected hatchery Chinook in 2003. Panel A and B display a histogram of $1 \mathrm{~mm}$ length bins for the LGR undetected and for LGR detected fish, respectively; panel $\mathrm{C}$ is the cumulative length frequency plots for LGR. Panels D,E, and F display the same information for LGS 47

Figure 4.5. Comparisons of length for detected and undetected hatchery Chinook in 2004. Panel A and B display a histogram of $1 \mathrm{~mm}$ length bins for the LGR undetected and for LGR detected fish, respectively; panel $\mathrm{C}$ is the cumulative length frequency plots for LGR. Panels D,E, and F display the same information for LGS .... 48

Figure 4.6. Comparisons of length for detected and undetected hatchery Chinook in 2005. Panel A and B display a histogram of $1 \mathrm{~mm}$ length bins for the LGR undetected and for LGR detected fish, respectively; panel $\mathrm{C}$ is the cumulative length frequency plots for LGR. Panels D,E, and F display the same information for LGS .... 49

Figure 4.7. Comparisons of length for detected and undetected wild steelhead in 2003. Panel A and B display a histogram of $1 \mathrm{~mm}$ length bins for the LGR undetected and for LGR detected fish, respectively; panel $\mathrm{C}$ is the cumulative length frequency plots for LGR. Panels D,E, and F display the same information for LGS .50

Figure 4.8. Comparisons of length for detected and undetected wild steelhead in 2004. Panel A and B display a histogram of $1 \mathrm{~mm}$ length bins for the LGR undetected and for LGR detected fish, respectively; panel $\mathrm{C}$ is the cumulative length frequency plots for LGR. Panels D,E, and F display the same information for LGS

Figure 4.9. Comparisons of length for detected and undetected wild steelhead in 2005. Panel A and B display a histogram of $1 \mathrm{~mm}$ length bins for the LGR undetected and for LGR detected fish, respectively; panel $\mathrm{C}$ is the cumulative length frequency plots for LGR. Panels D,E, and F display the same information for LGS ....

Figure 4.10. Comparisons of length for detected and undetected hatchery steelhead in 2003. Panel A and B display a histogram of $1 \mathrm{~mm}$ length bins for the LGR undetected and for LGR detected fish, respectively; panel $\mathrm{C}$ is the cumulative length frequency plots for LGR. Panels D,E, and F display the same information for LGS .... .53

Figure 4.11. Comparisons of length for detected and undetected hatchery steelhead in 2004. Panel A and B display a histogram of $1 \mathrm{~mm}$ length bins for the LGR undetected and for LGR detected fish, respectively; panel $\mathrm{C}$ is the cumulative length frequency plots for LGR. Panels D,E, and F display the same information for LGS . .54 
Figure 4.12. Comparisons of length for detected and undetected hatchery steelhead in 2005. Panel A and B display a histogram of $1 \mathrm{~mm}$ length bins for the LGR undetected and for LGR detected fish, respectively; panel $\mathrm{C}$ is the cumulative length frequency plots for LGR. Panels D,E, and F display the same information for LGS

Figure 5.1. Comparing the adult BON to LGR adult success rate between two groups with different juvenile passage routes (e.g., transported and in-river) ${ }^{1}$. Hatchery Chinook values are shown for individual hatcheries

Figure 5.2. Comparing the $\mathrm{BON}_{\text {juv }}$ to $\mathrm{BON}_{\text {adult }}$ survival rate between two groups with different juvenile passage routes (e.g., transported and in-river) ${ }^{1}$. Hatchery Chinook values are shown for individual hatcheries

Figure 6-1. Bootstrapped SAR (with jacks excluded) and upper and lower CI for wild Chinook and 5 hatchery groups of Chinook for migration years 1997-2006. Migration year 2006 is complete through 2-ocean returns only. The NPCC (2003) minimum 2\% SAR for listed wild populations is shown for reference

Figure 6.2. Two sets of $90 \%$ confidence intervals for Chinook overall SARs. Bootstrapped non parametric $90 \%$ confidence intervals are shown for overall SARs without jacks (dotted outline, grey fill) and with jacks (red outline, no fill). Wild Chinook and 5 groups of hatchery Chinook are shown. Migration year 2006 is complete through 2-ocean returns only .70

Figure 6.3. Bootstrapped SAR and upper and lower CI for aggregate wild Snake River steelhead, migration years 1997-2005. The NPCC (2003) minimum 2\% SAR for listed wild populations is shown for reference

Figure 6.4. Bootstrapped SAR and upper and lower CI for aggregate wild hatchery Snake River steelhead, migration years 1997-2005. The NPCC (2003) minimum 2\% SAR for listed wild populations is shown for reference

Figure B-1. Percent coefficient of variation $(C V)$ in LGR-BON survival $\left(S_{R}\right)$ for wild and hatchery steelhead and Chinook over migration years 1994-2004 analyzed in the CSS. The solid line depicts a logarithmic fit to the data, $\mathrm{CV}\left(\mathrm{S}_{\mathrm{R}}\right)=129.7-10.7$ $\log _{\mathrm{e}}($ Release $)$

Figure B-2. Percent coefficient of variation (CV) for SARs of C0 and T0 migration groups for wild and hatchery steelhead and Chinook over migration years 1994-2004 analyzed in the CSS. The solid line depicts a logarithmic fit to the data, $\mathrm{CV}(\mathrm{SAR})=152.8$ $-12.3$

Figure B-3. Percent coefficient of variation (CV) for the TIR of wild and hatchery steelhead (STH) and Chinook (CHN) over migration years 1994-2004 analyzed in the CSS. The solid line depicts a logarithmic fit to the data, CV(TIR) $=181.8-13.5$ $\log _{\mathrm{e}}($ Release $)$

Figure B-4. Sample size needed to detect a statistical difference in SARs (a one tailed test where $\alpha=0.05$ ). The $\mathrm{x}$ axis is the value of the lower of the two SARs tested. The number of smolts required at LGR is shown on the y axis. Each colored line displays a different magnitude in difference between two SARs

Figure B-5. Coefficient of variation around $S_{R}$ plotted vs. in-river smolt numbers at LGR. All points are for years when $S_{R}$ was estimated from LGR to BON without expansion. Estimates for 2007 (filled blue circles) and 2008 (filled red circles) are preliminary 
Figure B-6. Timing of PIT-tagged hatchery steelhead at Lower Granite Dam in 2008 that originated in the Clearwater (CLW) and Salmon (SAL) rivers based on run type (A- or B-run). Fish pre-assigned to study categories TWS and BWS prior to hatchery release, so timing at Lower Granite Dam (first dam encountered) should be nearly identical with only slight random variation, as demonstrated in this plot 


\section{Chapter 1 -- Introduction}

The Comparative Survival Study (CSS; BPA Project 199602000) began in 1996 with the objective of establishing a long term dataset of the survival rate of annual generations of salmon from their outmigration as smolts to their return to freshwater as adults to spawn (smolt-to-adult return rate; SAR). The study was implemented with the express need to address the question whether collecting juvenile fish at dams and transporting them downstream in barges and trucks and releasing them downstream of Bonneville Dam was compensating for the effect of the Federal Columbia River Power System (FCRPS) on survival of Snake Basin spring/summer Chinook salmon migrating through the hydrosystem.

The Completion of this annual report for the CSS signifies the $12^{\text {th }}$ outmigration year of hatchery spring/summer Chinook salmon marked with Passive Integrated Transponder (PIT) tags as part of the CSS and the $9^{\text {th }}$ complete brood year return as adults of those PIT-tagged fish (report covers adult returns from 1997-2006 hatchery Chinook juvenile migrations). In addition, the CSS has provided PIT-tags to on-going tagging operations for wild Chinook since 2002 (report covers adult returns from 19942006 wild Chinook juvenile migrations). The CSS tags wild steelhead on the lower Clearwater River and utilized wild and hatchery steelhead from other tagging operations in evaluations of transportation (report covers adult returns from 1997-2005 wild and hatchery steelhead migrations).

The primary purpose of this report is to update the time series of smolt-toadult survival rate data and related parameters with additional years of data since the completion of the CSS 10-yr retrospective analysis report (Schaller et al 2007). The 10 -yr report provided a synthesis of the results from this ongoing study, the analytical approaches employed, and the evolving improvements incorporated into the study as reported in CSS annual progress reports. This current report specifically addresses the constructive comments of the most recent regional technical review conducted by the Independent Scientific Advisory Board and Independent Scientific Review Panel (ISAB and ISRP 2007). This report completes the 3-salt returns from migration years 2004 for wild and hatchery Chinook and steelhead (all returns are to Lower Granite Dam). For wild and hatchery Chinook, this report also provides 3-salt returns from migration year 2005 and 2-salt returns from migration year 2006 through a cutoff date of August 13, 2008. For wild and hatchery steelhead, it provides completed 2 -salt returns for wild and hatchery steelhead that outmigrated in 2005 (any 3-salt returns of PIT-tagged steelhead are few, but will occur after July 1, 2008).

All of the Chinook salmon evaluated in the CSS study exhibit a stream-type life history. All study fish used in this report were uniquely identifiable based on a PIT-tag implanted in the body cavity during (or before) the smolt life stage and retained through their return as adults. These tagged fish can then be detected as juveniles and adults at several locations of the Snake and Columbia rivers. Reductions in the number of individuals detected as the tagged fish grow older provide estimates of survival. This allows comparisons of survival over different life stages between fish with different experiences in the hydrosystem (e.g. transportation vs. in-river migrants and migration through various numbers of dams) as illustrated in Figure 1.1. 


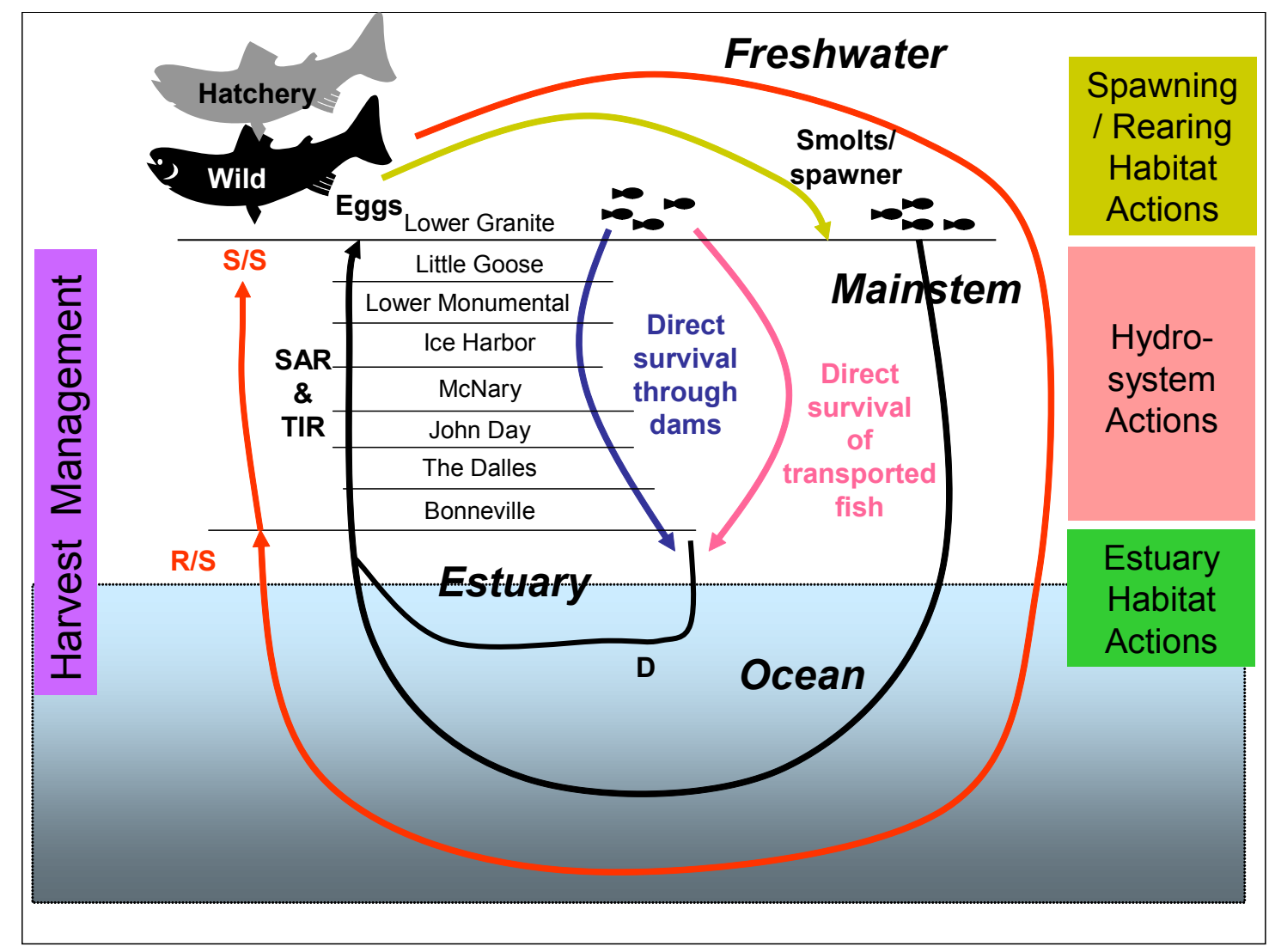

Figure 1.1. Salmonid life cycle in the Snake River and lower Columbia River basins (Source: Marmorek et al. 2004).

The CSS is a long term study within the Northwest Power and Conservation Council's Columbia Basin Fish and Wildlife Program (NPCC FWP) and is funded by Bonneville Power Administration (BPA). Study design and analyses are conducted through a CSS Oversight Committee with representation from Columbia River InterTribal Fish Commission (CRITFC), Idaho Department of Fish and Game (IDFG), Oregon Department of Fish and Wildlife (ODFW), U.S. Fish and Wildlife Service (USFWS), and Washington Department of Fish and Wildlife (WDFW). The Fish Passage Center (FPC) coordinates the PIT-tagging efforts, data management and preparation, and CSSOC work. The location of all tagging sites is identified in Figures 1.2 and 1.3. All draft and final written work products are subject to regional technical and public review and are available electronically on FPC and BPA websites:

FPC: http://www.fpc.org/documents/CSS.html BPA: http://www.efw.bpa.gov/searchpublications/index.aspx?projid . 


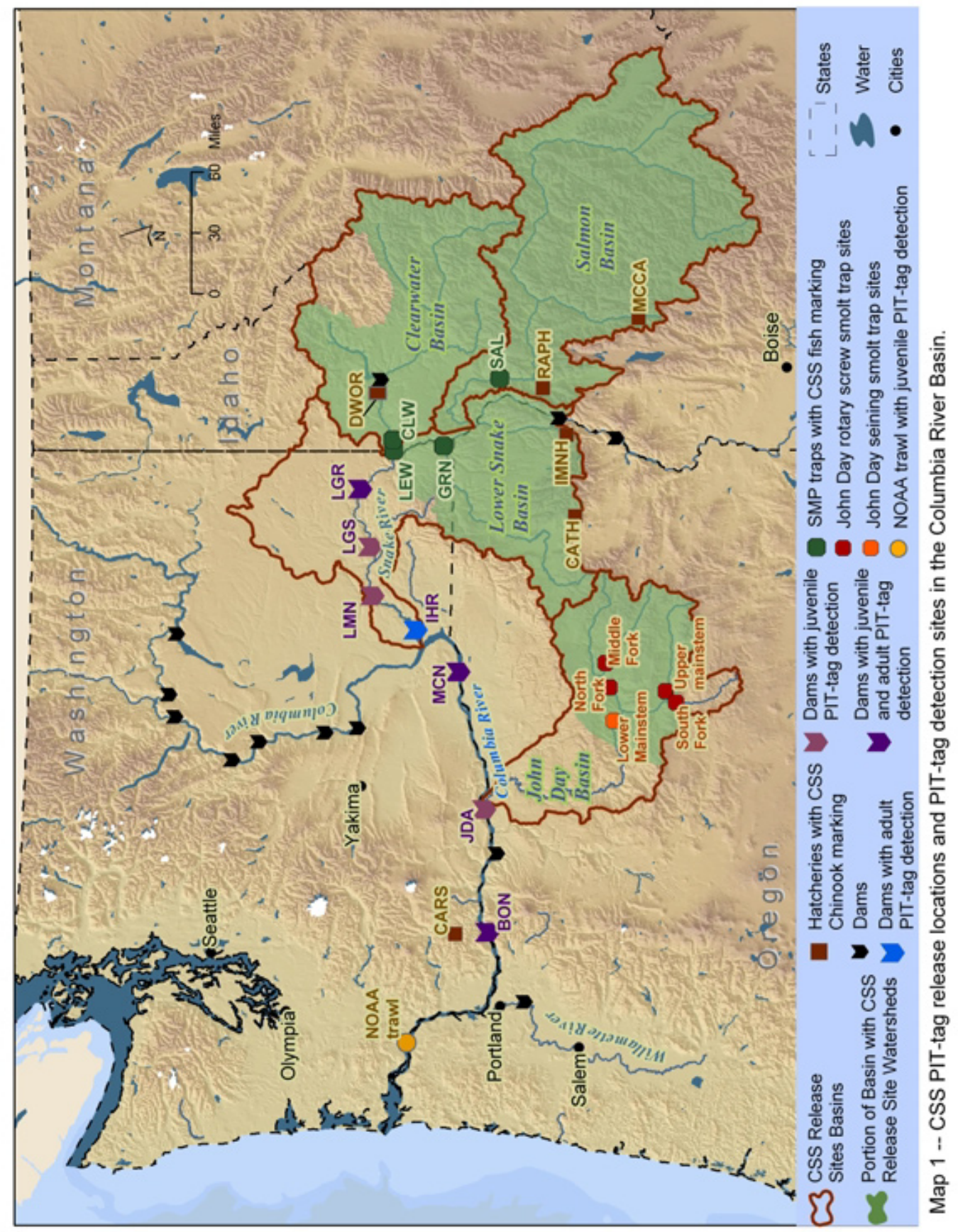

Figure 1.2. CSS PIT tag release locations and PIT-tag detection sites in the Columbia River Basin. 


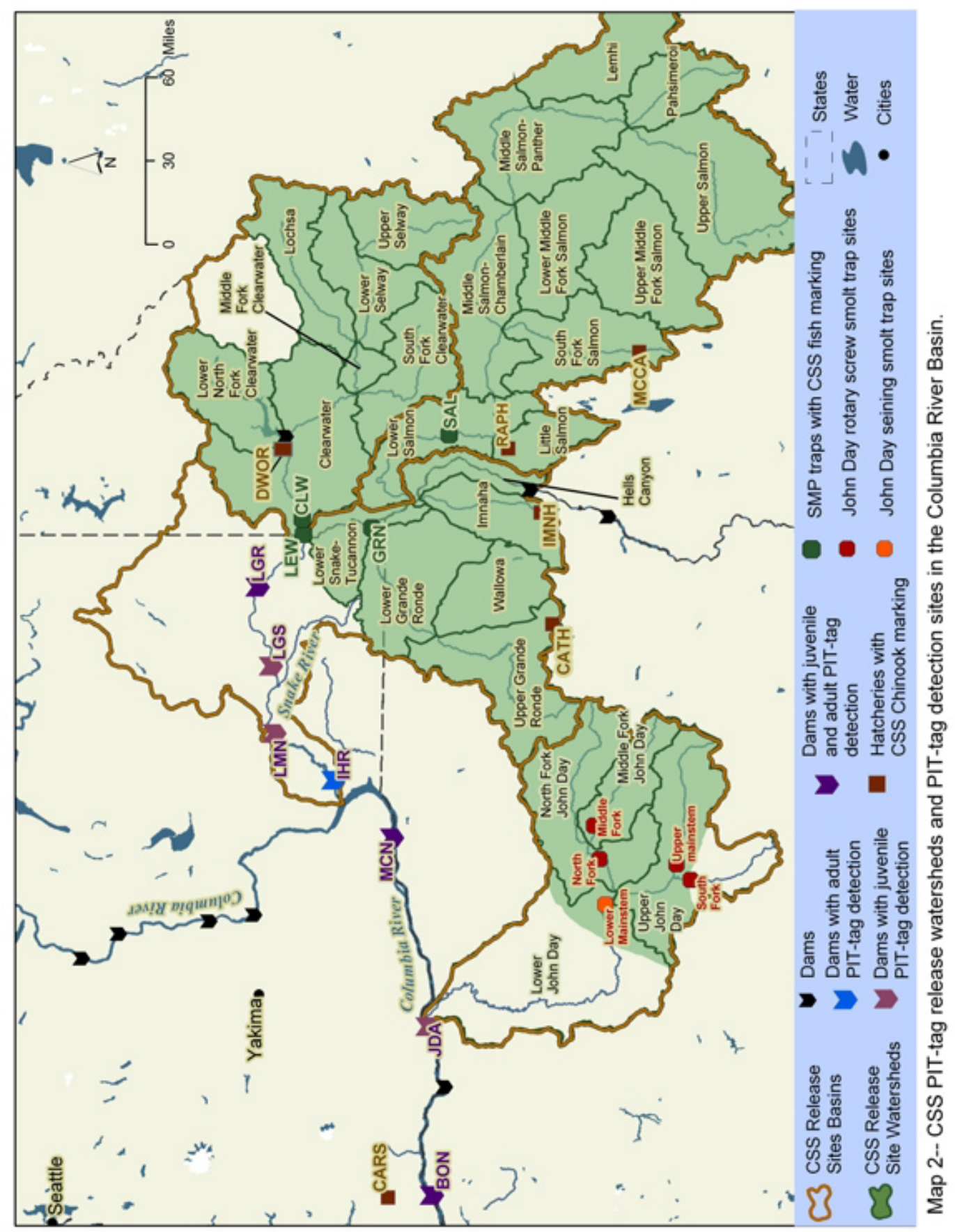

Figure 1.3. CSS PIT-tag release watersheds and PIT-tag detection sites in the Columbia River Basin.

\section{Development of the Comparative Survival Study}

Beginning in 1981, collection of fish at lower Snake River dams and transportation to below Bonneville dam was institutionalized as an operational program by the U.S. Army Corps of Engineers (USACE). The intention was to mitigate for mortality impacts associated with the FCRPS, and thus to increase survival of spring/ 
summer Chinook salmon. However, abundance of Snake River spring/summer Chinook salmon continued to decline. Fisheries that had been conducted at moderate levels in the Columbia River main stem during the 1950s and 1960s were all but closed by the mid 1970s. In 1992, the Snake River spring/summer Chinook salmon Evolutionarily Significant Unit (ESU) was listed under the federal Endangered Species Act (ESA). Spawning ground survey results in the mid-1990's indicated virtually complete brood year failure for some wild populations. For hatchery fish, low abundance was a concern as the Lower Snake River Compensation Plan (LSRCP) hatcheries began to collect program brood stock and produce juveniles.

The motivation for the CSS began with the region's fishery managers expressing concern that the benefits of transportation were less than anticipated (Olney et al. 1992, Mundy et al. 1994, and Ward et al. 1997). Experiments conducted by NMFS prior to the mid-1990s sought to assess whether transportation increased survival beyond that of smolts that migrated in-river through the dams and impoundments.

Regionally, opinions concerning the efficacy of transportation ranged from that of transportation being the best option to mitigate for the impacts of the FCRPS to, the survival of transported fish was insufficient to overcome those FCRPS impacts. Although the survival of fish transported around the FCRPS could be demonstrated to be generally higher than the survival of juveniles that migrated in the river, evidence on whether transportation contributed to significant increases in adult abundance of wild populations was unavailable. If the overall survival rate (egg to spawner) was insufficient for populations to at least persist, the issue would be moot (Mundy et al. 1994).

The objectives of the CSS design translate these issues about the efficacy of transportation into key response variables. The CSS uses the following two aspects for evaluating the efficacy of transportation: 1) empirical SARs compared to those needed for survival and recovery of the ESU; and 2) SAR comparisons between transport and in-river migration routes. In this broader context, the primary objective is to answer: "Are the direct and delayed impacts of the operation and configuration of the FCRPS sufficiently low to ensure that cumulative life-cycle survival is high enough to recover threatened and endangered populations?" Therefore we measure SARs against the regional management goal to maintain SARs between $2-6 \%$, where $2 \%$ is a minimum requirement and an average of $4 \%$ is maintained over multiple generations (NPCC 2003). The secondary objective is to answer: "is the survival of transported fish (SAR) higher than the survival (SAR) of fish migrating in-river?". Combining these objectives, effectiveness of transportation is assessed by whether 1) the survival (SAR) of fish collected at Snake River dams and diverted into barges is higher than the SAR of fish that migrate through reservoirs and pass these dams via the spillways and turbines; and 2) the SAR meets the regional objective (2-6\%) for the ESU.

The design and implementation of the CSS improved upon shortcomings of the methods that had previously been used to estimate and compare survival rates for transported fish and non-transported (in-river migrating) fish. These shortcomings resulted from the collection and handling protocols, the marking and recovery technology, the study objectives, the definition and use of a control population, and the inconsistency and duration of survival studies (Olney et al. 1992, Mundy et al. 1994, and Ward et al.1997). Transported and in-river fish groups were handled differently in the first juvenile fish studies. Whereas transported fish were captured at dams, tagged, and placed in trucks or barges, some in-river control groups of fish were transported back upstream for release. Thus, unlike the unmarked outmigration run-at-large, these marked in-river fish were therefore subjected to the same hydrosystem impacts multiple times whether they were subsequently collected and transported or remained in-river. 
The early mark-recapture studies used coded-wire tags (CWT) and freeze brands to mark juveniles collected at the dams. Therefore, Snake River basin origin of individual fish could not be identified, and CWT information could only be obtained from sacrificed fish. Evidence suggested that the process of guiding and collecting fish for either transport or bypass contributed to juvenile fish mortality and was cumulative when fish were bypassed multiple times. If such mortality differentially impacted the study fish, and was not representative of the in-river migrant run-at-large, measures of the efficacy of transportation would be biased.

All CSS study fish are uniquely identified with a PIT-tag, and the use of this new technology has provided substantial improvements in the evaluation of the efficacy of transportation. To ensure that all CSS study fish transported or migrating in-river experience the same effects from handling (thus improving the utility of an in-river control group relative to transportation), fish are tagged at hatcheries and wild fish are tagged at subbasin and main stem outmigrant traps upstream of the FCRPS (Figures 1.2 and 1.3). PIT-tagged juveniles are released near their marking station, allowing the numbers of fish and distribution across subbasins of origin to be predetermined. Recapture information can be collected without sacrificing each fish, and lower impacts due to trapping and handling occur where automated detection stations exist.

Within the Columbia and Snake River main stems, PIT-tag detectors at the dams now allow passage dates and locations to be recorded for both juvenile and adult PITtagged fish and provide the ability to link that information to the characteristics of each fish at time and location of release (Figures 1.2 and 1.3). Given sufficient numbers of fish among release groups and appropriate distribution across subbasins, ESUs, hatchery $v s$. wild, and outmigration season, survival rates of subgroups of fish with unique life history experience, or aggregate groups with common life history experiences, can be estimated at discrete or combined life-stages throughout their life cycle. The CSS PITtagging design and application allows the use of the Cormack-Jolly-Seber (CJS) method with multiple mark-recapture information to estimate survival of the total number of fish estimated to approach the upper most dam (Lower Granite Dam), thus representing the conditions that the majority of fish migrating through the hydrosystem experience.

\section{Data generated in the Comparative Survival Study}

The CSS is designed with the goal of obtaining annual estimates of smolt-toadult survival rates (SARs) for Snake River hatchery and wild spring/summer Chinook (hereafter, Chinook) and steelhead. Estimation of the overall, aggregate SAR of fish that are transported and those that migrate entirely in-river is key to evaluation of avoidance of jeopardy as well as progress towards recovery goals.

Another goal of the CSS has been to develop long-term indices of SAR ratios between transported and in-river fish. A common comparison, termed "Transport: Inriver" ratio, or TIR, is the SAR of transported fish divided by the SAR of in-river fish, with SAR being estimated for smolts passing Lower Granite Dam (LGR) and returning as adults back to LGR (LGR-LGR SARs). Estimates of TIR address the question of whether transportation provides an overall benefit to smolt-to-adult survival, compared to leaving smolts to migrate in-river, under the hydrosystem as currently configured. The overall value of transportation in avoiding jeopardy and promoting recovery depends on the extent to which it will account for all direct mortality (i.e., to smolts within the hydrosystem) and indirect, or "delayed", mortality (i.e., to smolts after passing BON) caused as a result of passage through the hydrosystem. However, because TIR compares 
SARs starting from collector projects, it does not provide a direct estimate of any delayed mortality specific to transported fish.

Related to TIR is " $D$ ", the ratio between transported fish and in-river fish of SAR from downstream of Bonneville Dam (BON) back to LGR (BON-LGR SARs). Estimates of $D$ isolate mortality occurring in juvenile salmon passage between Lower Granite and Bonneville dams from that occurring afterwards during time in the ocean and upon returning upriver as adults to Lower Granite Dam for transported smolts. A $D$ equal to one indicates that there is no difference in survival rate after hydrosystem passage; a $D$ less than one indicates that transported smolts die at a higher rate after passing BON than smolts that have migrated through the hydrosystem; a $D$ greater than one indicates that transported fish have higher survival after passing BON. The parameter $D$ has been used extensively in modeling the effects of the hydrosystem on Snake River Chinook salmon (Kareiva et al. 2000; Peters and Marmorek 2001; Wilson 2003; Zabel et al. 2005).

Estimation and comparison of annual SARs for hatchery and wild groups of smolts with different hydrosystem experiences between common start and end points are made for three categories of fish passage: tagged fish that are detected at Snake River collector dams (i.e., Lower Granite [LGR], Little Goose [LGS], or Lower Monumental $[\mathrm{LMN}])$ and transported $\left(\mathrm{T}_{0}\right)$; tagged fish collected at Snake River dams and returned to the river $\left(\mathrm{C}_{1}\right)$, or tagged fish never collected or transported $\left(\mathrm{C}_{0}\right)$ at the Snake River dams. These SARs and the ratios derived from them in this report are estimated for the entire migration year. The SARs developed for each of these study categories will be weighted by the proportion of the run-at-large (untagged and tagged fish) represented by these categories to provide overall annual SARs. Because no transported smolts and only a small number of in-river smolts are enumerated at BON, the BON-LGR SAR is estimated from the LGR-LGR SAR, adjusted by annual in-river survival rate estimates (through the hydrosystem) and assumed average direct transport survival rate from empirical studies.

The year 2006 marked an important change in fish transportation operations within the FCRPS. Transportation operations from 1997-2005 began April 1st and encompassed most of the emigrating groups of CSS marked fish. In 2006, the transportation operational protocol was altered to delay transporting fish until $\sim$ April 2024 and until May $1^{\text {st }}$ in 2007 and 2008. This change in operations affects the CSS study because the transportation protocol now allows a portion of the population to emigrate via the hydrosystem before transportation begins.

This 2006 management change coincided with the CSS change in methods of pre-assigning fish to bypass or transport routes, rather than forming transport and inriver cohorts at Snake River collector projects as was done through 2005. The new CSS approach facilitated evaluation of the 2006 change in transportation strategy. Although we report on returns to date from the 2006 out migration, the primary focus of this report is on out migration years through 2005. This is because the 2005 migration year represents the last year under the old transportation regime whereas returns from 2006 are still incomplete (i.e., we have only 2 -salt Chinook and 1 -salt steelhead returns to date) and are therefore preliminary results under the new CSS methodology.

Prior to 2006, the electronics at the dams were used to route fish during the outmigration either to raceways or back-to-river. The new method pre-assigns the tagged fish to two different study groups prior to their emigration through the hydrosystem. This is accomplished through FPC coordination with various marking agencies. By knowing what PIT tags are used for marking, FPC assigns individual PIT tags to two groups, and passes this information on to the separation by code facilities at each dam. One group (denoted as the transport-with-spill group (TWS) in this report) would reflect 
the untagged population, and these tagged fish would be routed the same direction as the untagged smolts at each of the collector dams where transportation occurs. The other group (denoted as the bypass-with-spill Group (BWS) in this report) would follow the default return-to-river routing at each collector dam throughout the season. For example, on entering the bypass facilities at the transportation sites two things can happen. If transportation is taking place, TWS group fish are transported and BWS group fish are bypassed. If transportation is not taking place, both groups are bypassed. Smolts in the two study groups created would experience different passage routes through the hydrosystem whenever transportation was occurring. In the future, these two groups will provide the opportunity to compare estimated SARs between transport and nontransportation management scenarios.

Combining Groups TWS and BWS provides a composite group comparable to what has been used in the CSS in all years through 2005. For the analyses work in this report, we used the combined group to estimate CJS reach survival rates, SARs, TIRs, and $\mathrm{D}$ as in past years. The estimated smolt numbers and adult return data for Group TWS provides a direct estimation of the annual overall SARs for 2006 migrants. These estimates will be compared with annual overall SARs computed using the original methods for that migration year.

To evaluate one component of the effectiveness of transportation relative to inriver migration, annual $\mathrm{SAR}$ ratios between $\mathrm{T}_{0}$ and $\mathrm{C}_{0}$ fish are compared, both from their passage of Lower Granite Dam as smolts until their return as adults to that dam (TIR, representing the direct effects of transportation versus in-river migration on survival in the freshwater migration corridor as well as the indirect, or delayed, effects in the estuary and ocean), and from their seaward migration from below Bonneville Dam until their return to Lower Granite Dam ( $D$, representing only delayed differential survival effects in the estuary, ocean, and during the adult upstream migration for transported fish). With the new pre-assigned groups of smolts, direct comparison of each year's existing management operations (mixture of spill, early season bypass, and later season transport) may be made with an operation that does not include transportation. This comparison will provide a second component in the evaluation of the effectiveness of transportation relative to in-river migration.

During the 2007 contract year, we programmed, debugged, and tested two new bootstrap computer applications to handle these developing improvements in the CSS. These two programs can handle tasks for migration years where fish are pre-assigned to two study groups before emigration through the hydrosystem. One group reflects the untagged fish experience under current hydrosystem operations (i.e., transportation during part of the emigration season) and the other group reflects a full season bypass operation.

This report will contain appendices that update tables from the 2006 CSS Annual Report and 10-yr Retrospective Analysis Report with data from the additional migration years. It will provide the entire available time series of numbers of PIT-tagged wild and hatchery juvenile Chinook salmon and steelhead used in the CSS analyses. It presents survival estimates by year, study group, and origin. Estimates of the major CSS study parameters $(S, \mathrm{SAR}$, TIR, and $D)$ are presented by species, origin, and treatment, including confidence intervals as sample sizes allow. Appendices of timing plots at Lower Granite Dam for outmigrating smolts and returning adults are also presented. 


\section{Chapter 2 -- Methods}

\section{Tagging}

Wild and hatchery smolts are marked with glass-encapsulated, passively induced transponders that are 11-12 $\mathrm{mm}$ in length and have a unique code to identify individual fish. These PIT-tags are normally implanted into the fish's body cavity using a handheld syringe, and they are generally retained and function throughout the life of the fish. Wild and hatchery Chinook and steelhead used in the CSS analyses were obtained from all available marking efforts in the Snake River basin above LGR (Appendix A). Wild Chinook from each tributary (plus fish tagged at the Snake River trap near Lewiston) were represented in the PIT-tag aggregates for migration years 1994 to 2006 (number and origin of PIT-tagged wild Chinook analyzed is in Table D-1). Wild steelhead smolts from each tributary (plus fish tagged at the Snake River trap near Lewiston) were represented in the PIT-tag aggregates for migration years 1997 to 2005 (number and origin of PITtagged wild steelhead analyzed is in Table D-3). Hatchery steelhead from each tributary, plus PIT-tag releases in the mainstem Snake River at the Lewiston trap and below Hells Canon Dam, were represented in the PIT-tag aggregates for migration years 1997 to 2005 (number and origin of PIT-tagged hatchery steelhead analyzed is in Table D-4). The origins of the wild Chinook, wild steelhead, and hatchery steelhead in the PIT-tag aggregates appear to be well spread across the drainages above LGR.

Hatchery yearling spring and summer Chinook were PIT-tagged for the CSS at specific hatcheries within the four drainages above LGR including the Clearwater, Salmon, Imnaha, and Grande Ronde Rivers (number and origin of PIT-tagged hatchery Chinook analyzed is in Table D-2). Hatcheries that accounted for a major portion of Chinook production in their respective drainages were selected. Since study inception, the CSS has PIT-tagged juvenile Chinook at McCall, Rapid River, Dworshak, and Lookingglass hatcheries. Chinook tagged at Lookingglass Hatchery included an Imnaha River stock released in the Imnaha River drainage and a Catherine Creek stock released in the Grande Ronde River drainage. This latter stock became available to the CSS in 2001 after the Lookingglass Hatchery complex changed its operation to rearing only Grande Ronde River basin endemic stocks. Based on past estimates of SARs, sufficient numbers of smolts were tagged to ensure enough returning adults for computing statistically rigorous SAR estimates.

Throughout this report, we will classify the Imnaha River Chinook as a summer stock (contrary to ODFW's classification) due to its high return rate of jacks and later timing of returning adults, which is consistent with the summer stock from McCall Hatchery stock. The average percentage of the total that return as jacks was higher for the summer Chinook stocks than for the spring Chinook stocks, and was the highest for Chinook from Imnaha River AP (Table D-41).

All attempts were made to make the PIT-tagged fish as representative of their untagged cohorts as possible. At trapping sites, sampling and tagging occur over the entire migration season. At the hatcheries, fish were obtained across a wide set of ponds and raceways to more accurately represent production. Tag loss and mortality of PIT-tagged fish were monitored, and the tagging files were transferred to the regional PTAGIS database in Portland, OR. The study requires that PIT-tagged fish are not 
necessarily routed or diverted at collector projects in the proportions that non-tagged fish are; consequently adjustments are made (described below) in estimation to more closely represent the experience of run-of-the-river (non-tagged) fish.

The Snake River basin fish used in SAR estimation were PIT-tagged and released in tributaries and mainstem locations upstream from LGR reservoir. Other investigators (Sanford and Smith 2002; Paulsen and Fisher 2005; Budy and Schaller 2007) have used smolts released both above LGR and at LGR for their estimates of SARs. Because all Snake River spring/summer Chinook must pass through LGR reservoir, we believe that smolts released upstream from LGR most closely reflect the impacts of the Lower Snake and Columbia River hydrosystem on the untagged run-at-large in-river migrating fish and thus we use only these release groups to compose the $\mathrm{C}_{0}$ group (fish that remained in-river throughout their migration) in this analysis; fish collected and marked at LGR do not have a similar experience (explained in more detail below).

\section{Estimation Overview}

Generally we estimated the survival of various life stages through known release and detected return numbers of PIT-tagged fish. The PIT-tags in juvenile fish are read as the fish pass through the coils of detectors installed in the collection/bypass channels at six Snake and Columbia River dams, including LGR, LGS, LMN, McNary (MCN), John Day (JDA), and BON (Figure 1.2 and 1.3). Upon arrival at LGR, LGS and LMN, smolts can go through three different routes of passage: over the spillway via typical spillway or removable spillway weir (RSW), or into the powerhouse and subsequently through the turbines, or diversion with screens and pipes into the collection and bypass facility. Those fish that pass over the spillway or through the turbines are not detected, but bypass facility detectors record the fish identification number and the time and date detected. Fish without PIT-tags that enter the collection facility are generally put in trucks or barges and transported to below BON, however collected PIT-tagged smolts are often returned to the river. In addition, PIT-tag detections are obtained from a special trawling operation (TWX) by NMFS in the lower Columbia River in the vicinity of Jones Beach. Returning adults with PIT-tags are detected in the fish ladders at LGR with nearly $100 \%$ probability. PIT-tag detection capability for returning adults has been added at BON, MCN, and IHR in more recent years, allowing additional adult return sites for analyses.

Over the years, we have developed a computer program to estimate the following quantities and confidence intervals: survival from hatchery release to LGR, reach survival estimates between each of the dams equipped with PIT-tag detectors; survival from outbound arrival at LGR dam until return to LGR as adults (LGR-LGR SAR); survival from outbound arrival at BON dam to LGR dam as adults (BON-LGR SAR); and the ratio of these SARs for smolts with different hydrosystem passage experience (TIR and $D$ ). Assessment of the variance of estimates of survival rates and ratios is necessary to describe the precision of these estimates for statistical inference and to help facilitate efficient monitoring of actions to mitigate effects of the hydrosystem. For a number of the quantities described above, theoretical estimates of variance are tractable. However, variance components of other quantities are often unknown or are extremely complicated and thus impracticable to estimate using theoretical variances. Therefore, we developed a nonparametric bootstrapping approach (Efron and Tibshirani 1993), where all quantities are estimated, and then a new sample of fish is drawn with replacement from the original sample, and the quantities are then estimated again. This resampling with replacement is conducted for 1000 iterations to produce a distribution of values that describes the mean and variance associated with the estimate. From the set of 1000 iterations, non- 
parametric $80 \%, 90 \%$, and $95 \%$ confidence intervals were computed for each parameter of interest. The $90 \%$ confidence intervals were chosen for reporting in the recent CSS annual reports in an attempt to better balance the making of Type I (failure to reject a false null hypothesis) and Type II (failure to accept a true alternative hypothesis) errors in comparisons study groups of fish for the various parameters of interest.

\section{Estimation of in-river survival rates}

The array of detection sites in the Snake and Columbia Rivers is analogous to multiple recaptures of tagged individuals, allowing for standard multiple mark-recapture survival estimates over several reaches of the hydrosystem using the Cormack-JollySeber (CJS) method (Cormack 1964; Jolly 1965; Seber 1965). This method was used to obtain estimates of survival and corresponding standard errors for up to six reaches between release site and tailrace of BON (survival estimates $S_{1}$ through $S_{6}$ ). An overall survival probability from LGR-BON, referred to as $S_{R}$, describes the direct impacts of the hydrosystem on the in-river population of smolts, and is the product of the reach survival estimates. Estimates of individual reach survival (e.g. LGR-LGS) can exceed $100 \%$; however, this is often associated with an underestimate of survival in preceding or subsequent reaches. Therefore, when computing an overall multi-reach survival estimate, we allow individual reach survival estimates to exceed $100 \%$. However, an estimate of survival rate for a specific reach was considered unreliable when its coefficient of variation exceeded $25 \%$. When direct estimates of $S_{R}$ were not possible or were unreliable, an expansion was necessary.

The total number of reaches for which survival was estimable was a function of the number of smolts in the initial release and recovery effort available in that year. Prior to 1998, there was limited PIT-tag detection capability at JDA and TWX. Therefore, reliable survival estimates in those years were possible only to the tailrace of LMN or MCN. In years subsequent to 1998, reliable survival estimates to the tailrace of JDA have been possible in most cases. Whenever direct estimation of survival to BON is not possible, then the following expansion was necessary. Survival estimates over the longest reach possible were converted to survival per mile using the number of miles in that reach. The estimates of survival per mile were then expanded to the number of miles between LGR and BON. However, because per mile survival rates thus generated were generally lower for the Snake River than for the lower Columbia River, direct estimates of in-river survival over the longest reach possible were preferable.

\section{Estimation of smolts in study categories}

For convenience, we made comparisons between SARs of groups of smolts with different hydrosystem experiences from a common starting and end point. Thus, LGR-LGR SARs were estimated for all groups even including smolts not detected at LGR. The population of PIT-tagged study fish arriving at LGR was partitioned into three categories of smolts related to the route of subsequent passage through the hydrosystem. Fish were "destined" to 1) pass in-river through the Snake River collector dams in a nonbypass channel route (spillways or turbines), 2) pass in-river through the dam's bypass channel, or 3) pass in a truck or barge to below BON. These three routes of hydrosystem passage defined the study categories $\mathrm{C}_{0}, \mathrm{C}_{1}$ and $\mathrm{T}_{0}$, respectively.

The PIT-tagged study groups should mimic the experience of the non-tagged fish

that they represent. For example, only first-time detected tagged smolts at a dam may be 
considered for inclusion in the transportation $\left(\mathrm{T}_{0}\right)$ group since non-tagged smolts were nearly always transported when they entered a bypass/collector facility (where PIT-tag detectors are in operation) at a Snake River dam. Smolts transported at LGR represented a larger group than the sum of smolts actually transported at all projects, because some smolts died while migrating in-river from LGR to either LGS or LMN. A proportion of those that died relative to the fraction of transported fish among total fish that survive migration past these collector dams (i.e. transported or in-river) were summed with fish that are actually transported to make up the total group of fish that were "destined" for transportation (LGR equivalents). Therefore, an estimated survival rate was needed to convert actual transport numbers at LGS and LMN into their LGR equivalents starting number. The actual transport numbers at LGR, LGS, and LMN are in Table A-34 for wild Chinook, A-36 for hatchery Chinook, A-39 for wild steelhead, and A-41 for hatchery steelhead. The PIT-tagged fish destined for transportation at LGR, LGS, and LMN together formed Category $\mathrm{T}_{0}$. Using the definitions presented in the following text box, the formula for estimating the number of fish in Category $T_{0}$ was

$$
T_{0}=X_{12}+\frac{X_{102}}{S_{2}}+\frac{X_{1002}}{S_{2} * S_{3}}
$$




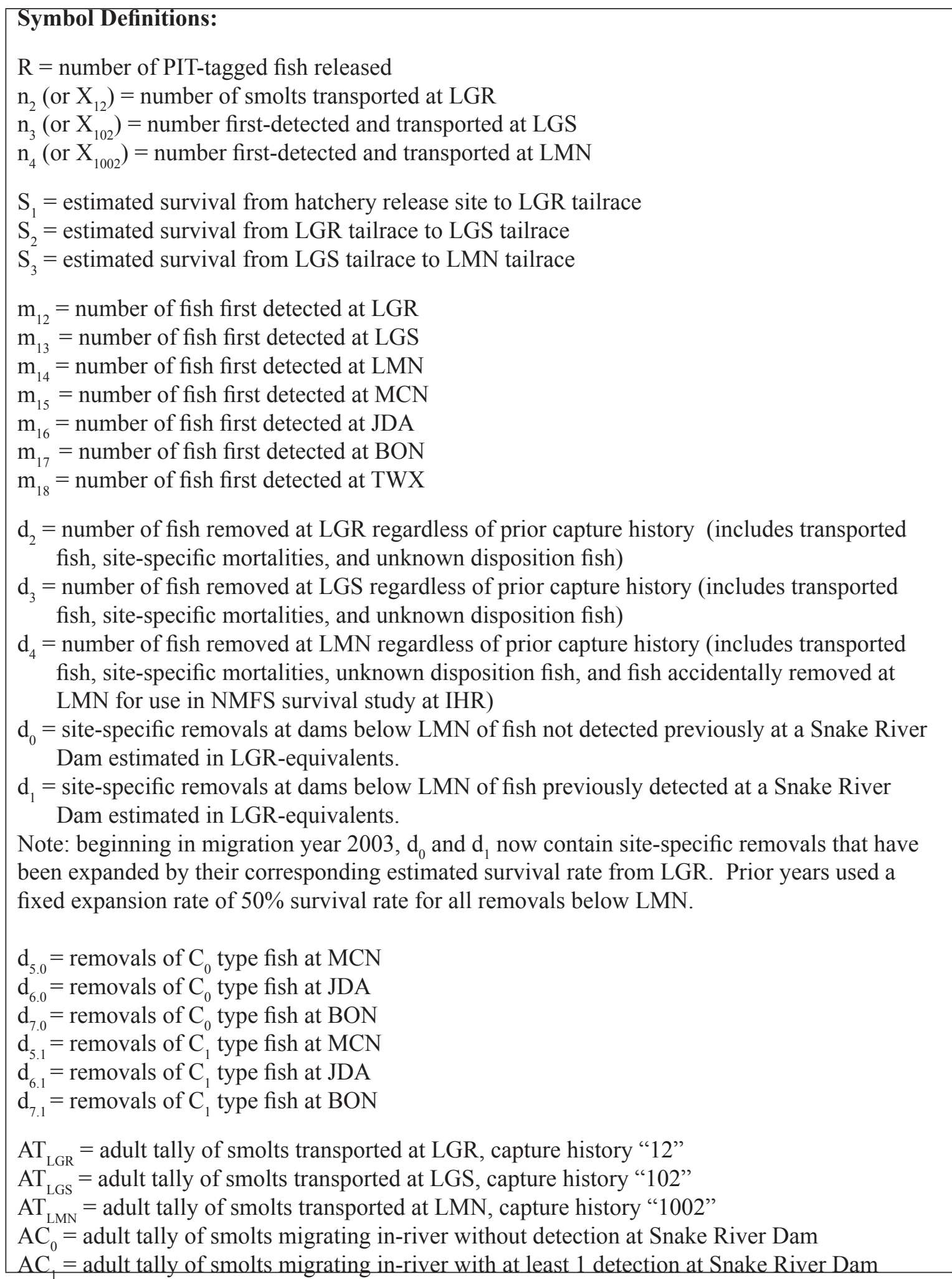

The PIT-tagged smolts that passed all Snake River dams undetected $\left(\mathrm{C}_{0}\right)$ were the group most representative of the non-tagged smolts that migrated in-river during the years covered in the report, never entering collection facilities at collector dams. Detected PIT-tagged fish were not representative because they do enter these facilities, and because non-tagged fish that entered a detection/collection facility were normally removed for transportation. The starting number of $\mathrm{C}_{0}$ fish was also computed in LGR equivalents, and therefore required estimates of survival. To estimate the number of smolts that were not detected at any of the collector projects, the number of smolts first 
detected (transported and non-transported) at LGR, LGS, and LMN (in LGR equivalents) was subtracted from the total number of smolts estimated to arrive at LGR. The number of smolts arriving LGR for is estimated by multiplying the release to LGR survival rate $\left(\mathrm{S}_{1}\right)$ and release number (equivalently, dividing number of smolts detected at LGR by the CJS estimate of seasonal LGR collection efficiency) specific for the smolt group of interest. Smolts detected at MCN, JDA, and BON were not excluded from the $\mathrm{C}_{0}$ group since fish entering the bypass facilities at these projects, both tagged and untagged, were generally returned to the river. However, any removal of fish (i.e., not return-to-river) at sites below LMN had to be taken into account. Using symbols defined in the text box, the formula for estimating the expected number of fish in Category $\mathrm{C}_{0}$ is

$$
C_{0}=R * S_{1}-\left(m_{12}+\frac{m_{13}}{S_{2}}+\frac{m_{14}}{S_{2} * S_{3}}\right)-d_{0}
$$

where, for migration years 1994-2002,

and beginning in 2003,

$$
d_{0}=\left(\frac{\left(d_{5.0}+d_{6.0}+d_{7.0}\right)}{0.5}\right)
$$

$$
d_{0}=\left(\frac{d_{5.0}}{S_{2} * S_{3} * S_{4}}+\frac{d_{6.0}}{S_{2} * S_{3} * S_{4} * S_{5}}+\frac{d_{7.0}}{S_{2} * S_{3} * S_{4} * S_{5} * S_{6}}\right)
$$

The last group of interest was comprised of fish that were detected at one or more Snake River dams and remained in-river below LMN. These PIT-tagged fish formed Category $\mathrm{C}_{1}$. The $\mathrm{C}_{1}$ category exists because a portion of the PIT-tagged smolts entering the detection/collection facility are returned to the river so reach survival estimates are possible. Although these fish do not mimic the general untagged population, they are of interest with regards to possible effects of passing through Snake River dam bypass/ collection systems on subsequent survival, and in investigating non-transport operations. Using symbols defined in the text box, the formula for estimating the expected number of fish in Category $\mathrm{C}_{1}$ is

$$
C_{1}=\left(m_{12}-d_{2}\right)+\left(\frac{\left(m_{13}-d_{3}\right)}{S_{2}}\right)+\left(\frac{\left(m_{14}-d_{4}\right)}{S_{2} * S_{3}}\right)-d_{1}
$$

where, for migration years 1994-2002,

and, beginning in 2003,

$$
d_{1}=\left(\frac{\left(d_{5.1}+d_{6.1}+d_{7.1}\right)}{0.5}\right)
$$

$$
d_{1}=\left(\frac{d_{5.1}}{S_{2} * S_{3} * S_{4}}+\frac{d_{6.1}}{S_{2} * S_{3} * S_{4} * S_{5}}+\frac{d_{7.1}}{S_{2} * S_{3} * S_{4} * S_{5} * S_{6}}\right)
$$

\section{Estimation of SARs and Ratios of SARs for Study Categories}

LGR has been the primary upriver evaluation site for many objectives of the CSS. Adults detected at LGR were assigned to a particular study category based on the study category they belonged to as a smolt (fish with no previous detections at any dam were 
automatically assigned to Category $\mathrm{C}_{0}$ ). In the $\mathrm{SAR}$ estimation, the adult steelhead count is the sum of the 1 to 3-ocean returns (only fish returning in the same year as their smolt outmigration, called minis, are excluded). The number of returning adults at LGR by age is in Table A-30 for wild steelhead and Table A-31 for hatchery steelhead. The adults Chinook count is the sum of the 2 to 4 -ocean returns. Chinook jacks and mini-jacks (1-ocean or less, precocial males) are excluded from SARs due to the limited contribution to spawning of these age classes. The number of returning adults (and jacks) at LGR by age is in Table A-29 for wild Chinook and Table A-32 for hatchery Chinook.

The formulas for computing SARs by study category (adult tally in numerator and estimated smolt number in denominator) were:

$$
\begin{gathered}
\operatorname{SAR}\left(T_{0}\right)=\frac{\left\{A T_{L G R}+A T_{L G S}+A T_{L M N}\right\}}{T_{0}} \\
\operatorname{SAR}\left(C_{0}\right)=\frac{\left\{A C_{0}\right\}}{C_{0}} \\
\operatorname{SAR}\left(C_{1}\right)=\frac{\left\{A C_{1}\right\}}{C_{1}}
\end{gathered}
$$

In past CSS Annual Reports, $\mathrm{SAR}\left(\mathrm{T}_{0}\right)$ was reported as the $\mathrm{SAR}_{2}\left(\mathrm{~T}_{0}\right)$ parameter. The difference between $\operatorname{SAR}\left(\mathrm{T}_{0}\right)$ and $\operatorname{SAR}\left(\mathrm{C}_{0}\right)$ was characterized as the ratio of these SARs and denoted as the TIR (transport: in-river ratio):

$$
T I R=\frac{\operatorname{SAR}\left(T_{0}\right)}{\operatorname{SAR}\left(C_{0}\right)}
$$

The statistical test of whether $\operatorname{SAR}\left(\mathrm{T}_{0}\right)$ is significantly $(\alpha=0.05)$ greater than $\mathrm{SAR}\left(\mathrm{C}_{0}\right)$ is conducted by evaluating whether TIR is significantly greater than 1 . We use the criteria that the lower limit of the non-parametric $90 \%$ confidence interval of TIR must exceed 1 (i.e., below this lower limit threshold occurs 5\% of the TIR estimates in rank order from the distribution of bootstrap iterations). This provides a statistical onetailed $(\alpha=0.05)$ test of $\mathrm{H}_{0}$ TIR $\leq 1$ versus $\mathrm{H}_{\mathrm{A}}$ TIR $>1$.

\section{Estimation of D}

Methods to estimate SARs from LGR to LGR for transported and in-river fish have been described above. This measurement of survival from smolts-to-adults includes survival rates through the hydrosystem as well as survival after smolts pass BON and return to LGR. Like the TIR, the parameter D is the ratio of SAR of transported smolts $\left(\mathrm{T}_{0}\right)$ relative to smolts migrating in-river $\left(\mathrm{C}_{0}\right)$, except that $\mathrm{SAR}$ is estimated from below BON instead of from LGR. If the value of $\mathrm{D}$ is around 1 , there is little or no differential mortality occurring between transported and in-river migrating smolts once they are both below BON. So, the D parameter is effectively:

$$
D=\frac{S A R_{B O N-L G R}\left(T_{0}\right)}{S A R_{B O N-L G R}\left(C_{0}\right)}
$$


The total number of smolts passing BON was not observed directly. However, the $\mathrm{D}$ parameter can be estimated by removing the portion of the $\mathrm{SAR}_{\mathrm{LGR}-\mathrm{LGR}}$ that contains the LGR to BON juvenile hydrosystem survival. So, the parameters $S_{T}$ and $S_{R}$ were divided out of their respective $\mathrm{SAR}_{\mathrm{LGR}-\mathrm{LGR}}$ values to estimate the $\mathrm{SAR}_{\mathrm{BON}-\mathrm{LGR}}$ for each study group. The resulting estimate of $\mathrm{D}$ was calculated as:

$$
D=\frac{\left(\frac{\operatorname{SAR}\left(T_{0}\right)}{S_{T}}\right)}{\left(\frac{\operatorname{SAR}\left(C_{0}\right)}{S_{R}}\right)}
$$

where $S_{R}$ is the estimated in-river survival from LGR tailrace to BON tailrace and $S_{T}$ is the assumed direct transportation survival rate (0.98) adjusted for in-river survival to the respective transportation sites for those fish transported from LGS or LMN.

In the denominator of $D$ (in-river portion), the quotient was simply $\operatorname{SAR}\left(\mathrm{C}_{0}\right) / S_{R}$, where $S_{R}$ was estimated through the CJS estimate (expanded to the entire hydro system if necessary). Errors in estimates of $S_{R}$ influenced the accuracy of $D$ estimates: recall that when it was not possible to estimate CJS in-river survival directly to BON tailrace, an expansion based on a "per mile" survival rate obtained from an upstream reach (where survival could be directly estimated) was instead applied to the remaining downstream reach.

In the numerator of $\mathrm{D}$ (transportation portion), the quotient was $\mathrm{SAR}\left(\mathrm{T}_{0}\right) / S_{T}$, where $S_{T}$ reflected an adjustment of the project-specific proportions of the transported PIT-tagged fish to mimic the proportions of untagged fish transported at the different projects. Calculation of $S_{T}$ included an estimate of survival to each transportation site, effectively putting $S_{T}$ into LGR equivalents similar to $\mathrm{SAR}\left(\mathrm{T}_{0}\right)$, with a fixed $98 \%$ survival rate for the fish once they were placed into the transportation vehicle (truck or barge). The resulting formula for estimating $S_{T}$ used estimates of the total number of PIT-tagged fish that would have been transported at each dam (estimates $\mathrm{t}_{\mathrm{j}}$ for the $\mathrm{j}^{\text {th }} \mathrm{dam}$ ) if all PITtagged fish had been routed to transport at the same rate as the untagged fish. The $S_{T}$ estimate was

$$
S_{T}=(0.98) * \frac{\left(t_{2}+t_{3}+t_{4}\right)}{\left(t_{2}+\frac{t_{3}}{S_{2}}+\frac{t_{4}}{S_{2} * S_{3}}\right)}
$$

where the $t_{i}$ s are estimates of the fraction of PIT-tagged fish that would have been transported at each dam ( $t_{j}$ for the $\mathrm{j}^{\text {th }}$ dam) if all PIT-tagged fish had been routed to transport at the same rate as the untagged fish. The estimates of $S_{\mathrm{T}}$ have ranged between 0.88 and 0.98 for Chinook and steelhead across the years evaluated in the report. Values for the $t_{f}$ are found in Tables A-34 for wild Chinook, A-36 for hatchery Chinook, A-39 for wild steelhead, and A-41 for hatchery steelhead.

A statistical test of whether $\mathrm{D}$ is significantly $(\alpha=0.05)$ greater than 1 was conducted in the same manner as was done with TIR. We use the criteria that the lower limit of the non-parametric $90 \%$ confidence interval of $\mathrm{D}$ must exceed 1 (i.e., below this 
lower limit threshold occurs $5 \%$ of the $\mathrm{D}$ estimates in rank order from the distribution of bootstrap iterations). This provides a statistical one-tailed ( $\alpha=0.05)$ test of $\mathrm{H}_{0} \mathrm{D} \leq 1$ versus $\mathrm{H}_{\mathrm{A}} \mathrm{D}>1$.

\section{Estimation of overall annual SARs (pre-2006 migration years)}

Annual estimates of SAR LGR-to-LGR reflective of the run-at-large for wild steelhead, hatchery steelhead, wild Chinook, and hatchery Chinook that outmigrated in 1997 to 2005 are computed by weighting the SARs computed with PIT-tagged fish for each respective study category by the proportion of the run-at-large transported and remaining in-river. The proportions of the run-at-large reflected by each of the CSS study categories $\mathrm{C}_{0}, \mathrm{C}_{1}$ and $\mathrm{T}_{0}$ were estimated as follows. First, we estimated the number of PIT-tagged smolts $t_{j}$ that would have been transported at each of the three Snake River collector dams $(j=2$ for $L G R, j=3$ for LGS, and $j=4$ for $L M N$ ) if these fish had been routed to transportation in the same proportion as the run-at-large. This estimation uses run-at-large collection and transportation data for these dams from the FPC Smolt Monitoring Program. The total estimated number transported across the three Snake River collector dams in LGR equivalents equals $\mathrm{T}_{0}{ }^{*}=\mathrm{t}_{2}+\mathrm{t}_{3} / \mathrm{S}_{2}+\mathrm{t}_{4} /\left(\mathrm{S}_{2} \mathrm{~S}_{3}\right)$. When a portion of the collected run-at-large fish is being bypassed as occurred in 1997, then there will be a component of the PIT-tagged fish also in that bypass category (termed $\mathrm{C}_{1}{ }^{*}$ in this discussion). In most years, the $\mathrm{C}_{1}{ }^{*}$ is at or near zero. When run-at-large bypassing occurs, $\mathrm{C}_{1}{ }^{*}=\left(\mathrm{T}_{0}+\mathrm{C}_{1}\right)-\mathrm{T}_{0}{ }^{*}$. The sum of estimated smolts in categories $\mathrm{C}_{0}, \mathrm{~T}_{0}{ }^{*}$, and $\mathrm{C}_{1}{ }^{*}$ is divided into each respective category's estimated smolt number to provide the proportions to be used in the weighted SAR computation.

The proportion of the run-at-large that each category of PIT-tagged fish represents is then multiplied by its respective study category-specific SAR estimate, i.e., $\mathrm{SAR}\left(\mathrm{C}_{0}\right)$, $\operatorname{SAR}\left(\mathrm{C}_{1}\right)$, and $\mathrm{SAR}\left(\mathrm{T}_{0}\right)$, and summed to produce an annual overall weighted $\mathrm{SAR}_{\text {LGR-to-LGR }}$ for each migration year except 2001 as follows:

$$
\begin{aligned}
& S A R_{\text {Annual }}=w\left(T_{0}^{*}\right) * \operatorname{SAR}\left(T_{0}\right) \\
& +w\left(C_{0}^{*}\right) * \operatorname{SAR}\left(C_{0}\right) \\
& \text { where, } \quad+w\left(C_{1}^{*}\right) * \operatorname{SAR}\left(C_{1}\right) \\
& T_{0}^{*}=\left(t_{2}\right)+\left(\frac{t_{3}}{S_{2}}\right)+\left(\frac{t_{4}}{S_{2} * S_{3}}\right) \\
& C_{1}^{*}=\left(T_{0}+C_{1}\right)-T_{0}^{*}
\end{aligned}
$$

and,

reflect the number of PIT-tag smolts in transport and bypass categories, respectively, if collected PIT-tag smolts were routed to transportation in the same proportion as run-at-large; and

$$
\begin{aligned}
& w\left(T_{0}^{*}\right)=\frac{T_{0}^{*}}{\left(T_{0}^{*}+C_{0}+C_{1}^{*}\right)} \text { is the transported smolt proportion, } \\
& w\left(C_{0}\right)=\frac{C_{0}}{\left(T_{0}^{*}+C_{0}+C_{1}^{*}\right)} \text { is the non-detected (LGR, LGS, LMN) smolt } \\
& 17
\end{aligned}
$$


proportion, and proportion.

$$
w\left(C_{1}^{*}\right)=1-w\left(T_{0}^{*}\right)-w\left(C_{0}\right) \text { is the bypass (LGR, LGS, LMN) smolt }
$$

\section{Estimation of overall annual SARs in migration year 2006}

With the new approach of pre-assignment into the Groups TWS and BWS, the estimation of annual overall SARs become much simpler. The Group TWS reflects the untagged fish passage experience under a given year's fish passage management scenario. Therefore, estimation of the annual overall SAR is simply the number of returning adults in this group divided by the estimated number of smolts arriving LGR (both detected and undetected). The estimated number of PIT-tagged smolts arriving LGR is obtained by multiplying the TWS group's release number by the estimated $\mathrm{S}_{1}$ (survival rate from release to LGR tailrace) obtained from running the CJS model on the combined TWS and BWS groups. The Group BWS has its migrants bypassed if collected at a dam throughout the season. Combining Groups TWS and BWS provides the original release group from which the standard $\mathrm{T}_{0}, \mathrm{C}_{0}$, and $\mathrm{C}_{1}$ study categories may be obtained for migration year 2006. The overall SAR for Group TWS migrants does not require a weighting of group-specific SARs; its overall SAR is directly estimated as the number of returning adults divided by the total population (i.e., detected and estimated undetected PIT-tag population) at LGR. 


\section{Chapter 3 -- \\ Annual SAR by Study Category, TIR, $S_{\mathrm{R}}$, and $D$ for Hatchery and Wild Spring/Summer Chinook Salmon and Steelhead: Patterns and Significance}

\section{General}

The following survival rates, patterns and trends were observed for the spring/ summer Chinook and summer steelhead PIT-tagged smolts analyzed in the CSS. The primary focus of comparisons was between the transported and in-river smolts. Key parameters for these comparisons were $\operatorname{SAR}\left(\mathrm{T}_{0}\right), \mathrm{SAR}\left(\mathrm{C}_{0}\right), \mathrm{SAR}\left(\mathrm{C}_{1}\right), \mathrm{S}_{\mathrm{R}}, \mathrm{TIR}, \mathrm{D}$, and the annual overall SARs (the latter parameter is presented in Chapter 6).

A combination of factors in 2001, such as exceptional environmental conditions, low in-river survival, and no-spill hydrosystem operations to maximized transportation of smolts, resulted in very few estimated Category $\mathrm{C}_{0}$ migrants. Obtaining a valid estimate of the number of PIT-tagged wild and hatchery steelhead in Category $\mathrm{C}_{0}$ in 2001 was also problematic due to the apparently large amount of residualism that year. Most inriver steelhead migrants with an adult return were actually detected as smolts in the lower river in 2002 (details in CSS 10-yr Retrospective Analysis Report). Returning adults of steelhead and Chinook that had no detections were more likely to have either completed their smolt migration in 2002 or passed undetected into the raceways during a computer outage in mid-May at LGR than traversed the entire hydrosystem undetected in 2001. Because of the uncertainty in passage route and timing of the undetected PITtagged migrants in 2001, and the likelihood that smolts passing through a bypass will have higher survival than those passing through the turbines of three consecutive dams, PIT-tagged $C_{1}$ migrants should provide a conservatively higher $S A R$ than $C_{0}$ migrants in that year, and would better bracket the in-river SAR potential for the run-at-large in 2001 . Due to these conditions, $\mathrm{C}_{1}$ data were used instead of $\mathrm{C}_{0}$ data in the computation of SAR, TIR, and D parameters and therefore is presented separately for comparison to other years in the multi-year geometric averages computed for $\mathrm{S}_{\mathrm{R}}$, TIR, and D.

Migration years 2004 and 2005 also had lower levels of spill at Lower Granite (LGR) and Little Goose (LGS) dams than in prior non-2001 years, resulting in high collection efficiency at those two dams and a lower than usual percentage of PIT-tagged smolts estimated to pass the three collector dams on the Snake River undetected $\left(\mathrm{C}_{0}\right.$ migrants). Migration year 2004 was less affected than 2005. In 2004, wild and hatchery Chinook had $>6 \%$ of the LGR population of PIT-tagged smolts in Category $\mathrm{C}_{0}$, while hatchery steelhead had only $2.3 \%$ and wild steelhead had only $2.6 \%$. In 2005, these percentages were much smaller at $1.4 \%$ for wild steelhead, $1.8 \%$ for hatchery steelhead, $4.0 \%$ for wild Chinook, and $4.9-7.9 \%$ for the five CSS hatchery Chinook groups (see Chapter 6 Tables $6.1-6.2,6.4-6.5$ ). This resulted in low numbers of PIT-tagged smolts in Category $\mathrm{C}_{0}$, which could create unreliable estimates of SARs for that category of fish. Therefore, the in-river group for 2005 is based on the combination of PIT-tagged $\mathrm{C}_{0}$ and $\mathrm{C}_{1}$ migrants for both Chinook and steelhead, while only steelhead in 2004 needed the combination of PIT-tagged $\mathrm{C}_{0}$ and $\mathrm{C}_{1}$ migrants to create the in-river group for SARs and related parameters.

Low number of PIT-tagged wild Chinook, wild steelhead, and hatchery steelhead 
smolts transported and small number of returning adults limited this study's ability to detect potential differences in SARs for smolts based on dam from which they were transported. The 90\% confidence intervals of the site-specific SARs were extremely wide and overlapping across all three dams in each year of study for wild Chinook (Table A-35), wild steelhead (Table A-40), and hatchery steelhead (Table A-42). Likewise, low number of PIT-tagged hatchery Chinook smolts transported from LGS prior to 2000 and from LMN in any year, as well as the small number of returning adults from these sites' transported fish, limited this study's ability to detect potential differences in sitespecific SARs. The $90 \%$ confidence intervals of the site-specific SARs are extremely wide and overlapping across all three dams in all years of study with the following exceptions (Tables A-37 and A-38). Based on non-overlapping 90\% confidence intervals, the hatchery Chinook transportation SAR at LGR was significantly higher than at LGS for Rapid River Hatchery Chinook in 1998 and 2001, McCall Hatchery Chinook in 1999, 2000, and 2001, and Imnaha Hatchery Chinook in 2000. The inability to evaluate site-specific SAR for all species and years does not impacted the conduct of this study since our goal has been to create an overall multi-dam estimate of transportation SAR for comparison with the SARs of in-river migrants. Also, these analyses are regarding comparisons within single years. For general comparisons between transportation SARs from different sites using a multi-year approach, see chapter four of our 10-year retrospective summary report.

The number of PIT-tagged wild Chinook, hatchery Chinook, wild steelhead, and hatchery steelhead utilized in the CSS analyses by location of origin are presented in Appendix Table A-1 to A-4, respectively. All tables in Chapter 3 that are found in Appendix A will be referenced as Table A- [\#] to distinguish from tables (Table 3.[\#]) that are located directly in the chapter.

\section{Wild Chinook}

Estimated numbers of wild Chinook smolts in each study category are presented in Table A-5 along with the estimated population of tagged fish arriving at LGR. The table provides a bootstrapped $90 \%$ confidence interval around each estimate, along with the number of returning adults in each study category. Most PIT-tagged wild Chinook were in the $\mathrm{C}_{1}$ study category due to the default operation of routing most PIT-tagged fish back to the river at the Snake River collector dams. Until 2002, the number of PITtagged wild Chinook actually transported was relatively small relative to the number of untagged wild Chinook transported. Beginning in 2002, the CSS coordinated with IDFG, ODFW, and CTUIR research programs to route 50\% (raised to $67 \%$ the following year) of the first-time detected PIT-tagged wild Chinook smolts at the Snake River transportation facilities to the raceways for transportation. This action has provided more PIT-tagged wild Chinook smolts in the transportation category in recent years. The individual reach survival estimates used to expand PIT-tag smolt counts in each study category to LGR equivalents are presented in Table A-21 for each migration year.

The estimated LGR-LGR SAR for PIT-tagged wild Chinook were generally low exceeding $2 \%$ in only 3 of 13 years for the SAR $\left(\mathrm{C}_{0}\right)$ and only one for the SAR $\left(\mathrm{T}_{0}\right)$ (Table 3.1 and Figure 3.1). Wild Chinook survival levels are far below those recommended $(2 \%)$ to maintain a stable population or $(4 \%)$ to achieve recovery (Marmorek et al. 1998). The estimated SARs were exceptionally low $<0.6 \%$ for both the $\operatorname{SAR}\left(\mathrm{C}_{0}\right)$ and $\mathrm{SAR}\left(\mathrm{T}_{0}\right)$ in 2003 to 2005, just as occurred in 1994 to 1996. The $\mathrm{SAR}\left(\mathrm{C}_{0}\right)$ was only $0.14 \%$ in 2001. 


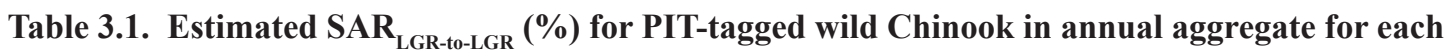
study category from 1994 to 2006 (with $90 \%$ confidence intervals).

\begin{tabular}{|c|c|c|c|c|c|c|}
\hline Mig. Year & & $\operatorname{SAR}\left(\mathrm{T}_{0}\right) \%$ & \multicolumn{2}{|r|}{$\operatorname{SAR}\left(C_{0}\right) \%$} & \multicolumn{2}{|c|}{$\operatorname{SAR}\left(C_{1}\right) \%$} \\
\hline 1994 & 0.45 & $(0.20-0.72)$ & 0.28 & $(0.11-0.51)$ & 0.07 & $(0.02-0.14)$ \\
\hline 1995 & 0.35 & $(0.17-0.57)$ & 0.37 & $(0.18-0.57)$ & 0.25 & $(0.18-0.32)$ \\
\hline 1996 & 0.50 & $(0.00-107)$ & 0.26 & $(0.10-0.48)$ & 0.13 & $(0.06-0.23)$ \\
\hline 1997 & 1.74 & $(0.44-3.27)$ & 2.35 & $(1.45-3.36)$ & 0.93 & $(0.60-1.32)$ \\
\hline 1998 & 1.18 & $(0.71-1.70)$ & 1.36 & $(1.05-1.70)$ & 1.07 & $(0.91-1.22)$ \\
\hline 1999 & 2.43 & $(1.85-3.07)$ & 2.13 & $(1.78-2.50)$ & 1.89 & $(1.76-2.04)$ \\
\hline 2000 & 1.43 & $(0.74-2.14)$ & 2.39 & $(2.08-2.72)$ & 2.33 & $(2.12-2.52)$ \\
\hline 2001 & 1.28 & $(0.54-2.14)$ & \multicolumn{2}{|c|}{ Assume $=\operatorname{SAR}\left(C_{1}\right)$} & 0.14 & $(0.10-0.18)$ \\
\hline 2002 & 0.80 & $(0.57-1.04)$ & 1.22 & $(0.99-1.45)$ & 0.99 & $(0.84-1.14)$ \\
\hline 2003 & 0.34 & $(0.24-0.45)$ & 0.33 & $(0.23-0.43)$ & 0.17 & $(0.12-0.23)$ \\
\hline 2004 & 0.53 & $(0.42-0.63)$ & 0.49 & $(0.26-0.74)$ & 0.22 & $(0.16-0.29)$ \\
\hline 2005 & 0.23 & $(0.17-0.29)$ & \multicolumn{4}{|c|}{$0.11^{\mathrm{A}} \quad(0.07-0.15)$} \\
\hline $2006^{\text {B }}$ & 0.61 & $(0.49-0.74)$ & 0.69 & $(0.47-0.94)$ & 0.37 & $(0.26-0.48)$ \\
\hline $\begin{array}{l}\text { Average } \\
90 \% \text { CI }\end{array}$ & $\begin{array}{l}0.91 \\
(0.59\end{array}$ & $-1.24)$ & $\begin{array}{l}1.00 \\
(0.59\end{array}$ & $-1.24)$ & $\begin{array}{r}0.71 \\
(0.32\end{array}$ & 1.10) \\
\hline
\end{tabular}

${ }^{\mathrm{A}}$ In-river SAR is combination of groups $\mathrm{C}_{0}$ and $\mathrm{C}_{1}$

${ }^{\text {B }}$ Mig. year 2006 data is combined groups TWS \& BWS; incomplete with 2-salt adult returns as of $8 / 13 / 2008$.

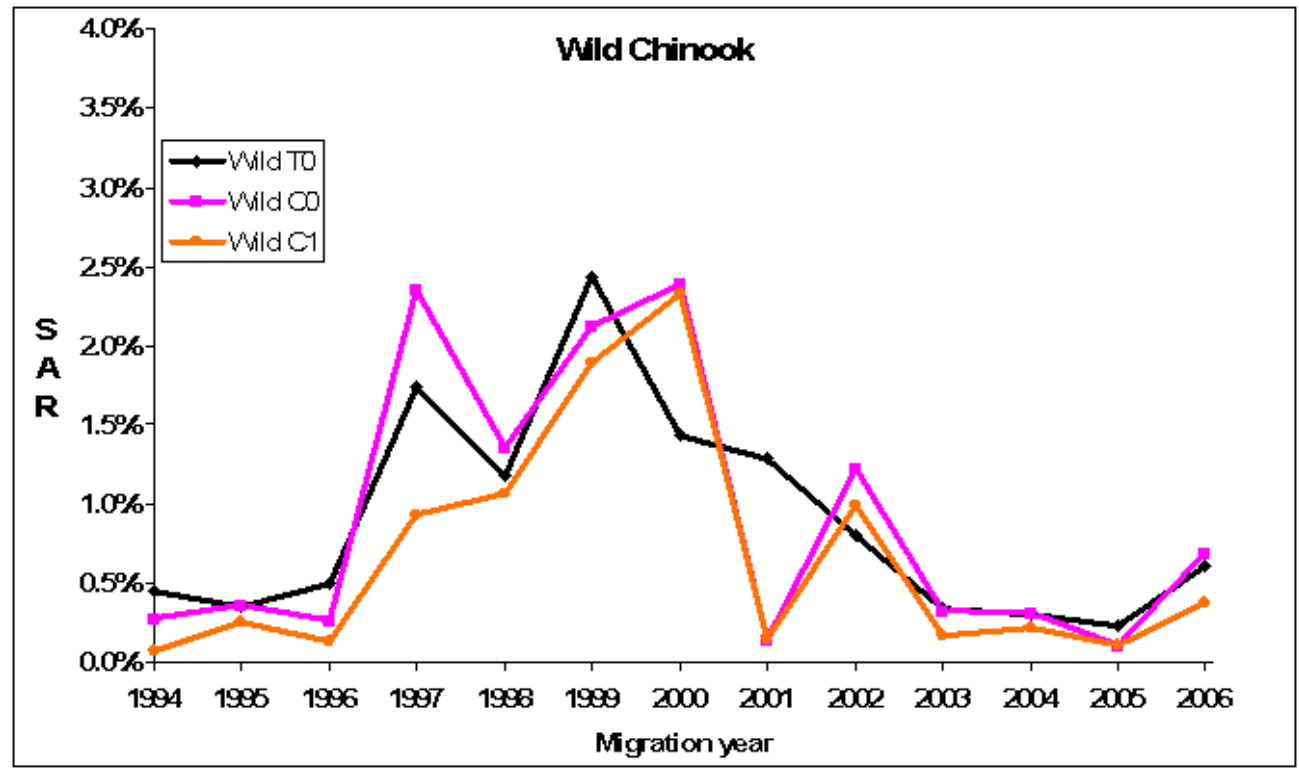

Figure 3.1. Estimated LGR-LGR SAR for PIT-tagged wild Chinook aggregate in transport $\left[\operatorname{SAR}\left(\mathrm{T}_{0}\right)\right]$ and in-river $\left[\operatorname{SAR}\left(\mathrm{C}_{0}\right)\right.$ and $\left.\operatorname{SAR}\left(\mathrm{C}_{1}\right)\right]$ study categories for migration years 1994 to 2006 (incomplete adult returns for 2006). 
The estimated in-river survival $\left(\mathrm{S}_{\mathrm{R}}\right)$ for migration from LGR tailrace to BON tailrace had considerable annual variability (Table A-13), and a geometric mean of 0.46. The annual trend in $S_{R}$ for wild Chinook is presented in Figure 3.3 and discussed later when comparisons are made to CSS PIT-tagged hatchery Chinook.

The TIR is a measure of the relative annual performance for the transported $\mathrm{T}_{0}$ and in-river $\mathrm{C}_{0}$ smolts. Due to the $\mathrm{T}_{0}$ smolts having an average survival about twice that of the $\mathrm{C}_{0}$ smolts $(0.98 \%$ versus $0.46 \%)$, the TIR for wild Chinook should have an "expected value" of 2. The estimated TIRs for wild Chinook (Table A-13) had a range of 0.60 to 2.12 and geometric mean of 1.07 for the 12-yr series without 2001, and only exceeds 2 in 2001 and 2005. The 90\% confidence intervals of TIR tend to be large due to small sample sizes. The annual trend in TIR for wild Chinook is presented in Figure 3.4 and discussed later when comparisons are made to CSS PIT-tagged hatchery Chinook

A TIR $>1$, which indicates a positive effect for transportation, was estimated in 7 of the 11 years for wild Chinook (Table 3.2). However, the lower limit of the $90 \%$ confidence interval for TIR only exceeded 1 in 2001 and 2005, which demonstrates statistical significance for that year. The remaining years of PIT-tag data for wild Chinook show a pattern whereby transportation is generally not beneficial.

In the absence of differential delayed mortality of transported fish post-BON compared to in-river migrants, D should average 1. Only the 2001 and $2005 D$ estimate were $>1$. The 12-yr geometric mean (excluding 2001) of D was 0.53 for wild Chinook. It should be noted that the $90 \%$ confidence intervals around the estimated D show relatively low precision in most of the years available, indicating the difficulty of getting precise D estimates with the small sample sizes of PIT-tagged wild Chinook available. Table 3.2 shows a statistically significant D $>1$ was not achieved in 2001 or 2005 for wild Chinook, in spite of earlier demonstrating a statistically significant TIR for that year. The annual trend in D for wild Chinook is presented later in Figure 3.5 when comparisons are made to CSS PIT-tagged hatchery Chinook.

Table 3.2. PIT-tagged wild Chinook estimated $\theta$ for TIR and $D$ and corresponding lower limit of non-parametric confidence interval, which provides a one-tail $(\alpha=0.05)$ test of $H_{0}: \theta \leq 1$ versus $H_{A}: \theta>1$. Note: either $\theta>1$ or $\theta$ lower limit $>1$ are highlighted in red .

\begin{tabular}{|l|c|c|c|c|}
\hline \multirow{2}{*}{$\begin{array}{l}\text { M i g r } \\
\text { Year }\end{array}$} & \multicolumn{4}{|c|}{ Wild Chinook } \\
\cline { 2 - 5 } & TIR & TIR Lower Limit & D & D Lower Limit \\
\hline 1994 & $\mathbf{1 . 6 2}$ & 0.62 & 0.36 & 0.13 \\
\hline 1995 & 0.95 & 0.39 & 0.42 & 0.17 \\
\hline 1996 & $\mathbf{1 . 9 2}$ & 0.00 & 0.92 & 0.00 \\
\hline 1997 & 0.74 & 0.17 & 0.40 & 0.08 \\
\hline 1998 & 0.87 & 0.50 & 0.55 & 0.31 \\
\hline 1999 & $\mathbf{1 . 1 4}$ & 0.82 & 0.72 & 0.52 \\
\hline 2000 & 0.60 & 0.32 & 0.32 & 0.17 \\
\hline $2001^{\mathrm{A}}$ & $\mathbf{8 . 9 6}$ & $\mathbf{3 . 6 1}$ & $\mathbf{2 . 1 6}$ & 0.87 \\
\hline $2002^{203}$ & 0.65 & 0.45 & 0.44 & 0.29 \\
\hline 2003 & $\mathbf{1 . 0 6}$ & 0.68 & 0.68 & 0.43 \\
\hline 2004 & $\mathbf{1 . 0 9}$ & 0.68 & 0.45 & 0.27 \\
\hline $2005^{\mathrm{B}}$ & $\mathbf{2 . 1 4}$ & $\mathbf{1 . 4 0}$ & $\mathbf{1 . 0 6}$ & 0.63 \\
\hline $2006^{\mathrm{C}}$ & 0.88 & 0.60 & 0.54 & 0.34 \\
\hline
\end{tabular}

${ }^{A} \mathrm{SAR}\left(\mathrm{C}_{1}\right)$ used in 2001 in derivation of TIR and $\mathrm{D}$.

${ }^{\mathrm{B}}$ In-river SAR is combination of groups $\mathrm{C}_{0}$ and $\mathrm{C}_{1}$ in derivation of TIR and $\mathrm{D}$.

${ }^{\mathrm{C}}$ Mig. year 2006 data is combined groups TWS \& BWS; incomplete with 2-salt adult returns as of $8 / 13 / 2008$. 


\section{Hatchery Chinook (with comparisons to wild Chinook)}

Estimated numbers of hatchery Chinook smolts in each study category are presented in Tables A-6 to A-10 for fish from Rapid River, Dworshak, Catherine Creek, McCall, and Imnaha hatcheries, respectively, along with the estimated population of tagged fish arriving at Lower Granite Dam. These tables provide a bootstrapped 90\% confidence interval around each estimate, along with the number of returning adults in each study category.

The estimated LGR-LGR SAR for hatchery Chinook (Tables 3.3 to 3.7) were low for the $\operatorname{SAR}\left(\mathrm{C}_{0}\right)$ and generally less than or equal to wild Chinook (Table 3.1 and Figure 3.2 [top plot]). In general, estimates of $\mathrm{SAR}\left(\mathrm{C}_{1}\right)$ were less than $\mathrm{SAR}\left(\mathrm{C}_{0}\right)$ whenever separate estimates for both groups $\mathrm{C}_{0}$ and $\mathrm{C}_{1}$ were possible (Figure 3.2 [middle plot]). Whereas, $\operatorname{SAR}\left(\mathrm{T}_{0}\right)$ was not as low in general for hatchery Chinook and, except for Dworshak Hatchery, tended to be greater than the wild Chinook (Figure 3.2 [bottom plot]).

There is considerable within-year variability in SAR performance between hatchery Chinook populations (Figure 3.2). However, the between-year variability is generally similar between hatcheries, as well as between hatchery groups in the aggregate and wild Chinook. The aggregate hatchery groups appear to have the potential for surrogate representation of the wild Chinook regarding annual survival rate trends, but not in the magnitude of survival rates.

The SARs for the PIT-tagged hatchery Chinook are generally in the same range as the PIT-tagged wild Chinook for the $\mathrm{C}_{0}$ smolts. McCall hatchery summer Chinook are the only hatchery population with an average $\mathrm{SAR}\left(\mathrm{C}_{0}\right)$ equal to wild Chinook, all others exhibit lower $\mathrm{SAR}\left(\mathrm{C}_{0}\right)$ values (Figure 3.2 top). SARs for the hatchery $\mathrm{T}_{0}$ smolts had mixed performance relative to wild $\mathrm{T}_{0}$ smolts (Figure 3.2 bottom). Two hatcheries (Dworshak and Catherine Creek) exhibited lower $\mathrm{T}_{0}$ than wild smolts. The other three hatcheries (Rapid River, McCall, and Imnaha) exhibited greater $\mathrm{T}_{0}$ than wild smolts. The $\mathrm{C}_{1}$ category for the hatchery smolts had average SARs that were lower than the $\mathrm{C}_{0}$ SARs for all hatcheries except Catherine Creek (Tables 3.3 to 3.7 and Figure 3.2 middle). 

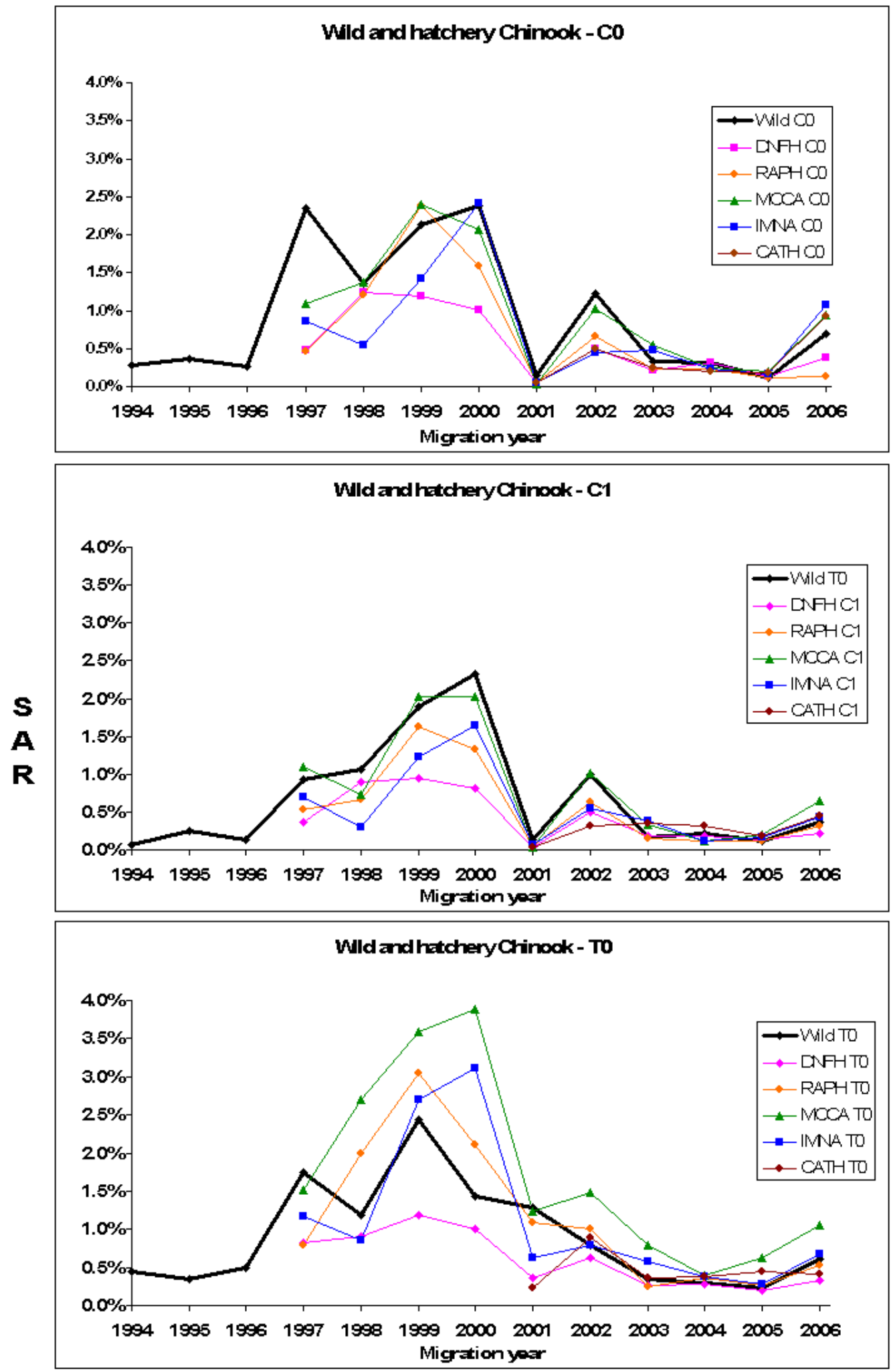

Figure 3.2 Trend in $\operatorname{SAR}\left(C_{0}\right)$ (top plot), $\operatorname{SAR}\left(C_{1}\right)$ (middle plot) and $\operatorname{SAR}\left(T_{0}\right)$ (bottom plot) for PITtagged Snake River wild and hatchery spring/summer Chinook in migration years 1994 to 2006. 


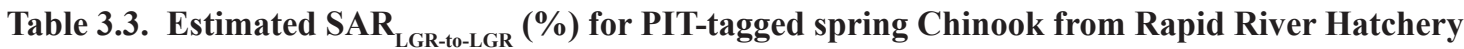
for each study category from 1997 to 2006 (with $90 \%$ confidence intervals).

\begin{tabular}{|c|c|c|c|}
\hline Mig. Year & $\operatorname{SAR}\left(\mathrm{T}_{0}\right) \%$ & $\operatorname{SAR}\left(\mathrm{C}_{0}\right) \%$ & $\operatorname{SAR}\left(C_{1}\right) \%$ \\
\hline 1997 & $0.79 \quad(0.57-1.01)$ & $0.45 \quad(0.31-0.63)$ & $0.53 \quad(0.39-0.68)$ \\
\hline 1998 & $2.00 \quad(1.80-2.21)$ & $1.20 \quad(0.95-1.48)$ & $0.67 \quad(0.56-0.79)$ \\
\hline 1999 & $3.04 \quad(2.78-3.31)$ & $2.37 \quad(2.07-2.68)$ & $1.63(1.46-1.79)$ \\
\hline 2000 & $2.10 \quad(1.91-2.28)$ & $1.59 \quad(1.40-1.81)$ & $1.33 \quad(1.07-1.58)$ \\
\hline 2001 & $1.08 \quad(0.96-1.21)$ & $\left\{\right.$ Assume $\left.=\operatorname{SAR}\left(\mathrm{C}_{1}\right)\right\}$ & $0.05 \quad(0.02-0.08)$ \\
\hline 2002 & $1.01 \quad(0.86-1.16)$ & $0.67 \quad(0.55-0.79)$ & $0.63 \quad(0.53-0.74)$ \\
\hline 2003 & $(0.18-0.32)$ & $(0.17-0.29)$ & $0.15 \quad(0.08-0.24)$ \\
\hline 2004 & $0.36 \quad(0.29-0.43)$ & $0.23 \quad(0.11-0.39)$ & $0.12 \quad(0.07-0.16)$ \\
\hline 2005 & $0.27 \quad(0.21-0.34)$ & \multicolumn{2}{|c|}{$0.12^{\mathrm{A}} \quad(0.07-0.16)$} \\
\hline $2006^{\mathrm{B}}$ & $0.52 \quad(0.44-0.61)$ & $0.42 \quad(0.34-0.51)$ & $0.31 \quad(0.26-0.36)$ \\
\hline $\begin{array}{l}\text { Average } \\
90 \% \text { CI }\end{array}$ & $\begin{array}{l}1.14 \\
(0.60-1.67)\end{array}$ & $\begin{array}{l}0.81 \\
(0.34-1.28)\end{array}$ & $\begin{array}{l}0.60 \\
(0.26-0.94)\end{array}$ \\
\hline
\end{tabular}

${ }^{\bar{A}}$ In-river SAR is combination of groups $\mathrm{C}_{0}$ and $\mathrm{C}_{1}$

${ }^{\text {B }}$ Mig. year 2006 data is combined groups TWS \& BWS; incomplete with 2-salt adult returns as of $8 / 13 / 2008$.

Table 3.4. Estimated SAR LGR-to-LGR $(\%)$ for PIT-tagged spring Chinook from Dworshak Hatchery for each study category from 1997 to 2006 (with $90 \%$ confidence intervals).

\begin{tabular}{|c|c|c|c|}
\hline Mig. Year & $\operatorname{SAR}\left(\mathrm{T}_{0}\right) \%$ & $\operatorname{SAR}\left(C_{0}\right) \%$ & $\operatorname{SAR}\left(C_{1}\right) \%$ \\
\hline 1997 & $0.83 \quad(0.52-1.19)$ & $0.47 \quad(0.26-0.72)$ & $0.36 \quad(0.21-0.54)$ \\
\hline 1998 & $0.90 \quad(0.77-1.02)$ & $1.25 \quad(1.08-1.42)$ & $0.90 \quad(0.77-1.04)$ \\
\hline 1999 & $1.18 \quad(1.01-1.35)$ & $1.19 \quad(1.01-1.37)$ & $0.95 \quad(0.82-1.07)$ \\
\hline 2000 & $1.00 \quad(0.88-1.12)$ & $1.01 \quad(0.87-1.16)$ & $0.81 \quad(0.62-1.02)$ \\
\hline 2001 & $0.36 \quad(0.29-0.43)$ & $\left\{\right.$ Assume $\left.=\operatorname{SAR}\left(C_{1}\right)\right\}$ & $0.04 \quad(0.02-0.07)$ \\
\hline 2002 & $0.62 \quad(0.49-0.75)$ & $0.50 \quad(0.42-0.58)$ & $0.50 \quad(0.40-0.58)$ \\
\hline 2003 & $0.26 \quad(0.19-0.33)$ & $0.21 \quad(0.16-0.27)$ & $0.18 \quad(0.10-0.27)$ \\
\hline 2004 & $0.28 \quad(0.23-0.35)$ & $0.32 \quad(0.21-0.44)$ & $0.18 \quad(0.13-0.25)$ \\
\hline 2005 & $0.20 \quad(0.16-0.26)$ & \multicolumn{2}{|c|}{$0.14^{\mathrm{A}} \quad(0.10-0.19)$} \\
\hline $2006^{\mathrm{B}}$ & $0.33 \quad(0.26-0.40)$ & $0.38 \quad(0.31-0.45)$ & $0.22 \quad(0.18-0.25)$ \\
\hline $\begin{array}{l}\text { Average } \\
90 \% \text { CI }\end{array}$ & $\begin{array}{l}0.60 \\
(0.39-0.80)\end{array}$ & $\begin{array}{l}0.61 \\
(0.34-0.87)\end{array}$ & $\begin{array}{l}0.46 \\
(0.25-0.67)\end{array}$ \\
\hline
\end{tabular}

${ }^{\mathrm{A}}$ In-river SAR is combination of groups $\mathrm{C}_{0}$ and $\mathrm{C}_{1}$

${ }^{\text {B }}$ Migration year 2006 is incomplete with Age 2-salt adult returns through 8/13/2008. 
Table 3.5. Estimated SAR LGR-to-LGR $(\%)$ for PIT-tagged spring Chinook from Catherine Creek AP for each study category from 2001 to 2006 (with $90 \%$ confidence intervals).

\begin{tabular}{|c|c|c|c|}
\hline Mig. Year & $\operatorname{SAR}\left(T_{0}\right) \%$ & $\operatorname{SAR}\left(C_{0}\right) \%$ & $\operatorname{SAR}\left(C_{1}\right) \%$ \\
\hline 2001 & $0.23 \quad(0.12-0.35)$ & $\left\{\right.$ Assume $\left.=\operatorname{SAR}\left(\mathrm{C}_{1}\right)\right\}$ & $0.04 \quad(0.00-0.09)$ \\
\hline 2002 & $0.89 \quad(0.59-1.20)$ & $0.49 \quad(0.28-0.74)$ & $0.32 \quad(0.18-0.50)$ \\
\hline 2003 & $0.36 \quad(0.20-0.56)$ & $0.25 \quad(0.10-0.41)$ & $0.35 \quad(0.14-0.61)$ \\
\hline 2004 & $0.38 \quad(0.21-0.57)$ & $0.20 \quad(0.00-0.60)$ & $0.32 \quad(0.11-0.54)$ \\
\hline 2005 & $0.44 \quad(0.24-0.65)$ & \multicolumn{2}{|c|}{$0.18^{\mathrm{A}} \quad(0.04-0.35)$} \\
\hline $2006^{\mathrm{B}}$ & $0.41 \quad(0.21-0.61)$ & $0.92 \quad(0.55-1.34)$ & $0.44 \quad(0.21-0.73)$ \\
\hline $\begin{array}{l}\text { Average } \\
90 \% \text { CI }\end{array}$ & $\begin{array}{l}0.45 \\
(0.27-0.64)\end{array}$ & $\begin{array}{l}0.41 \\
(0.11-0.71)\end{array}$ & $\begin{array}{l}0.29 \\
(0.15-0.44)\end{array}$ \\
\hline
\end{tabular}

${ }^{\mathrm{A}}$ In-river SAR is combination of groups $\mathrm{C}_{0}$ and $\mathrm{C}_{1}$

${ }^{\text {B }}$ Mig. year 2006 data is combined groups TWS \& BWS; incomplete with 2-salt adult returns as of 8/13/2008.

Table 3.6. Estimated SAR LGR-to-LGR $(\%)$ for PIT-tagged summer Chinook from McCall Hatchery for each study category from 1997 to 2006 (with $90 \%$ confidence intervals).

\begin{tabular}{|c|c|c|c|}
\hline Mig. Year & $\operatorname{SAR}\left(T_{0}\right) \%$ & $\operatorname{SAR}\left(C_{0}\right) \%$ & $\operatorname{SAR}\left(C_{1}\right) \%$ \\
\hline 1997 & $1.51 \quad(1.26-1.77)$ & $1.09 \quad(0.88-1.34)$ & $1.10 \quad(0.92-1.29)$ \\
\hline 1998 & $2.69 \quad(2.44-2.96)$ & $1.38 \quad(1.05-1.69)$ & $0.73 \quad(0.62-0.87)$ \\
\hline 1999 & $3.59 \quad(3.29-3.87)$ & $2.40 \quad(2.12-2.69)$ & $2.03 \quad(1.82-2.26)$ \\
\hline 2000 & $3.88 \quad(3.60-4.18)$ & $2.06 \quad(1.84-2.29)$ & $2.03 \quad(1.68-2.38)$ \\
\hline 2001 & $1.24 \quad(1.10-1.38)$ & $\left\{\right.$ Assume $\left.=\operatorname{SAR}\left(\mathrm{C}_{1}\right)\right\}$ & $0.04 \quad(0.01-0.07)$ \\
\hline 2002 & $(1.27-1.70)$ & $1.03 \quad(0.87-1.20)$ & $1.02(0.89-1.18)$ \\
\hline 2003 & $0.79 \quad(0.68-0.92)$ & $0.54 \quad(0.45-0.62)$ & $0.34 \quad(0.24-0.46)$ \\
\hline 2004 & $0.40 \quad(0.34-0.48)$ & $0.25 \quad(0.09-0.44)$ & $0.12 \quad(0.07-0.16)$ \\
\hline 2005 & $0.62 \quad(0.54-0.71)$ & \multicolumn{2}{|c|}{$0.20^{\mathrm{A}} \quad(0.16-0.26)$} \\
\hline $2006^{\mathrm{B}}$ & $1.06 \quad(0.93-1.21)$ & $0.95 \quad(0.78-1.12)$ & $0.64 \quad(0.50-0.77)$ \\
\hline $\begin{array}{l}\text { Average } \\
90 \% \text { CI }\end{array}$ & $\begin{array}{l}1.73 \\
(1.01-2.44)\end{array}$ & $\begin{array}{l}1.10 \\
(0.63-1.57)\end{array}$ & $\begin{array}{l}0.89 \\
(0.44-1.35)\end{array}$ \\
\hline
\end{tabular}

${ }^{\mathrm{A}}$ In-river SAR is combination of groups $\mathrm{C}_{0}$ and $\mathrm{C}_{1}$

${ }^{B}$ Mig. year 2006 data is combined groups TWS \& BWS; incomplete with 2-salt adult returns as of $8 / 13 / 2008$. 
Table 3.7. Estimated SAR LGR-to-LGR $(\%)$ for PIT-tagged summer Chinook from Imnaha River AP for each study category from 1997 to 2006 (with $90 \%$ confidence intervals).

\begin{tabular}{|c|c|c|c|}
\hline Mig. Year & $\operatorname{SAR}\left(\mathrm{T}_{0}\right) \%$ & $\operatorname{SAR}\left(C_{0}\right) \%$ & $\operatorname{SAR}\left(C_{1}\right) \%$ \\
\hline 1997 & $1.16 \quad(0.77-1.60)$ & $0.86 \quad(0.53-1.22)$ & $0.69 \quad(0.48-0.93)$ \\
\hline 1998 & $0.85 \quad(0.65-1.09)$ & $0.55 \quad(0.28-0.83)$ & $0.30 \quad(0.20-0.42)$ \\
\hline 1999 & $2.69 \quad(2.28-3.08)$ & $1.43 \quad(1.08-1.82)$ & $1.22 \quad(0.98-1.49)$ \\
\hline 2000 & $3.11 \quad(2.77-3.44)$ & $2.41 \quad(2.01-2.83)$ & $1.64 \quad(1.22-2.08)$ \\
\hline 2001 & $0.62 \quad(0.49-0.78)$ & $\left\{\right.$ Assume $\left.=\operatorname{SAR}\left(\mathrm{C}_{1}\right)\right\}$ & $0.06 \quad(0.01-0.11)$ \\
\hline 2002 & $0.79 \quad(0.56-1.04)$ & $0.45 \quad(0.29-0.63)$ & $0.55 \quad(0.38-0.72)$ \\
\hline 2003 & $0.58 \quad(0.40-0.75)$ & $0.48 \quad(0.34-0.62)$ & $0.38 \quad(0.20-0.59)$ \\
\hline 2004 & $0.38 \quad(0.26-0.49)$ & $0.23 \quad(0.07-0.48)$ & $0.11 \quad(0.04-0.20)$ \\
\hline 2005 & $0.28 \quad(0.18-0.40)$ & \multicolumn{2}{|c|}{$0.16^{\mathrm{A}} \quad(0.08-0.26)$} \\
\hline $2006^{\text {B }}$ & $0.68 \quad(0.50-0.88)$ & $1.07 \quad(0.76-1.39)$ & $0.43 \quad(0.26-0.59)$ \\
\hline $\begin{array}{l}\text { Average } \\
90 \% \text { CI }\end{array}$ & $\begin{array}{l}1.11 \\
(0.54-1.68)\end{array}$ & $\begin{array}{l}0.85 \\
(0.41-1.29)\end{array}$ & $\begin{array}{l}0.60 \\
(0.27-0.92)\end{array}$ \\
\hline
\end{tabular}

${ }^{\mathrm{A}}$ In-river SAR is combination of groups $\mathrm{C}_{0}$ and $\mathrm{C}_{1}$

${ }^{B}$ Mig. year 2006 data is combined groups TWS \& BWS; incomplete with 2-salt adult returns as of $8 / 13 / 2008$.

Estimated in-river survival rates from LGR tailrace to BON tailrace $\left(S_{R}\right)$ in the more recent years of 2004 and 2005 have been consistently lower than the 9-yr geometric mean (0.51) covering 1997-2000 and 2002-2006 (Tables A-14 to A-18), although not as low as the in-river survival estimates during the drought year 2001. In-river survival $\left(S_{R}\right.$ ranging from 0.48 to 0.60 ) improved in 2006 as flows and spill levels were higher than the preceding two years. The individual reach survival estimates for each migration year and hatchery used to compute $S_{R}$ are presented in Tables A-22 to A-26. Annual trends in $S_{R}$ over the period 1994 to 2006 (hatchery Chinook beginning 1997) are presented in Figure 3.3 for both wild and hatchery Chinook.

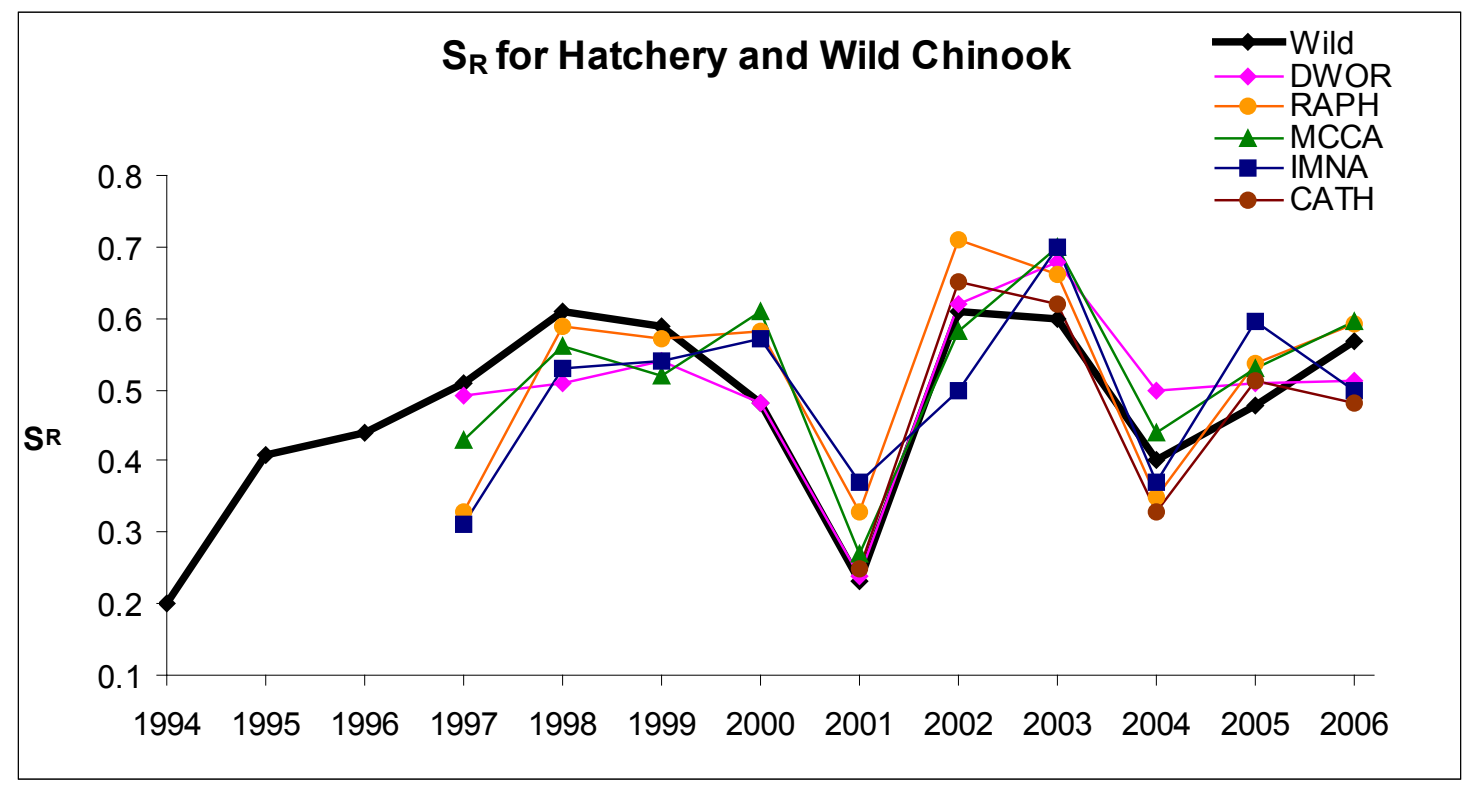

Figure 3.3. Trend in in-river survival $\left(S_{R}\right)$ for PIT-tagged Snake River wild and hatchery spring/ summer Chinook in migration years 1994 to 2004. 
TIR had substantial variability between hatcheries and between years. In 2001, all hatchery Chinook TIRs were very large as illustrated with $\ln (\mathrm{TIR})$ in Figure 3.9. Excluding migration year 2001, geometric mean TIRs covering the 9 years from 1997-2000 and 20022006 have been around 1.5 for Rapid River, McCall, and Imnaha Hatchery Chinook (Tables A-14, A-17, and A-18). For Dworshak Hatchery Chinook, the 9-yr geometric mean TIR was 1.08 (Table A-15). Although Catherine Creek AP hatchery Chinook have a shorter time series of data (Table A-16), this stocks' TIRs tend to follow the former three hatcheries closer than Dworshak Hatchery. Trends in TIR (log transformed) are presented in Figure 3.4 .

The lower limit of the $90 \%$ confidence interval for TIR exceeded 1 in nearly half of the hatchery Chinook TIR estimates, demonstrating a statistical significance (Tables 3.8 and 3.9). Statistically significant TIR $>1$ occurred for Rapid River Hatchery in 8 of 10 years, Dworshak Hatchery in 1 of 10 years, Catherine Ck Hatchery in 2 of 6 years, McCall Hatchery in 7 of 10 years, and Imnaha Hatchery in 4 of 10 years. For hatchery spring/ summer Chinook smolts, transportation was generally beneficial and smolt transport was highly beneficial in 2001 with TIR $>5$ at each hatchery (Tables 3.8 and 3.9). However, the generally lower annual TIRs for Dworshak Hatchery reveal a more limited potential for transportation to benefit that stock.

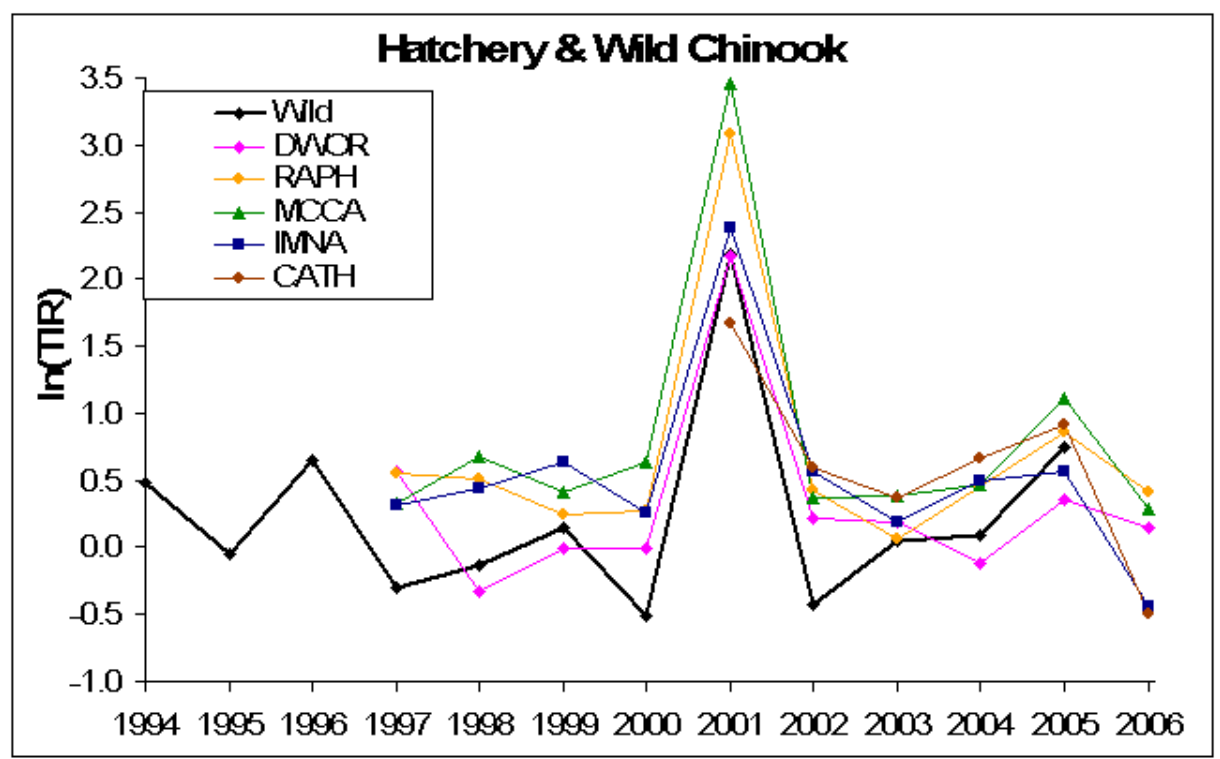

Figure 3.4. Trend in TIR (log-transformed) for PIT-tagged Snake river hatchery and wild Chinook for migration years 1994 to 2006. 
Table 3.8. Estimated TIR and corresponding lower limit of non-parametric confidence interval, which provides a one-tail $(\alpha=0.05)$ test of $H_{0}$ : TIR $\leq 1$ versus $H_{A}$ : TIR $>1$, of PIT-tagged wild Chinook compared to hatchery spring Chinook. TIR $>1$ and TIR lower limit $>1$ are highlighted in red.

\begin{tabular}{|c|c|c|c|c|c|c|c|c|}
\hline \multirow{3}{*}{$\begin{array}{l}\text { Migr. } \\
\text { Year }\end{array}$} & \multirow{2}{*}{\multicolumn{2}{|c|}{ Wild Chinook }} & \multicolumn{6}{|c|}{\begin{tabular}{|c|} 
Hatchery Spring Chinook \\
\end{tabular}} \\
\hline & & & \multicolumn{2}{|c|}{ Rapid River $\mathbf{H}$} & \multicolumn{2}{|c|}{ Dworshak H } & \multicolumn{2}{|c|}{ Catherine Ck AP } \\
\hline & TIR & $\mathbf{L L}$ & TIR & $\mathbf{L L}$ & TIR & $\mathbf{L L}$ & TIR & $\mathbf{L L}$ \\
\hline 1997 & 0.74 & 0.17 & 1.73 & 1.08 & 1.75 & 0.92 & & \\
\hline 1998 & 0.87 & 0.50 & 1.66 & 1.32 & 0.72 & 0.59 & & \\
\hline 1999 & 1.14 & 0.82 & 1.28 & 1.11 & 0.99 & 0.81 & & \\
\hline 2000 & 0.60 & 0.32 & 1.32 & 1.13 & 0.99 & 0.82 & & \\
\hline $2001^{\mathrm{A}}$ & 8.96 & 3.61 & 21.7 & 13.3 & 8.76 & 5.04 & 5.33 & 0 \\
\hline 2002 & 0.65 & 0.45 & 1.5 & 1.20 & 1.24 & 0.93 & 1.81 & 1.02 \\
\hline 2003 & 1.06 & 0.68 & 1.07 & 0.73 & 1.21 & 0.81 & 1.46 & 0.64 \\
\hline 2004 & 1.09 & 0.68 & 1.57 & 0.88 & 0.89 & 0.59 & 1.94 & 0 \\
\hline $2005^{\text {B }}$ & 2.14 & 1.40 & 2.36 & 1.59 & 1.43 & 0.97 & 2.48 & 1.02 \\
\hline $2006^{C}$ & 0.88 & 0.60 & 1.25 & 0.96 & 0.87 & 0.65 & 0.45 & .0 .02 \\
\hline
\end{tabular}

${ }^{A} \mathrm{SAR}\left(\mathrm{C}_{1}\right)$ used in 2001 in derivation of TIR.

${ }^{\mathrm{B}}$ In-river $\mathrm{SAR}$ is combination of groups $\mathrm{C}_{0}$ and $\mathrm{C}_{1}$ in derivation of TIR.

${ }^{\mathrm{C}} \mathrm{Mig}$. year 2006 data is combined groups TWS \& BWS; incomplete with 2-salt adult returns as of $8 / 13 / 2008$. 
Table 3.9. Estimated TIR and corresponding lower limit of non-parametric confidence interval, which provides a one-tail $(\alpha=0.05)$ test of $H_{0}: T I R \leq 1$ versus $H_{A}: T I R>1$, of PIT-tagged wild Chinook compared to hatchery summer Chinook. TIR $>1$ and TIR lower limit $>1$ are highlighted in red.

\begin{tabular}{|c|c|c|c|c|c|c|}
\hline \multirow{3}{*}{$\begin{array}{l}\text { Migr. } \\
\text { Year }\end{array}$} & \multirow{2}{*}{\multicolumn{2}{|c|}{ Wild Chinook }} & \multicolumn{4}{|c|}{ Hatchery Summer Chinook } \\
\hline & & & \multicolumn{2}{|c|}{ McCall H } & \multicolumn{2}{|c|}{ Imnaha AP } \\
\hline & TIR & LL & TIR & $\mathbf{L L}$ & TIR & $\mathbf{L L}$ \\
\hline 1997 & 0.74 & 0.17 & 1.38 & 1.06 & 1.36 & 0.83 \\
\hline 1998 & 0.87 & 0.50 & 1.96 & 1.54 & 1.55 & 0.93 \\
\hline 1999 & 1.14 & 0.82 & 1.49 & 1.29 & 1.89 & 1.40 \\
\hline 2000 & 0.60 & 0.32 & 1.89 & 1.67 & 1.29 & 1.06 \\
\hline $2001^{\mathrm{A}}$ & 8.96 & 3.61 & 31.9 & 7.90 & 10.8 & 4.94 \\
\hline 2002 & 0.65 & 0.45 & 1.44 & 1.18 & 1.75 & 1.07 \\
\hline 2003 & 1.06 & 0.68 & 1.47 & 1.18 & 1.21 & 0.80 \\
\hline 2004 & 1.09 & 0.68 & 1.59 & 0.87 & 1.64 & 0.54 \\
\hline $2005^{\text {B }}$ & 2.14 & 1.40 & 3.02 & 2.33 & 1.77 & 0.91 \\
\hline $2006^{\mathrm{C}}$ & 0.88 & 0.60 & 1.11 & 0.89 & 0.64 & 0.43 \\
\hline
\end{tabular}

${ }^{\mathrm{A}} \mathrm{SAR}\left(\mathrm{C}_{1}\right)$ used in 2001 in derivation of TIR.

${ }^{\mathrm{B}}$ In-river $\mathrm{SAR}$ is combination of groups $\mathrm{C}_{0}$ and $\mathrm{C}_{1}$ in derivation of TIR.

${ }^{\mathrm{C}}$ Mig. year 2006 data is combined groups TWS \& BWS; incomplete with 2-salt adult returns as of 8/13/2008.

NOTE: need to update WCH columns here

In the absence of differential delayed mortality, D should average close to 1. However, except for 2001 when estimated D exceeded 1 at each hatchery, the remaining years have seen a 10-yr geometric mean D of 0.63 at Dworshak Table A-15), 0.80 at Imnaha (Table A-18), 0.84 at Rapid River (Table A-14), and 0.96 at McCall (Table A-17) hatcheries. A statistically significant $\mathrm{D}>1$ was demonstrated for Chinook from Rapid River, Dworshak, and Imnaha hatcheries in 2001 and McCall Hatchery in 2001 and 2005 (Tables 3.10 and 3.11). Trends in D (log transformed) are presented in Figure 3.5.

Table 3.10. Estimated $D$ and corresponding lower limit of non-parametric confidence interval, which provides a one-tail $(\alpha=0.05)$ test of $H_{0}: D \leq 1$ versus $H_{A}: D>1$, of PIT-tagged wild Chinook compared to hatchery spring Chinook. D $>1$ and $D$ lower limit $>1$ are highlighted in red.

\begin{tabular}{|c|c|c|c|c|c|c|c|c|}
\hline \multirow{2}{*}{$\begin{array}{l}\text { Migr. } \\
\text { Year }\end{array}$} & \multirow{2}{*}{\multicolumn{2}{|c|}{ Wild Chinook }} & \multicolumn{6}{|c|}{ Hatchery Spring Chinook } \\
\hline & & & \multicolumn{2}{|c|}{ Rapid River $\mathbf{H}$} & \multicolumn{2}{|c|}{ Dworshak H } & \multicolumn{2}{|c|}{ Catherine Ck AP } \\
\hline 1997 & 040 & 0.08 & 0.61 & 037 & 088 & 040 & & \\
\hline 1998 & 055 & 031 & 1.01 & 0.80 & 0.37 & 0.30 & & \\
\hline 1999 & 0.72 & 0.52 & 0.79 & 0.65 & 0.60 & 0.47 & & \\
\hline 2000 & 0.32 & 0.17 & 0.82 & 0.66 & 0.53 & 0.42 & & \\
\hline $2001^{\mathrm{A}}$ & 2.16 & 0.87 & 7.33 & 4.40 & 2.21 & 1.23 & 1.38 & 0.03 \\
\hline 2002 & 0.44 & 0.29 & 1.14 & 0.87 & 0.84 & 0.61 & 1.23 & 0.59 \\
\hline 2003 & 0.68 & 0.43 & 0.75 & 0.50 & 0.88 & 0.58 & 0.94 & 0.41 \\
\hline 2004 & 0.45 & 0.27 & 0.57 & 0.31 & 0.46 & 0.29 & 0.95 & 0 \\
\hline $2005^{\mathrm{B}}$ & 1.06 & 0.63 & 1.31 & 0.84 & 0.77 & 0.51 & 1.32 & 0.50 \\
\hline $2006^{\mathrm{C}}$ & 0.54 & 0.34 & 0.84 & 0.63 & 0.54 & 0.40 & 0.24 & 0.11 \\
\hline
\end{tabular}

${ }^{A} \mathrm{SAR}\left(\mathrm{C}_{1}\right)$ used in 2001 in derivation of $\mathrm{D}$.

${ }^{\mathrm{B}}$ In-river SAR is combination of groups $\mathrm{C}_{0}$ and $\mathrm{C}_{1}$ in derivation of $\mathrm{D}$.

${ }^{\mathrm{C}}$ Mig. year 2006 data is combined groups TWS \& BWS; incomplete with 2-salt adult returns as of $8 / 13 / 2008$. 
Table 3.11. Estimated $D$ and corresponding lower limit of non-parametric confidence interval, which provides a one-tail $(\alpha=0.05)$ test of $H_{0}: D \leq 1$ versus $H_{A}: D>1$, of PIT-tagged wild Chinook compared to hatchery summer Chinook. $\mathrm{D}>1$ and $\mathrm{D}$ lower limit $>1$ are highlighted in red.

\begin{tabular}{|c|c|c|c|c|c|c|}
\hline \multirow{3}{*}{$\begin{array}{l}\text { Migr. } \\
\text { Year }\end{array}$} & \multirow{2}{*}{\multicolumn{2}{|c|}{ Wild Chinook }} & \multicolumn{4}{|c|}{ Hatchery Summer Chinook } \\
\hline & & & & & & \\
\hline & D & $\mathrm{LL}$ & D & $\mathrm{LL}$ & D & $\mathrm{LL}$ \\
\hline 1997 & 0.40 & 0.08 & 0.64 & 0.43 & 0.45 & 0.24 \\
\hline 1998 & 0.55 & 0.31 & 1.16 & 0.89 & 0.87 & 0.51 \\
\hline 1999 & 0.72 & 0.52 & 0.87 & 0.72 & 1.11 & 0.75 \\
\hline 2000 & 0.32 & 0.17 & 1.24 & 0.98 & 0.82 & 0.56 \\
\hline $2001^{\mathrm{A}}$ & 2.16 & 0.87 & 8.95 & 4.87 & 4.15 & 1.83 \\
\hline 2002 & 0.44 & 0.29 & 0.87 & 0.68 & 0.95 & 0.54 \\
\hline 2003 & 0.68 & 0.43 & 1.09 & 0.85 & 0.91 & 0.57 \\
\hline 2004 & 0.45 & 0.27 & 0.72 & 0.37 & 0.94 & 0.27 \\
\hline $2005^{\mathrm{B}}$ & 1.06 & 0.63 & 1.67 & 1.23 & 1.11 & 0.54 \\
\hline $2006^{\mathrm{C}}$ & 0.54 & 0.34 & 0.74 & 0.59 & 0.37 & 0.25 \\
\hline
\end{tabular}

${ }^{\mathrm{A}} \mathrm{SAR}\left(\mathrm{C}_{1}\right)$ used in 2001 in derivation of $\mathrm{D}$.

${ }^{\mathrm{B}}$ In-river $\mathrm{SAR}$ is combination of groups $\mathrm{C}_{0}$ and $\mathrm{C}_{1}$ in derivation of $\mathrm{D}$.

${ }^{\mathrm{C}}$ Mig. year 2006 data is combined groups TWS \& BWS; incomplete with 2-salt adult returns as of $8 / 13 / 2008$.

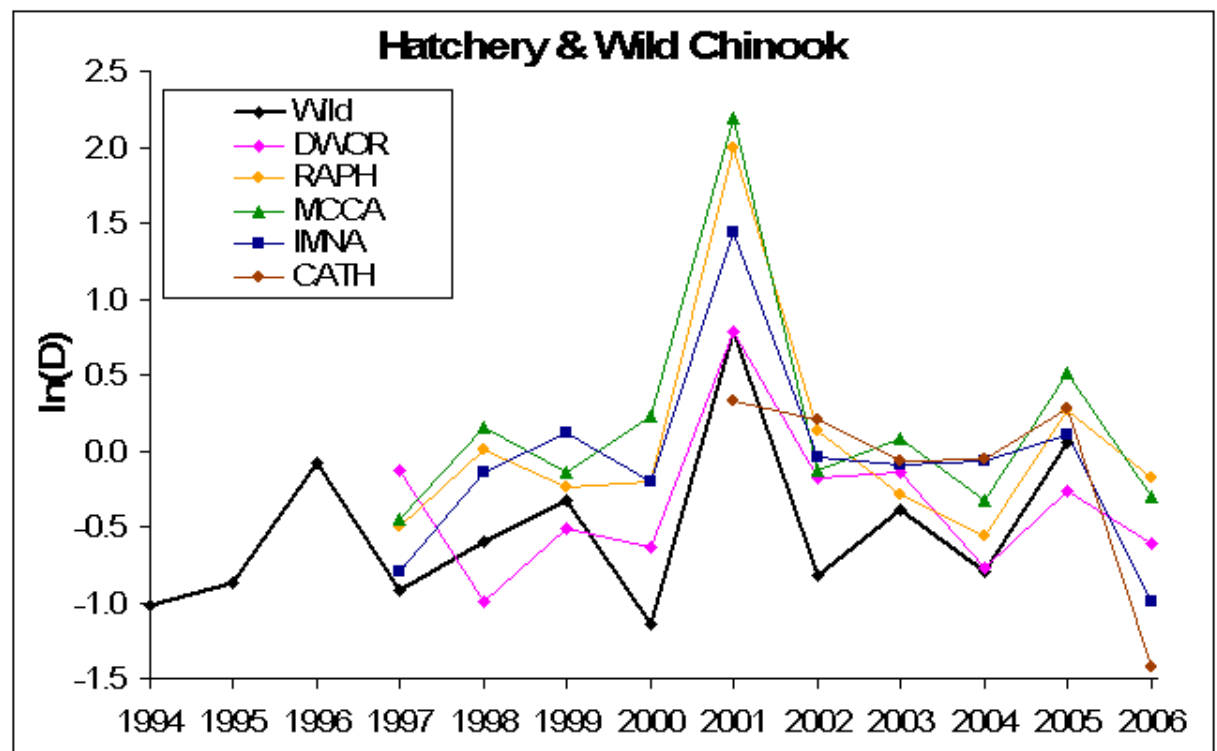

Figure 3.5. Trend in $D$ (log-transformed) for PIT-tagged Snake River hatchery and wild Chinook in migration years 1994-2006.

Although wild and hatchery populations demonstrated differences in magnitude for some parameters (TIR, D, and SARs), the annual patterns of these parameters were similar among wild and hatchery populations. In-river survival $\left(S_{R}\right)$ of the wild population tracked closely with survival of hatchery populations across years (Figure 3.3). Although TIRs were higher for Snake River hatcheries than for wild fish, the TIR 
pattern for the wild population tracked well with those of the hatchery populations across years (Figure 3.4). Similarly, Snake River hatchery fish had higher D values than wild fish, but wild and hatchery Ds also tracked well across years (Figure 3.5).

\section{Wild steelhead (with comparisons to wild Chinook)}

The estimated number of PIT-tagged wild steelhead smolts (with bootstrapped $90 \%$ confidence intervals) arriving at LGR for each CSS study category, $\mathrm{T}_{0}, \mathrm{C}_{0}$, and $\mathrm{C}_{1}$, are presented in Table A-11 along with the associated number of returning adults in each study category. Through migration year 2002, few PIT-tagged wild steelhead were in the $\mathrm{T}_{0}$ study category due to the default operation of routing most PIT-tagged fish back to the river at the Snake River collector dams. Until 2003, the number of PIT-tagged wild steelhead actually transported has been relatively small relative to the number of untagged wild steelhead transported. Beginning in 2003, more PIT-tagged wild steelhead have become available in the transport group as state and tribal research programs allowed a portion of their PIT-tagged wild steelhead smolts to be routed to the raceways at Snake River transportation facilities.

The SARs for PIT-tagged wild steelhead were generally low for the $\mathrm{C}_{0}$ groups (average $0.71 \%$ ) and never exceed 2\% (Table 3.12 and Figure 3.6). The SARs for the $\mathrm{T}_{0}$ groups were greater (average 1.84\%) and exceeded $2 \%$ in 4 of the 9 years analyzed (1999 -2005). The sample sizes for wild steelhead have been small, which results in few adult returns and rather large 90\% confidence intervals for the SAR estimates (Table 3.12).

Table 3.12. Estimated SAR LGR-to-LGR $(\%)$ for PIT-tagged wild steelhead in annual aggregate for each study category from 1997 to 2005 (with $90 \%$ confidence intervals).

\begin{tabular}{|c|c|c|c|c|c|}
\hline Mig. Year & $\operatorname{SAR}\left(\mathrm{T}_{0}\right)$ & SAR(C & & SAR & \\
\hline 1997 & $1.45 \quad(0.36-2.80)$ & 0.66 & $(0.00-1.34)$ & 0.23 & $(0.10-0.39)$ \\
\hline 1998 & $0.21 \quad(0.0-0.63)$ & 1.07 & $(0.51-1.73)$ & 0.21 & $(0.12-0.33)$ \\
\hline 1999 & $3.07 \quad(1.74-4.66)$ & 1.35 & $(0.80-1.96)$ & 0.76 & $(0.60-0.94)$ \\
\hline 2000 & $(1.55-4.11)$ & 1.92 & $(1.40-2.49)$ & 1.81 & $(1.59-2.03)$ \\
\hline 2001 & $2.49 \quad(0.93-4.37)$ & $\{$ Assu & $\left.\mathrm{ne}=\operatorname{SAR}\left(\mathrm{C}_{1}\right)\right\}$ & 0.07 & $(0.03-0.10)$ \\
\hline 2002 & $2.84 \quad(1.52-4.43)$ & 0.67 & $(0.46-0.90)$ & 0.94 & $(0.77-1.11)$ \\
\hline 2003 & $(1.52-2.51)$ & 0.45 & $(0.27-0.66)$ & 0.52 & $(0.37-0.66)$ \\
\hline 2004 & $0.87 \quad(0.65-1.11)$ & \multicolumn{4}{|c|}{$0.06^{\mathrm{A}} \quad(0.02-0.11)$} \\
\hline $2005^{\mathrm{B}}$ & $0.82 \quad(0.62-1.04)$ & \multicolumn{4}{|c|}{$0.18^{\mathrm{A}} \quad(0.12-0.26)$} \\
\hline $\begin{array}{l}\text { Average } \\
90 \% \text { CI }\end{array}$ & $\begin{array}{l}1.84 \\
(1.26-2.41)\end{array}$ & $\begin{array}{l}0.71 \\
(0.37\end{array}$ & $-1.06)$ & $\begin{array}{l}0.5 \\
(0.2\end{array}$ & $-0.85)$ \\
\hline
\end{tabular}

${ }^{\mathrm{A}}$ In-river SAR is combination of groups $\mathrm{C}_{0}$ and $\mathrm{C}_{1}$

B Migration year 2005 is incomplete until 3-salt returns (if any) occur after 7/1/2008 at GRA. 


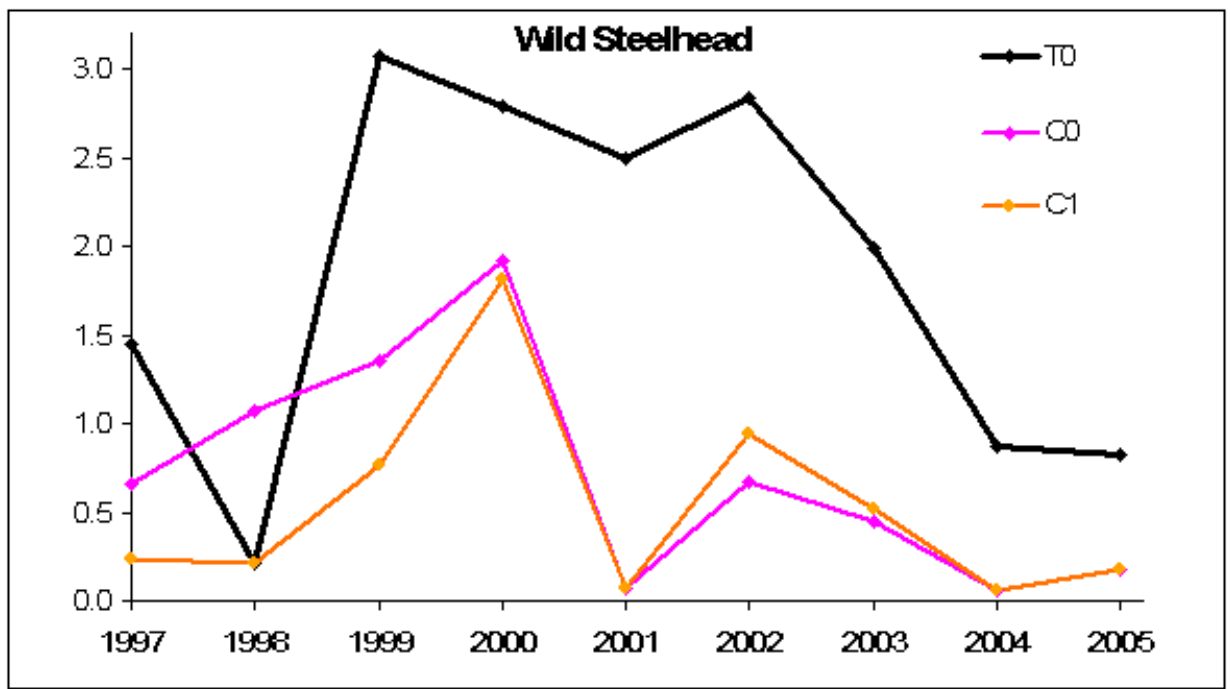

Figure 3.6. Estimated LGR-LGR SAR for PIT-tagged wild steelhead aggregate in transport $\left[\operatorname{SAR}\left(T_{0}\right)\right]$ and in-river $\left[\operatorname{SAR}\left(C_{0}\right)\right.$ and $\left.\operatorname{SAR}\left(C_{1}\right)\right]$ study categories for migration years 1997 to 2005 (incomplete adult returns for 2005).

For PIT-tagged wild steelhead, the geometric mean of $S_{R}$ for 1997 to 2005, excluding 2001, was 0.37 (Table A-19). In 2001, the estimated $S_{\mathrm{R}}$ is very low (0.038) as it includes both dead and holdover steelhead as mortalities. Over these same 8 years, the wild Chinook $S_{R}$ estimates had a geometric mean of 0.53 , which was $43 \%$ higher. The individual reach survival estimates for each migration year used to obtain $S_{R}$ are presented in Table A-27. Although starting in 1997 at the same level, the trend in the annual $S_{R}$ estimates for wild steelhead diverged in 1998 and then remained lower over the years $(1998$ - 2005) than that of wild Chinook, but with a similar pattern across those years (Figure 3.7).

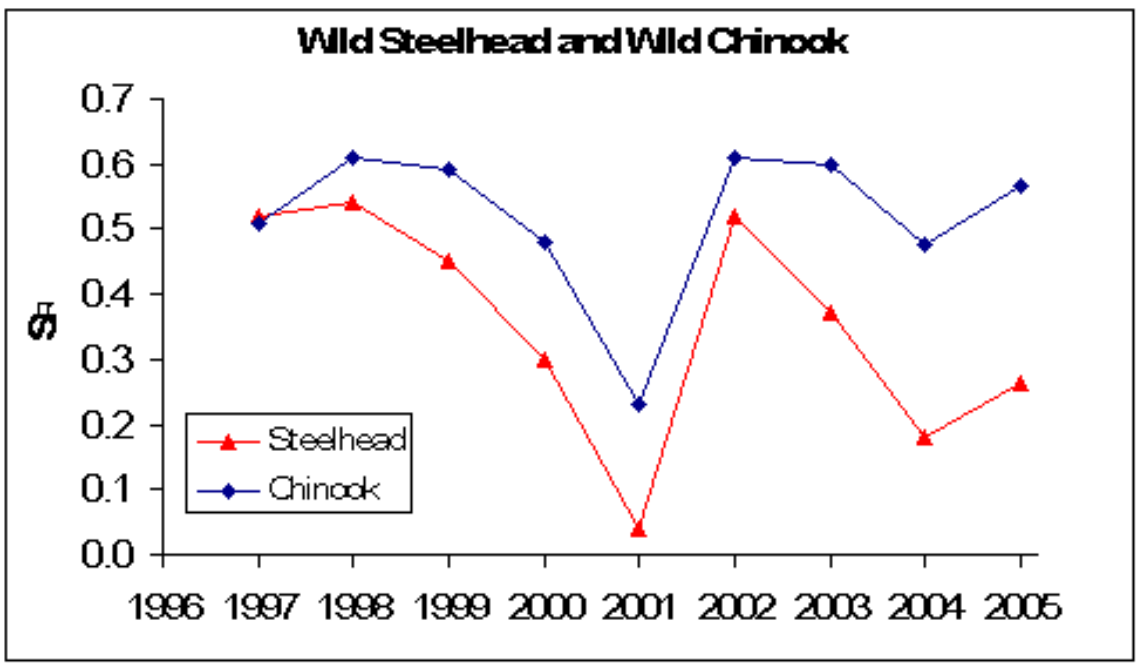

Figure 3.7. Trend in in-river survival $\left(S_{R}\right)$ for PIT-tagged Snake River wild steelhead and wild Chinook for migration years 1997 to 2005. 
The TIR estimates for wild steelhead, though based on small sample sizes, generally exceeded 1, with a geometric mean of 2.55 for 1997 to 2005, excluding 2001. The 2001 TIR estimate was very high $\sim 37$, due to exceptionally low in-river wild steelhead survival in that drought year. The 1998 migration year was the only year with estimated TIR $<1$. The lower limit of the $90 \%$ confidence interval for TIR was $>1$ in 6 of 9 years (1999 and 2001-2005), which demonstrates a statistical significance for those years (Table 3.13). For PIT-tagged wild steelhead smolts, transportation was generally beneficial and smolt transportation was highly beneficial in 2001 (Table 3.13). From 1999 to 2005, PIT-tagged wild steelhead exhibited a similar trend in TIR across years to that of PIT-tagged wild Chinook, but with a higher magnitude in TIR for each of these years (Figure 3.8).

Table 3.13. Estimated TIR and corresponding lower limit of non-parametric confidence interval, which provides a one-tail $(\alpha=0.05)$ test of $H_{0}:$ TIR $\leq 1$ versus $H_{A}$ : TIR $>1$, of PIT-tagged wild steelhead compared to wild Chinook. TIR $>1$ and TIR lower limit $>1$ are highlighted in red.

\begin{tabular}{|c|c|c|c|c|}
\hline \multirow{2}{*}{$\begin{array}{l}\text { Migr. } \\
\text { Year }\end{array}$} & \multicolumn{2}{|c|}{ Wild Steelhead } & \multicolumn{2}{|c|}{ Wild Chinook } \\
\hline & TIR & Lower Limit & TIR & Lower Limit \\
\hline 1997 & 2.20 & 0 & 0.74 & 0.17 \\
\hline 1998 & 0.20 & 0 & 0.87 & 0.50 \\
\hline 1999 & 2.28 & 1.15 & 1.14 & 0.82 \\
\hline 2000 & 1.45 & 0.77 & 0.60 & 0.32 \\
\hline $2001^{\mathrm{A}}$ & 37.0 & 10.6 & 8.96 & 3.61 \\
\hline 2002 & 4.25 & 2.12 & 0.65 & 0.45 \\
\hline 2003 & 4.41 & 2.74 & 1.06 & 0.68 \\
\hline 2004 & $14.3^{\mathrm{B}}$ & $7.32^{\text {в }}$ & 1.09 & 0.68 \\
\hline $2005^{\text {В С }}$ & 4.55 & 2.89 & 2.12 & 1.30 \\
\hline
\end{tabular}

${ }^{\mathrm{A}} \mathrm{SAR}\left(\mathrm{C}_{1}\right)$ used in 2001 in derivation of TIR.

${ }^{\mathrm{B}}$ In-river $\mathrm{SAR}$ is combination of groups $\mathrm{C}_{0}$ and $\mathrm{C}_{1}$ in derivation of TIR.

${ }^{\mathrm{C}}$ Migration year 2005 is incomplete until 3-salt returns (if any) occur after 7/1/2008 at GRA.

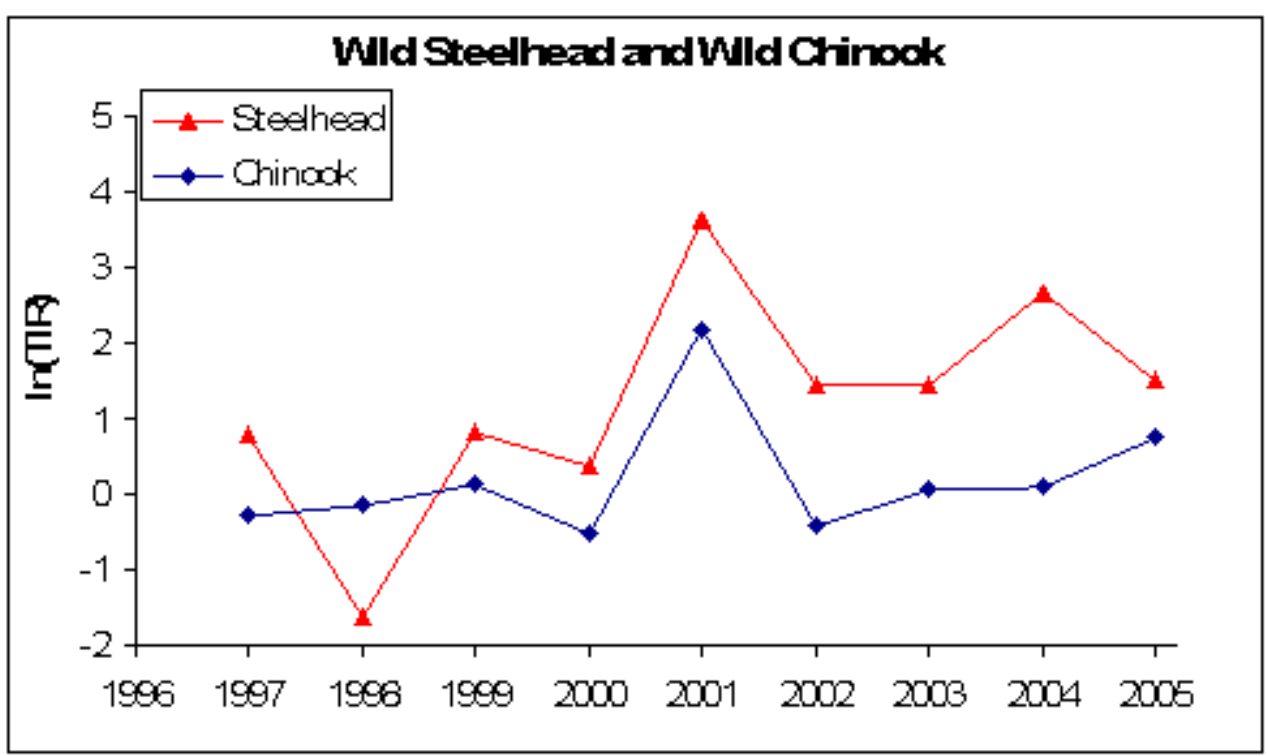

Figure 3.8. Trend in TIR (log transformed) for PIT-tagged wild steelhead and wild Chinook from migration years 1997 to 2005. 
The estimate of $D$ was $>1$ in 7 of 9 years for wild steelhead (Table 3.14). In three of those years (2002 - 2004), the lower limit of the $90 \%$ confidence interval for D was $>1$, which demonstrates a statistical significance for those years (Table 3.14). The D estimates for 1997-2000 and 2002-2005 had a geometric mean of 0.99 for wild steelhead compared to 0.53 for wild Chinook (Tables A-13 and A-19). This finding along with the trend across years shown in Figure 3.9, suggests a very different response to transportation as a recovery tool for listed wild Chinook and wild steelhead.

Table 3.14. Estimated $D$ and corresponding lower limit of non-parametric confidence interval, which provides a one-tail $(\alpha=0.05)$ test of $H_{0}: D \leq 1$ versus $H_{A}: D>1$, of PIT-tagged wild steelhead compared to wild Chinook. $\mathrm{D}>1$ and $\mathrm{D}$ lower limit $>1$ are highlighted in red.

\begin{tabular}{|l|c|c|c|c|}
\hline \multirow{2}{*}{$\begin{array}{c}\text { Mear } \\
\text { Year. }\end{array}$} & \multicolumn{2}{|c|}{ Wild Steelhead } & \multicolumn{2}{c|}{ Wild Chinook } \\
\cline { 2 - 5 } & $\mathbf{D}$ & Lower Limit & D & Lower Limit \\
\hline 1997 & $\mathbf{1 . 1 8}$ & 0.00 & 0.40 & 0.08 \\
\hline 1998 & 0.11 & 0.00 & 0.55 & 0.31 \\
\hline 1999 & $\mathbf{1 . 0 7}$ & 0.53 & 0.72 & 0.52 \\
\hline 2000 & 0.50 & 0.27 & 0.32 & 0.17 \\
\hline $2001^{\mathrm{A}}$ & $\mathbf{1 . 4 6}$ & 0.40 & $\mathbf{2 . 1 6}$ & 0.87 \\
\hline 2002 & $\mathbf{2 . 2 4}$ & $\mathbf{1 . 0 9}$ & 0.44 & 0.29 \\
\hline 2003 & $\mathbf{1 . 7 5}$ & $\mathbf{1 . 0 4}$ & 0.68 & 0.43 \\
\hline 2004 & $\mathbf{2 . 6 9}$ & $\mathbf{1 . 2 9}$ & & B \\
\hline $2005^{\mathrm{BC}}$ & $\mathbf{1 . 2 6}$ & 0.77 & 0.45 & 0.27 \\
\hline
\end{tabular}

${ }^{A} \operatorname{SAR}\left(\mathrm{C}_{1}\right)$ used in 2001 in derivation of $\mathrm{D}$.

${ }^{\mathrm{B}}$ In-river $\mathrm{SAR}$ is combination of groups $\mathrm{C}_{0}$ and $\mathrm{C}_{1}$ in derivation of $\mathrm{D}$.

${ }^{\mathrm{C}}$ Migration year 2005 is incomplete until 3-salt returns (if any) occur after 7/1/2008 at GRA.

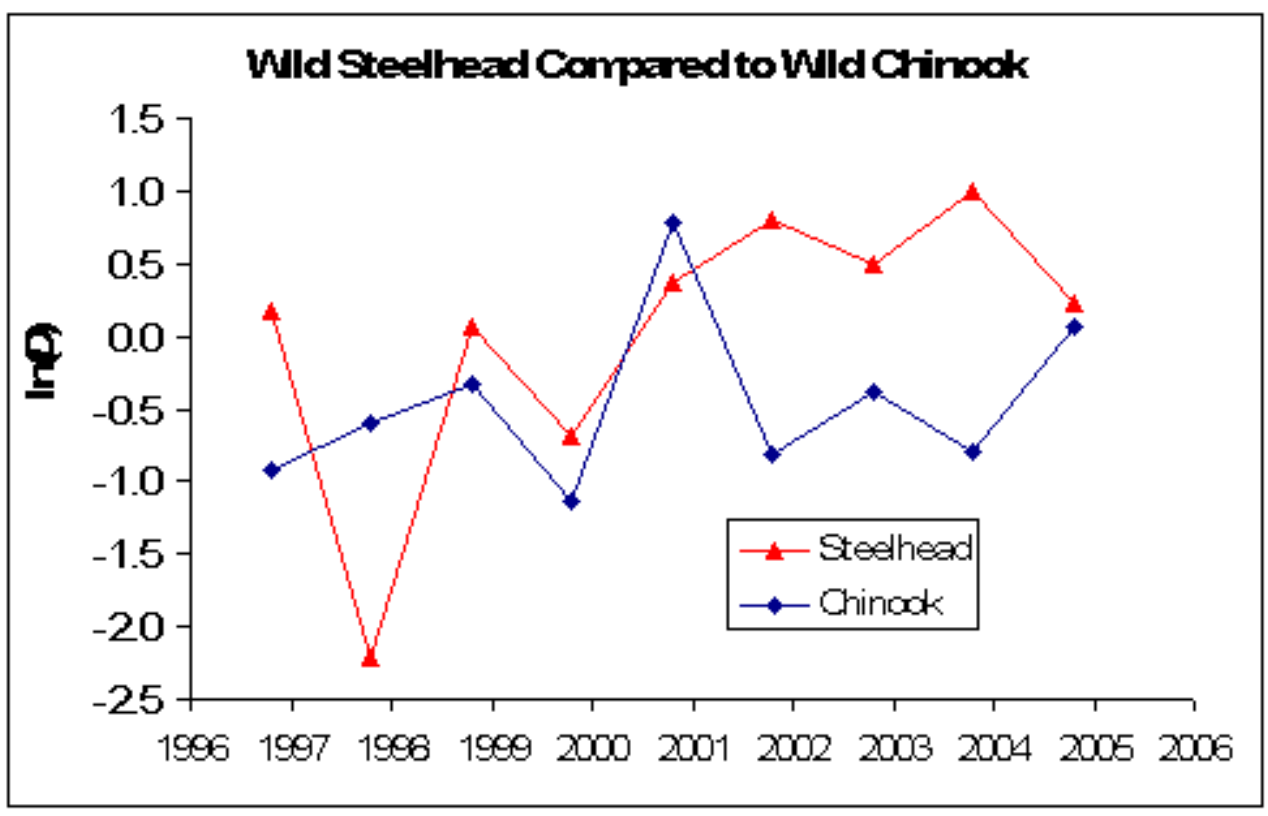

Figure 3.9. Trend in $D$ (log-transformed) for PIT-tagged Snake River wild steelhead and wild Chinook in migration years 1997-2005. 
The estimated number of PIT-tagged hatchery steelhead smolts (with bootstrapped $90 \%$ confidence intervals) arriving at LGR for each CSS study category, $\mathrm{T}_{0}, \mathrm{C}_{0}$, and $\mathrm{C}_{1}$, is presented in Table A-12 along with the associated number of returning adults in each study category. Except in 2003, the number of PIT-tagged hatchery steelhead transported has been small relative to the number of untagged hatchery steelhead transported. In 2003, more PIT-tagged hatchery steelhead have become available in the transport group as hatchery programs routed a portion of their PIT-tagged hatchery steelhead smolts to the raceways at Snake River transportation facilities.

Estimated SARs for hatchery steelhead in-river migrants $\left[\mathrm{SAR}\left(\mathrm{C}_{0}\right)\right]$ are exceptionally low (average $0.56 \%$ ) and only exceeded $1 \%$ in 1999 (Table 3.15). The SARs for the transported smolts $\left[\mathrm{SAR}\left(\mathrm{T}_{0}\right)\right]$ were higher than the SARs of in-river migrants, averaging $1.33 \%$ and exceeding $2 \%$ in 2000, 2004, and 2005 . The pattern of inter-annual variability for SARs was similar for hatchery and wild steelhead (Figure 3.10).

Table 3.15. Estimated SAR LGR-to-LGR $(\%)$ for PIT-tagged hatchery steelhead in annual aggregate for each study category from 1997 to 2005 (with $90 \%$ confidence intervals).

\begin{tabular}{|c|c|c|c|}
\hline Mig. Year & $\operatorname{SAR}\left(T_{0}\right)$ & $\operatorname{SAR}\left(C_{0}\right)$ & $\operatorname{SAR}\left(C_{1}\right)$ \\
\hline 1997 & $0.52 \quad(0.24-0.81)$ & $0.24 \quad(0.09-0.39)$ & $(0.12-0.22)$ \\
\hline 1998 & $0.51 \quad(0.22-0.84)$ & $(0.61-1.19)$ & $(0.17-0.28)$ \\
\hline 1999 & $(0.51-1.33)$ & $(0.79-1.31)$ & $(0.51-0.69)$ \\
\hline 2000 & $(1.22-3.07)$ & $0.95 \quad(0.71-1.19)$ & $(0.92-1.18)$ \\
\hline 2001 & $(0.24-1.78)$ & $\left\{\right.$ Assume $\left.=\operatorname{SAR}\left(\mathrm{C}_{1}\right)\right\}$ & $0.016(0.005-0.03)$ \\
\hline 2002 & $(0.32-2.11)$ & $0.70 \quad(0.54-0.88)$ & $0.73 \quad(0.61-0.85)$ \\
\hline 2003 & $(1.50-2.13)$ & $(0.52-0.86)$ & $(0.26-0.47)$ \\
\hline 2004 & $(1.17-3.27)$ & \multicolumn{2}{|c|}{$0.21^{\mathrm{A}} \quad(0.15-0.26)$} \\
\hline $2005^{\mathrm{B}}$ & $(1.28-2.83)$ & \multicolumn{2}{|c|}{$0.24^{\mathrm{A}} \quad(0.18-0.30)$} \\
\hline $\begin{array}{l}\text { Average } \\
90 \% \text { CI }\end{array}$ & $\begin{array}{l}1.33 \\
(0.96-1.71)\end{array}$ & $\begin{array}{l}0.56 \\
(0.35-0.76)\end{array}$ & $\begin{array}{l}0.40 \\
(0.22-0.58)\end{array}$ \\
\hline
\end{tabular}

${ }^{\mathrm{A}}$ In-river SAR is combination of groups $\mathrm{C}_{0}$ and $\mathrm{C}_{1}$

${ }^{\text {B }}$ Migration year 2005 is incomplete until 3-salt returns (if any) occur after 7/1/2008 at GRA. 


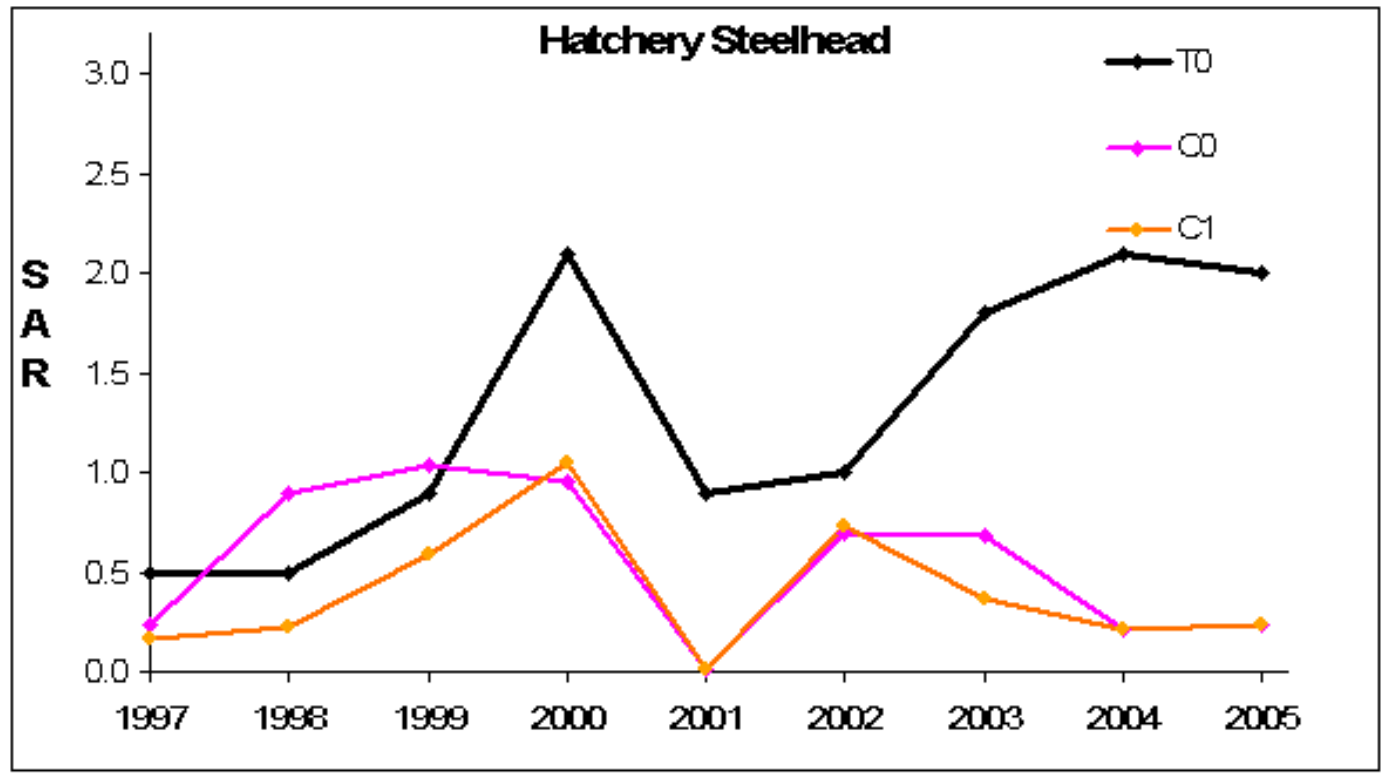

Figure 3.10. Estimated LGR-LGR SAR for PIT-tagged hatchery steelhead aggregate in transport $\left[\operatorname{SAR}\left(T_{0}\right)\right]$ and in-river $\left[\operatorname{SAR}\left(C_{0}\right)\right.$ and $\left.\operatorname{SAR}\left(C_{1}\right)\right]$ study categories for migration years 1997 to 2005 (incomplete adult returns for 2005).

For PIT-tagged hatchery steelhead, the geometric mean of $S_{R}$ for 1997 to 2005, excluding 2001, was 0.36 (Table A-20), a level close to the 0.37 estimate for wild steelhead (Table A-19). In 2001, the estimated $S_{\mathrm{R}}$ is very low (0.038) as it includes both dead and holdover steelhead as mortalities. Both hatchery and wild steelhead had the same estimated magnitude of $S_{R}$ for 2001. The individual reach survival estimates for each migration year used to obtain $S_{R}$ are presented in Table A-28. A similar trend in annual $S_{R}$ estimates for 1997-2005 is observed between wild and hatchery steelhead (Figure 3.11).

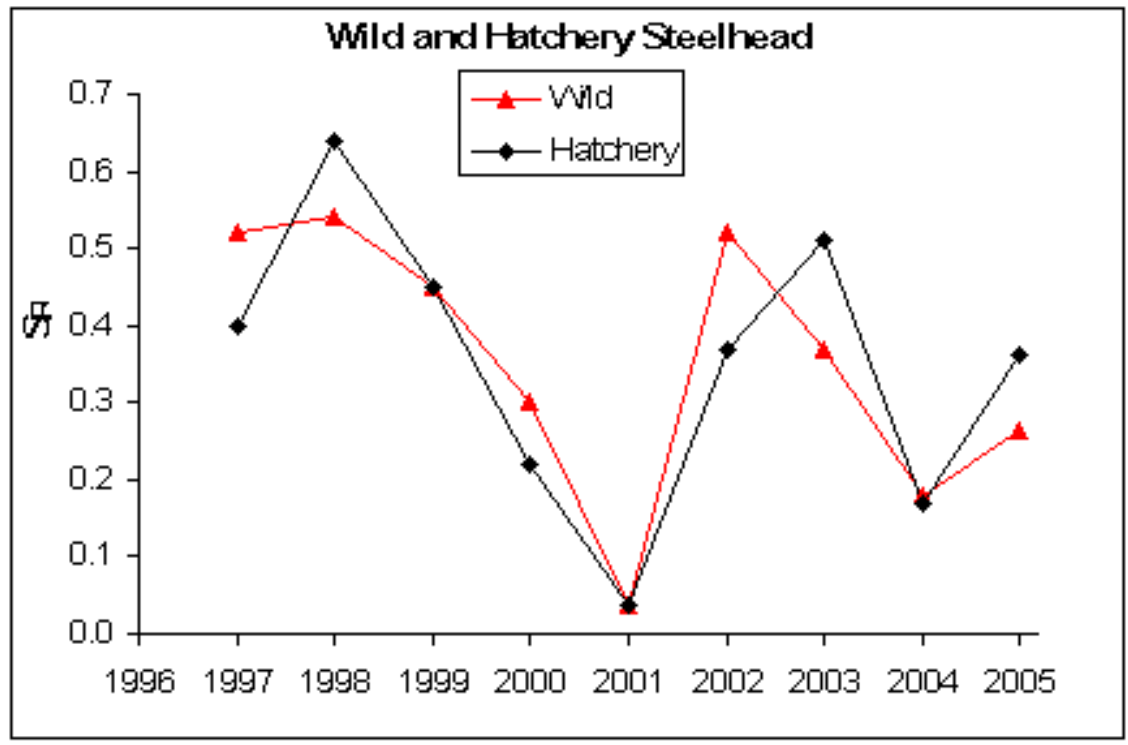

Figure 3.11. Trend in in-river survival $\left(S_{R}\right)$ for PIT-tagged Snake River hatchery and wild steelhead for migration years 1997 to 2005. 
In the 8 years excluding 2001, the hatchery steelhead TIR had a geometric mean of 2.32 (Table A-20), which was 9\% lower than the 2.55 geometric mean of wild steelhead (Table A-19). In 7 of 9 years (1997 and 2000 to 2005), the hatchery steelhead TIR exceeded 1. A statistically significant TIR $>1$ was demonstrated in four years, 2000 and 2003-2005. For hatchery steelhead smolts, transportation was generally beneficial, though not as beneficial as for wild steelhead (Table 3.16). In spite of the extremely wide confidence intervals of the $2001 \mathrm{TIR}$ for hatchery steelhead, transportation was highly beneficial to all steelhead that year as demonstrated in the TIR trend across years for both hatchery and wild steelhead (Figure 3.12).

Table 3.16. Estimated TIR and corresponding lower limit of non-parametric confidence interval, which provides a one-tail $(\alpha=0.05)$ test of $H_{0}$ : TIR $\leq 1$ versus $H_{A}$ : TIR $>1$, of PIT-tagged hatchery steelhead compared to wild steelhead. TIR $>1$ and TIR lower limit $>1$ are highlighted in red.

\begin{tabular}{|l|c|c|c|c|}
\hline \multirow{2}{*}{$\begin{array}{l}\text { Migr. } \\
\text { Year }\end{array}$} & \multicolumn{2}{|c|}{ Hatchery Steelhead } & \multicolumn{2}{c|}{ Wild Steelhead } \\
\cline { 2 - 5 } & TIR & Lower Limit & TIR & Lower Limit \\
\hline 1997 & $\mathbf{2 . 2 1}$ & 0.99 & $\mathbf{2 . 2 0}$ & 0.00 \\
\hline 1998 & 0.58 & 0.23 & 0.20 & 0.00 \\
\hline 1999 & 0.87 & 0.48 & $\mathbf{2 . 2 8}$ & $\mathbf{1 . 1 5}$ \\
\hline 2000 & $\mathbf{2 . 2 0}$ & $\mathbf{1 . 2 2}$ & $\mathbf{1 . 4 5}$ & 0.77 \\
\hline $2001^{\mathrm{A}}$ & $\mathbf{5 9 . 7}$ & 0.00 & $\mathbf{3 7 . 0}$ & $\mathbf{1 0 . 6}$ \\
\hline 2002 & $\mathbf{1 . 5 1}$ & 0.38 & $\mathbf{4 . 2 5}$ & $\mathbf{2 . 1 2}$ \\
\hline 2003 & $\mathbf{2 . 6 5}$ & $\mathbf{1 . 9 3}$ & $\mathbf{4 . 4 1}$ & $\mathbf{2 . 7 4}$ \\
\hline $2004^{\mathrm{B}}$ & $\mathbf{1 0 . 3}$ & $\mathbf{5 . 4 3}$ & $\mathbf{1 4 . 3}$ & $\mathbf{7 . 1 9}$ \\
\hline $2005^{\mathrm{BC}}$ & $\mathbf{8 . 4 4}$ & $\mathbf{5 . 0 4}$ & $\mathbf{4 . 5 5}$ & $\mathbf{2 . 8 9}$ \\
\hline
\end{tabular}

${ }^{\mathrm{A}} \mathrm{SAR}\left(\mathrm{C}_{1}\right)$ used in 2001 in derivation of TIR.

${ }^{B}$ In-river SAR is combination of groups $\mathrm{C}_{0}$ and $\mathrm{C}_{1}$ in derivation of TIR.

${ }^{\mathrm{C}}$ Migration year 2005 is incomplete until 3-salt returns (if any) occur after 7/1/2008 at GRA.

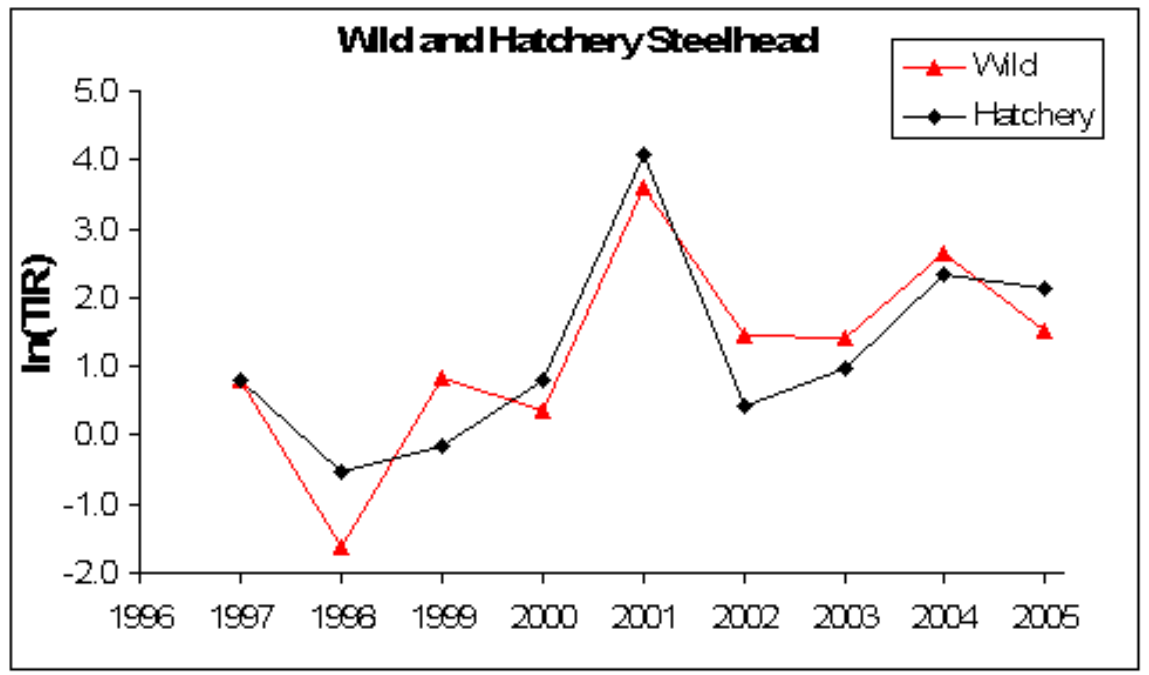

Figure 3.12. Trend in TIR (log-transformed) for PIT-tagged Snake River hatchery and wild steelhead in migration years 1997 to 2005. 
The estimate of $\mathrm{D}$ was $>1$ in 4 of 9 years for hatchery steelhead. A lower limit of the $90 \%$ confidence interval for $\mathrm{D}>1$, which demonstrates a statistical significance, was only obtained in 2005, although 2003 was close with its lower limit of D at 0.99 (Table 3.17). The D estimates for 1997-2000 and 2002-2005 had a geometric mean of 0.89 for hatchery steelhead, approximately $10 \%$ lower than that of wild steelhead (Tables A-19 and A-20; trend across years in Figure 3.13). Although differences arise between the estimates for wild and hatchery steelhead, these data suggest that steelhead as a whole respond more favorably to transportation than do the listed wild Chinook.

Table 3.17. Estimated $D$ and corresponding lower limit of non-parametric confidence interval, which provides a one-tail $(\alpha=0.05)$ test of $H_{0}: D \leq 1$ versus $H_{A}: D>1$, of PIT-tagged hatchery steelhead compared to wild steelhead. $D>1$ is highlighted in red and $D$ lower limit $>1$ is highlighted in yellow.

\begin{tabular}{|l|c|c|c|c|}
\hline \multirow{2}{*}{$\begin{array}{c}\text { Migr. } \\
\text { Year }\end{array}$} & \multicolumn{2}{|c|}{ Hatchery Steelhead } & \multicolumn{2}{c|}{ Wild Steelhead } \\
\cline { 2 - 5 } & $\mathbf{D}$ & Lower Limit & D & Lower Limit \\
\hline 1997 & 0.92 & 0.36 & $\mathbf{1 . 1 8}$ & 0.00 \\
\hline 1998 & 0.39 & 0.16 & 0.11 & 0.00 \\
\hline 1999 & 0.41 & 0.22 & $\mathbf{1 . 0 7}$ & 0.53 \\
\hline 2000 & 0.55 & 0.30 & 0.50 & 0.27 \\
\hline $2001^{\mathrm{A}}$ & $\mathbf{2 . 4 0}$ & 0.00 & $\mathbf{1 . 4 6}$ & 0.40 \\
\hline 2002 & 0.60 & 0.14 & $\mathbf{2 . 2 4}$ & $\mathbf{1 . 0 9}$ \\
\hline 2003 & $\mathbf{1 . 4 3}$ & 0.99 & $\mathbf{1 . 7 5}$ & $\mathbf{1 . 0 4}$ \\
\hline $2004^{\mathrm{B}}$ & $\mathbf{1 . 8 5}$ & 0.91 & $\mathbf{2 . 6 9}$ & $\mathbf{1 . 2 9}$ \\
\hline $2005^{\mathrm{BC}}$ & $\mathbf{3 . 1 9}$ & $\mathbf{1 . 8 6}$ & $\mathbf{1 . 2 6}$ & 0.77 \\
\hline
\end{tabular}

${ }^{A} \mathrm{SAR}\left(\mathrm{C}_{1}\right)$ used in 2001 in derivation of $\mathrm{D}$.

${ }^{\mathrm{B}}$ In-river $\mathrm{SAR}$ is combination of groups $\mathrm{C}_{0}$ and $\mathrm{C}_{1}$ in derivation of $\mathrm{D}$.

${ }^{\mathrm{C}}$ Migration year 2005 is incomplete until 3-salt returns (if any) occur after 7/1/2008 at GRA.

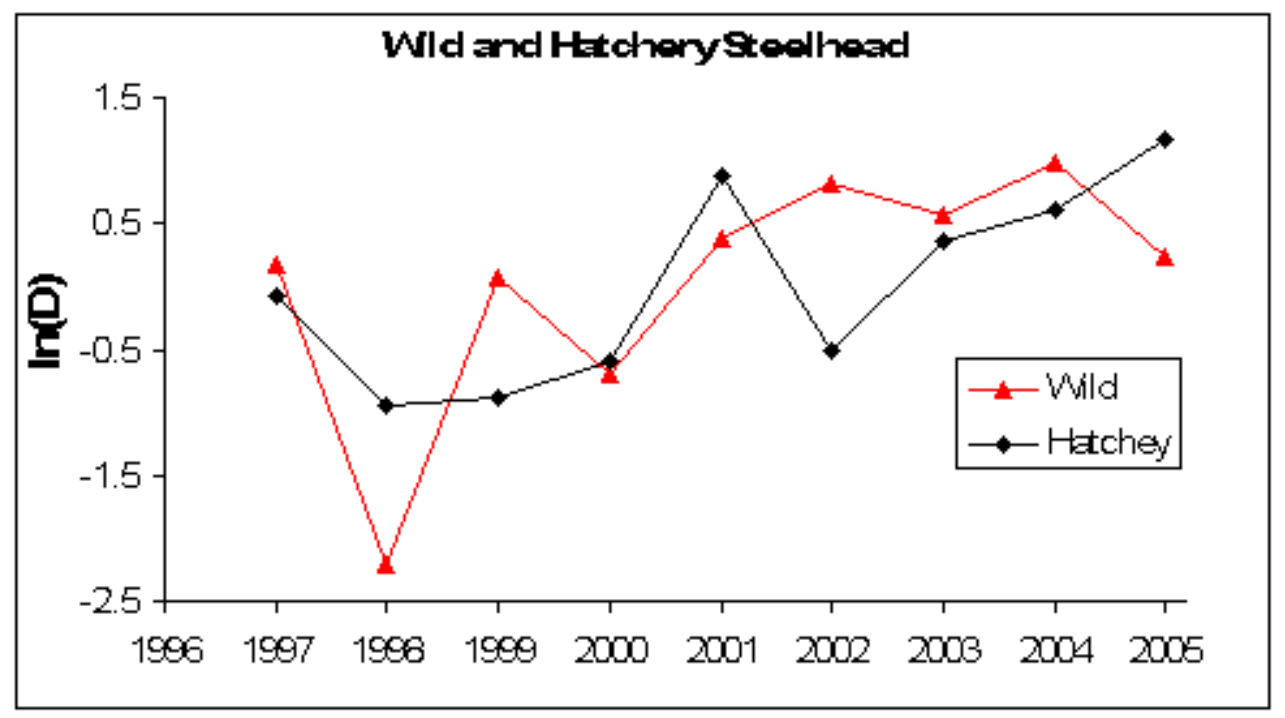

Figure 3.13. Trend in $D$ (log-transformed) for PIT-tagged Snake River hatchery and wild steelhead in migration years 1997-2005. 


\section{Discussion}

The analysis of the CSS study groups for wild spring/summer Chinook, hatchery spring Chinook, hatchery summer Chinook, wild steelhead, and hatchery steelhead has demonstrated considerable variability in smolt survivals among study groups and between years.

The TIR parameters estimates have been used as the initial indicator of potential benefit for smolt transportation for each study grouping. The combination of exceptionally low in-river smolt survivals in 2001 and generally average survivals for transported smolts resulted in exceptionally large TIR values for all study categories. These TIRs indicate a substantial benefit for smolt transportation in 2001, under unusual environmental conditions, extreme drought, and hydrosystem operations which included no spill and maximization of smolt transportation.

For the rest of the CSS evaluation years, TIR estimates indicate the relative smolt transportation performance as follows: Wild spring/summer Chinook lacked a consistent positive pattern and lacked demonstrated statistical significance, thus indicating a lack of benefit. Hatchery spring and summer Chinook had a positive performance pattern and moderate demonstration of statistical significance indicating a benefit. Wild and hatchery steelhead had a positive performance pattern and some demonstrated statistical significance, although small sample sizes reduce the confidence on the extent of benefit.

For the majority of smolt groups analyzed across species and wild and hatchery production, the $\operatorname{SAR}\left(\mathrm{C}_{1}\right)$ was less than the $\mathrm{SAR}\left(\mathrm{C}_{0}\right)$, indicating that the process of being "collected" to the point necessary for PIT-tag detection and subsequently migrating inriver compromised smolt survival.

The $\mathrm{D}$ values were also $<1$ for the majority of the smolt groups analyzed, indicating that smolt collection and transportation compromises post Bonneville Dam survival. This reduction in smolt viability is potentially due to the stress, injury, and disease exposure associated with the "collection" process (Budy et al. 2002; Marmorek et al. 2004). If the detrimental effects of the "collection" process can be substantially reduced, then there is an opportunity to substantially improve SARs for bypassed and transported salmonid smolts. 


\section{Chapter 4 -- \\ Evaluation of Smolt Size Effects on Collection at Lower Granite and Little Goose Dams}

\section{Introduction}

Recent analyses suggest the existence of a negative relationship between smolt size and detection probabilities for certain groups of PIT tagged fish at Little Goose (LGS) and Lower Monumental (LMN) dams (Williams et al. 2005; Zabel et al. 2005). This implies that the bypass systems on Federal Columbia River Power System (FCRPS) are negatively size selective for salmon smolts. It should be noted that these publications focused on fish that were measured, marked and released after their entry into the bypass system at LGR; this precludes any analysis of passage at LGR.

The majority of transported fish are transported from LGR for all species concerned in the CSS (Tables A-34, A-36, A-39, and A-41). Therefore, in order to evaluate the transportation program, it makes sense to evaluate the potential size differences at this location. Analyses in this memo and CSS reports utilize data for fish that are marked above LGR and enter the LGR bypass system similar to the run at large.

A size difference at LGR and other dams for wild Chinook was also addressed in the CSS 2006 annual report. Chapter 9 of that report used both a mark-recapture model building exercise and a direct comparison of lengths. The data set included PIT tagged fish from the Snake River and Clearwater River traps. To limit the confounding effects of changing hydrosystem operations on detection probabilities, the data set was restricted from 11 April - 10 May within each of the years 1998-2006.

The model selection exercise resulted in "no clear indication of a strong relationship between individual size and detection probability at LGR, or any site downstream" for wild Chinook in each year where testing was possible (1999, 2000, 2002, and 2005-2006; CSS 2006 Annual Report, Chapter 9). In that same chapter, when using t-tests to compare fish detected at LGR versus fish not detected at LGR for each of the years 1998-2006, there was a significant difference in size at marking only for 1998 and 1999; the magnitude of these differences were equal to or less than $2 \mathrm{~mm}$.

Although no results in the CSS thus far have indicated that a size-related bias exists in the detection facilities within the FCRPS, this chapter continues to test for such a phenomenon. So, this chapter is an extension of the aforementioned work. Here, we use a larger set of data than in Chapter 9 of the 2006 annual report. This allowed for comparisons across all four species/rear-type groups used in the CSS. This is the first comparison of this type for wild and hatchery steelhead groups used in the CSS.

\section{Methods}

We compared length at marking for wild and hatchery Chinook and steelhead detected at LGR versus those without LGR detections in the years 2003-2005. These comparisons were then repeated for the LGS facility. The data set included fish marked at sites relatively close to LGR (Snake River trap, Salmon River trap, Grande Ronde River, Clearwater River trap and Imnaha River trap). Because this was not a markrecapture exercise, we did not include a temporal restriction in the data. These two modifications increased the size of the sample from what was used in chapter 9 of the 
2006 annual report. In the case of wild Chinook and steelhead, the fish used were a subset of the CSS PIT-tagged fish; the hatchery groups marked at these trap sites were not necessarily PIT-tagged for the CSS project.

A differential size-based mortality could introduce a confounding source of variation between detected and non-detected fish, so we began with a population of fish that were known to have survived past the site of interest. This population was then split into detected and undetected groups.

For example, at LGS the population of Hatchery steelhead was reduced to fish detected at some site downriver from LGS. Then, the population was divided into those detected at LGS versus fish not detected at LGS. The size at marking data for these groups was presented in a visual format as histograms and cumulative length frequency plots.

In each figure, Panel A and B display a histogram of 1mm length bins for the LGR undetected and for LGR detected fish, respectively. In cases where the collection efficiency is high, the number of fish passing LGR with a detection is higher than the number of fish passing without a detection. Panel $\mathrm{C}$ is the cumulative length frequency plots for LGR. Panels D, E, and F display the same information for LGS.

\section{Results}

Wild Chinook are shown in Figures 4.1 to 4.3. In each case, the distribution of lengths for the LGR and the LGS detected group matches well with the complement of undetected fish. When comparing the median value in each plot for all six cases, the median length for detected fish is lower in two, higher in one and the same value on three occasions. These results do not support the hypothesis that there is a negatively size biased selection at LGR or LGS for wild Chinook. Additionally, the magnitude of the size differences was very small (1-1.5 mm where LGR detected fish were smaller than non detected fish).

The distribution of the data is more complex for hatchery Chinook than for wild Chinook (Figures 4.4 to 4.6). There are multiple Chinook hatcheries of varying distance from LGR and each has its own emigration timing. However, the non-detected fish still appear similar to their detected counterparts at LGR and LGS with all modes present in each graph. The median value is higher for the detected fish in three cases and less in 3 cases. When differing, the magnitude is less than $2 \mathrm{~mm}$. Again, these results do not support a hypothesis of negatively size biased selection at LGR or LGS.

The wild and hatchery steelhead (Figures 4.7 to 4.12) distributions generally appear similar in each category. There are few fish in the LGS non-detected category for 2004 and 2005. Across all twelve cases, the median value is less for the detected fish in ten cases, and equal in two cases. The magnitude of the difference of the median value is 4 or fewer for both wild and hatchery steelhead. Steelhead therefore, may exhibit a small size bias in the bypass system. 


\section{Discussion}

We did not find any evidence of a size bias for wild or hatchery Chinook at LGR or LGS in this or any of the other analyses (see introduction) that have been done in regards to this subject. Conversely, Zabel et al. (2005) and Williams et al. (2005) did find a bias in the recapture probability at dams downriver of LGR (i.e., LGS, LMN, $\mathrm{MCN}$ ) for Chinook and steelhead. The reason for this lack of agreement is not known. The population of fish analyzed by Zabel et al. (2005) and Williams et al. (2005) was captured, tagged and released at LGR while the population of fish studied in the CSS was captured, tagged, and released upriver of LGR at various traps. Whether or not this plays a part in this discrepancy may be an area for future work.

This is the first time this subject has been broached for steelhead in the CSS. A small difference (4mm-2mm) in length was found between detected and undetected groups. The effects of this difference in median values across the large range in length of fish that pass through the hydrosystem over the course of a migration season are not known.

There are a few implications of a size bias in regards to the CSS. Can this affect survival estimates using CJS methodology? Both Williams et al. 2005 and Zabel et al. 2005 demonstrated that CJS estimates of survival were robust to fish size biases in collection efficiency in the FCRPS. So, how may this affect adult returns?

One hypothesis is that a smaller sized fish would be more subject to predation, less smoltified, and ostensibly less able to produce an adult return as compared to a larger counterpart. It is not known if size differences of these magnitudes would affect returns. The range of lengths in each group shown here are approximately from $100 \mathrm{~mm}$ to $200 \mathrm{~mm}$. With a difference of $4 \mathrm{~mm}$ in the median values, it is not clear how this would translate into a particular disadvantage in burst speed or ability to evade predators for bypassed fish. The TIR ratio's presented in this report would refute the hypothesis that collected steelhead are especially unfit since the TIR ratios for hatchery and wild steelhead in 2003-2005 are some the highest values when compared to wild or hatchery Chinook in the same years. The usual comparison is to evaluate if a TIR is significantly greater than 1. Since wild and hatchery steelhead TIRs in 2003 to 2005 were all significantly greater than 1, there would not be a change if the value of the TIR increased.

Additionally, the goal of the CSS is to address the question whether collecting juvenile fish at dams and transporting them in barges and trucks downstream of Bonneville Dam is compensating for the effect of the Federal Columbia River Power System (FCRPS) on survival of Snake Basin spring/summer Chinook salmon migrating through the hydrosystem. Hypothetically, if there were an apparent negative size bias in the collection system on the FCRPS, this would not change the utility of using TIR ratios to evaluate transportation because collecting fish at the dams is part and parcel of the transportation system. 


\section{Wild Chinook}

Lower Granite Dam Comparisons

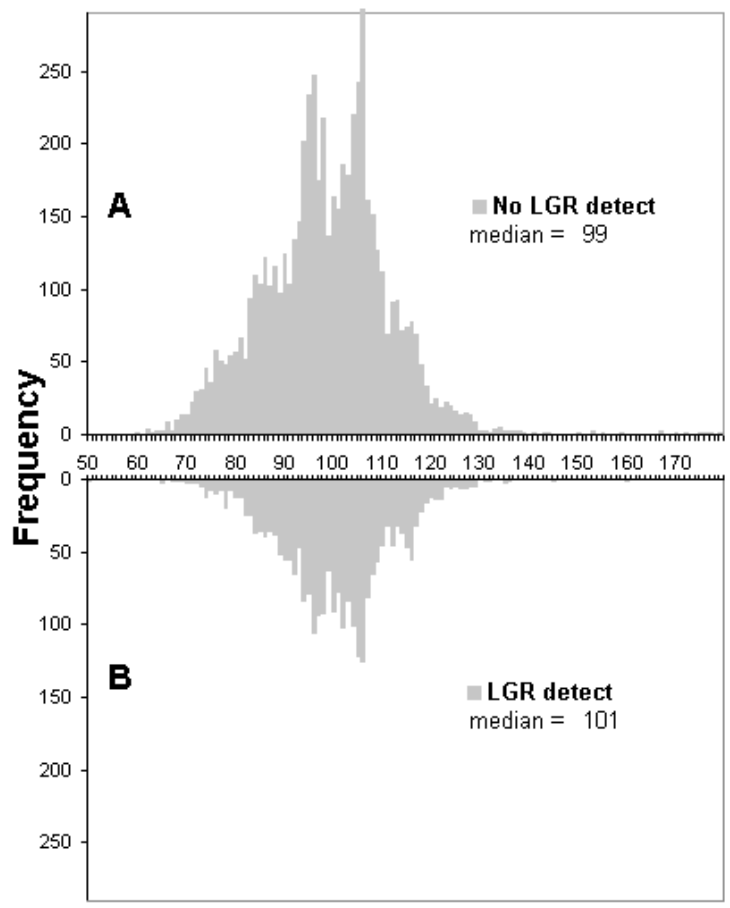

Fork length (1mm bins)

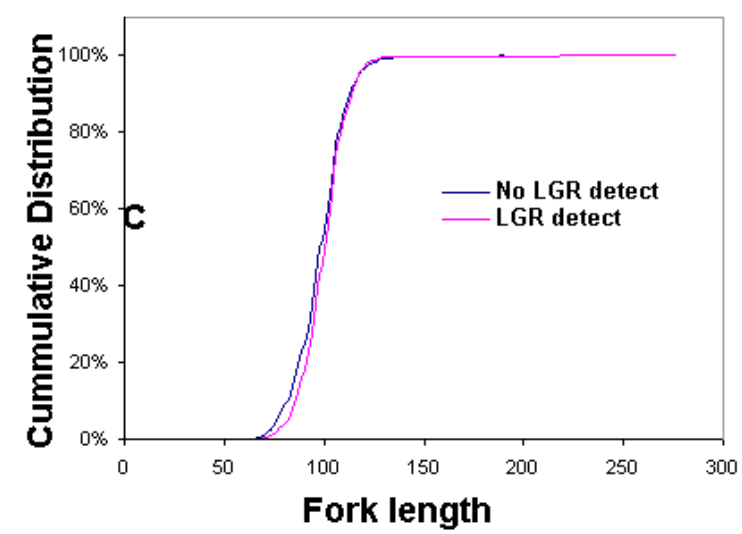

Little Goose Dam Comparisons

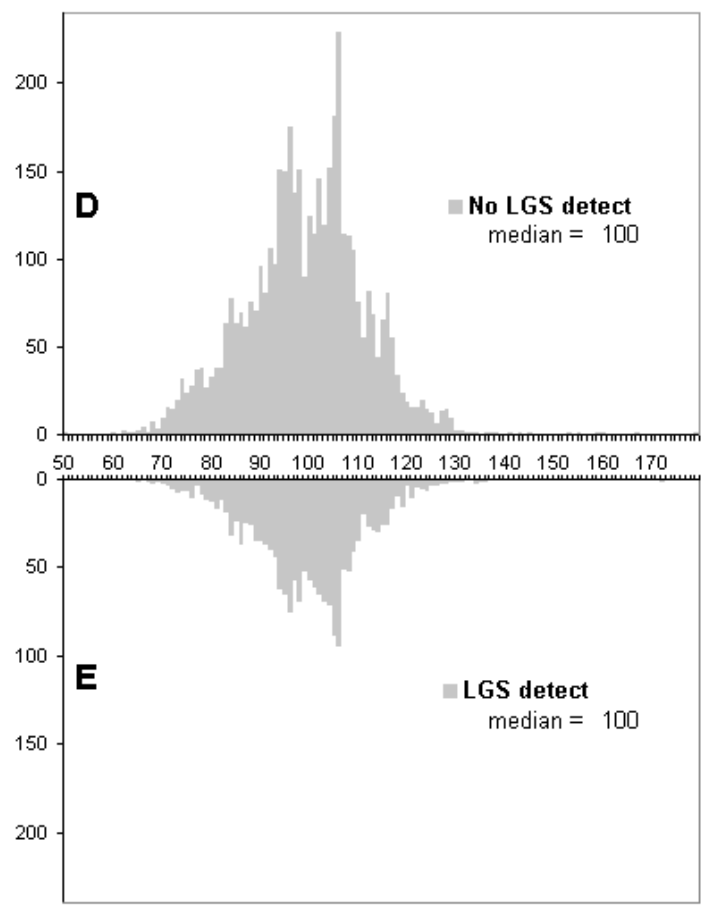

Fork length (1mm bins)

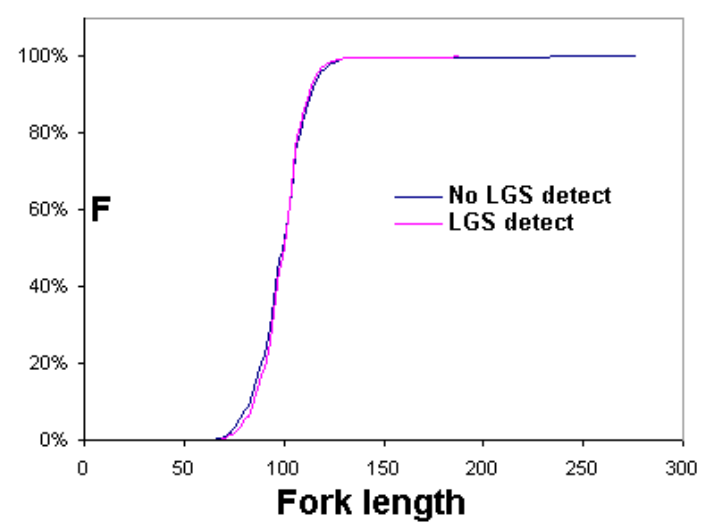

Figure 4.1. Comparisons of length for detected and undetected wild Chinook in 2003. Panel A and B display a histogram of $1 \mathrm{~mm}$ length bins for the LGR undetected and for LGR detected fish, respectively; panel $C$ is the cumulative length frequency plots for LGR. Panels D,E, and F display the same information for LGS. 


\section{Wild Chinook}

Lower Granite Dam Comparisons

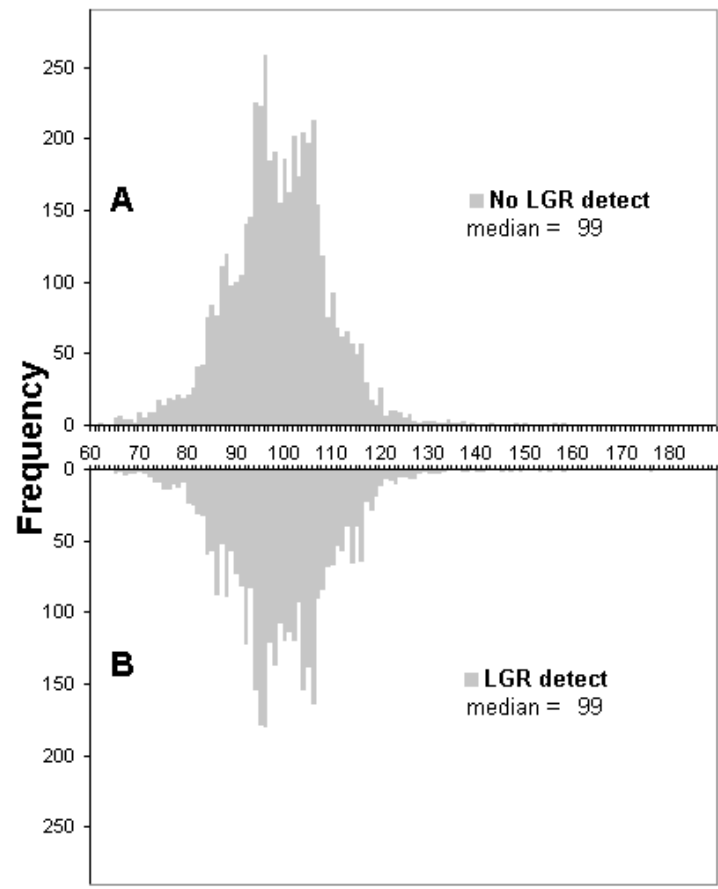

Fork length (1mm bins)

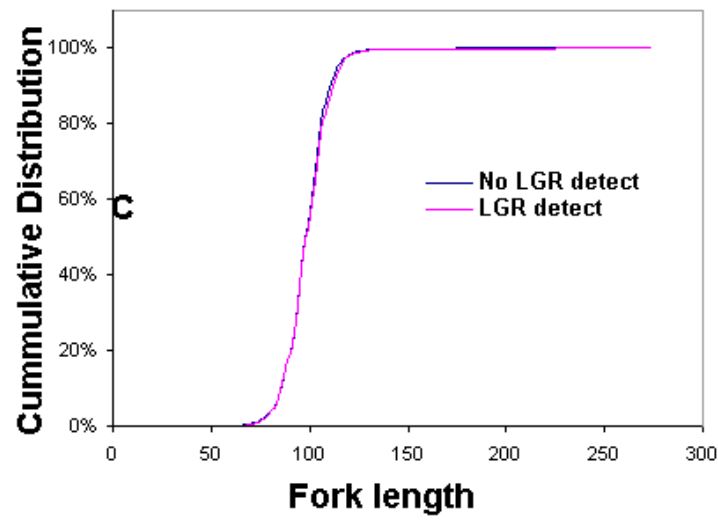

Little Goose Dam Comparisons

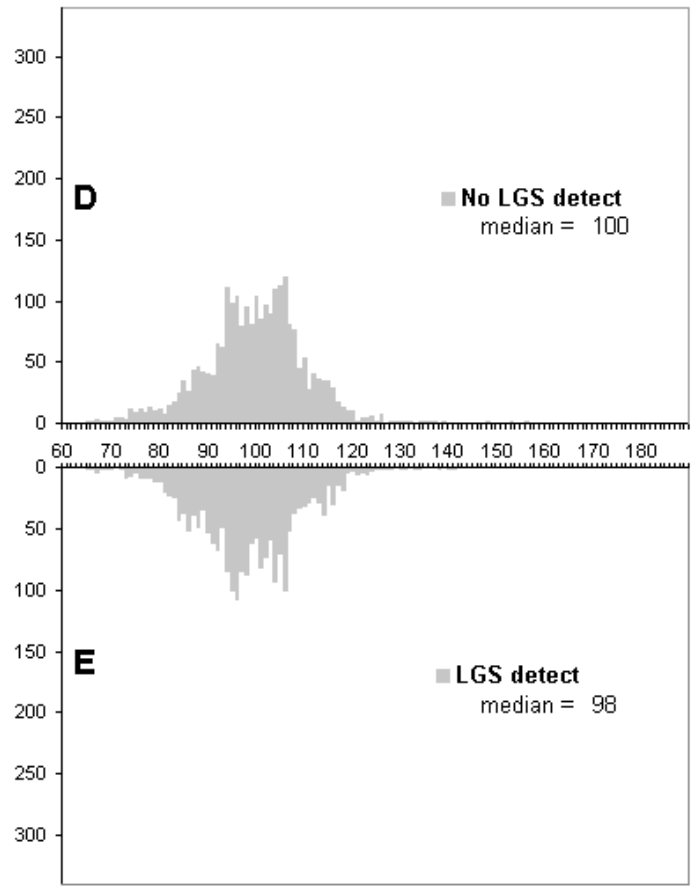

Fork length (1mm bins)

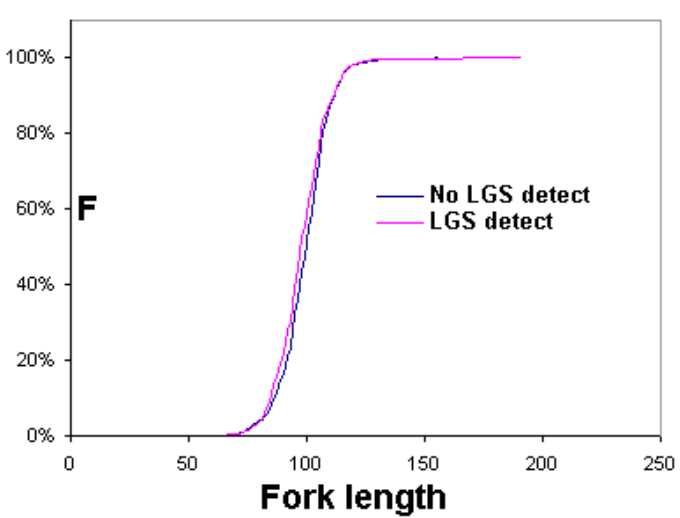

Figure 4.2. Comparisons of length for detected and undetected wild Chinook in 2004. Panel A and B display a histogram of $1 \mathrm{~mm}$ length bins for the LGR undetected and for LGR detected fish, respectively; panel $\mathrm{C}$ is the cumulative length frequency plots for LGR. Panels D,E, and F display the same information for LGS. 


\section{Wild Chinook}

Lower Granite Dam Comparisons

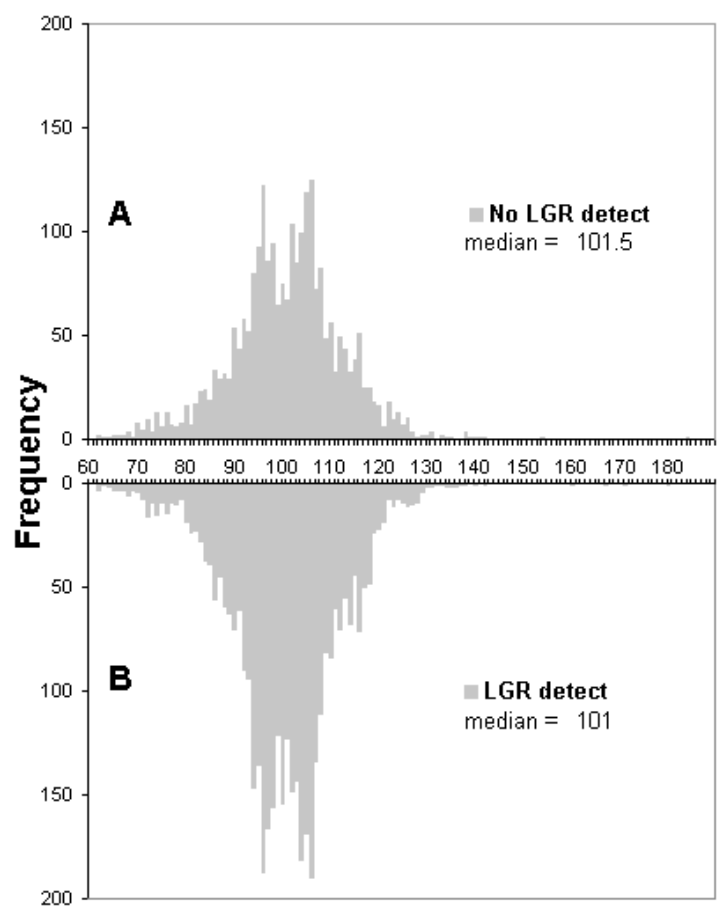

Fork length (1mm bins)

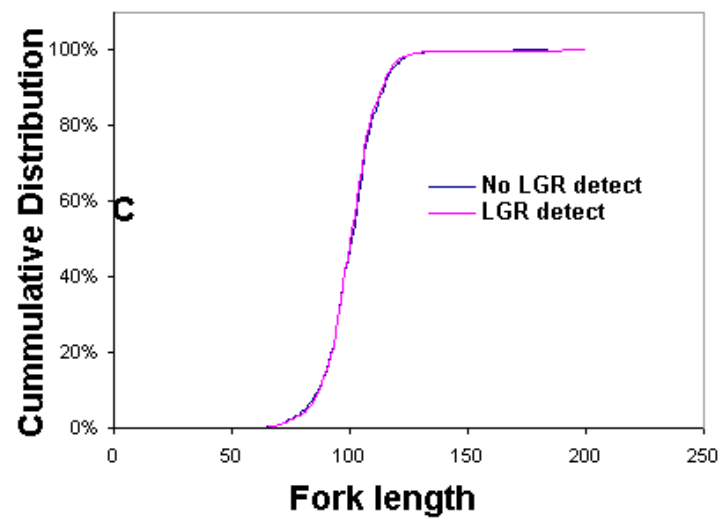

Little Goose Dam Comparisons

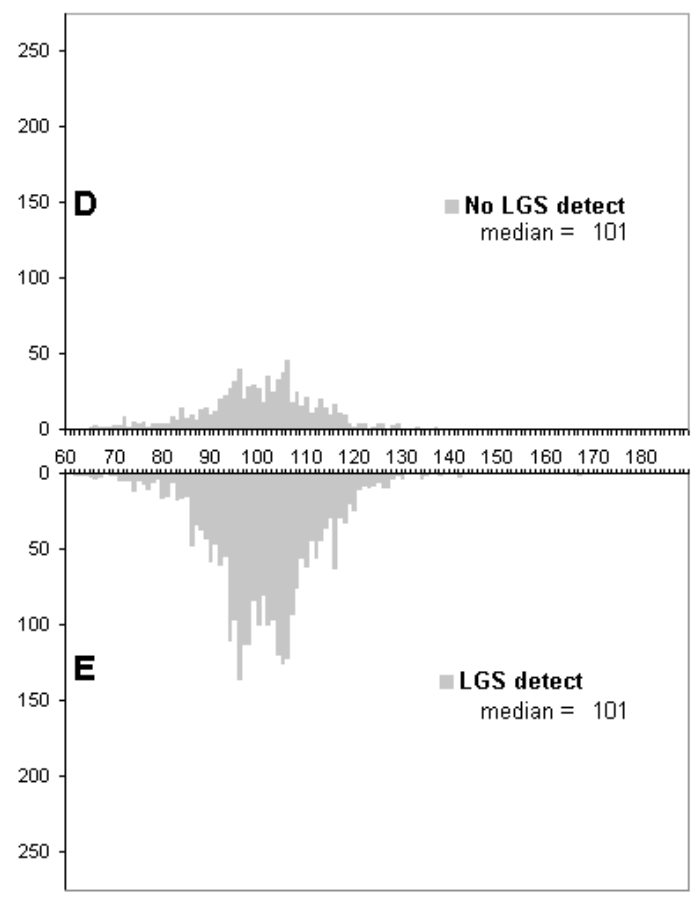

Fork length (1mm bins)

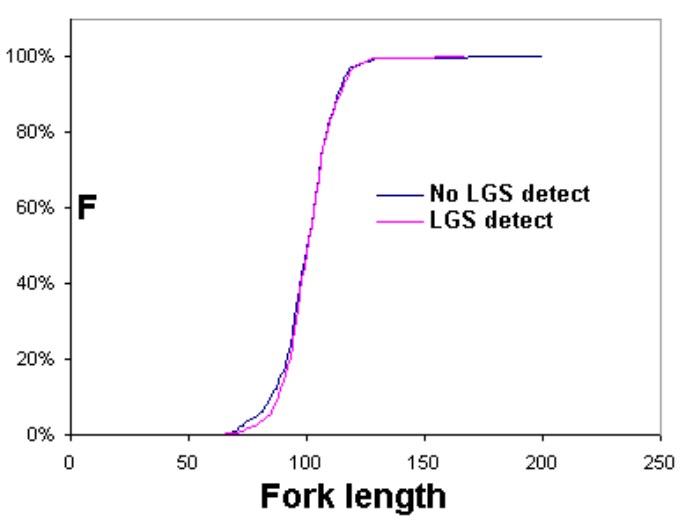

Figure 4.3. Comparisons of length for detected and undetected wild Chinook in 2005. Panel A and B display a histogram of $1 \mathrm{~mm}$ length bins for the LGR undetected and for LGR detected fish, respectively; panel $\mathrm{C}$ is the cumulative length frequency plots for LGR. Panels D,E, and F display the same information for LGS. 
2003 Hatchery Chinook

Lower Granite Dam Comparisons

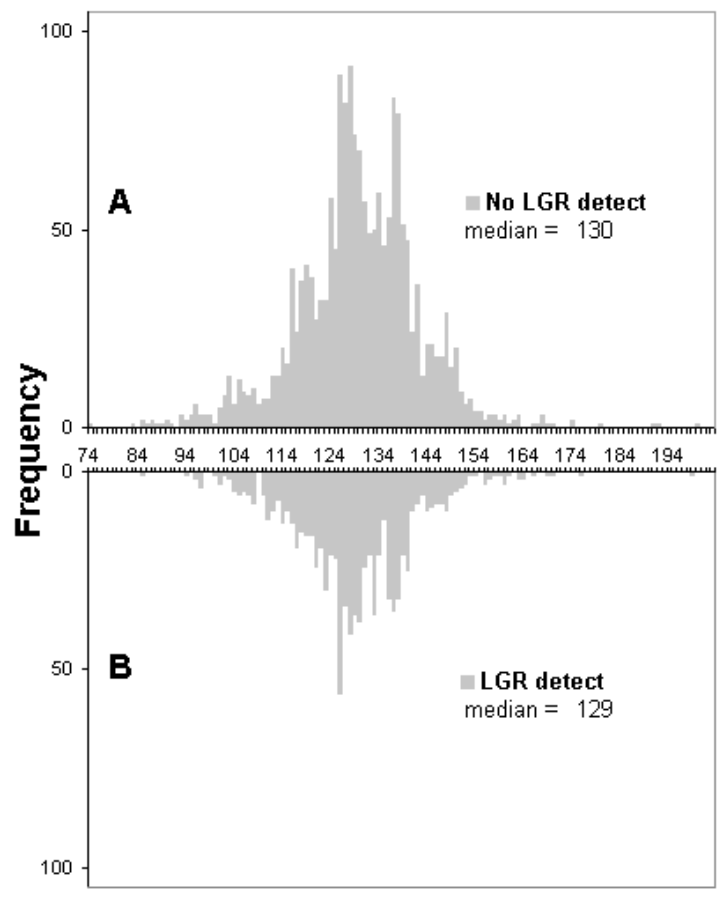

Fork length (1mm bins)

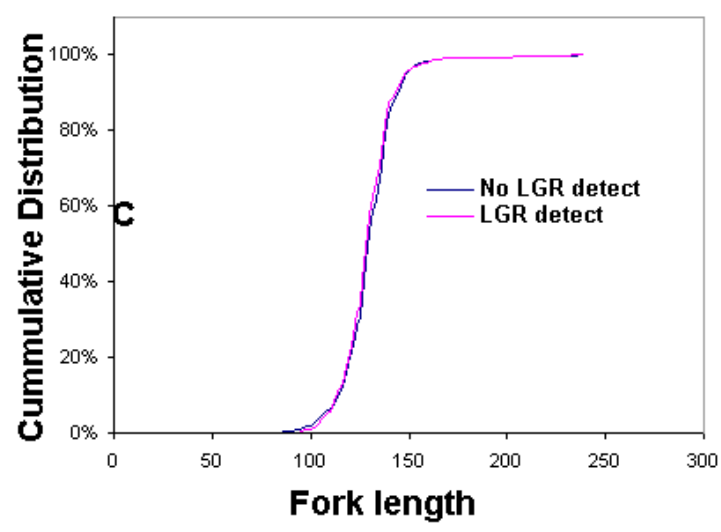

Little Goose Dam Comparisons
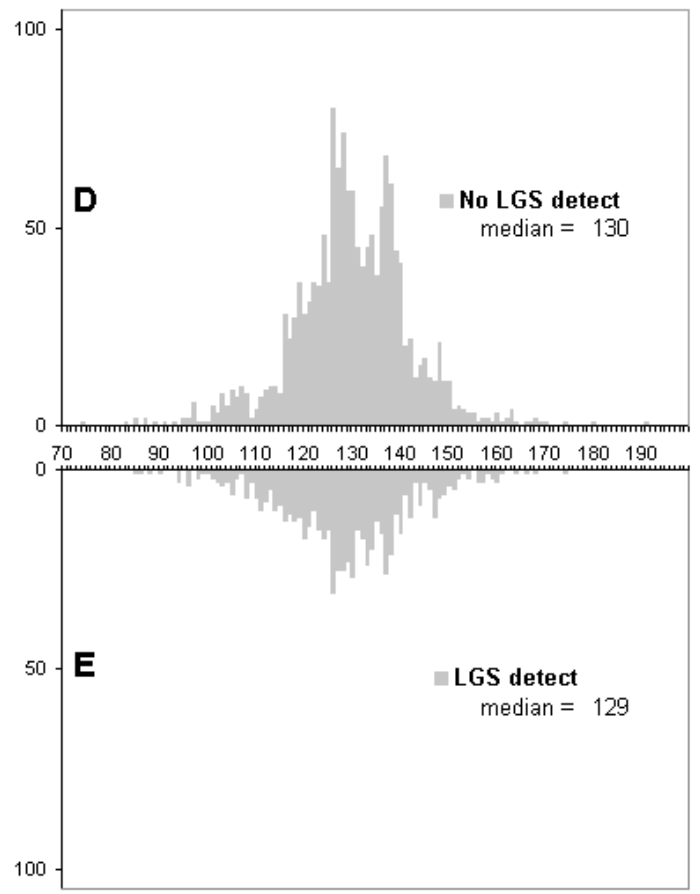

Fork length (1mm bins)

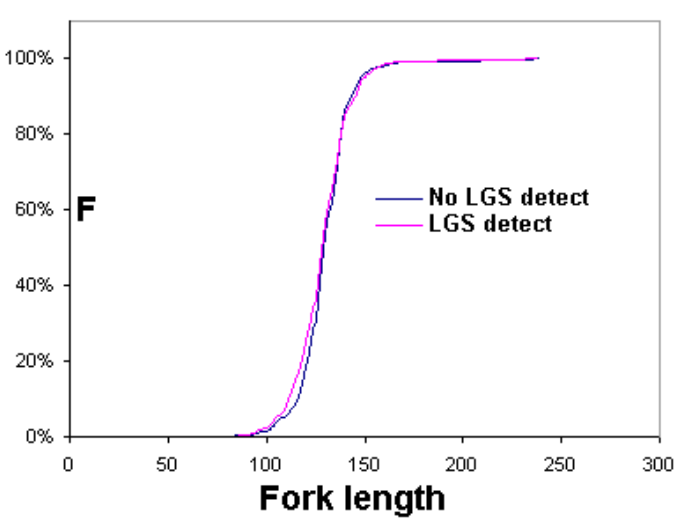

Figure 4.4. Comparisons of length for detected and undetected hatchery Chinook in 2003. Panel A and B display a histogram of $1 \mathrm{~mm}$ length bins for the LGR undetected and for LGR detected fish, respectively; panel $C$ is the cumulative length frequency plots for LGR. Panels D,E, and F display the same information for LGS. 


\section{Hatchery Chinook}

Lower Granite Dam Comparisons

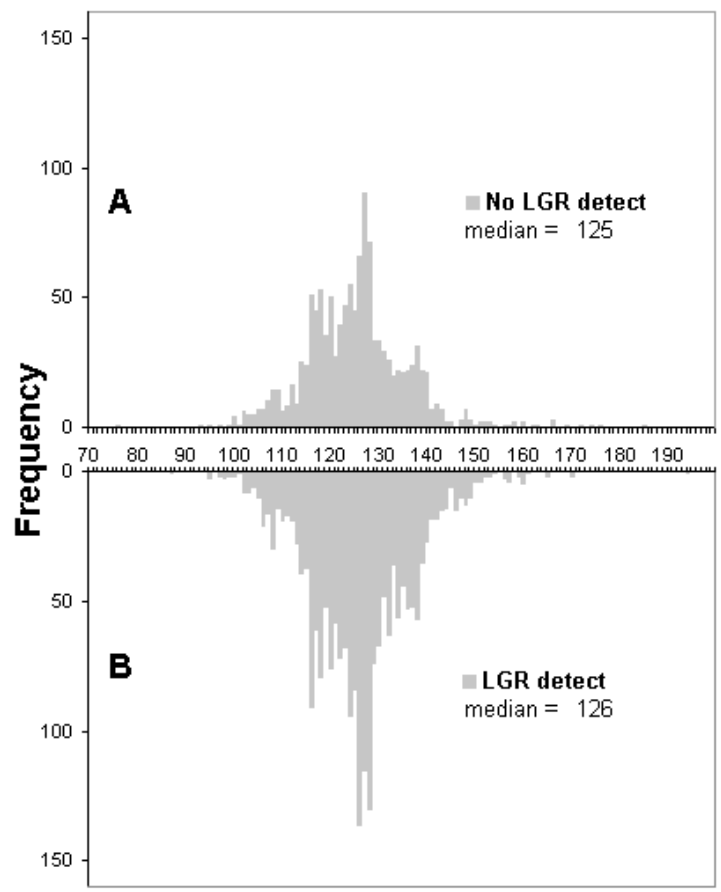

Fork length (1mm bins)

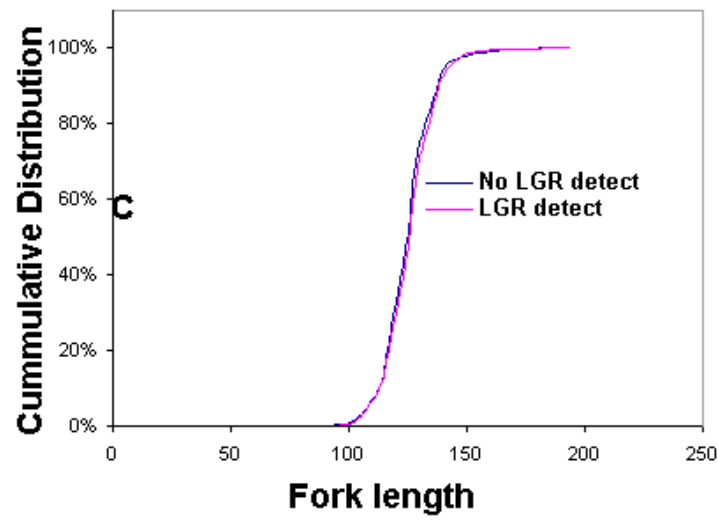

Little Goose Dam Comparisons

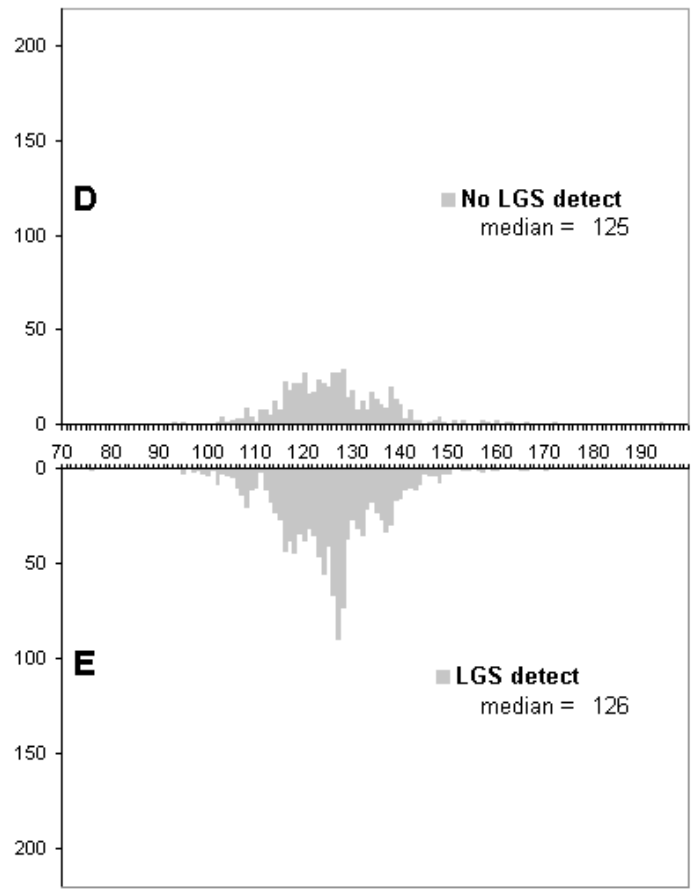

Fork length (1mm bins)

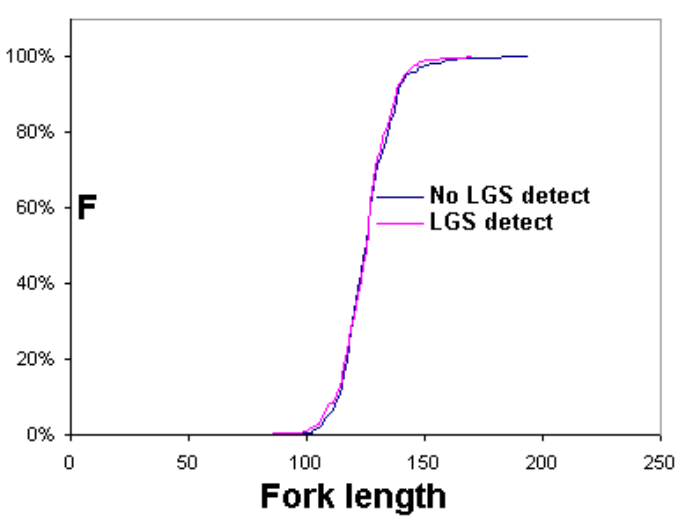

Figure 4.5. Comparisons of length for detected and undetected hatchery Chinook in 2004. Panel A and B display a histogram of $1 \mathrm{~mm}$ length bins for the LGR undetected and for LGR detected fish, respectively; panel $\mathrm{C}$ is the cumulative length frequency plots for LGR. Panels D,E, and F display the same information for LGS. 
2005 Hatchery Chinook

Lower Granite Dam Comparisons

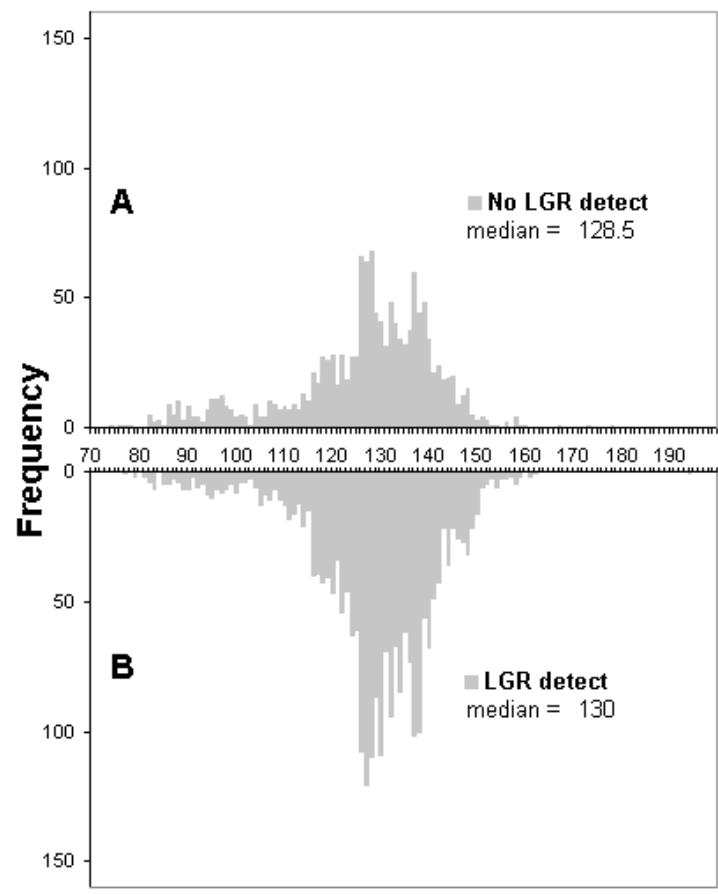

Fork length (1mm bins)

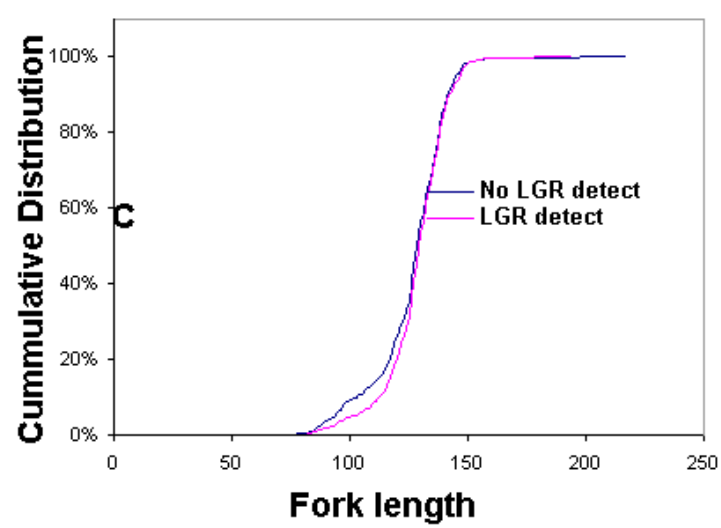

Little Goose Dam Comparisons
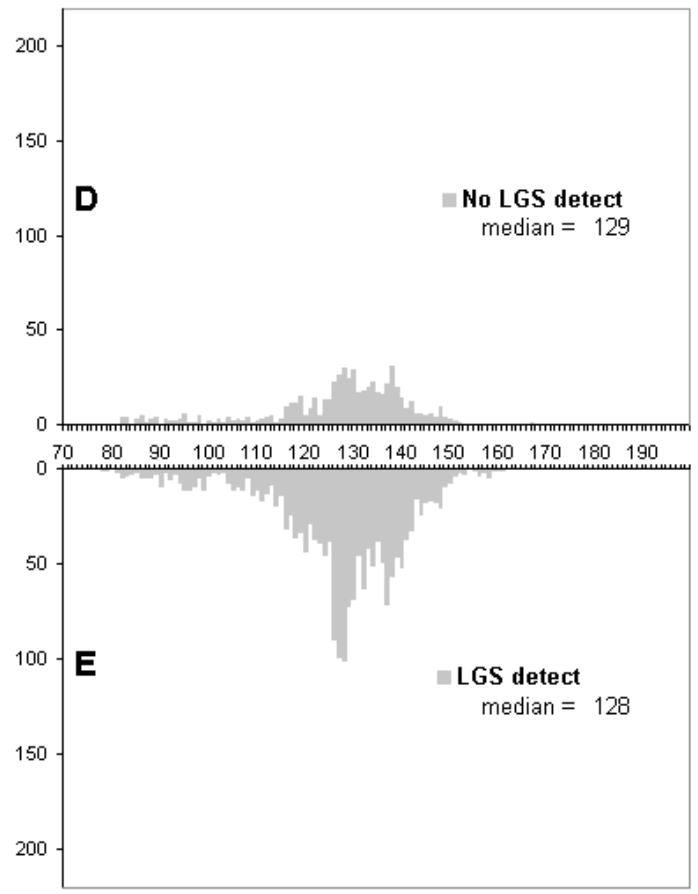

Fork length (1mm bins)

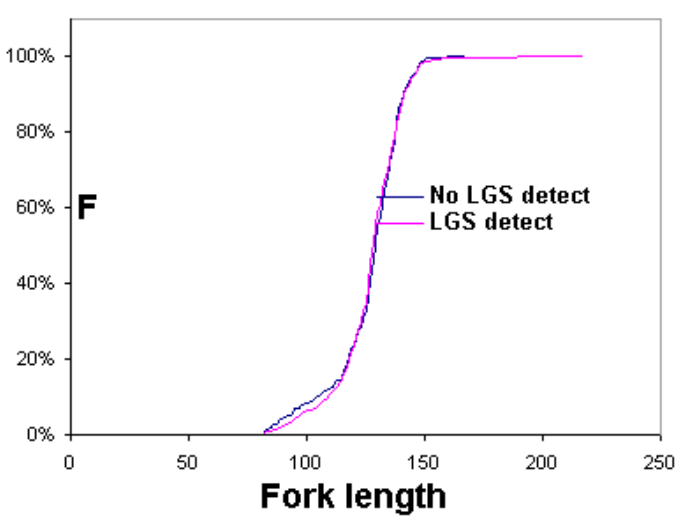

Figure 4.6. Comparisons of length for detected and undetected hatchery Chinook in 2005. Panel A and B display a histogram of $1 \mathrm{~mm}$ length bins for the LGR undetected and for LGR detected fish, respectively; panel $\mathrm{C}$ is the cumulative length frequency plots for LGR. Panels D,E, and F display the same information for LGS. 


\section{Wild steelhead}

Lower Granite Dam Comparisons

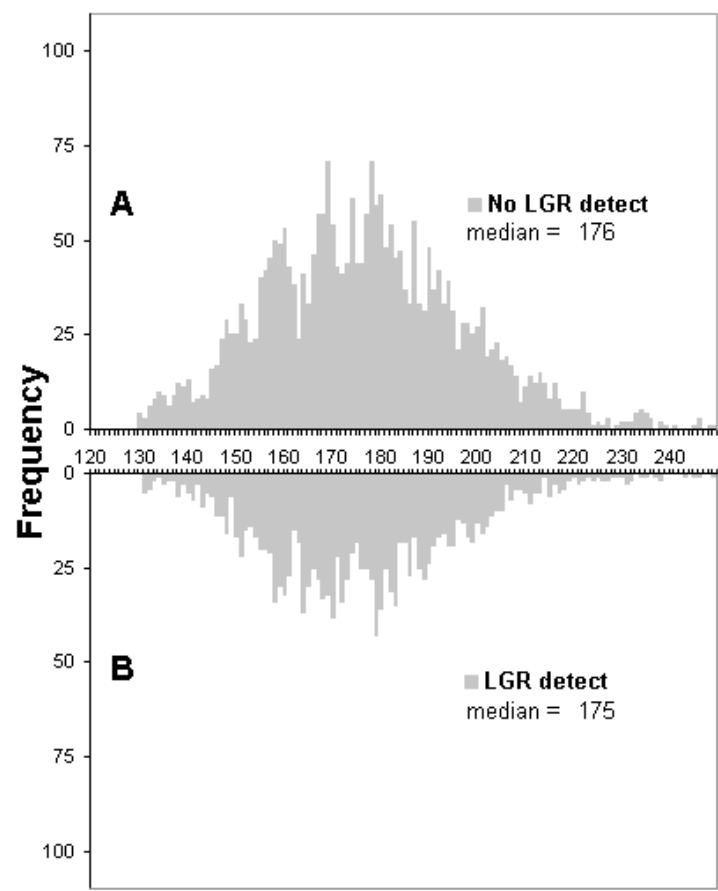

Fork length (1mm bins)

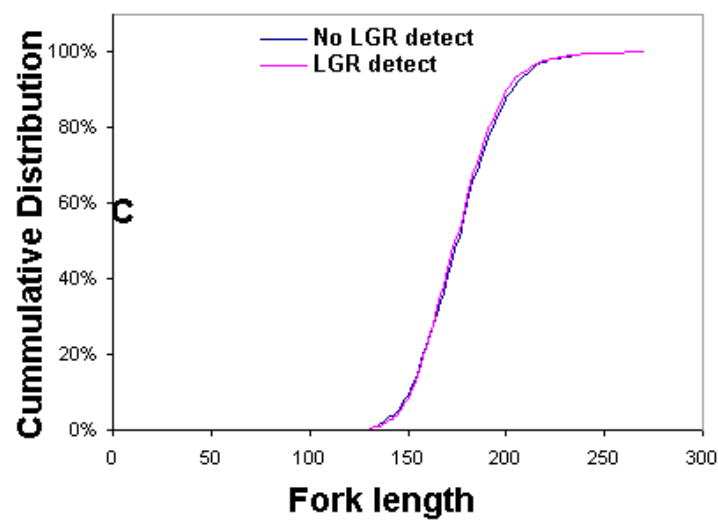

Little Goose Dam Comparisons
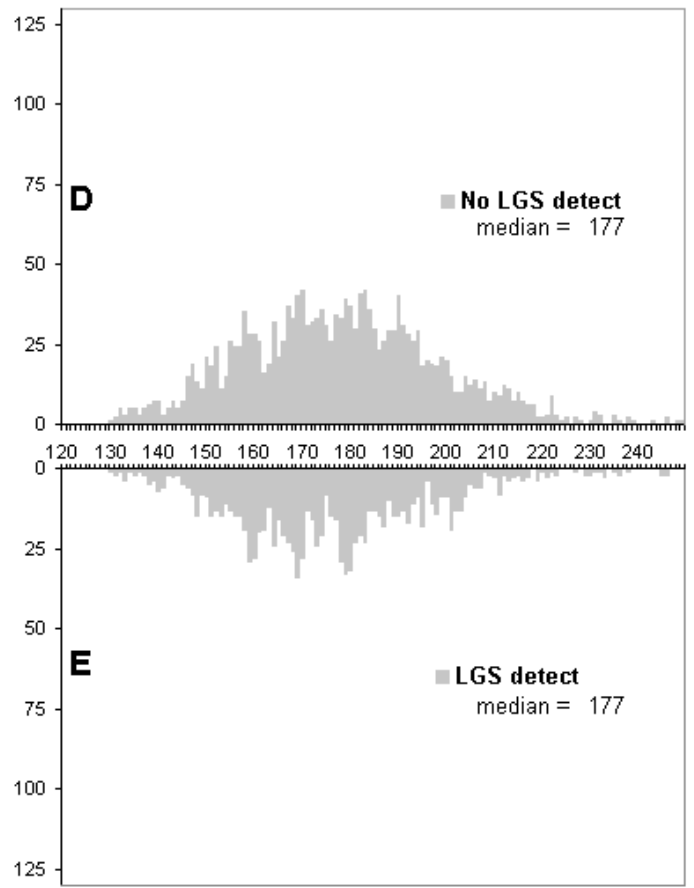

Fork length (1mm bins)

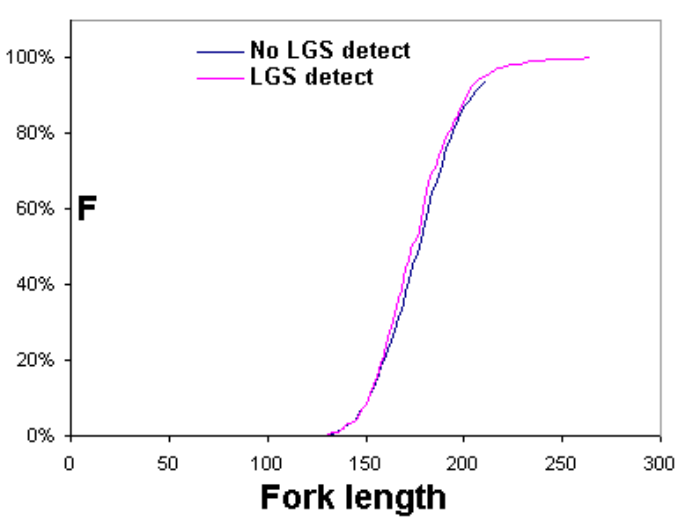

Figure 4.7. Comparisons of length for detected and undetected wild steelhead in 2003. Panel A and B display a histogram of $1 \mathrm{~mm}$ length bins for the LGR undetected and for LGR detected fish, respectively; panel $C$ is the cumulative length frequency plots for LGR. Panels D,E, and F display the same information for LGS. 


\section{Wild steelhead}

Lower Granite Dam Comparisons

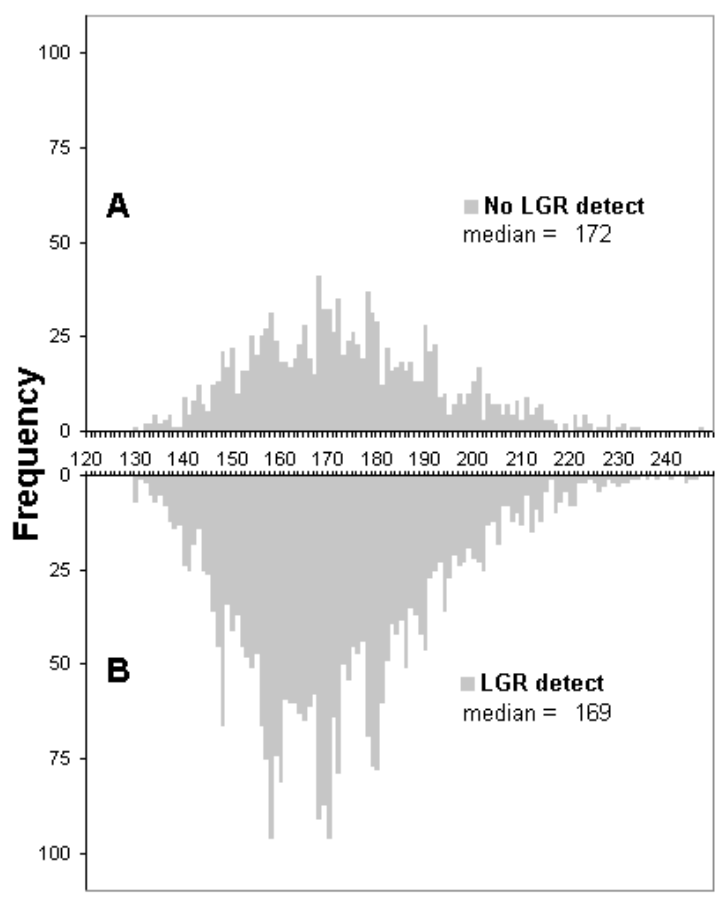

Fork length (1mm bins)

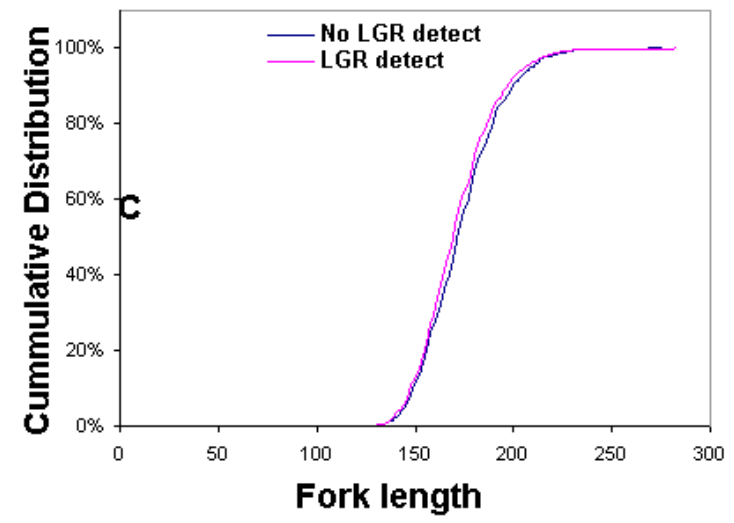

Little Goose Dam Comparisons

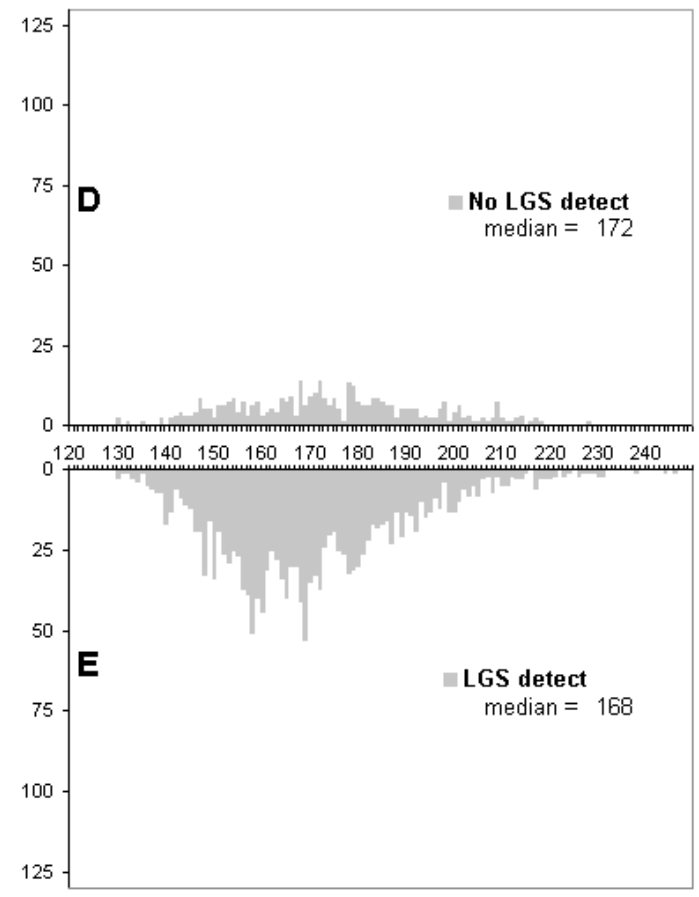

Fork length (1mm bins)

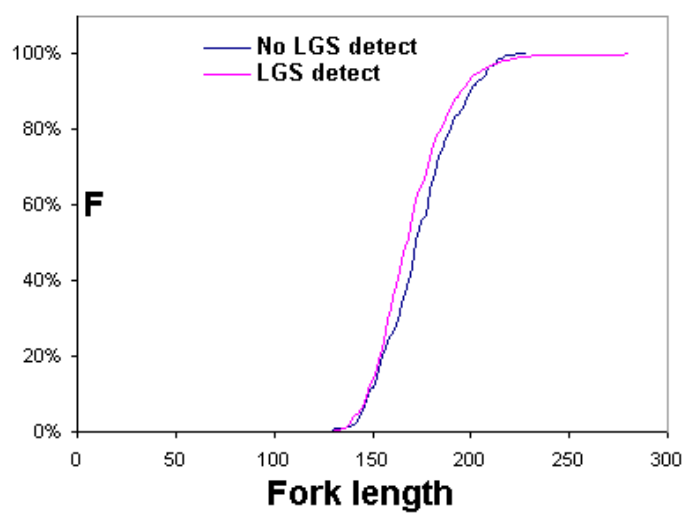

Figure 4.8. Comparisons of length for detected and undetected wild steelhead in 2004. Panel A and B display a histogram of $1 \mathrm{~mm}$ length bins for the LGR undetected and for LGR detected fish, respectively; panel $\mathrm{C}$ is the cumulative length frequency plots for LGR. Panels D,E, and F display the same information for LGS. 
2005 Wild steelhead

Lower Granite Dam Comparisons

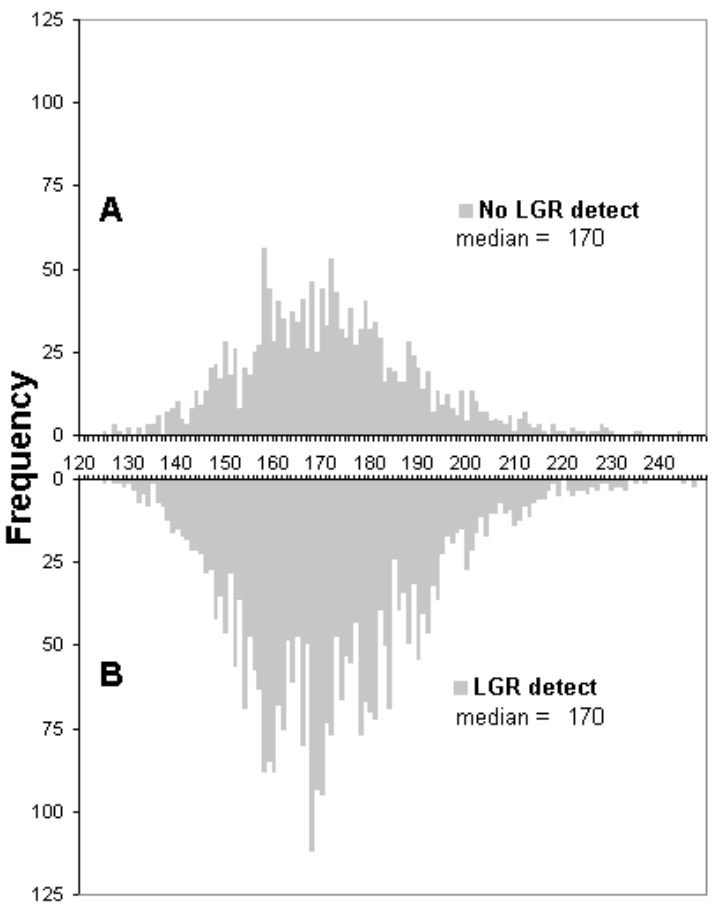

Fork length (1mm bins)

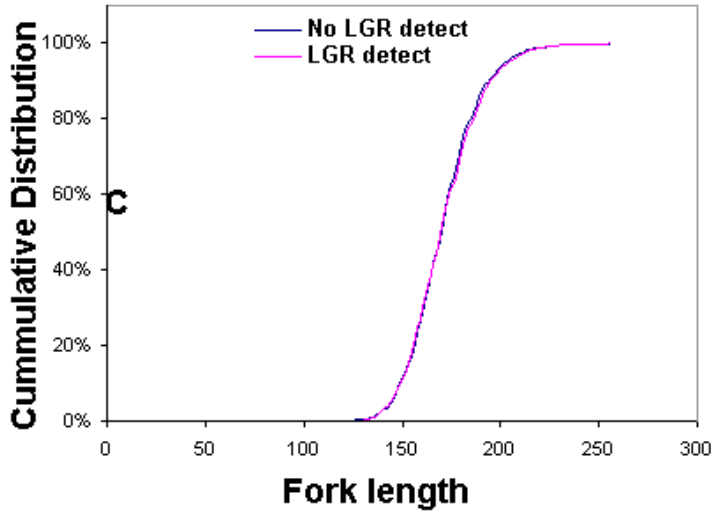

Little Goose Dam Comparisons

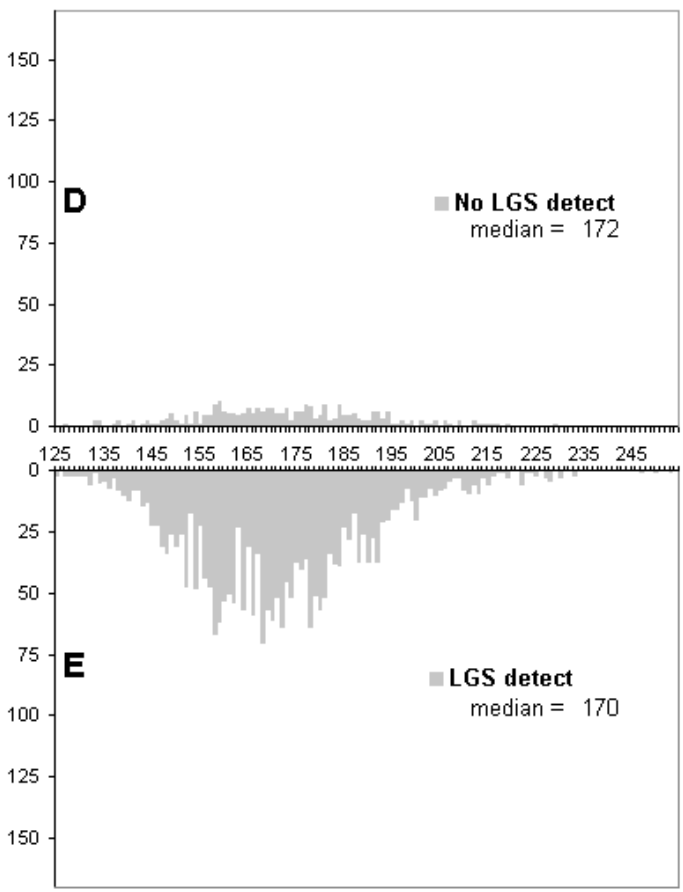

Fork length (1mm bins)

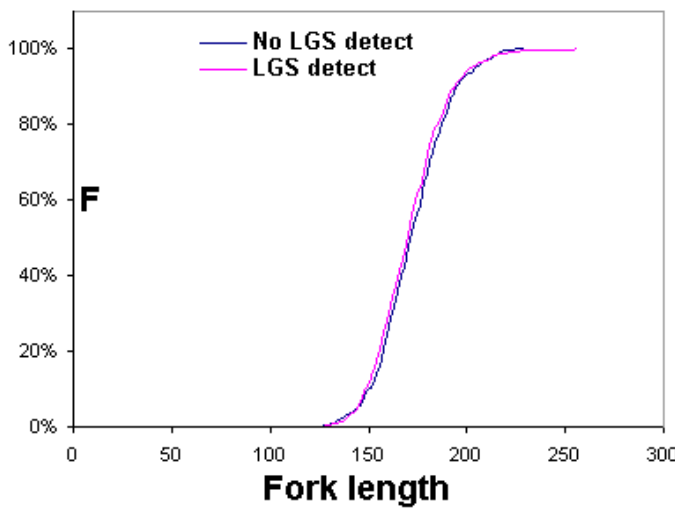

Figure 4.9. Comparisons of length for detected and undetected wild steelhead in 2005. Panel A and B display a histogram of $1 \mathrm{~mm}$ length bins for the LGR undetected and for LGR detected fish, respectively; panel $\mathrm{C}$ is the cumulative length frequency plots for LGR. Panels D,E, and F display the same information for LGS. 


\section{Hatchery steelhead}

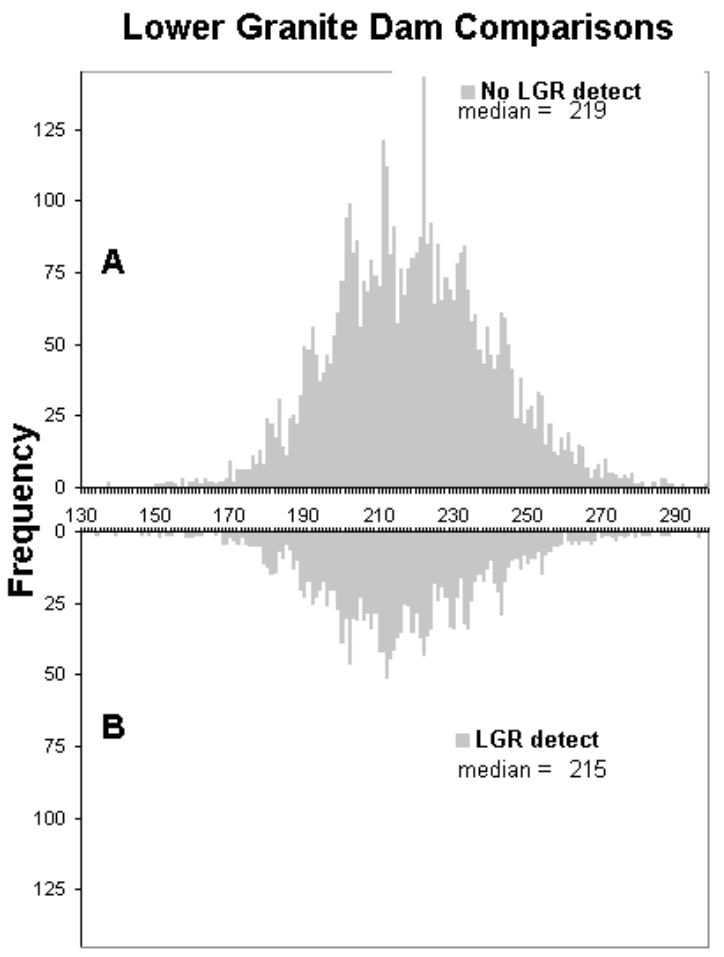

Fork length (1mm bins)

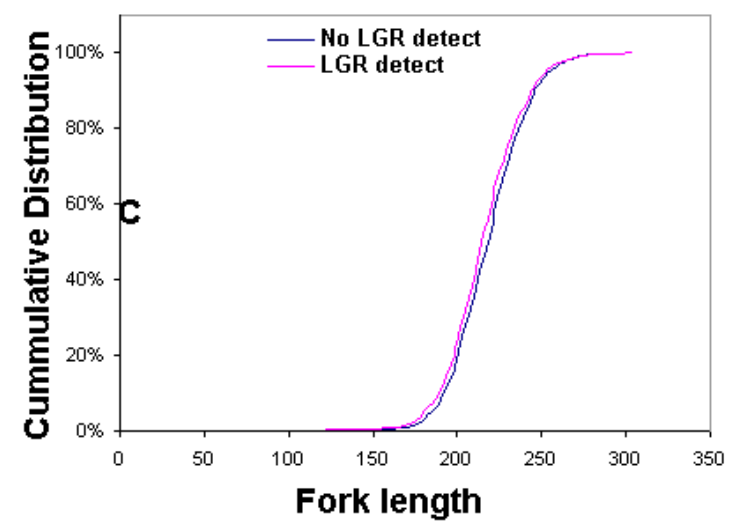

Little Goose Dam Comparisons

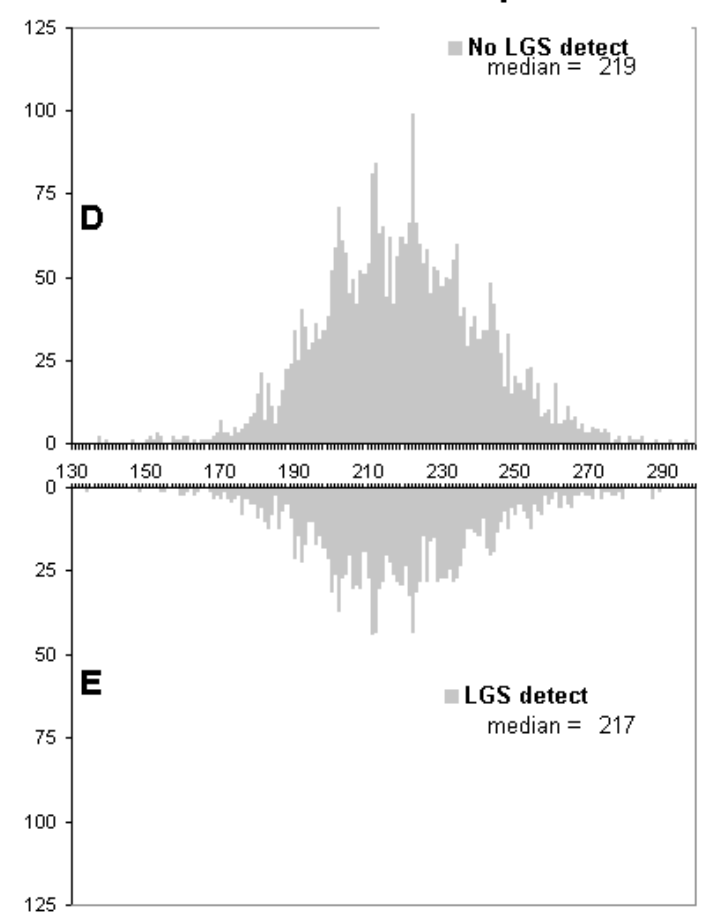

Fork length (1mm bins)

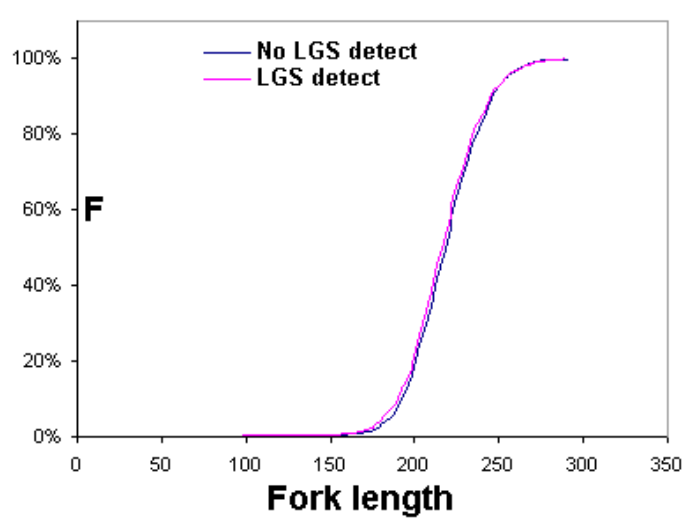

Figure 4.10. Comparisons of length for detected and undetected hatchery steelhead in 2003. Panel A and B display a histogram of 1 $\mathrm{mm}$ length bins for the LGR undetected and for LGR detected fish, respectively; panel $\mathrm{C}$ is the cumulative length frequency plots for LGR. Panels D,E, and F display the same information for LGS. 


\section{Hatchery steelhead}

Lower Granite Dam Comparisons

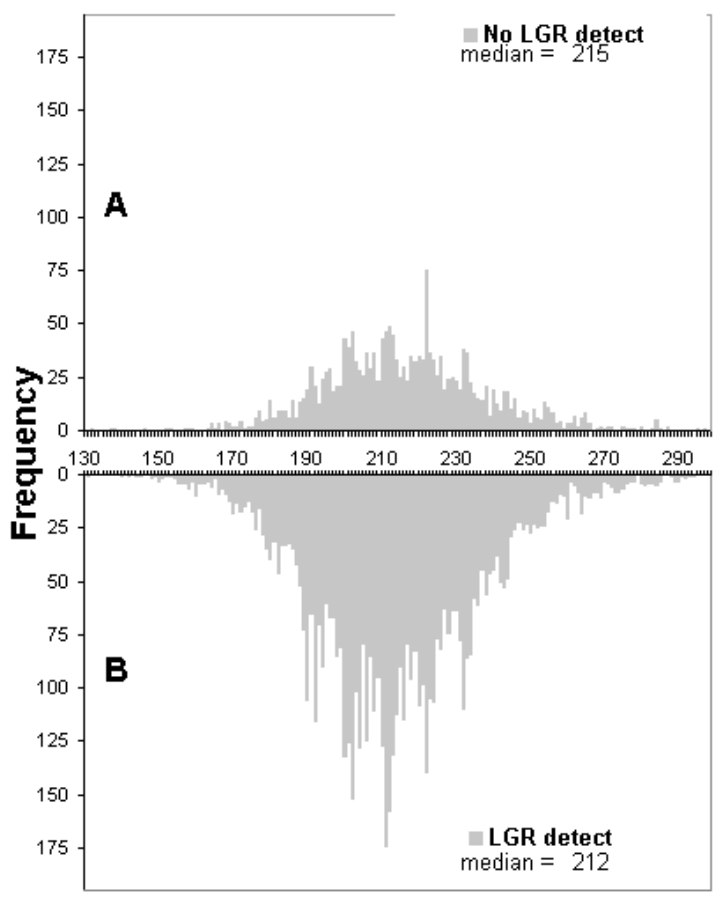

Fork length (1mm bins)

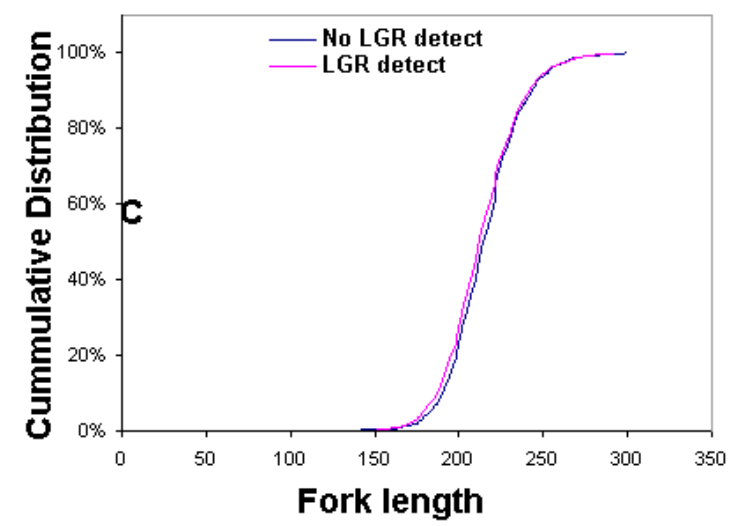

Little Goose Dam Comparisons

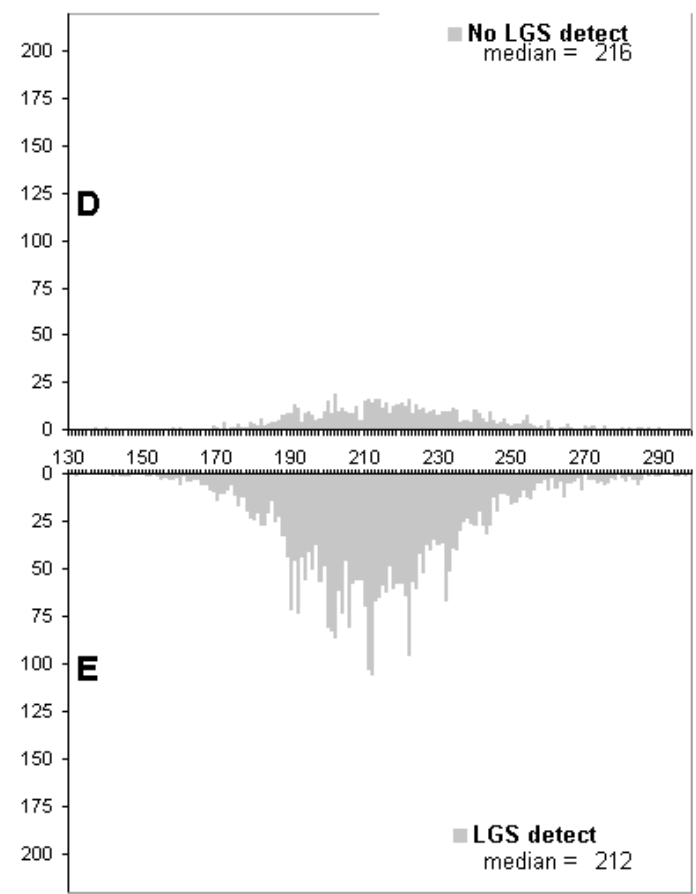

Fork length (1 $1 \mathrm{~mm}$ bins)

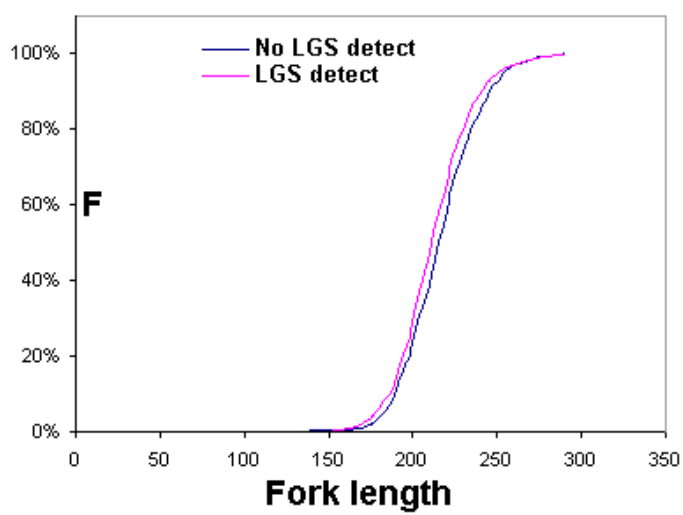

Figure 4.11. Comparisons of length for detected and undetected hatchery steelhead in 2004. Panel $A$ and $B$ display a histogram of $1 \mathrm{~mm}$ length bins for the LGR undetected and for LGR detected fish, respectively; panel $C$ is the cumulative length frequency plots for LGR. Panels D,E, and F display the same information for LGS. 


\section{Hatchery steelhead}

Lower Granite Dam Comparisons

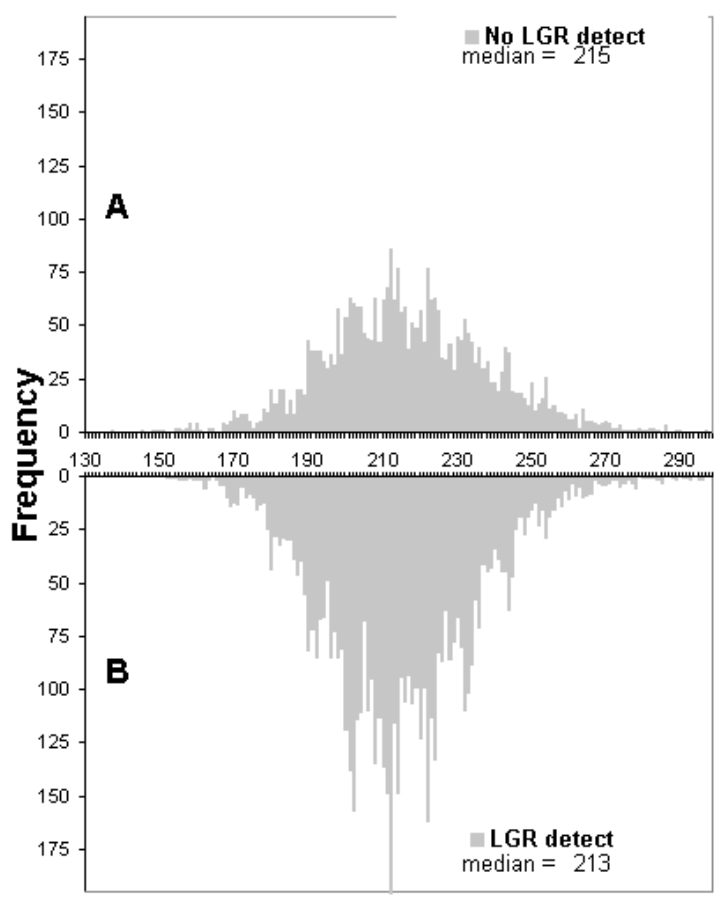

Fork length (1mm bins)

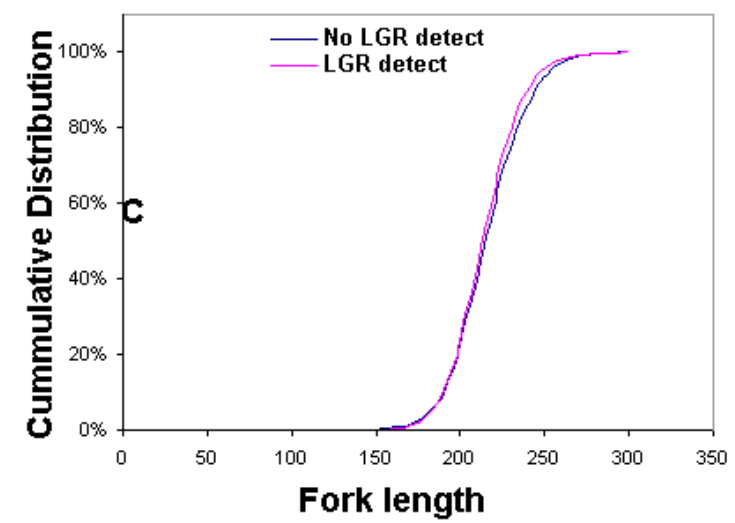

Little Goose Dam Comparisons
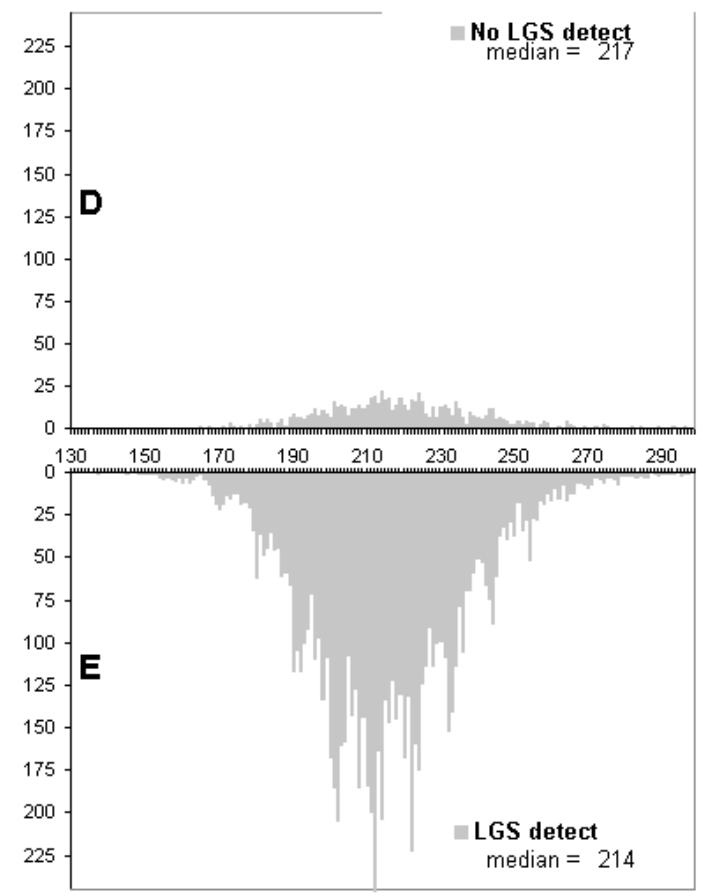

Fork length (1mm bins)

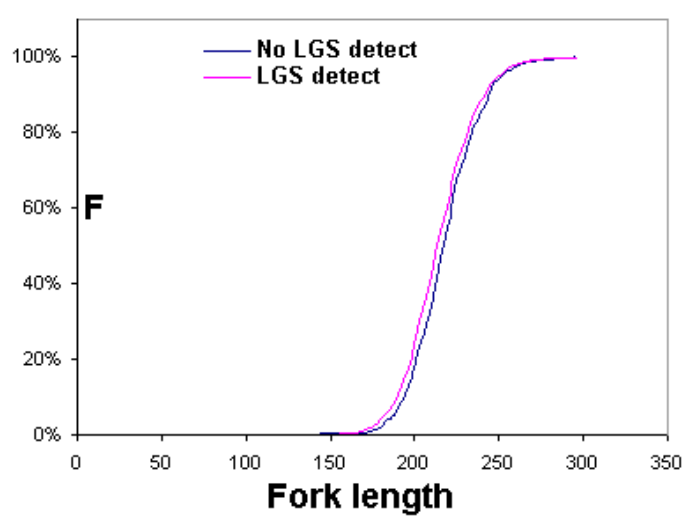

Figure 4.12. Comparisons of length for detected and undetected hatchery steelhead in 2005. Panel A and B display a histogram of $1 \mathrm{~mm}$ length bins for the LGR undetected and for LGR detected fish, respectively; panel $\mathrm{C}$ is the cumulative length frequency plots for LGR. Panels D,E, and F display the same information for LGS. 


\section{Chapter 5 -- \\ Associations between smolt outmigration experience and return rates.}

\section{Introduction}

Given that estimates of TIR ratios and $D$ both rely on smolt-to-adult survival rates (SARs) based on adult detections at Lower Granite Dam (LGR), these values include both an ocean mortality component and one occurring during upstream migration (i.e., between Bonneville Dam, BON, and LGR) in the year of adult return. Splitting that

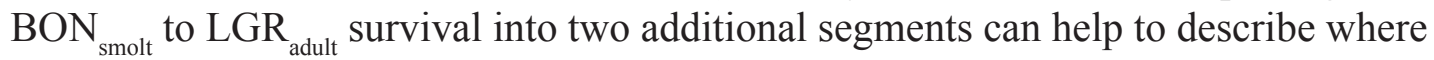
any differences in survival took place. In the 2005 and 2006 reports, we initiated an analysis/comparison of the inter-dam 'drop out' (i.e., mortality) rates of hatchery and wild Chinook salmon and extended that analyses in the 2006 report. Here we have updated adult success rates for recent groups in the CSS and used these to indirectly estimate an ocean survival parameter. We used data on the number of PIT-tagged adults passing various dams to estimate a success rate for returning adults from BON to LGR. Using data collected at PIT-tag interrogation systems on adult fishways, this quantity can be directly estimated and compared between the transport $\left(\mathrm{T}_{0}\right)$ and in-river $\left(\mathrm{C}_{0}\right.$ and $\left.\mathrm{C}_{1}\right)$ study categories in the CSS. Ocean survival (e.g., BON as juvenile to BON as adult) can be estimated indirectly by removing the upstream losses from other estimates based on SARs.

\section{Methods}

Hatchery and wild sp/su Chinook and steelhead marked with PIT tags as juvenile fish in the Snake River basin, were monitored at mainstem dams on their downstream migration, and after spending 1 to 3 years in the ocean, the survivors were detected as they passed upstream through the hydro system. PIT-tag detection systems have been installed in the fish ladders at BON, MCN, ICH, and LGR dams and allowed the tracking of PIT-tagged adults as they passed from lower Columbia River projects to upstream Snake River projects. The adult fish traverse about 286 river miles and encounter eight dams from BON to LGR inclusive. Once fish negotiate BON, they pass through a tribal fishery (between BON and MCN) and a sport fishery in both the Columbia and Snake Rivers. The detections of adults decrease at upriver sites as a result the combination of harvest, straying, and mortality.

The adult success rate is the proportion of returning PIT-tagged adults detected at LGR to those that passed BON. To determine this, we required an estimate of number of PIT-tagged adults passing BON in the fish ladders. Beginning with return year 2002 there was the capability to detect nearly all PIT-tagged adult fish passing the three ladders at BON. However, since a portion of the fish swim over the weir crests and don't pass through the orifices where the detection equipment is installed, the detection rate for PIT-tagged adult fish at BON remains less than 100\%. We used upstream adult PIT-tag detections that were not detected at BON (e.g., unique MCA, IHA, and LGR detections) to estimate the BON detection efficiency. This parameter was then used to expand the number of BON adult detections in the adult success rate. The adult success rate was calculated as: 


$$
\text { Adult.success.rate }=\frac{G R A_{\text {count }}}{\left(B O N_{\text {count }} \div B O N_{\text {efficiency }}\right)}
$$

The efficiency was calculated specific to each group of interest and applied to each subset of that group (i.e., the transport and in-river sets). Also, because the $\mathrm{C}_{1}$ and $\mathrm{C}_{0}$ groups have a much smaller sample size than the $\mathrm{T}_{0}$ group, and few adults returned overall, we combined the $\mathrm{C}_{0}$ and $\mathrm{C}_{1}$ group $\left(\mathrm{C}_{\mathrm{X}}\right)$ when calculating these adult parameters. For example, we first calculated efficiency at BON using all the adult detections within a species type and juvenile migration year. Then, this parameter was used when estimating the adult success rate for the $T_{0}$ and the $C_{X}$ subset from that group.

The use of fish detected upstream that were not detected at BON to estimate BON efficiency is the best available measurement of this parameter. However, this nominal estimator of efficiency could be inaccurate if fish passed BON undetected and through straying/harvest/mortality were never again detected. This problem is alleviated when comparing these two rates in a fraction (e.g., Success $\left.{ }_{\mathrm{TO}} / \mathrm{Success}_{\mathrm{CX}}\right)$. The assumption here is that the rate for passing BON undetected and never being detected again is the same for the transported and in-river fish. Since these two are fish from the same species/hatchery this seems reasonable.

To calculate survival in the ocean both the juvenile and adult hydrosystem survival components must be removed from the SARs. We used the D parameter (see chapter $2 \& 3$ ) for a particular group and divided by the adult success rate proportion for that same group. The result is an estimate that compares ocean survival of fish that were transported to ocean survival for fish with an in-river history:

\section{Results}

$$
\text { Ocean.survival }=\frac{\left(\frac{\operatorname{SAR}\left(T_{0}\right)}{S_{T}}\right)}{\left(\frac{\operatorname{SAR}\left(C_{0}\right)}{S_{R}}\right)} \div \frac{\text { Success }_{T_{0}}}{\text { Success }_{C_{x}}}
$$

The counts for 2003-2005 CSS groups at BON and LGR are shown in table 5.1. The geometric mean efficiency for Chinook ranged from $94.6 \%$ to $97.5 \%$ across migration year groups. This is similar to those calculated for Chinook in the 2005 annual report (range: 93.1\% to 98.3\%; CSS 2005 annual report, Table 58). The adult success rates calculated from these counts are shown in table 5.2 along with the ratio of these parameters (i.e., Success $_{\mathrm{TO}} /$ Success $_{\mathrm{CX}}$ ).

Bootstrapped $90 \%$ confidence intervals are shown for these parameters as well (calculated with program $\mathrm{R}$ version 2.7.1). In cases where each of the individual fish detected at upstream sites are also detected at BON, the efficiency and the adult success rate are $100 \%$. This was the case for the 2005 Imnaha hatchery Chinook $\mathrm{C}_{\mathrm{x}}$ group. This resulted in no confidence interval because there was no indication from these data that any of the adults did not successful migrate from BON to LGR.

The ratio of adult success rates for transported to in-river fish was typically below one (Figure 5.1). Within the hatchery Chinook group, the McCall hatchery fish had values 
at or above one while the other four Chinook hatcheries had ratios below one in each of the years 2003-2005. Wild steelhead always had values below one over these years.

The ratio of ocean survival is displayed in Figure 5.2. Here, many values are above one. There is a marked contrast between the adult success ratio for wild steelhead and this parameter. The values for hatchery steelhead are also now all well above one. Wild Chinook, while having ratio of adult success rates at or near one in all years, had very low values in the years 2003-2004 for the ocean survival component ratio.

Table 5.1. Counts of adults at LGR and BON for all CSS groups for the migration years 2003-2005. Counts are shown for fish with two different routes of passage as emigrating juveniles (transported $\left[\mathrm{T}_{0}\right]$ and in-river groups $\left.\left[\mathrm{C}_{\mathrm{X}}\right]\right)$. The "adds" column is for any individual adults seen at any upstream facility (MCA, ICH, or LGR) and not seen at BON; BON efficiency is calculated with these counts.

\begin{tabular}{|c|c|c|c|c|c|c|c|}
\hline & LGR-T $_{0}$ & BON-T ${ }_{0}$ & $\begin{array}{c}\text { BON-T }_{0} \\
\text { adds }\end{array}$ & LGR-C $_{x}$ & BON-C ${ }_{x}$ & $\begin{array}{c}\mathrm{BON}^{-\mathrm{C}_{\mathrm{x}}} \\
\text { adds }\end{array}$ & $\begin{array}{c}\text { BON } \\
\text { efficiency }\end{array}$ \\
\hline \multicolumn{8}{|l|}{2003} \\
\hline HCH-CATH & 9 & 10 & 1 & 13 & 14 & 1 & $92.3 \%$ \\
\hline HCH-DWOR & 34 & 44 & 3 & 50 & 57 & 3 & $94.4 \%$ \\
\hline HCH-IMNA & 30 & 39 & 0 & 43 & 51 & 2 & $97.8 \%$ \\
\hline HCH-MCCA & 111 & 124 & 6 & 137 & 154 & 6 & $95.9 \%$ \\
\hline HCH-RAPH & 33 & 52 & 2 & 50 & 52 & 5 & $93.7 \%$ \\
\hline $\mathrm{WCH}$ & 30 & 29 & 2 & 51 & 55 & 4 & $93.3 \%$ \\
\hline WST & 44 & 53 & 2 & 52 & 57 & 2 & $96.5 \%$ \\
\hline HST & 83 & 105 & 1 & $\begin{array}{c}81 \\
\text { Geomean } \\
\text { (Steelhead) }\end{array}$ & $\begin{array}{c}99 \\
\mathbf{9 7 . 3 \%}\end{array}$ & $\begin{array}{c}3 \\
\text { Geomean } \\
\text { (Chinook) }\end{array}$ & $\begin{array}{l}98.1 \% \\
\mathbf{9 4 . 6} \%\end{array}$ \\
\hline \multicolumn{8}{|l|}{2004} \\
\hline HCH-CATH & 11 & 14 & 0 & 7 & 7 & 1 & $95.5 \%$ \\
\hline HCH-DWOR & 61 & 121 & 3 & 46 & 66 & 1 & $97.9 \%$ \\
\hline HCH-IMNA & 26 & 41 & 1 & 8 & 12 & 0 & $98.1 \%$ \\
\hline HCH-MCCA & 84 & 113 & 1 & 25 & 40 & 0 & $99.4 \%$ \\
\hline HCH-RAPH & 70 & 88 & 2 & 23 & 25 & 2 & $96.6 \%$ \\
\hline $\mathrm{WCH}$ & 68 & 88 & 2 & 48 & 59 & 2 & $97.4 \%$ \\
\hline WST & 39 & 60 & 1 & 5 & 7 & 0 & $98.5 \%$ \\
\hline HST & 10 & 9 & 2 & $\begin{array}{c}33 \\
\text { Geomean } \\
\text { (Steelhead) }\end{array}$ & $\begin{array}{c}39 \\
\mathbf{9 7 . 3 \%}\end{array}$ & $\begin{array}{c}0 \\
\text { Geomean } \\
\text { (Chinook) }\end{array}$ & $\begin{array}{l}96.0 \% \\
\mathbf{9 7 . 5 \%}\end{array}$ \\
\hline \multicolumn{8}{|l|}{2005} \\
\hline HCH-CATH & 11 & 14 & 1 & 4 & 4 & 1 & $90.0 \%$ \\
\hline HCH-DWOR & 43 & 65 & 2 & 30 & 35 & 1 & $97.1 \%$ \\
\hline HCH-IMNA & 17 & 23 & 0 & 8 & 8 & 0 & $100.0 \%$ \\
\hline HCH-MCCA & 141 & 168 & 2 & 41 & 49 & 0 & $99.1 \%$ \\
\hline HCH-RAPH & 55 & 69 & 5 & 20 & 23 & 1 & $93.9 \%$ \\
\hline $\mathrm{WCH}$ & 38 & 48 & 1 & 15 & 19 & 0 & $98.5 \%$ \\
\hline WST & 40 & 51 & 1 & 17 & 17 & 5 & $91.9 \%$ \\
\hline HST & 18 & 29 & 1 & $\begin{array}{c}43 \\
\text { Geomean } \\
\text { (Steelhead) }\end{array}$ & $\begin{array}{c}56 \\
\mathbf{9 4 . 8 \%}\end{array}$ & $\begin{array}{c}1 \\
\text { Geomean } \\
\text { (Chinook) }\end{array}$ & $\begin{array}{l}97.7 \% \\
\mathbf{9 6 . 4 \%}\end{array}$ \\
\hline
\end{tabular}


Table 5.2. Adult success rates for all CSS groups for the migration years 2003-2005. Adult success rate for the transported $\left(T_{0}\right)$ and in-river groups $\left(C_{X}\right)$, and the ratio $T_{0} / C_{X}$ are each shown with their $90 \%$ confidence interval.

\begin{tabular}{cccccc} 
M.Year & $\begin{array}{c}\text { Rear } / \\
\text { Species }\end{array}$ & Hatchery & Success $\mathbf{T}_{\mathbf{0}}$ & Success $_{\mathbf{x}}$ & $\begin{array}{c}\text { Adult success } \\
\text { ratio }_{\mathbf{o}} / \mathbf{C}_{\mathbf{x}}\end{array}$ \\
\hline 2003 & HCH & CATH & $0.831(0.579-1.106)$ & $0.857(0.681-1.031)$ & $0.969(0.625-1.5)$ \\
& HCH & DWOR & $0.729(0.606-0.845)$ & $0.828(0.739-0.914)$ & $0.881(0.709-1.077)$ \\
& HCH & IMNA & $0.753(0.643-0.865)$ & $0.825(0.731-0.916)$ & $0.912(0.758-1.099)$ \\
& HCH & MCCA & $0.858(0.800-0.912)$ & $0.853(0.804-0.899)$ & $1.006(0.910-1.102)$ \\
& HCH & RAPH & $0.595(0.485-0.705)$ & $0.901(0.811-0.987)$ & $0.660(0.520-0.824)$ \\
& WCH & & $0.966(0.882-1.054)$ & $0.865(0.777-0.949)$ & $1.116(0.972-1.301)$ \\
& HST & & $0.775(0.705-0.837)$ & $0.802(0.735-0.868)$ & $0.966(0.848-1.092)$ \\
& WST & & $0.801(0.709-0.896)$ & $0.880(0.799-0.953)$ & $0.910(0.772-1.064)$ \\
& HCH & CATH & $0.750(0.518-0.923)$ & $0.955(0.667-1.27)$ & $0.786(0.492-1.179)$ \\
& HCH & DWOR & $0.494(0.413-0.571)$ & $0.682(0.585-0.771)$ & $0.723(0.574-0.901)$ \\
& HCH & IMNA & $0.622(0.500-0.747)$ & $0.654(0.429-0.884)$ & $0.951(0.646-1.507)$ \\
& HCH & MCCA & $0.739(0.664-0.803)$ & $0.621(0.497-0.745)$ & $1.189(0.962-1.504)$ \\
& HCH & RAPH & $0.768(0.693-0.842)$ & $0.889(0.756-1.04)$ & $0.865(0.707-1.043)$ \\
& WCH & & $0.752(0.676-0.824)$ & $0.792(0.698-0.881)$ & $0.950(0.814-1.103)$ \\
& HST & & $1.067(0.801-1.448)$ & $0.812(0.698-0.902)$ & $1.313(0.948-1.907)$ \\
& WST & & $0.640(0.541-0.742)$ & $0.704(0.375-0.987)$ & $0.910(0.611-1.762)$ \\
& HCH & CATH & $0.707(0.500-0.909)$ & $0.900(0.464-1.846)$ & $0.786(0.346-1.667)$ \\
HCH & DWOR & $0.642(0.544-0.738)$ & $0.832(0.711-0.934)$ & $0.772(0.634-0.95)$ \\
HCH & IMNA & $0.739(0.588-0.889)$ & $1.000(1-1)^{\mathrm{A}}$ & $0.739(0.588-0.889)$ \\
HCH & MCCA & $0.832(0.782-0.879)$ & $0.829(0.736-0.917)$ & $1.003(0.890-1.145)$ \\
HCH & RAPH & $0.748(0.658-0.833)$ & $0.816(0.659-0.954)$ & $0.917(0.737-1.173)$ \\
WCH & & $0.780(0.673-0.884)$ & $0.778(0.621-0.929)$ & $1.003(0.797-1.304)$ \\
& HST & & $0.606(0.448-0.76)$ & $0.750(0.658-0.847)$ & $0.808(0.579-1.058)$ \\
WST & & $0.721(0.624-0.819)$ & $0.919(0.731-1.138)$ & $0.784(0.582-1.022)$
\end{tabular}

A All fish detected at GRA (and other upstream sites) were also detected at BON. 


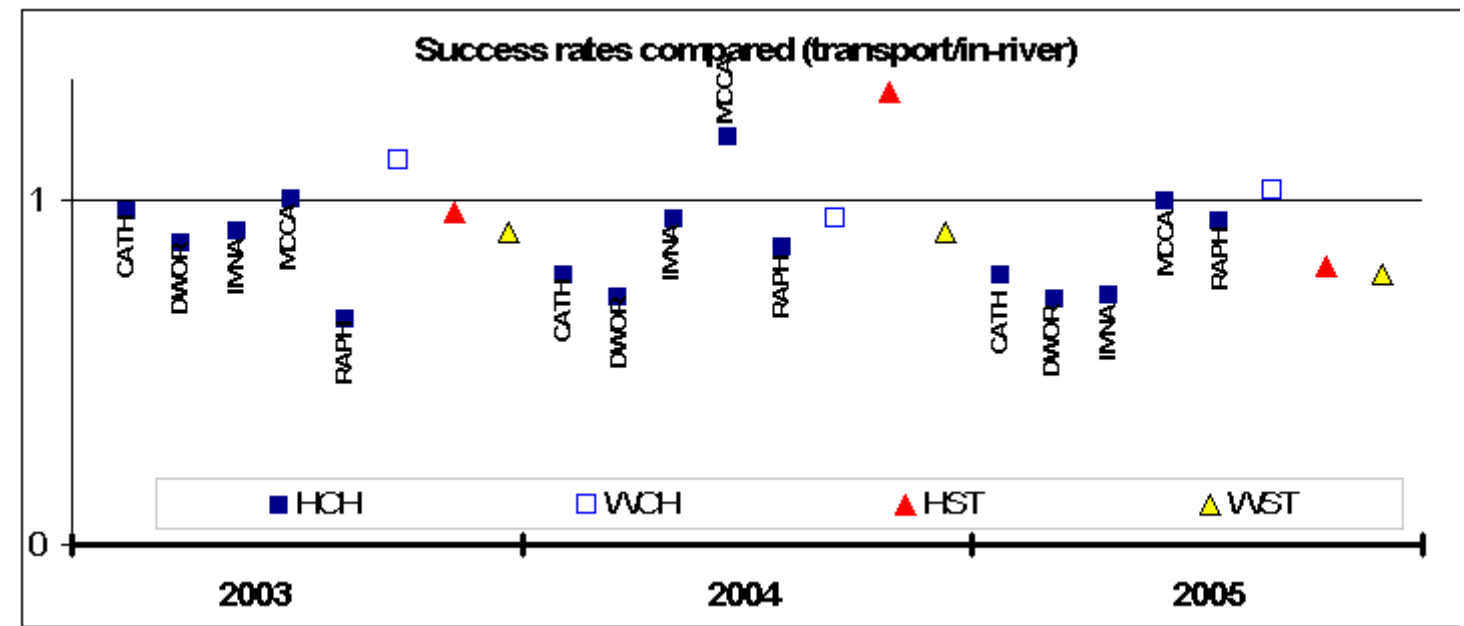

${ }^{1}$ These adult success rates are combined here as a fraction with the transported fish ( $\mathrm{T}_{0}$ group) in the numerator and the in-river group $\left(\mathrm{C}_{\mathrm{X}}=\mathrm{C}_{1}+\mathrm{C}_{0}\right.$ groups $)$ in the denominator. When the value is above 1, the transportation group adults migrated from BON to LGR at a higher rate than the in-river group, when less than one, the opposite is true. Losses during the BON to LGR migration can be attributed to straying, harvest, and natural mortality.

Figure 5.1. Comparing the adult BON to LGR adult success rate between two groups with different juvenile passage routes (e.g., transported and in-river) ${ }^{1}$. Hatchery Chinook values are shown for individual hatcheries. 


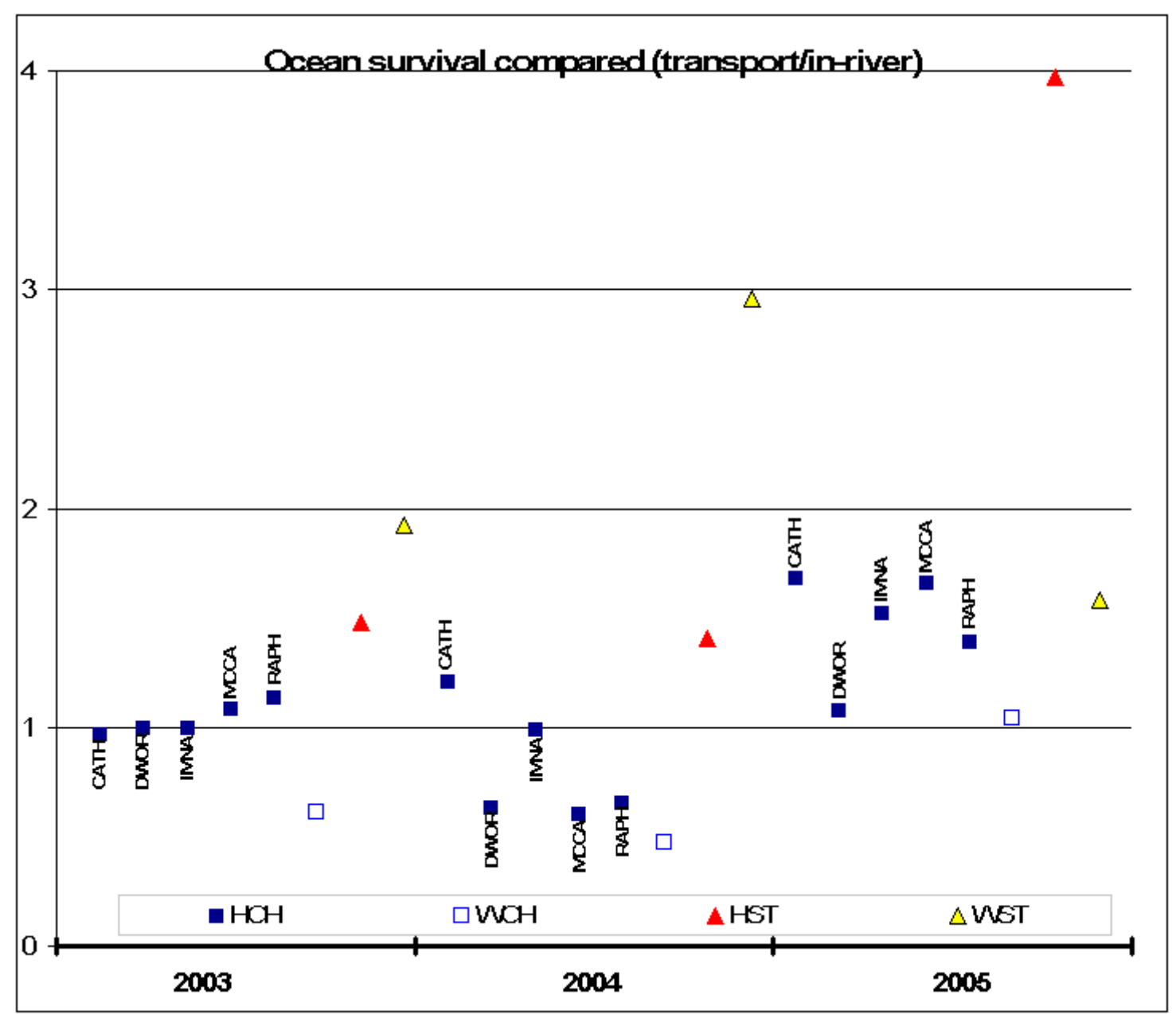

${ }^{1}$ These adult success rates are combined here as a fraction with the transported fish in the numerator and the in-river group in the denominator. When the value is above 1, the transportation group adults survived from $\mathrm{BON}_{\mathrm{juv}}$ to $\mathrm{BON}_{\text {adult }}$ at a higher rate than the in-river group, when less than one the opposite is true.

Figure 5.2. Comparing the $\mathrm{BON}_{\text {juv }}$ to $\mathrm{BON}_{\text {adult }}$ survival rate between two groups with different juvenile passage routes (e.g., transported and in-river) ${ }^{1}$. Hatchery Chinook values are shown for individual hatcheries.

\section{Discussion}

The D parameter represents the differential delayed mortality between transported and in-river subsets of CSS groups. This parameter is at its highest for 4 out of 5 hatchery Chinook groups during 2005 as compared to 2003 and 2004 (Dworshak hatchery did not show this pattern; Tables 3.10 and 3.11). Because the D parameter is a differential expression, this could have resulted from decreasing post-Bonneville survival for in-river fish, an increase for transported fish or both. However, it seems that most of these effects are evident in the ocean component of the post-Bonneville survival. The adult success rate ratios for these groups are typically below one in these years. This result may indicate that transportation of hatchery Chinook interferes with the adult success rate. A lower adult success rate may be due to impaired homing, straying, mortality and/or longer travel times/greater exposure to harvest. The consequence is that any benefits of transportation decrease for these groups.

The distance of these hatcheries from LGR probably also plays a role in these 
results. The distances from release site to LGR are 116, 209, 283, 378, and 463

kilometers for Dworshak, Imnaha, Rapid River, Catherine Creek, and McCall hatcheries respectively. The McCall hatchery consistently had the highest ratio of adult success rates within the hatchery groups across years. The CSS 2005 report also had evidence to support a distance from release effect on upstream homing/survival. This is also consistent with results of Solazzi et al. (1991).

Wild Chinook display a similar pattern as hatchery Chinook. The D parameter is the highest during 2005, and these effects appear to be more evident in the ocean component than the adult component. However, the adult success rate ratio for wild Chinook is nearer to and above one when many hatchery groups are not. This may indicate that wild Chinook are more strongly imprinted at the time they enter the hydrosystem or at least the effects of transportation on their adult success rate is less than for hatchery Chinook.

The D parameter is generally higher for wild and hatchery steelhead over the years 2003-2005 than for other CSS groups of fish (Tables 3.10, 3.11, 3.12, and 3.17). Again, these measurements increased consistently across years (hatchery steelhead) or were highest during 2005 (wild steelhead). Except in one case these results are much stronger in the ocean component than the adult return component.

In chapter 4 of this report there was a slight difference found in the median length between bypassed and in-river steelhead for 2003-2005. If this difference resulted in an ostensibly less fit transported fish, and this would make the transported population more susceptible to predation, one would expect the ocean component differential for these groups to be less than one. However, since the opposite is true, if there is an effect of this size difference it does not preclude a positive effect of transportation in the ocean component.

The adult success parameter measures the overall results of straying/harvest/ mortality during the adult return. When expressed as a ratio (assuming that harvest pressure is similar for in-river and transport subsets of any particular CSS group) this expresses the difference due to the effects of straying and natural mortality between these two subsets. Although, natural mortality may be similar between these two subgroups as well, conservatively this parameter expresses the combined difference in natural mortality, straying, and any changes in harvest pressure as a result of straying. Transportation affected the ratio of adult success rates in almost every permutation examined here. These results indicate that during 2003-2005 while transportation effects as compared to in-river groups can increase or decrease ocean survival, they almost always decrease the potential for adults to return to their natal habitat and thereby contribute to their original population. 


\section{Chapter 6 -- \\ Overall Annual SAR Patterns}

\section{General}

Success of any hydrosystem mitigation strategy will require achievement of smolt-to-adult survival rates sufficient to meet recovery and rebuilding objectives, in combination with a program to maintain or achieve adequate survival in other life stages. An independent peer review of the transportation program in the early 1990s (Mundy et al. 1994) concluded: "[u]nless a minimum level of survival is maintained for listed species sufficient for them to at least persist, the issue of the effect of transportation is moot."

The Northwest Power and Conservation Council (2003) mainstem amendments to the Fish and Wildlife Program adopted as an interim objective, to “...contribute to achieving smolt-to-adult return rates (SARs) in the 2-6 percent range (minimum 2 percent; average 4 percent) for listed Snake River and upper Columbia salmon and steelhead." The NPCC (2003) also called for evaluation of the scientific soundness and achievability of, and impact of ocean conditions on, these SAR objectives. Analyses in this chapter address the extent to which wild Snake River spring/summer Chinook and steelhead population aggregates may be meeting the NPCC (2003) interim biological objectives, and factors influencing the overall SARs.

The NPCC 2-6\% SAR objectives have a scientific basis in analyses by the Plan for Analyzing and Testing Hypotheses (PATH), conducted in support of the 2000 Biological Opinion. Marmorek et al. (1998) found that median SARs of 4\% were necessary to meet the NMFS interim 48-year recovery standard for Snake River spring/summer Chinook; meeting the 100-year interim survival standard required a median SAR of at least 2\%. PATH analyses did not identify specific SARs necessary for steelhead survival and recovery, however, historic steelhead SARs before FCRPS completion were somewhat greater than those of spring/summer Chinook (Marmorek et al. 1998). Currently, the Interior Columbia River Technical Recovery Team (IC-TRT) is developing biological recovery criteria based on the Viable Salmonid Population concepts (McElhaney et al. 2001). Additional SAR objectives may be associated with the IC-TRT recovery criteria when adopted or incorporated into a Recovery Plan. Regardless of specific future SAR objectives, the same types of data and analytical methods will be required in the future to evaluate the overall effectiveness of the hydrosystem mitigation strategy.

The NPCC 2-6\% SAR objective for Chinook addresses the total adult return including jacks. Therefore, in this chapter we present estimates of overall SAR with jacks included and our standard reporting statistic of SARs with jacks excluded. All analyses earlier in this report (and prior CSS reports) are based on strictly adult (age 2-salt and older) fish; this includes the generation of SARs by study category, TIRs, D, and adult upstream migration success rates. By using only 2-salt and older returning Chinook adults in the estimation of the key CSS parameters, we are assuring that the results will be more directly reflective of the primary spawning populations (females and older males) in each drainage above LGR.

The primary objective in this chapter is to update the long-term SAR data series for CSS study fish. In Tables 6.1 to 6.4, the overall annual SARs (Chinook jacks 
excluded) for all migration years are based on the weighting of group-specific SARs by the estimated proportion of run-at-large reflected by each group. This is the method used in all prior CSS reports. Beginning in 2006, the CSS initiated the approach of preassigning PIT-tagged fish into two major groups. One group (Group TWS) reflects the untagged fish passage experience under a given year's fish passage management scenario. The other group (Group BWS) has its migrants bypassed if collected at a dam throughout the season. Combining Groups TWS and BWS provides the original release group from which the standard $\mathrm{T}_{0}, \mathrm{C}_{0}$, and $\mathrm{C}_{1}$ study categories may be obtained for migration year 2006. The overall SAR for Group TWS migrants does not require a weighting of group-specific SARs; its overall SAR is directly estimated as the number of returning adults divided by the total population (i.e., detected and estimated undetected PIT-tag population) at LGR. Using the 2006 return data of 2-salt spring/summer Chinook adult returns, a comparison is made in Table 6.3 between the overall annual SARs computed with the original and pre-assignment methodologies. Lastly, the overall SARs with jacks included is presented for all 13 years of PIT-tagged wild Chinook data and 10 years of PIT-tagged hatchery Chinook data (except for Catherine Creek hatchery Chinook, which has only 6-year history). The effect of including jacks in the overall SAR estimates are presented for the wild Chinook aggregate and each of the five CSS hatchery groups.

\section{Yearling Chinook (jacks excluded from adult return)}

\section{Wild Chinook}

The 13-yr geometric mean SAR for 1994-2006 (Table 6.1) was 0.72\% (jacks excluded). Figure 6.1 shows that the overall SAR for wild Chinook (presented without jacks) was very low (seldom exceeding 0.5\%) in 6 of the 13 years (1994-1996 and 20032005), and only exceeded $2 \%$ in 1999 . There is the potential for the 2006 SAR to reach near $1 \%$ if next year sees an above average proportion of 3-salt returns (see Table A-29 for annual age composition of returning PIT-tagged wild Chinook since 1994).

Table 6.1. Study-specific SARs and weights (estimated proportion of run-at-large reflected by each study category) used to estimate the annual SARs for wild Chinook with jacks excluded.

\begin{tabular}{|c|c|c|c|c|c|c|c|c|}
\hline \multirow[t]{2}{*}{$\begin{array}{l}\text { Migr } \\
\text { Year }\end{array}$} & \multicolumn{3}{|c|}{$\begin{array}{l}\text { Population proportion } \\
\text { in study categorv }{ }^{A}\end{array}$} & \multicolumn{3}{|c|}{$\begin{array}{c}\text { SAR for } \\
\text { study category }(\%) \\
\end{array}$} & \multirow{2}{*}{\multicolumn{2}{|c|}{$\begin{array}{c}\text { Weighted } \\
\text { SAR }_{\text {LGR-to-LGR }}(\%) \\
(90 \% \mathrm{CI})\end{array}$}} \\
\hline & $T_{0}$ & $\mathrm{C}_{0}$ & $\mathrm{C}_{1}$ & $\operatorname{sar}\left(T_{0}\right)$ & $\left.\operatorname{sarC}_{0}\right)$ & $\operatorname{sar}\left(C_{1}\right)$ & & \\
\hline 1994 & 0.863 & 0.137 & & 0.45 & 0.28 & & 0.43 & $(0.22-0.66)$ \\
\hline 1995 & 0.805 & 0.141 & 0.054 & 0.35 & 0.37 & 0.25 & 0.35 & $(0.20-0.52)$ \\
\hline 1996 & 0.706 & 0.255 & 0.039 & 0.50 & 0.26 & 0.13 & 0.42 & $(0.06-0.84)$ \\
\hline 1997 & 0.572 & 0.239 & 0.189 & 1.74 & 2.35 & 0.93 & 1.73 & $(0.97-2.68)$ \\
\hline 1998 & 0.815 & 0.185 & & 1.18 & 1.36 & & 1.21 & $(0.82-1.64)$ \\
\hline 1999 & 0.863 & 0.137 & & 2.43 & 2.13 & & 2.39 & $(1.89-2.94)$ \\
\hline 2000 & 0.709 & 0.269 & 0.022 & 1.43 & 2.39 & 2.34 & 1.71 & $(1.22-2.24)$ \\
\hline 2001 & 0.989 & 0.011 & & 1.28 & & & 1.27 & $(0.54-2.11)$ \\
\hline 2002 & 0.709 & 0.273 & 0.018 & 0.80 & 1.22 & 0.99 & 0.92 & $(0.75-1.10)$ \\
\hline 2003 & 0.692 & 0.294 & 0.014 & 0.34 & 0.33 & 0.17 & 0.34 & $(0.26-0.41)$ \\
\hline 2004 & 0.928 & 0.071 & 0.001 & 0.53 & 0.49 & 0.22 & 0.52 & $(0.43-0.63)$ \\
\hline 2005 & 0.926 & 0.040 & 0.035 & 0.23 & & & 0.22 & $(0.17-0.28)$ \\
\hline $2006^{D}$ & 0.667 & 0.159 & 0.174 & 0.61 & 0.69 & 0.37 & 0.58 & $(0.49-0.68)$ \\
\hline
\end{tabular}

${ }^{\mathrm{A}}$ Estimated proportion of total smolt population (tagged and untagged) at LGR in each study category.

${ }^{\text {в }}$ Migration year 2001 uses $\operatorname{SAR}\left(C_{1}\right)$ with the $C_{0}$ population proportion in the weighted SAR computation.

${ }^{\mathrm{C}}$ In-river SAR is combination of groups $\mathrm{C}_{0}$ and $\mathrm{C}_{1}$

${ }^{D}$ Mig. year 2006 data is combined groups TWS \& BWS; incomplete with 2-salt adult returns as of $8 / 13 / 2008$. 

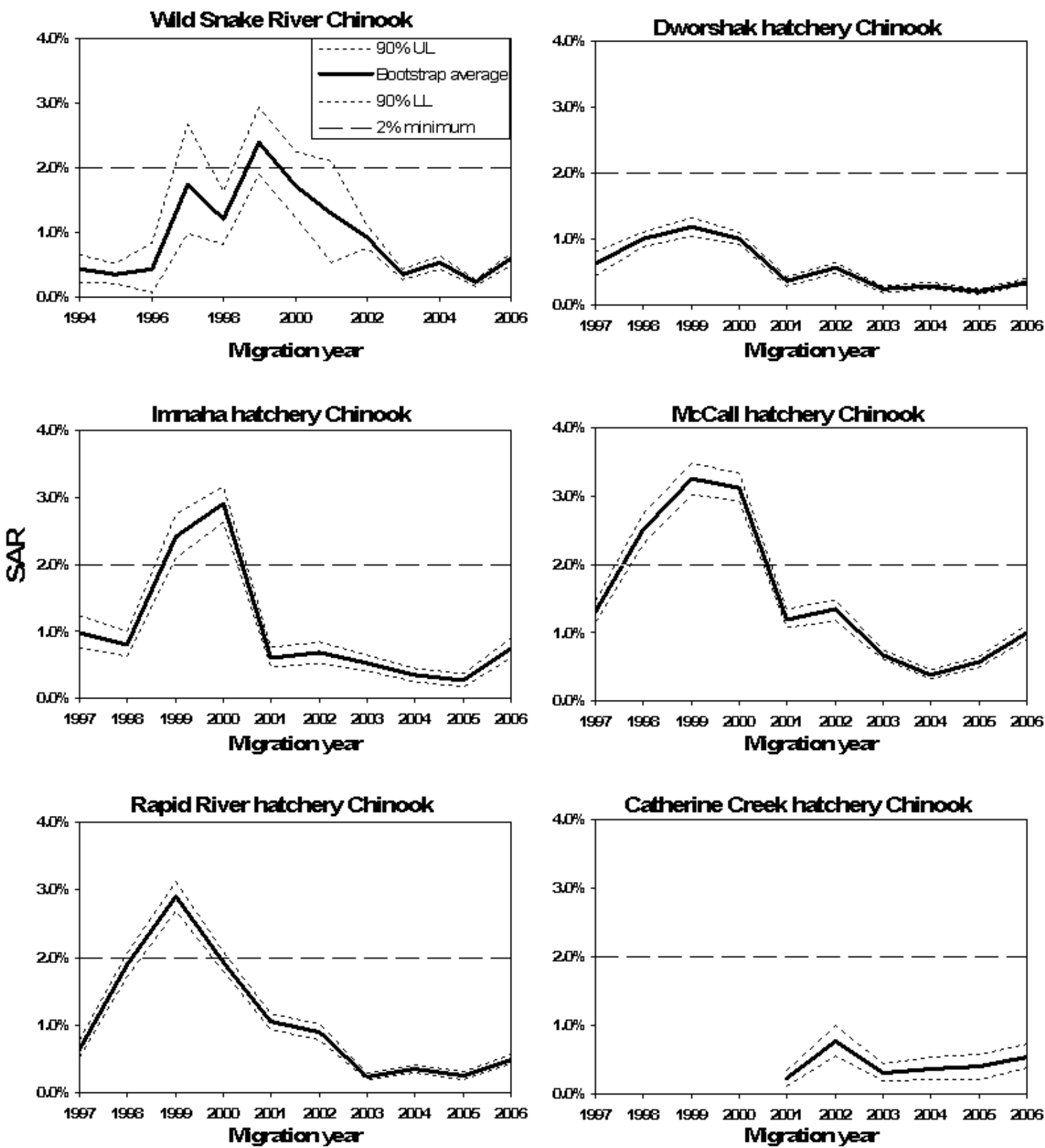

Figure 6-1. Bootstrapped SAR (with jacks excluded) and upper and lower CI for wild Chinook and 5 hatchery groups of Chinook for migration years 1997-2006. Migration year 2006 is complete through 2-ocean returns only. The NPCC (2003) minimum $2 \%$ SAR for listed wild populations is shown for reference.

\section{Hatchery Chinook}

The 10-yr geometric mean SAR (jacks excluded) for hatchery Chinook without jacks was $0.48 \%$ for Dworshak Hatchery spring Chinook, $0.76 \%$ for Rapid River Hatchery spring Chinook, $1.23 \%$ for McCall Hatchery summer Chinook, and $0.81 \%$ for Imnaha Hatchery summer Chinook (Table 6-2). The 6-yr geometric mean SAR without jacks for Catherine Creek Hatchery spring Chinook was $0.40 \%$. The estimated SARs for Snake River hatchery spring/summer Chinook only exceeded 2\% for selected hatcheries in 1998, 1999, and 2000. From 1998 to 2000, the SARs for McCall Hatchery summer Chinook was always greater than $2 \%$, while Imnaha Hatchery summer Chinook's SARs were greater than 2\% in two years, and Rapid 
River Hatchery spring Chinook's SARs were greater than $2 \%$ in only one year. The trend in SARs for the Snake River hatchery spring/summer Chinook tracked closely with the aggregate wild Chinook SARs during 1997-2006 (Figure 6-1).

Table 6.2. Study-specific SARs and weights (estimated proportion of run-at-large reflected by each study category) used to estimate the annual SARs for hatchery Chinook with jacks excluded.

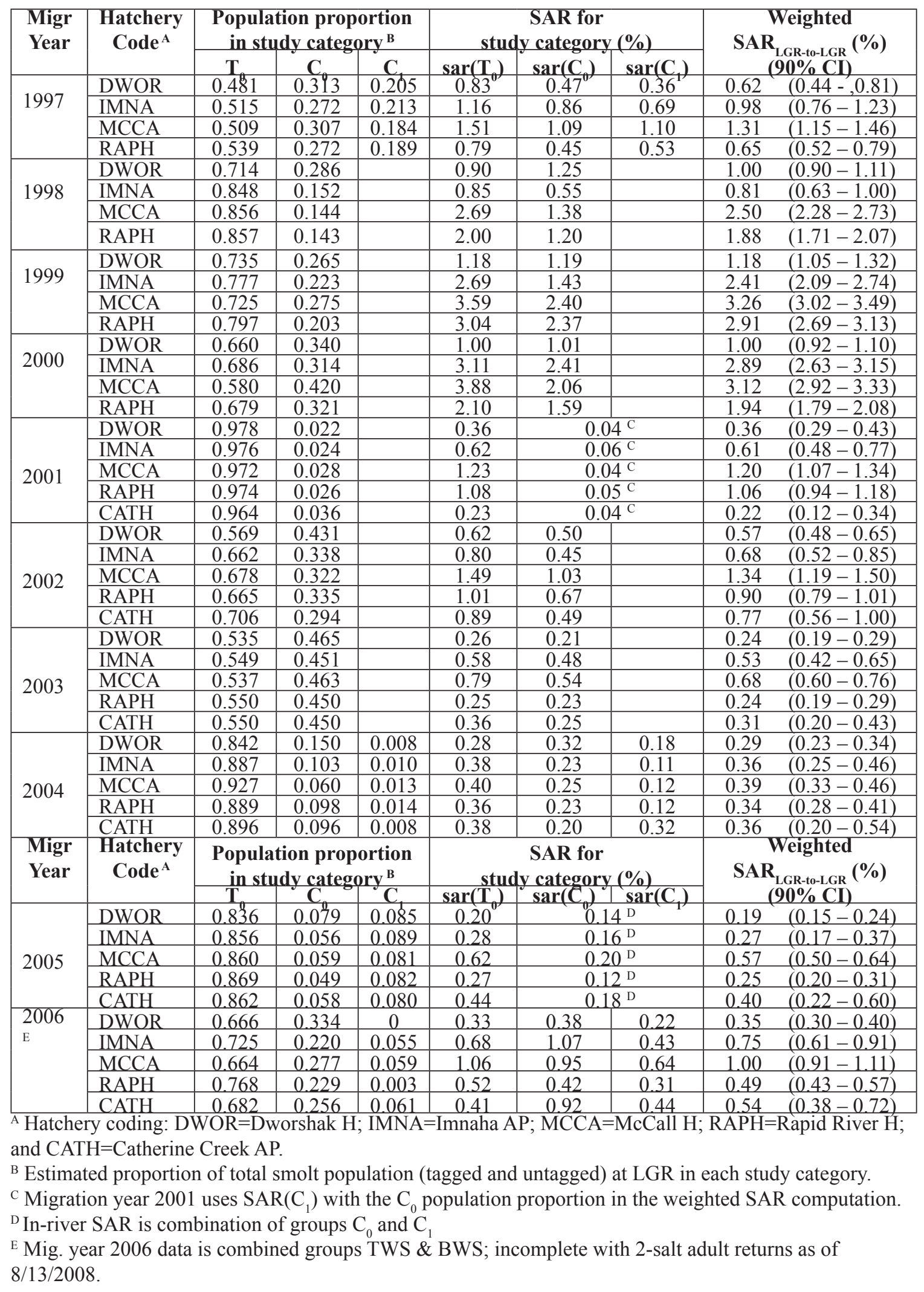




\section{Wild Chinook}

When jacks were included, the estimated SARs for Snake River wild spring/ summer Chinook were still less than the NPCC minimum 2\% SAR objective in 12 of 13 years, with only 1999 exceeding the minimum (Table 6-3). The 13-yr geometric mean SAR for $1994-2006$ (Table 6.3) increased only 4 percentage points to $0.76 \%$ when jacks were included in the total adult return count. Over these 13 years the proportion of jacks in the wild Chinook returns averaged only $4.6 \%$. Wild Chinook exhibited only negligible changes in the $90 \%$ confidence interval (shaded area) based on whether overall SARs include or exclude jacks across the 13-year time series (Figure 3-2, top left plot). Both estimates shows that current annual SARs for PIT-tagged wild Chinook remain well below the NPCC minimum.

Table 6-3. Study-specific SARs and weights (estimated proportion of run-at-large reflected by each study category) used to estimate the annual SARs for wild Chinook with jacks included.

\begin{tabular}{|c|c|c|c|c|c|c|c|c|}
\hline \multirow[t]{2}{*}{$\begin{array}{l}\text { Migr } \\
\text { Year }\end{array}$} & \multicolumn{3}{|c|}{$\begin{array}{l}\text { Population proportion } \\
\text { in study category }{ }^{\mathrm{A}}\end{array}$} & \multicolumn{3}{|c|}{$\begin{array}{c}\text { SAR for } \\
\text { study category }(\%) \\
\end{array}$} & \multirow{2}{*}{\multicolumn{2}{|c|}{$\begin{array}{c}\text { Weighted } \\
\text { SAR }_{\text {LGR-to-LGR }}(\%) \\
(90 \% \text { CI })\end{array}$}} \\
\hline & $T_{0}$ & $\mathrm{C}_{0}$ & $\mathrm{C}_{1}$ & $\operatorname{sar}\left(T_{0}\right)$ & $\left.\operatorname{sarC}_{0}\right)$ & $\operatorname{sar}\left(C_{1}\right)$ & & \\
\hline 1994 & 0.863 & 0.137 & & 0.50 & 0.28 & & 0.47 & $(0.24-0.70)$ \\
\hline 1995 & 0.805 & 0.141 & 0.054 & 0.35 & 0.37 & 0.26 & 0.35 & $(0.19-0.52)$ \\
\hline 1996 & 0.706 & 0.255 & 0.039 & 0.50 & 0.26 & 0.17 & 0.43 & $(0.06-0.85)$ \\
\hline 1997 & 0.572 & 0.239 & 0.189 & 1.74 & 2.50 & 0.98 & 1.78 & $(0.99-2.73)$ \\
\hline 1998 & 0.815 & 0.185 & & 1.18 & 1.56 & & 1.25 & $(0.84-1.70)$ \\
\hline 1999 & 0.863 & 0.137 & & 2.60 & 2.19 & & 2.55 & $(2.03-3.09)$ \\
\hline 2000 & 0.709 & 0.269 & 0.022 & 1.43 & 2.43 & 2.37 & 1.72 & $(1.25-2.20)$ \\
\hline 2001 & 0.989 & 0.011 & & 1.46 & \multicolumn{2}{|c|}{$0.15^{\mathrm{B}}$} & 1.45 & $(0.70-2.32)$ \\
\hline 2002 & 0.709 & 0.273 & 0.018 & 0.90 & 1.38 & 1.07 & 1.04 & $(0.83-1.24)$ \\
\hline 2003 & 0.692 & 0.294 & 0.014 & 0.34 & 0.33 & 0.20 & 0.34 & $(0.26-0.42)$ \\
\hline 2004 & 0.928 & 0.071 & 0.001 & 0.54 & 0.49 & 0.23 & 0.54 & $(0.44-0.64)$ \\
\hline 2005 & 0.926 & 0.040 & 0.035 & 0.25 & \multicolumn{2}{|c|}{$0.12^{\mathrm{C}}$} & 0.24 & $(0.18-0.30)$ \\
\hline $\begin{array}{l}2006 \\
D\end{array}$ & 0.667 & 0.159 & 0.174 & 0.67 & 0.78 & 0.40 & 0.64 & $(0.54-0.75)$ \\
\hline
\end{tabular}

${ }^{\mathrm{A}}$ Estimated proportion of total smolt population (tagged and untagged) at LGR in each study category.

${ }^{B}$ Migration year 2001 uses $\operatorname{SAR}\left(\mathrm{C}_{1}\right)$ with the $\mathrm{C}_{0}$ population proportion in the weighted SAR computation.

${ }^{\mathrm{C}}$ In-river $\mathrm{SAR}$ is combination of groups $\mathrm{C}_{0}$ and $\mathrm{C}_{1}$

D Mig. year 2006 data is combined groups TWS \& BWS; incomplete with 2-salt adult returns as of $8 / 13 / 2008$. 
WILD

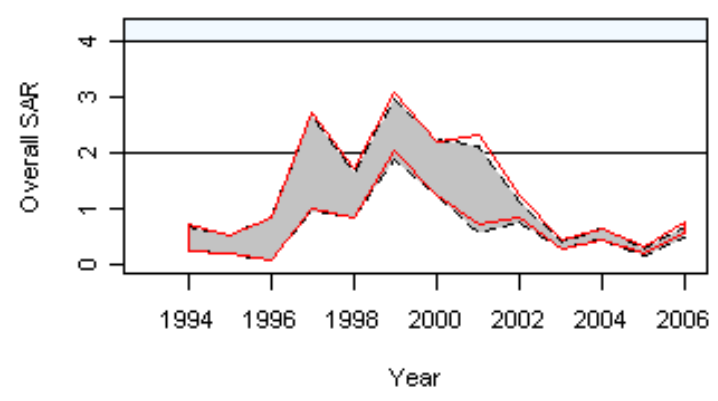

IMNA

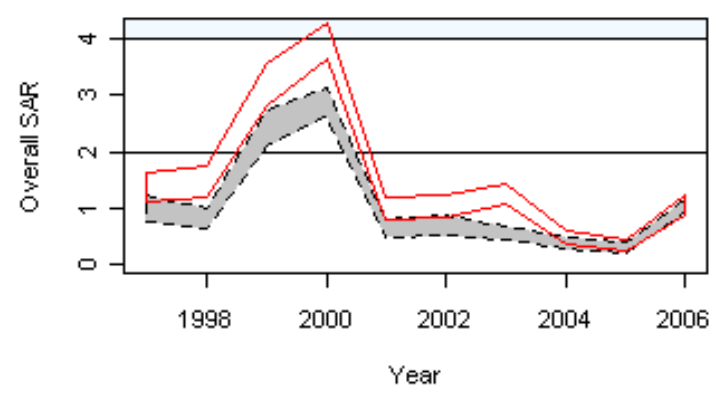

RAPH

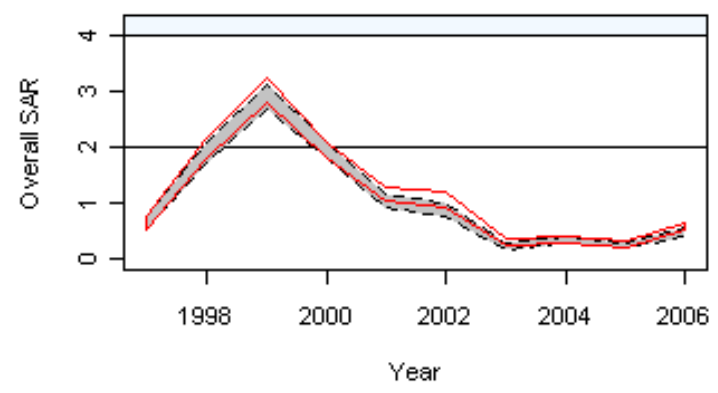

DWOR

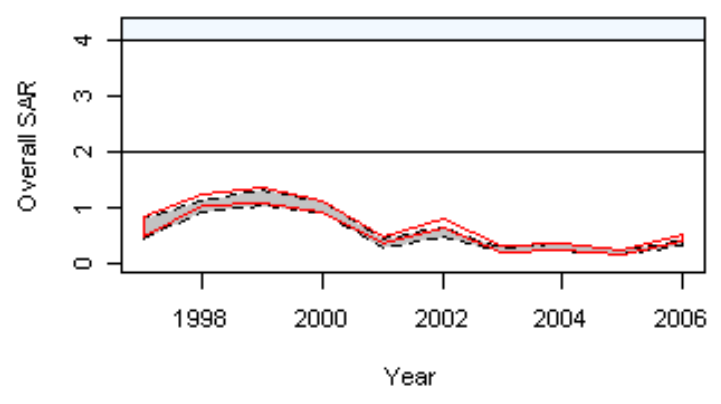

MCCA

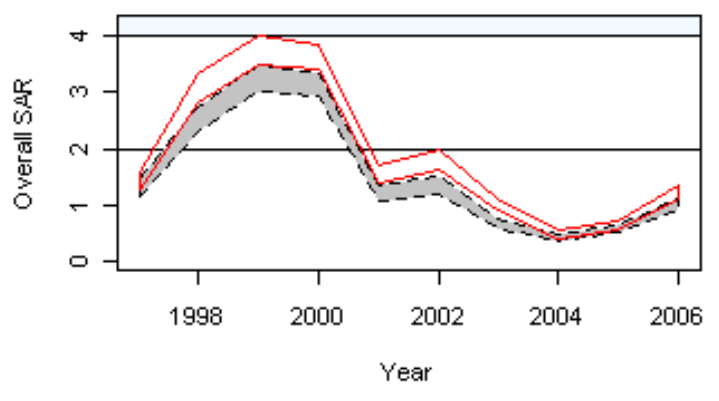

CATH

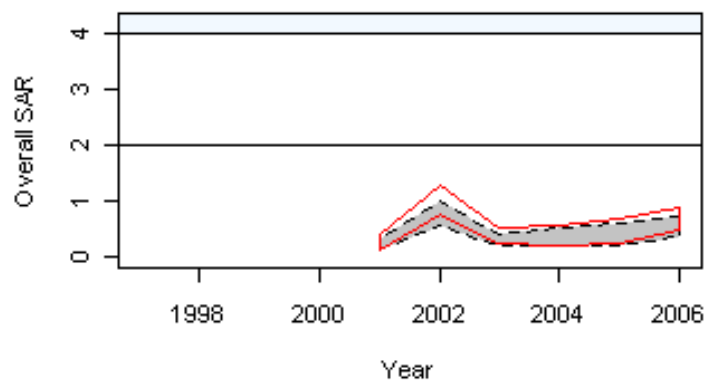

Figure 6.2. Two sets of $90 \%$ confidence intervals for Chinook overall SARs. Bootstrapped non parametric $\mathbf{9 0 \%}$ confidence intervals are shown for overall SARs without jacks (dotted outline, grey fill) and with jacks (red outline, no fill). Wild Chinook and 5 groups of hatchery Chinook are shown. Migration year 2006 is complete through 2-ocean returns only.

\section{Hatchery Chinook}

With the addition of jacks to the total adult count, the 10-yr geometric mean SAR for Dworshak Hatchery spring Chinook increased 5 percentage points to $0.53 \%$, Rapid River Hatchery spring Chinook increased 8 percentage points to $0.84 \%$, McCall Hatchery summer Chinook increased 27 percentage points to $1.50 \%$, and Imnaha Hatchery summer Chinook increased 36 percentage points to $1.17 \%$ (Table 6.4). The 6-yr geometric mean SAR for Catherine Creek Hatchery spring Chinook increased 9 percentage points to $0.49 \%$. The summer stocks of McCall and Imnaha hatcheries had the highest increase in SARs with the addition of jacks. Over these 10 years, the proportion of jacks in the overall return averaged $17.8 \%$ for McCall Hatchery and $31.8 \%$ for Imnaha Hatchery, compared to only $8.3 \%$ for Dworshak Hatchery and $9.4 \%$ for Rapid River Hatchery. Over the shorter 5 years of data for Catherine Creek Hatchery, the proportion of jacks averaged 13.6\%. The spring Chinook stocks (Dworshak, Rapid River, and Catherine Creek) exhibited only negligible changes in the $90 \%$ confidence intervals (shaded area) based on whether overall SARs include or exclude jacks across 
the available time series (Figure 6-2). However, the summer Chinook stocks (McCall and Imnaha) exhibited significant changes in 90\% confidence intervals (shaded area) based on whether overall SARs include or exclude jacks, due to the higher jack rate with those stocks.

Table 6.4. Study-specific SARs and weights (estimated proportion of run-at-large reflected by each study category) used to estimate the annual SARs for hatchery Chinook with jacks included.

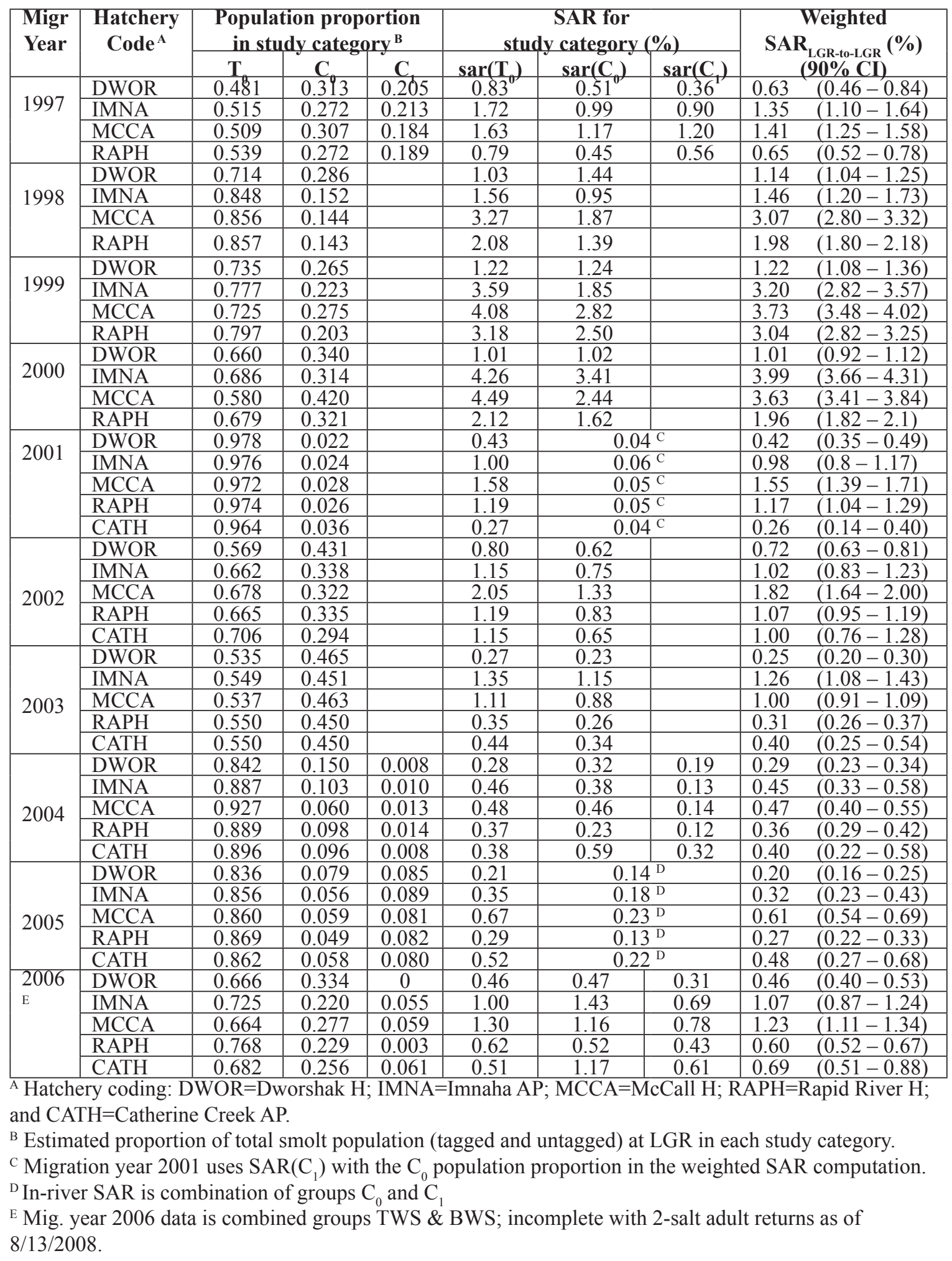


Estimating overall SARs based on pre-assignment of fish prior to release

The results of computing the overall annual SARs for the 2006 PIT-tagged spring/summer wild and hatchery Chinook (based on 2-salt returns only) with the two methodologies are presented in Table 6.5. The overall annual SARs computed directly from Group T matched closely with the original weighted SARs. When small shifts in point estimate were observed, there was the same shift in the corresponding upper and lower limits of the $90 \%$ confidence intervals, indicating that precision about the estimate appears unchanged by which method was being used. We anticipate greater accuracy in the estimated overall annual SAR using the pre-assignment approach since that method has fewer parameters being estimated during intermediate steps before arriving at the overall annual SAR estimate.

Table 6.5. Comparison of estimated overall annual SARs between original weighted SARs method and pre-assigned Group TWS method for 2-salt returns from 2006 wild and hatchery juvenile spring/ summer Chinook migration.

\begin{tabular}{|c|c|c|c|c|c|c|}
\hline \multirow{2}{*}{$\begin{array}{l}\text { Site } \\
\text { Code }\end{array}$} & \multicolumn{2}{|c|}{ Group TWS } & \multicolumn{3}{|c|}{ SAR(TWS) with 90\% CI (\%) } & \multirow{2}{*}{$\begin{array}{l}\text { Original Weighted } \\
\text { SAR }_{\text {LGR-to-LGR }}(\%) \\
(90 \% \text { CI })\end{array}$} \\
\hline & $\begin{array}{c}\text { Smolts } \\
\text { (estimate) }\end{array}$ & $\begin{array}{l}\text { Adults }{ }^{B} \\
\text { (count) }\end{array}$ & Estimate & $\begin{array}{l}\text { Lower } \\
\text { Limit }\end{array}$ & $\begin{array}{l}\text { Upper } \\
\text { Limit }\end{array}$ & \\
\hline DWOR & 29,405 & 101 & 0.36 & 0.30 & 0.42 & $0.35 \quad(0.30-0.40)$ \\
\hline IMNA & 8,761 & 60 & 0.68 & 0.55 & 0.85 & $(0.61-0.91)$ \\
\hline MCCA & 21,834 & 213 & 0.99 & 0.87 & 1.10 & $1.00 \quad(0.91-1.11)$ \\
\hline RAPH & 26,738 & 124 & 0.49 & 0.42 & 0.56 & $(0.43-0.57)$ \\
\hline CATH & 4,308 & 21 & 0.49 & 0.32 & 0.67 & $(0.38-0.72)$ \\
\hline WILD & 15,119 & 82 & 0.54 & 0.46 & 0.64 & $0.58 \quad(0.49-0.68)$ \\
\hline
\end{tabular}

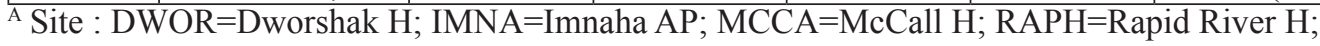

$\mathrm{CATH}=$ Catherine Creek AP; and WILD=aggregate of wild stocks.

${ }^{\text {B }}$ Mig. year 2006 data is combined groups TWS \& BWS; incomplete with 2-salt adult returns as of 


\section{Wild Steelhead}

The estimated SARs for Snake River wild steelhead exceeded the NPCC minimum 2\% SAR objective in 4 of 9 years (Figure 6.3), but were consistently less than the NPCC 4\% recommended average. The estimated SARs for Snake River wild steelhead were closer to the NPCC minimum $2 \%$ SAR objective than were those of wild spring summer Chinook. However, the geometric mean was only $1.35 \%$ (Table 6.6).

Table 6.6. Study-specific SARs and weights (estimated proportion of run-at-large reflected by each study category) used to estimate the annual SARs for wild steelhead.

\begin{tabular}{|c|c|c|c|c|c|c|c|}
\hline \multirow[t]{2}{*}{$\begin{array}{l}\text { Migr } \\
\text { Year }\end{array}$} & \multicolumn{3}{|c|}{$\begin{array}{l}\text { Population proportion } \\
\text { in study category }{ }^{\mathrm{A}}\end{array}$} & \multicolumn{3}{|c|}{$\begin{array}{l}\text { SAR for } \\
\text { study category }(\%)\end{array}$} & \multirow{2}{*}{$\begin{array}{l}\text { Weighted } \\
\text { SAR } \\
(90 \% \text { CI }) \\
\text { (90R-LG) }\end{array}$} \\
\hline & $T_{1}$ & $\mathrm{C}_{\mathrm{H}}$ & C & $\operatorname{sar}\left(T_{0}\right)$ & $\operatorname{sar}\left(C_{0}\right)$ & $\operatorname{sar}(C)$ & \\
\hline 1997 & 0.715 & 0.122 & 0.163 & 1.45 & 0.66 & 0.23 & $1.16(0.37-2.12)$ \\
\hline 1998 & 0.892 & 0.108 & & 0.21 & 1.07 & & $0.30 \quad(0.07-0.66)$ \\
\hline 1999 & 0.869 & 0.131 & & 3.07 & 1.35 & & $(1.68-4.19)$ \\
\hline 2000 & 0.846 & 0.144 & 0.009 & 2.79 & 1.92 & 1.82 & $(1.62-3.72)$ \\
\hline 2001 & 0.992 & 0.008 & & 2.49 & $0.07^{\mathrm{B}}$ & 0.07 & $(0.97-4.49)$ \\
\hline 2002 & 0.675 & 0.309 & 0.016 & 2.84 & 0.67 & 0.94 & $2.14(1.24-3.21)$ \\
\hline 2003 & 0.723 & 0.262 & 0.015 & 1.99 & 0.45 & 0.52 & $(1.22-1.94)$ \\
\hline $2004^{C}$ & 0.974 & 0.026 & 0.000 & 0.87 & \multicolumn{2}{|c|}{0.06 (combined $\mathrm{C}_{0}, \mathrm{C}_{1}$ ) } & $0.85 \quad(0.63-1.08)$ \\
\hline $2005^{C, D}$ & 0.930 & 0.014 & 0.055 & 0.82 & \multicolumn{2}{|c|}{0.18 (combined $\mathrm{C}, \mathrm{C}$ ) } & $(0.59-0.98)$ \\
\hline
\end{tabular}

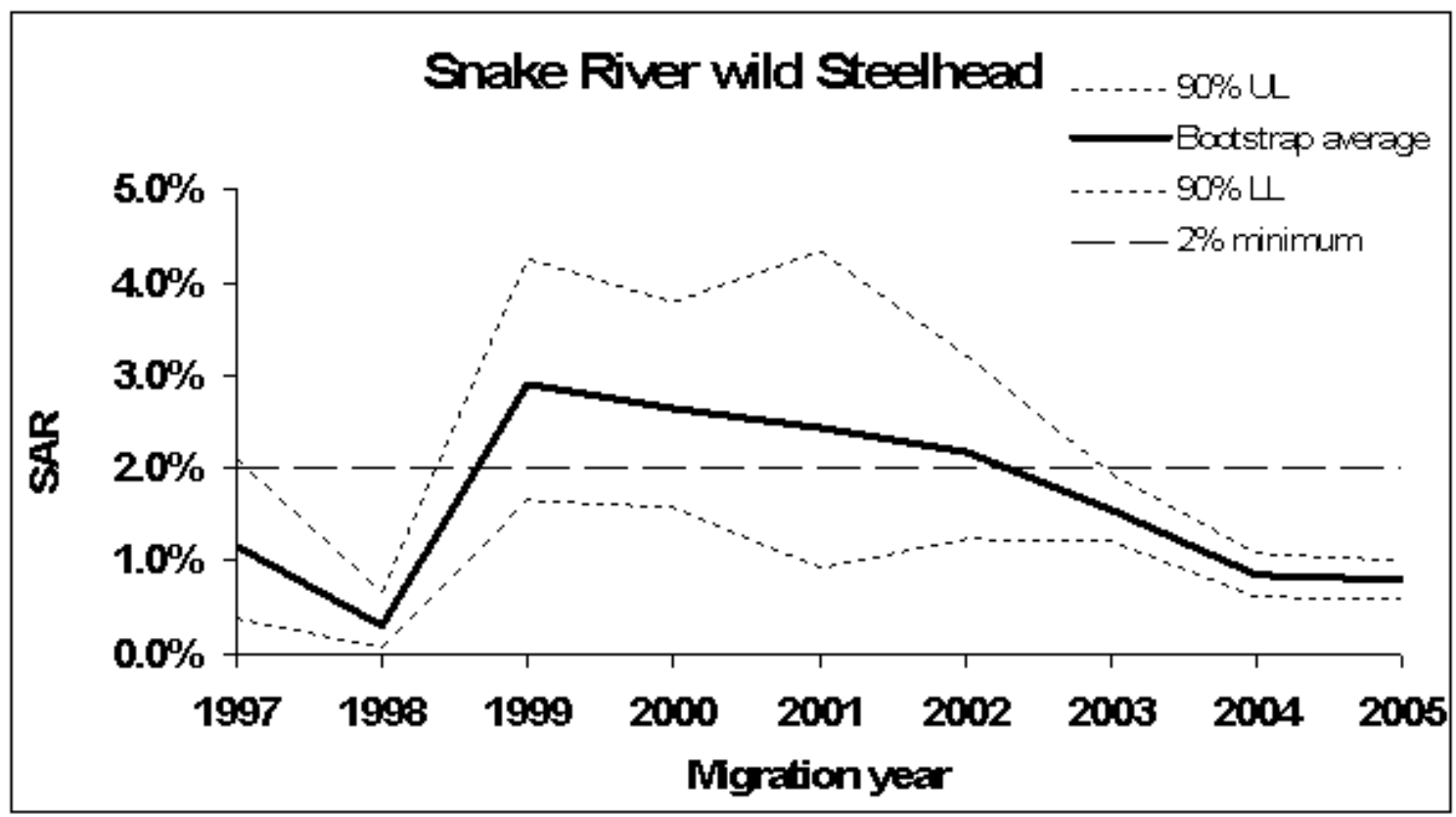

Figure 6.3. Bootstrapped SAR and upper and lower CI for aggregate wild Snake River steelhead, migration years 1997-2005. The NPCC (2003) minimum $2 \%$ SAR for listed wild populations is shown for reference.

\section{Hatchery Steelhead}

Hatchery steelhead SARs generally tracked wild steelhead SARs during 1997-2003 (Figures 6.3 and 6.4). The geometric mean SAR for aggregate hatchery steelhead during 
Table 6.7. Study-specific SARs and weights (estimated proportion of run-at-large reflected by each study category) used to estimate the annual SARs for hatchery steelhead.

\begin{tabular}{|c|c|c|c|c|c|c|c|}
\hline \multirow[t]{2}{*}{$\begin{array}{l}\text { Migr } \\
\text { Year }\end{array}$} & \multicolumn{3}{|c|}{$\begin{array}{l}\text { Population proportion } \\
\text { in study category } \mathrm{A}\end{array}$} & \multicolumn{3}{|c|}{$\begin{array}{l}\text { SAR for } \\
\text { study category }(\%)\end{array}$} & \multirow{2}{*}{$\begin{array}{l}\text { Weighted } \\
\text { SAR }_{\text {LGR-to-LGR }}(\%) \\
(90 \% \text { CI })\end{array}$} \\
\hline & $\mathbf{T}_{0}$ & $\mathbf{C}_{0}$ & $\mathbf{C}_{1}$ & $\operatorname{Sar}\left(\mathbf{T}_{0}\right)$ & $\operatorname{sar}\left(C_{0}\right)$ & $\operatorname{sar}\left(C_{1}\right)$ & \\
\hline 1997 & 0.608 & 0.140 & 0.252 & 0.52 & 0.24 & 0.17 & $0.39 \quad(0.22-0.59)$ \\
\hline 1998 & 0.873 & 0.127 & & 0.51 & 0.89 & & $0.56 \quad(0.30-0.85)$ \\
\hline 1999 & 0.848 & 0.150 & 0.002 & 0.90 & 1.04 & 0.59 & $0.92 \quad(0.59-1.30)$ \\
\hline 2000 & 0.817 & 0.183 & & 2.10 & 0.95 & & $1.89 \quad(1.18-2.70)$ \\
\hline 2001 & 0.979 & 0.019 & 0.003 & 0.94 & $0.016^{\mathrm{B}}$ & 0.016 & $0.92 \quad(0.24-1.74)$ \\
\hline 2002 & 0.700 & 0.300 & & 1.06 & 0.70 & & $0.95 \quad(0.40-1.72)$ \\
\hline 2003 & 0.690 & 0.305 & 0.005 & 1.81 & 0.68 & 0.37 & $1.46 \quad(1.24-1.68)$ \\
\hline $2004^{\mathrm{C}}$ & 0.973 & 0.023 & 0.004 & 2.13 & $0.21 \quad(\mathrm{co}$ & ined $\left.C_{0}, C_{1}\right)$ & $2.08 \quad(1.15-3.19)$ \\
\hline $2005^{\mathrm{C}, \mathrm{D}}$ & 0.890 & 0.019 & 0.091 & 2.03 & $0.24 \quad(\mathrm{co}$ & ined $C_{0}, C$ ) & $1.83(1.17-2.55)$ \\
\hline
\end{tabular}

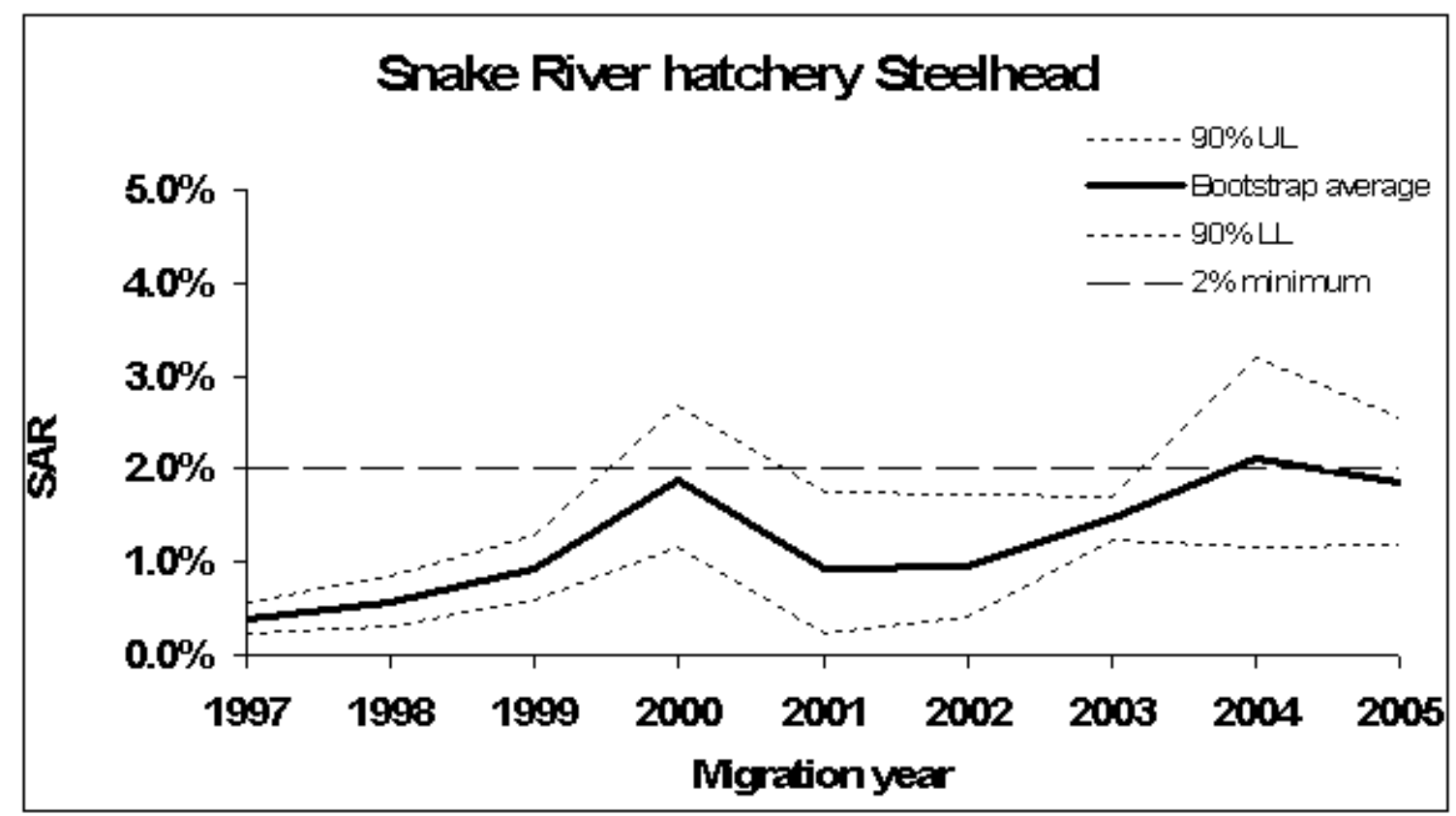

Figure 6.4. Bootstrapped SAR and upper and lower CI for aggregate wild hatchery Snake River steelhead, migration years 1997-2005. The NPCC (2003) minimum 2\% SAR for listed wild populations is shown for reference.

\section{Discussion}

The additional SARs added in this report essentially complete the overall SARs through the migration year 2005 for wild spring/summer Chinook, hatchery spring Chinook, hatchery summer Chinook, wild steelhead, and hatchery steelhead. The results shown here for the 2006 Chinook groups are preliminary but should include the majority 
of the returning fish.

The SARs for Snake River wild spring/summer Chinook were above the NPCC interim objectives in only one of the 13 years with estimates. Snake River wild steelhead SARs met the minimum objective in 4 of 9 years. However, the most recent years for wild steelhead had lower values and the geometric mean remains below $2 \%$. Wild spring/summer Chinook SARs summarized in this report did not include jacks as recruits, and were thus a conservative estimate relative to the NPCC (2003) objectives, which implicitly included jacks (Marmorek et al. 1998). Although, on average jacks comprised only $4.6 \%$ of total wild Chinook returns, and the observed SARs fell far short of NPCC objectives. Future CSS reports will include jacks when comparing spring/summer Chinook SARs to the NPCC objectives to maintain consistency with the original PATH analysis.

SARs for hatchery spring/summer Chinook are similar to those for the aggregate wild Chinook population in the years 1997-2006 suggesting similar factors influence their survival during the smolt migration and estuary and ocean life stages. There were differences among Chinook hatcheries within a single year such as Dworshak NFH which showed generally poorer SARs than Rapid River, McCall and Imnaha; conversely, the McCall and Imnaha hatcheries typically had among the highest SARs within a year.

In summary, it appears that both Snake River spring/summer Chinook and steelhead wild populations are still not consistently meeting the NPCC 2-6\% interim SAR objective. The 10-year CSS retrospective report found that the SARs for these populations were strongly related to water travel time; an index that influences the smolt migration rate, and is indirectly related to spill and other hydrosystem factors. Although Snake River hatchery Chinook exhibited a generally more positive response to transportation and relatively lower levels of differential mortality than wild populations, annual SARs of wild and hatchery Snake River Chinook were highly correlated across years. In view of this high correlation, continuing the CSS time series of hatchery SARs will be important to augment wild Chinook SAR information following future years of low escapements, in addition to providing valuable management information for the 
specific hatcheries.

\section{References}

Berggren, T., H. Franzoni, L. Basham, P. Wilson, H. Schaller, C. Petrosky, E. Weber, and R. Boyce. 2005. Comparative Survival Study (CSS) of PIT-tagged Spring/ Summer Chinook and PIT-tagged Summer Steelhead. 2005 Annual Report, BPA Contract \# 19960200.

Berggren T., P. McHugh, P. Wilson, H. Schaller, C. Petrosky, E. Weber, and R. Boyce. 2006. Comparative Survival Study (CSS) of PIT-tagged Spring/Summer Chinook and Summer Steelhead. 2006 Annual Report. BPA Contract \# 19960200.

Budy, P., and H. Schaller. 2007. Evaluating Tributary Restoration Potential for Pacific Salmon Recovery. Ecological Applications.

Budy, P., G.P. Thiede, N. Bouwes, C.E. Petrosky, and H. Schaller. 2002. Evidence linking delayed mortality of Snake River salmon to their earlier hydrosystem experience. North American Journal of Fisheries Management 22:35-51.

Cormack, R.M. 1964. Estimates of survival from the sightings of marked animals. Biometrika 51:429-438.

Efron, B. and R.J. Tibshirani. 1993. An introduction to the bootstrap. Chapman \& Hall, NY.

ISAB (Independent Scientific Advisory Board) and ISRP (Independent Scientific Review Panel). 2007. ISAB and ISRP Review of the CSS Ten-Year Retrospective Summary Report. Prepared for Northwest Power and Conservation Council, Columbia River Basin Indian Tribes and National Marine Fisheries Service. ISAB 2007-6. November 19, 2007

Jolly, G.M. 1965. Explicit estimates from capture-recapture data with both death and immigration- stochastic model. Biometrika 52:225-247.

Kareiva, P., M. Marvier, and M. McClure. 2000. Recovery and management options for spring/summer chinook salmon in the Columbia River basin. Science 290: 977979.

Marmorek, D.R., C.N. Peters and I. Parnell (eds.). 1998. PATH final report for fiscal year 1998. Compiled and edited by ESSA Technologies, Ltd., Vancouver, B.C. Available from Bonneville Power Administration, Portland, Oregon (http://www. efw.bpa.gov/Environment/PATH/reports/ISRP1999CD/PATH\%20Reports/WOE_ 
Report/).

Marmorek, D.R., M. Porter, I.J. Parnell and C. Peters, eds. 2004. Comparative Survival Study Workshop, February 11-13, 2004; Bonneville Hot Springs Resort. Draft Report compiled and edited by ESSA Technologies Ltd., Vancouver, B.C. for Fish Passage Center, Portland, OR and the US Fish and Wildlife Service, Vancouver, WA. 137 pp.

McElhany, P., M.H. Ruckelshaus, M.J. Ford, T.C. Wainwright, and E.P. Bjorkstedt. 2000. Viable salmonid populations and the recovery of evolutionarily significant units. U.S. Dept. Commerce, NOAA Tech. Memo. NMFS-NWFSC-42, 156 p.

Mundy, P.R., D. Neeley, C.R. Steward, T. Quinn, B.A. Barton, R.N. Williams, D. Goodman, R.R. Whitney, M.W. Erho, and L.W. Botsford. 1994. Transportation of juvenile salmonids from hydroelectric projects in the Columbia River Basin; an independent peer review. Final Report. U.S. Fish and Wildlife Service, 911 N.E. 11th Ave., Portland, OR. 97232-4181.

NPCC (Northwest Power and Conservation Council). 2003. Mainstem Amendments to the Columbia River Basin Fish and Wildlife Program. Council Document 200311 .

Olney, F., B. Heinith, R. Woodin, C. Tuss, C. Petrosky and M. Filardo. 1992. Review of salmon and steelhead transportation studies in the Columbia and Snake Rivers, 1984 to 1989. Ad Hoc Transportation Review Group report submitted to the Columbia Basin Fish and Wildlife Authority. December 31, 1992.

Paulsen, C.M. and T. Fisher. 2005. Do habitat actions affect juvenile survival? Information:Theoretic Approach applied to endangered Snake River Chinook salmon. Transaction of American Fisheries Society, 134: 68-85.

Peters, C.N., and D.R. Marmorek. 2001. Application of decision analysis to evaluate recovery actions for threatened Snake River spring and summer Chinook salmon (Oncorhynchus tshawytscha). Canadian Journal of Fisheries and Aquatic Sciences 58(12):2431-2446.

R Development Core Team (2008). R: A language and environment for statistical computing. R Foundation for Statistical Computing, Vienna, Austria. ISBN 3-900051-07-0, URL http://www.R-project.org.

Sanford, B.P. and S.G. Smith. 2002. Estimation of smolt-to-adult return percentages for Snake River Basin anadromous salmonids, 1990-1997. Journal of Agricultural Biological and Environmental Statistics 7:243-263.

Schaller H., P. Wilson, S. Haeseker, C. Petrosky, E. Tinus, T. Dalton, R. Woodin, E. Weber, N. Bouwes, T. Berggren, J. McCann, S. Rassk, H. Franzoni, and P. McHugh. 2007. Comparative Survival Study (CSS) of PIT-tagged Spring/ Summer Chinook and Summer Steelhead. Ten-year Retrospective Summary 
Report. BPA Contract \# 19960200.

Seber, G.A.F. 1965. A note on the multiple recapture census. Biometrika 52:249-259.

Solazzi, M.F., T.E. Nickelson, S.L. Johnson. 1991. Survival, contribution, and return of hatchery coho salmon (Oncorhynchus kisutch) released from freshwater, estuarine, and marine environments. Canadian Journal of Fisheries and Aquatic Sciences 48:248-253.

Ward, D., R. Boyce, F. Young and F. Olney. 1997. A review and assessment of transportation studies for Juvenile Chinook salmon in the Snake River. NAJFM 17:652-662.

Williams, J.G., S.G. Smith, R.W. Zabel, W.D. Muir, M.D. Scheuerell, B.D. Sandford, D.M. Marsh, R.A. McNatt, and S. Achord. 2005. Effects of the Federal Columbia River Power System on salmonid populations. NOAA Technical Memorandum NMFS-NWFSC-63. ( http://www.nwfsc.noaa.gov ).

Wilson, P.H. 2003. Using population projection matrices to evaluate recovery strategies for Snake River spring and summer Chinook salmon.

Zabel, R.W., T. Wagner, J.L. Congleton, S.G. Smith, J.G. Williams. 2005. Survival and selection of migrating salmon from capture-recapture models with individual traits. Ecological Applications. 15: 1427-1439.

Zabel, R.W., M.D. Scheuerell, M.M. McClure, and J.G. Williams. 2006. The interplay between climate variability and density dependence in the population viability of Chinook salmon. Conservation Biology 20:190-200. 


\section{Appendix A}

\section{Supporting Tables of PIT-Tag Marking Data and Estimates of Survival and Major CSS Parameters}

This appendix includes the time series of data by smolt migration year that are compiled annually by the CSS. These tables support analyses presented in Chapter 3. The information is organized by species (stream type Chinook salmon and steelhead) and origin (wild and hatchery) following the steps of the survival estimations and comparisons.

- Numbers, origins, and release sites of PIT-tagged juvenile fish used in the study are presented.

- Estimated size of each study category is presented: numbers of tagged smolts detected at Snake River collector dams and transported $\left(\mathrm{T}_{0}\right)$, never collected or transported $\left(\mathrm{C}_{0}\right)$, or collected and returned to the river $\left(\mathrm{C}_{1}\right)$; and counts of returning adults grouped by study category detected at Bonneville and Lower Granite dams.

- The two comparative transport and in-river SAR ratios (TIR and D) are presented, as well as the in-river reach survivals $\left(\mathrm{S}_{\mathrm{R}}\right)$ used to estimate $\mathrm{D}$.

- Survival estimates from the CJS method of in-river migrating juvenile fish through specific reaches.

- Age distribution of returning adult PIT-tagged Chinook and steelhead detected at Lower Granite Dam.

- Number of PIT-tagged smolts transported at each collector dam (plus estimated number if tagged fish had been transported in same proportion as the untagged population) and site-specific SAR estimates.

Tables A-1 to A-4 present PIT-tag release numbers of wild and hatchery Chinook and steelhead in locations above LGR.

Table A-1. Number of PIT-tagged wild Chinook parr/smolts from the four tributaries above Lower Granite Dam and Snake River trap used in the CSS analyses for migration years 1994 to 2006.

\begin{tabular}{|c|c|c|c|c|c|c|}
\hline \multirow[b]{2}{*}{$\begin{array}{l}\text { Migr. } \\
\text { Year }\end{array}$} & \multicolumn{6}{|c|}{ Number of PIT-tagged wild Chinook utilized in CSS by location of origin } \\
\hline & $\begin{array}{l}\text { Total PIT } \\
\text { Tags }\end{array}$ & $\begin{array}{l}\text { Clearwater } \\
\text { River } \\
\text { (Rkm 224) }\end{array}$ & $\begin{array}{l}\text { Snake River } \\
\text { trap }^{1} \\
(\text { Rkm 225) }\end{array}$ & $\begin{array}{l}\text { Grande } \\
\text { Ronde River } \\
\text { (Rkm 271) }\end{array}$ & $\begin{array}{l}\text { Salmon } \\
\text { River } \\
\text { (Rkm 303) }\end{array}$ & $\begin{array}{l}\text { Imnaha } \\
\text { River } \\
\text { (Rkm 308) }\end{array}$ \\
\hline 1994 & 49,657 & & 1,423 & 8,828 & 27,725 & 3,391 \\
\hline 1995 & 74,639 & 17,605 & 1,948 & 12,330 & 40,609 & 2,148 \\
\hline 1996 & 21,523 & 2,246 & 913 & 7,079 & 7,016 & 4,269 \\
\hline 1997 & 9,781 & 671 & None & 3,870 & 3,543 & 1,697 \\
\hline 1998 & 33,836 & 4,681 & 921 & 8,644 & 11,179 & 8,411 \\
\hline 1999 & 81,493 & 13,695 & 3,051 & 11,240 & 43,323 & 10,184 \\
\hline 2000 & 67,841 & 9,921 & 1,526 & 7,706 & 39,609 & 9,079 \\
\hline 2001 & 47,775 & 3,745 & 29 & 6,354 & 23,107 & 14,540 \\
\hline 2002 & 67,286 & 14,060 & 1,077 & 9,715 & 36,051 & 6,428 \\
\hline 2003 & 103.012 & 15,106 & 381 & 14.057 & 60.261 & 13.165 \\
\hline 2004 & 99.743 & 17214 & 541 & 12,104 & 56,153 & 13,731 \\
\hline 2005 & 111152 & 23897 & 318 & 9243 & 67829 & 9865 \\
\hline 2006 & 51905 & 8678 & 2,639 & 10,463 & 28,998 & 1,127 \\
\hline \multicolumn{2}{|c|}{ Average \% of total } & $16.05 \%$ & $1.63 \%$ & $13.76 \%$ & $50.96 \%$ & $11.55 \%$ \\
\hline
\end{tabular}

${ }^{1}$ Snake River trap collects fish originating in Salmon, Imnaha, and Grande Ronde rivers. 
Table A-2. Hatchery spring/summer Chinook PIT-tagged and released in Snake River basin specifically for CSS (long time series), 1997 to 2006.

\begin{tabular}{|c|c|c|c|c|c|c|}
\hline Hatchery & $\begin{array}{l}\text { Migr. } \\
\text { Year }\end{array}$ & $\begin{array}{l}\text { Hatchery } \\
\text { Release }\end{array}$ & $\begin{array}{l}\text { Fish } \\
\# / / \mathbf{l b}\end{array}$ & $\begin{array}{l}\text { Median Length } \\
\text { at Tagging }(\mathrm{mm})\end{array}$ & $\begin{array}{l}\text { PIT Tags } \\
\text { Released }\end{array}$ & $\begin{array}{l}\text { PIT Tag } \\
\text { Proportion }\end{array}$ \\
\hline $\begin{array}{l}\text { Rapid River H } \\
\text { (RAPH) } \\
\text { Spring Run }\end{array}$ & $\begin{array}{l}1997 \\
1998 \\
1999 \\
2000 \\
2001 \\
2002 \\
2003 \\
2004 \\
2005 \\
2006\end{array}$ & $\begin{array}{l}85,838 \\
896,170 \\
2,847,283 \\
2,462,354 \\
736,601 \\
2,669,476 \\
2,330,557 \\
2,762,058 \\
2,761,430 \\
2,530,528\end{array}$ & $\begin{array}{l}20.5 \\
20.3 \\
17.9 \\
19.2 \\
18.8 \\
19.8 \\
18.8 \\
24.5 \\
19.1 \\
19.3\end{array}$ & $\begin{array}{l}100^{\mathrm{A}} \\
117 \\
120 \\
119 \\
118 \\
122 \\
119 \\
\text { (none taken) } \\
124 \\
121-128^{\mathrm{B}}\end{array}$ & $\begin{array}{l}40,451 \\
48,336 \\
47,812 \\
47,747 \\
55,085 \\
54,908 \\
54,763 \\
51,969 \\
51,975 \\
114,097^{\text {в }}\end{array}$ & $\begin{array}{l}0.4712 \\
0.0539 \\
0.0168 \\
0.0194 \\
0.0748 \\
0.0206 \\
0.0235 \\
0.0188 \\
0.0188 \\
0.1132^{\mathrm{B}}\end{array}$ \\
\hline $\begin{array}{l}\text { Dworshak H } \\
\text { (DWOR) } \\
\text { Spring Run }\end{array}$ & $\begin{array}{l}1997 \\
1998 \\
1999 \\
2000 \\
2001 \\
2002 \\
2003 \\
2004 \\
2005 \\
2006\end{array}$ & $\begin{array}{l}53,078 \\
973,400 \\
1,044,511 \\
1,017,873 \\
333,120 \\
1,000,561 \\
1,033,982 \\
1,078,923 \\
1,072,359 \\
1,007,738\end{array}$ & $\begin{array}{l}12.7 \\
20.9 \\
21.0 \\
24.0 \\
19.7 \\
20.1 \\
21.4 \\
20.2 \\
19.2 \\
20.0\end{array}$ & $\begin{array}{l}118 \\
121 \\
116 \\
112 \\
121 \\
119 \\
120 \\
113 \\
112 \\
108-115^{\mathrm{B}}\end{array}$ & $\begin{array}{l}14,080 \\
47,703 \\
47,845 \\
47,743 \\
55,139 \\
54,725 \\
54,708 \\
51,616 \\
51,819 \\
113,670^{\text {B }}\end{array}$ & $\begin{array}{l}0.2653 \\
0.0490 \\
0.0458 \\
0.0469 \\
0.1655 \\
0.0547 \\
0.0529 \\
0.0478 \\
0.0483 \\
0.1128^{\mathrm{B}}\end{array}$ \\
\hline Hatchery & $\begin{array}{l}\text { Migr. } \\
\text { Year }\end{array}$ & $\begin{array}{l}\text { Hatchery } \\
\text { Release }\end{array}$ & $\begin{array}{l}\text { Fish } \\
\# / / \text { lb }\end{array}$ & $\begin{array}{l}\text { Median Length } \\
\text { at Tagging }(\mathrm{mm})\end{array}$ & $\begin{array}{l}\text { PIT Tags } \\
\text { Released }\end{array}$ & $\begin{array}{l}\text { PIT Tag } \\
\text { Proportion }\end{array}$ \\
\hline $\begin{array}{l}\text { Catherine Ck AP } \\
\text { (CATH) } \\
\text { Spring Run }\end{array}$ & $\begin{array}{l}2001 \\
2002 \\
2003 \\
2004 \\
2005 \\
2006\end{array}$ & $\begin{array}{l}136,833 \\
180,343 \\
105,292 \\
162,614 \\
189,580 \\
68,820\end{array}$ & $\begin{array}{l}19.7 \\
18.6 \\
12.8 \\
23.2 \\
25.1 \\
22.7\end{array}$ & $\begin{array}{l}117^{\mathrm{A}} \\
115^{\mathrm{A}} \\
123^{\mathrm{A}} \\
109^{\mathrm{A}} \\
106^{\mathrm{A}} \\
102^{\mathrm{A}}\end{array}$ & $\begin{array}{l}20,915 \\
20,796 \\
20,628 \\
20,994 \\
20,839 \\
20958\end{array}$ & $\begin{array}{l}0.1529 \\
0.1153 \\
0.1959 \\
0.1291 \\
0.1099 \\
0.3045\end{array}$ \\
\hline $\begin{array}{l}\text { McCall H } \\
\text { (MCCA) } \\
\text { Summer Run }\end{array}$ & $\begin{array}{l}1997 \\
1998 \\
1999 \\
2000 \\
2001 \\
2002 \\
2003 \\
2004 \\
2005 \\
2006\end{array}$ & $\begin{array}{l}238,647 \\
393,872 \\
1,143,083 \\
1,039,930 \\
1,076,846 \\
1,022,550 \\
1,053,660 \\
1,088,810 \\
1,047,530 \\
1,096,130\end{array}$ & $\begin{array}{l}17.1 \\
17.5 \\
23.9 \\
23.3 \\
19.4 \\
23.0 \\
21.1 \\
20.9 \\
20.9 \\
18.1\end{array}$ & $\begin{array}{l}128 \\
126 \\
117 \\
117 \\
129 \\
122 \\
121 \\
\text { (none taken) } \\
121 \\
126\end{array}$ & $\begin{array}{l}52,652 \\
47,340 \\
47,985 \\
47,705 \\
55,124 \\
54,734 \\
74,317 \\
71,363 \\
71,725 \\
51895\end{array}$ & $\begin{array}{l}0.2206 \\
0.1202 \\
0.0420 \\
0.0459 \\
0.0512 \\
0.0535 \\
0.0705 \\
0.0655 \\
0.0685 \\
0.0473\end{array}$ \\
\hline $\begin{array}{l}\text { Imnaha AP } \\
\text { (IMNA) } \\
\text { Summer Run }\end{array}$ & $\begin{array}{l}1997 \\
1998 \\
1999 \\
2000 \\
2001 \\
2002 \\
2003 \\
2004 \\
2005 \\
2006 \\
\end{array}$ & $\begin{array}{l}50,911 \\
93,108 \\
184,725 \\
179,797 \\
123,014 \\
303,737 \\
268,426 \\
398,469 \\
435,186 \\
320,752 \\
\end{array}$ & $\begin{array}{l}17.0 \\
21.1 \\
18.5 \\
19.1 \\
16.0 \\
14.1 \\
16.3 \\
26.1 \\
24.5 \\
27.1 \\
\end{array}$ & $\begin{array}{l}122 \\
122 \\
117^{\mathrm{A}} \\
113^{\mathrm{A}} \\
121^{\mathrm{A}} \\
121^{\mathrm{A}} \\
123^{\mathrm{A}} \\
98^{\mathrm{A}} \\
105^{\mathrm{A}} \\
205^{\mathrm{A}} \\
\end{array}$ & $\begin{array}{l}13,378 \\
19,825 \\
19,939 \\
20,819 \\
20,922 \\
20,920 \\
20,904 \\
20,910 \\
20,917 \\
20,623 \\
\end{array}$ & $\begin{array}{l}0.2628 \\
0.2129 \\
0.1079 \\
0.1158 \\
0.1701 \\
0.0689 \\
0.0779 \\
0.0525 \\
0.0481 \\
0.0643 \\
\end{array}$ \\
\hline
\end{tabular}

${ }^{\mathrm{A}}$ Tagged in fall $\sim 5$ months before release; otherwise tagged in spring 1-2 months before release.

${ }^{B}$ Includes cooperative use of Corps of Engineers marked fish in BWS group 
Table A-3. Number of PIT-tagged wild steelhead smolts from four tributaries above Lower Granite Dam (plus Snake River trap) used in the CSS for migration years 1997 to 2005.

\begin{tabular}{|c|c|c|c|c|c|c|}
\hline \multirow[b]{2}{*}{$\begin{array}{l}\text { Migr. } \\
\text { Year }\end{array}$} & \multicolumn{6}{|c|}{ Number of PIT-tagged wild steelhead (>130 mm) utilized in CSS by location of origin } \\
\hline & $\begin{array}{l}\text { Total PIT } \\
\text { Tags }\end{array}$ & $\begin{array}{l}\text { Clearwater } \\
\text { River } \\
(\text { Rkm 224) }\end{array}$ & $\begin{array}{l}\text { Snake River } \\
\operatorname{trap}^{\mathrm{A}} \\
\left(\operatorname{Rkm}^{225}\right)\end{array}$ & $\begin{array}{l}\text { Grande } \\
\text { Ronde River } \\
\text { (Rkm 271) }\end{array}$ & $\begin{array}{l}\text { Salmon } \\
\text { River } \\
\text { (Rkm 303) }\end{array}$ & $\begin{array}{l}\text { Imnaha } \\
\text { River } \\
\text { (Rkm 308) }\end{array}$ \\
\hline 1997 & 7,703 & 5,518 & 68 & 248 & 1,158 & 711 \\
\hline 1998 & 10,512 & 4,131 & 1,032 & 887 & 1,683 & 2,779 \\
\hline 1999 & 15,763 & 5,095 & 886 & 1,628 & 5,569 & 2,585 \\
\hline 2000 & 24,254 & 8,688 & 1,211 & 3,618 & 6,245 & 4,492 \\
\hline 2001 & 24,487 & 8,845 & 867 & 3,370 & 7,844 & 3,561 \\
\hline 2002 & 25,183 & 10,206 & 2,368 & 3,353 & 6,136 & 3,120 \\
\hline 2003 & 24,284 & 5,885 & 1,197 & 4,261 & 6,969 & 5,972 \\
\hline 2004 & 25,156 & 7,642 & 1,922 & 2,977 & 7,102 & 5,513 \\
\hline $2005^{\mathrm{B}}$ & 25,002 & 8,391 & 1,349 & 3,773 & 5,652 & 4,437 \\
\hline \multicolumn{2}{|c|}{ Average $\%$ of total } & $35.3 \%$ & $6.0 \%$ & $13.2 \%$ & $26.5 \%$ & $18.2 \%$ \\
\hline
\end{tabular}

${ }^{A}$ Snake River trap located at Lewiston, ID, collects wild steelhead originating in Grande Ronde, Salmon, and Imnaha rivers.

B Total includes 1,400 PIT-tagged wild steelhead released in Asotin Creek, above Lewiston ID.

Table A-4. Number of PIT-tagged hatchery steelhead smolts from four tributaries above Lower Granite Dam (plus mainstem Snake River) used in the CSS for migration years 1997 to 2005.

\begin{tabular}{|c|c|c|c|c|c|c|c|}
\hline \multirow[b]{2}{*}{$\begin{array}{l}\text { Migr. } \\
\text { Year }\end{array}$} & \multicolumn{7}{|c|}{ Number of PIT-tagged hatchery steelhead utilized in CSS by location of origin } \\
\hline & $\begin{array}{l}\text { Total } \\
\text { PIT Tags }\end{array}$ & $\begin{array}{l}\text { Clearwater } \\
\text { River } \\
\text { (Rkm 224) }\end{array}$ & $\begin{array}{l}\text { Snake } \\
\text { River } \\
\text { trap } \\
\text { (Rkm } \\
\text { 225) } \\
\end{array}$ & $\begin{array}{l}\text { Grande } \\
\text { Ronde } \\
\text { River } \\
\text { (Rkm 271) }\end{array}$ & $\begin{array}{l}\text { Salmon } \\
\text { River } \\
\text { (Rkm } \\
\text { 303) }\end{array}$ & $\begin{array}{l}\text { Imnaha } \\
\text { River } \\
\text { (Rkm } \\
\text { 308) }\end{array}$ & $\begin{array}{l}\text { Snake River } \\
\text { at Hells } \\
\text { Canyon Dam } \\
(\text { Rkm 397) }\end{array}$ \\
\hline 1997 & 35,705 & 12,872 & 725 & 6,039 & 9,394 & 6,379 & 296 \\
\hline 1998 & 30,913 & 8,451 & 4,209 & 4,904 & 8,457 & 4,604 & 288 \\
\hline 1999 & 36,968 & 11,486 & 3,925 & 5,316 & 9,132 & 6,808 & 301 \\
\hline 2000 & 32,000 & 8,488 & 3,290 & 5,348 & 8,173 & 6,436 & 265 \\
\hline 2001 & 29,099 & 9,155 & 3,126 & 4,677 & 7,859 & 3,995 & 287 \\
\hline 2002 & 26,573 & 7,819 & 4,722 & 3,888 & 7,011 & 2,839 & 294 \\
\hline 2003 & 26,379 & 4,912 & 4,171 & 3,113 & 7,764 & 6,123 & 296 \\
\hline 2004 & 19,879 & 3,400 & 4,841 & 2,263 & 4,072 & 5,098 & 205 \\
\hline 2005 & 23,520 & 7,228 & 3,354 & 2,395 & 3,684 & 6,802 & 57 \\
\hline \multicolumn{2}{|c|}{$\begin{array}{l}\text { Average \% of } \\
\text { total }\end{array}$} & $28.3 \%$ & $12.4 \%$ & $14.5 \%$ & $25.1 \%$ & $18.8 \%$ & $0.9 \%$ \\
\hline
\end{tabular}

${ }^{1}$ Snake River trap located at Lewiston, ID, collects hatchery steelhead released in Grande Ronde, Salmon, and Imnaha rivers, and below Hells Canyon Dam. 
Tables A-5 to A-12 present estimated number of smolts per study category with associated $90 \%$ confidence interval and number of returning adults per study category for PIT-tagged wild and hatchery Chinook and steelhead.

Table A-5. Estimated number of PIT-tagged wild Chinook (aggregate of fish tagged in 10-month period between July 25 and May 20) arriving Lower Granite Dam in each of the three study categories from 1994 to 2006 (with $90 \%$ confidence intervals), with detected adults at Lower Granite (GRA) and Bonneville (BON) adult ladders.

\begin{tabular}{|c|c|c|c|c|c|c|}
\hline \multirow[t]{2}{*}{$\begin{array}{l}\text { Migr. } \\
\text { Year }\end{array}$} & \multirow{2}{*}{$\begin{array}{l}\text { Estimated smolt } \\
\text { population at LGR } \\
\text { (with } 90 \% \mathrm{CI} \text { ) }\end{array}$} & \multirow[t]{2}{*}{$\begin{array}{l}\text { Study } \\
\text { category }\end{array}$} & \multirow{2}{*}{\multicolumn{2}{|c|}{$\begin{array}{l}\text { Estimated smolt numbers } \\
\text { in each study category } \\
\text { (with } 90 \% \mathrm{CI} \text { ) }\end{array}$}} & \multicolumn{2}{|c|}{$\begin{array}{l}\text { Detected adults } \\
\text { (2-salt \& older) }\end{array}$} \\
\hline & & & & & GRA & BON \\
\hline 1994 & $\begin{array}{l}15,260 \\
(15,008-15,520)\end{array}$ & $\begin{array}{l}\mathrm{T}_{0} \\
\mathrm{C}_{0} \\
\mathrm{C}\end{array}$ & $\begin{array}{l}2,004 \\
1,801 \\
4.431\end{array}$ & $\begin{array}{l}(1,922-2,084) \\
(1,693-1,911) \\
(4,275-4.618)\end{array}$ & $\begin{array}{l}9 \\
5 \\
3\end{array}$ & \\
\hline 1995 & $\begin{array}{l}20,206 \\
(19,950-20,457)\end{array}$ & $\begin{array}{l}\mathrm{T}_{0}^{1} \\
\mathrm{C}_{0} \\
\mathrm{C}_{1}\end{array}$ & $\begin{array}{r}2,283 \\
2,709 \\
14,206 \\
14,413)\end{array}$ & $\begin{array}{l}(2,202-2,367) \\
(2,602-2,812) \\
(13,997-\end{array}$ & $\begin{array}{l}8 \\
8 \\
10 \\
36\end{array}$ & \\
\hline 1996 & $\begin{array}{l}7,868 \\
(7,682-8,070)\end{array}$ & $\begin{array}{l}\mathrm{T}_{0} \\
\mathrm{C}_{0} \\
\mathrm{C}\end{array}$ & $\begin{array}{r}400 \\
1,917 \\
5,209\end{array}$ & $\begin{array}{l}(365-434) \\
(1,805-2,034) \\
(5,057-5,366)\end{array}$ & $\begin{array}{l}2 \\
5 \\
7\end{array}$ & \\
\hline 1997 & $\begin{array}{l}2,898 \\
(2,784-3,024)\end{array}$ & $\begin{array}{l}\mathrm{T}_{0}^{1} \\
\mathrm{C}_{0} \\
\mathrm{C}\end{array}$ & $\begin{array}{r}230 \\
680 \\
1.936\end{array}$ & $\begin{array}{l}(207-255) \\
(614-757) \\
(1.843-2.028)\end{array}$ & $\begin{array}{l}4 \\
16 \\
18\end{array}$ & \\
\hline 1998 & $\begin{array}{l}17,363 \\
(17,172-17,562)\end{array}$ & $\begin{array}{l}\mathrm{T}_{0}^{1} \\
\mathrm{C}_{0} \\
\mathrm{C}_{1}\end{array}$ & $\begin{array}{r}1,271 \\
3,081 \\
12,276 \\
12,444)\end{array}$ & $\begin{array}{l}(1,214-1,330) \\
(2,976-3,187) \\
(12,111-\end{array}$ & $\begin{array}{l}15 \\
42 \\
131\end{array}$ & \\
\hline 1999 & $\begin{array}{l}33,662 \\
(33,343-33,988)\end{array}$ & $\begin{array}{l}\mathrm{T}_{0} \\
\mathrm{C}_{0} \\
\mathrm{C}_{1}\end{array}$ & $\begin{array}{r}1,768 \\
4,469 \\
26,140 \\
26.424)\end{array}$ & $\begin{array}{l}(1,697-1,841) \\
(4,339-4,595) \\
(25,855-\end{array}$ & $\begin{array}{l}43 \\
95 \\
495\end{array}$ & \\
\hline 2000 & $\begin{array}{l}25,053 \\
(24,721-25,397)\end{array}$ & $\begin{array}{l}\mathrm{T}_{0} \\
\mathrm{C}_{0} \\
\mathrm{C}_{1}\end{array}$ & $\begin{array}{r}839 \\
6,494 \\
16,833 \\
17.087)\end{array}$ & $\begin{array}{l}(790-890) \\
(6,321-6,686) \\
(16,574-\end{array}$ & $\begin{array}{l}12 \\
155 \\
392\end{array}$ & $\begin{array}{l}21 \\
184 \\
456\end{array}$ \\
\hline 2001 & $\begin{array}{l}22,415 \\
(22,234-22,595)\end{array}$ & $\begin{array}{l}\mathrm{T}_{0} \\
\mathrm{C}_{0} \\
\mathrm{C}_{1}\end{array}$ & $\begin{array}{r}547 \\
231 \\
20,307 \\
20.491)\end{array}$ & $\begin{array}{l}(512-587) \\
(208-253) \\
(20,124-\end{array}$ & $\begin{array}{l}7 \\
1^{\mathrm{A}} \\
29\end{array}$ & $\begin{array}{l}10 \\
1^{\mathrm{A}} \\
32\end{array}$ \\
\hline 2002 & $\begin{array}{l}23,356 \\
(22,995-23,697)\end{array}$ & $\begin{array}{l}\mathrm{T}_{0} \\
\mathrm{C}_{0} \\
\mathrm{C}_{1}\end{array}$ & $\begin{array}{r}3,886 \\
6,218 \\
12,687 \\
12,922)\end{array}$ & $\begin{array}{l}(3,775-3,995) \\
(6,042-6,395) \\
(12,455-\end{array}$ & $\begin{array}{l}31 \\
76 \\
125\end{array}$ & $\begin{array}{l}41 \\
86 \\
137\end{array}$ \\
\hline 2003 & $\begin{array}{l}31,093 \\
(30,705-31,472)\end{array}$ & $\begin{array}{l}\mathrm{T}_{0} \\
\mathrm{C}_{0} \\
\mathrm{C}_{1}\end{array}$ & $\begin{array}{r}8,713 \\
8,919 \\
12,744 \\
12,952)\end{array}$ & $\begin{array}{l}(8,556-8,881) \\
(8,701-9,124) \\
(12,538-\end{array}$ & $\begin{array}{l}30 \\
29 \\
22\end{array}$ & $\begin{array}{l}29 \\
33 \\
22\end{array}$ \\
\hline 2004 & $\begin{array}{l}32,546 \\
(32,297-32,815)\end{array}$ & $\begin{array}{l}\mathrm{T}_{0} \\
\mathrm{C}_{0} \\
\mathrm{C}_{1}\end{array}$ & $\begin{array}{c}12,887 \\
13,067) \\
2,264 \\
16,561 \\
16.785)\end{array}$ & $\begin{array}{l}(12,721- \\
(2,167-2,348) \\
(16,363-\end{array}$ & $\begin{array}{l}68 \\
11 \\
37\end{array}$ & $\begin{array}{l}88 \\
15 \\
44\end{array}$ \\
\hline 2005 & $\begin{array}{l}35,216 \\
(34,945-35,489)\end{array}$ & $\begin{array}{l}\mathrm{T}_{0} \\
\mathrm{C}_{0} \\
\mathrm{C}_{1}\end{array}$ & $\begin{array}{c}15,910 \\
16,116) \\
1,358 \\
17,066 \\
17,276)\end{array}$ & $\begin{array}{l}(15,702- \\
(1,297-1,425) \\
(16,854-\end{array}$ & $\begin{array}{l}38 \\
1 \\
14\end{array}$ & $\begin{array}{l}48 \\
1 \\
18\end{array}$ \\
\hline $2006^{\mathrm{B}}$ & $\begin{array}{l}22,587 \\
(22,284-22,875)\end{array}$ & $\begin{array}{l}\mathrm{T}_{0} \\
\mathrm{C}_{0} \\
\mathrm{C}\end{array}$ & $\begin{array}{r}9,670 \\
3,466 \\
8,691\end{array}$ & $\begin{array}{l}(9,497-9,853) \\
(3,339-3,592) \\
(8,525-8,875)\end{array}$ & $\begin{array}{l}59 \\
24 \\
32 \\
\end{array}$ & $\begin{array}{l}66 \\
31 \\
40\end{array}$ \\
\hline
\end{tabular}

${ }^{\mathrm{A}}$ One returning adult with no detections may have inadvertently been transported.

${ }^{\text {B }}$ Migr. year 2006 data is combined groups TWS \& BWS; incomplete with 2-salt adult returns as of $8 / 13 / 2008$. 
Table A-6. Estimated number of PIT-tagged spring Chinook from Rapid River Hatchery arriving Lower Granite Dam in each of the three study categories from 1997 to 2006 (with 90\% confidence intervals), with detected adults at Lower Granite (GRA) and Bonneville (BON) adult ladders.

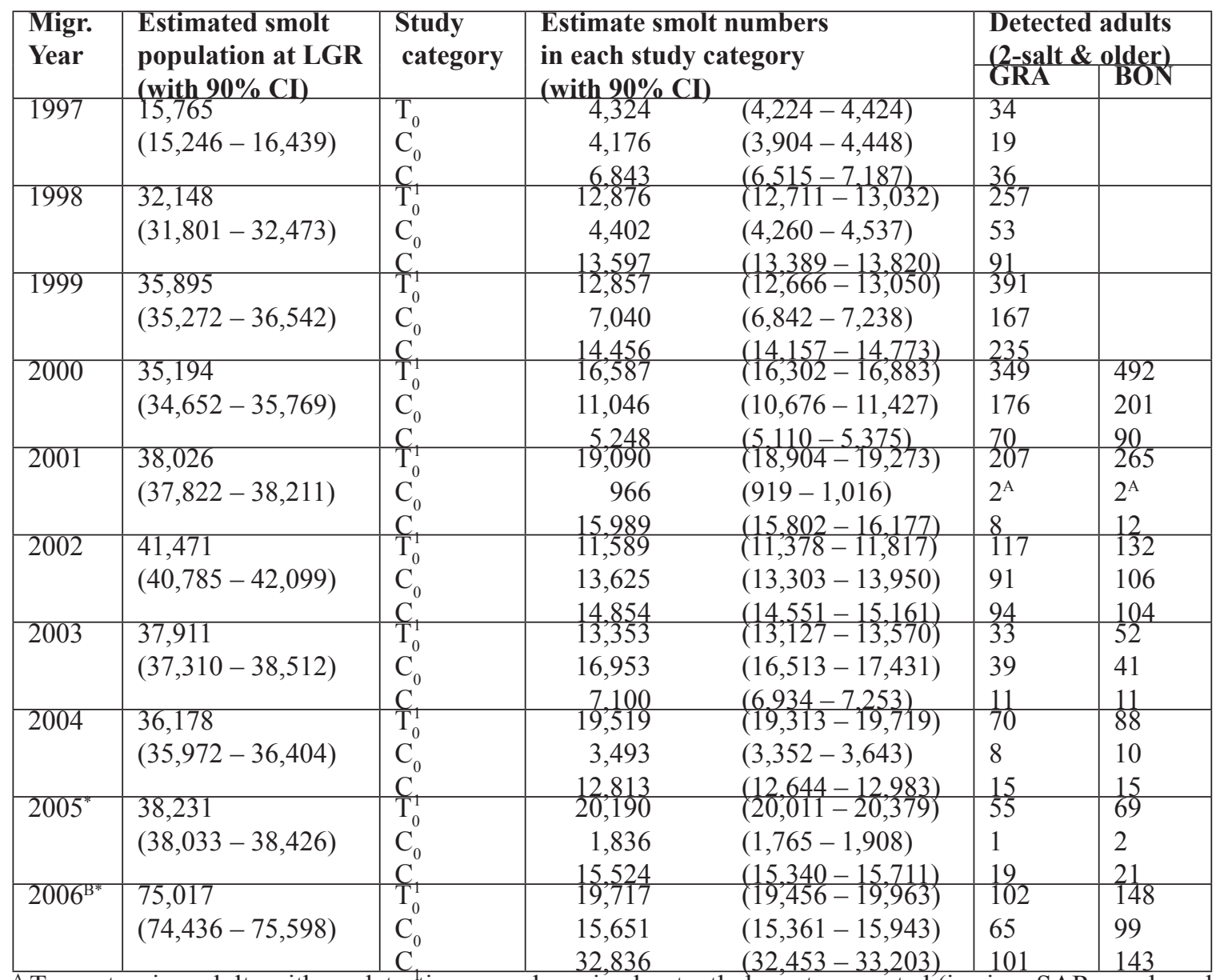

${ }^{\mathrm{A}}$ Two returning adults with no detections may have inadvertently been transported (in-river SARs are based solely on Category $\mathrm{C}_{1}$ fish in 2001).

${ }^{\text {B }}$ Migr. year 2006 data is combined groups TWS \& BWS; incomplete with 2-salt adult returns as of $8 / 13 / 2008$.

${ }^{*}$ Release above LGR includes COE fish. 
Table A-7. Estimated number of PIT-tagged spring Chinook from Dworshak Hatchery arriving Lower Granite Dam in each of the three study categories from 1997 to 2006 (with $90 \%$ confidence intervals), with detected adults at Lower Granite (GRA) and Bonneville (BON) adult ladders.

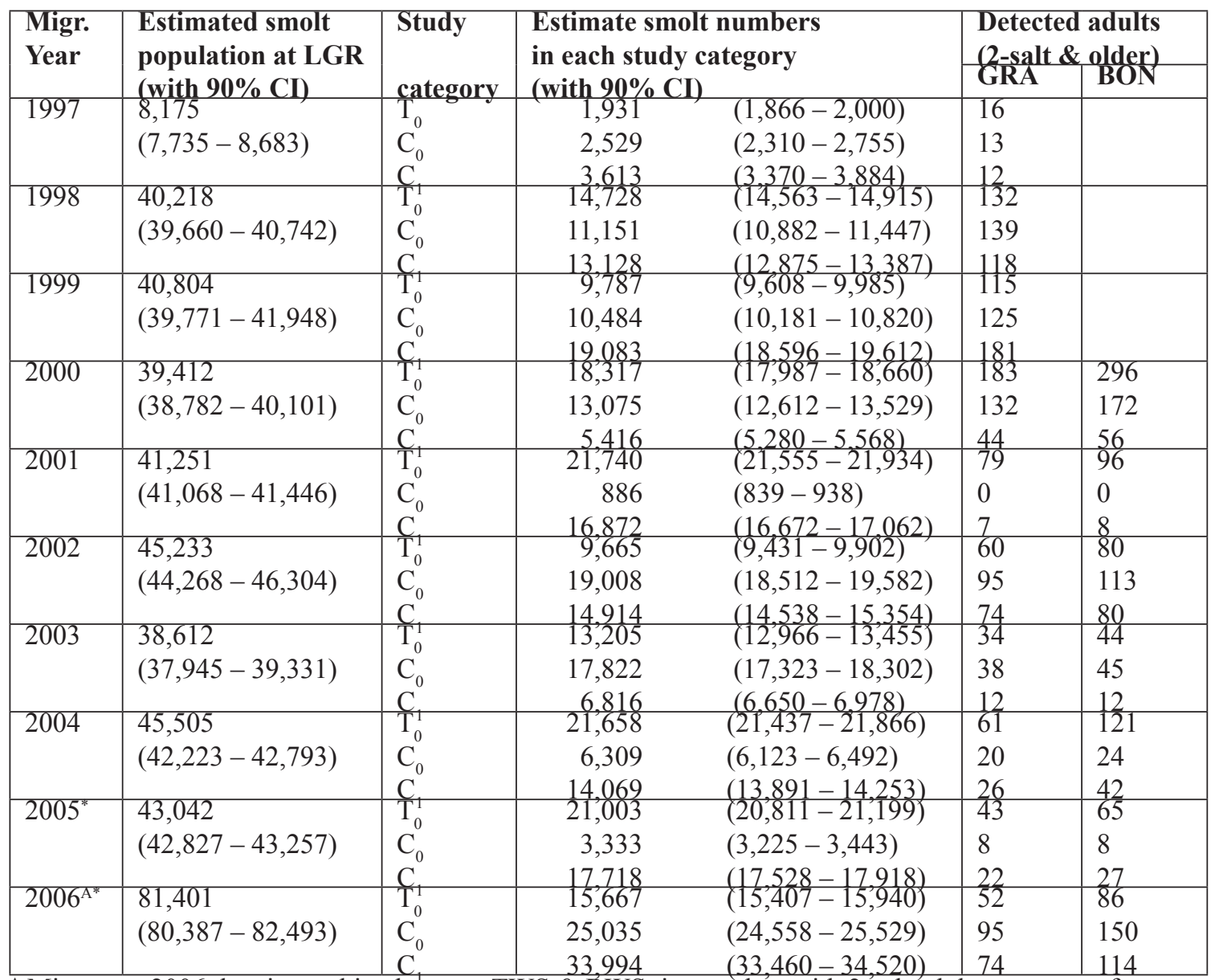

${ }^{\mathrm{A}}$ Migr. year 2006 data is combined groups TWS \& BWS; incomplete with 2-salt adult returns as of 8/13/2008.

* Release above LGR includes COE fish. 
Table A-8. Estimated number of PIT-tagged spring Chinook from Catherine Creek Acclimation Pond arriving Lower Granite Dam in each of the three study categories from 2001 to 2006 (with 90\% confidence intervals), with detected adults at Lower Granite (GRA) and Bonneville (BON) adult ladders.

\begin{tabular}{|c|c|c|c|c|c|c|}
\hline $\begin{array}{l}\text { Migr. } \\
\text { Year }\end{array}$ & $\begin{array}{l}\text { Estimated smolt } \\
\text { population at LGR }\end{array}$ & $\begin{array}{l}\text { Study } \\
\text { category }\end{array}$ & \multicolumn{2}{|c|}{$\begin{array}{l}\text { Estimate smolt numbers } \\
\text { in each study category }\end{array}$} & \multicolumn{2}{|c|}{$\begin{array}{l}\text { Detected adults } \\
\text { (2-salt \& older) } \\
\text { GRA BON }\end{array}$} \\
\hline 2001 & $\begin{array}{l}\text { (with 90\% Cl) } \\
10,885 \\
(10,747-11,021)\end{array}$ & $\begin{array}{l}\mathrm{T}_{0} \\
\mathrm{C}_{0} \\
\mathrm{C}_{1}\end{array}$ & $\begin{array}{r}\text { (with 90\% } \\
4,790 \\
379 \\
4,642\end{array}$ & $\begin{array}{l}(4,683-4,899) \\
(345-414) \\
(4,540-4,738)\end{array}$ & $\begin{array}{l}11 \\
0 \\
2\end{array}$ & $\begin{array}{l}18 \\
0 \\
3\end{array}$ \\
\hline 2002 & $\begin{array}{l}8,435 \\
(8,181-8,709)\end{array}$ & $\begin{array}{l}\mathrm{T}_{0} \\
\mathrm{C}_{0} \\
\mathrm{C}_{1}\end{array}$ & $\begin{array}{l}2,697 \\
2,445 \\
3,120\end{array}$ & $\begin{array}{l}(2,600-2,797) \\
(2,312-2,590) \\
(2,992-3,258)\end{array}$ & $\begin{array}{l}24 \\
12 \\
10\end{array}$ & $\begin{array}{l}33 \\
11 \\
10\end{array}$ \\
\hline 2003 & $\begin{array}{l}7,202 \\
(6,926-7,493)\end{array}$ & $\begin{array}{l}\mathrm{T}_{0} \\
\mathrm{C}_{0} \\
\mathrm{C}_{1}\end{array}$ & $\begin{array}{l}2,494 \\
3,222 \\
1,412\end{array}$ & $\begin{array}{l}(2,390-2,593) \\
(3,026-3,437) \\
(1,346-1,486)\end{array}$ & $\begin{array}{l}9 \\
8 \\
5\end{array}$ & $\begin{array}{l}10 \\
8 \\
6\end{array}$ \\
\hline 2004 & $\begin{array}{l}5,348 \\
(5,225-5,469)\end{array}$ & $\begin{array}{l}\mathrm{T}_{0} \\
\mathrm{C}_{0} \\
\mathrm{C}_{1}\end{array}$ & $\begin{array}{r}2,877 \\
507 \\
1,875\end{array}$ & $\begin{array}{l}(2,787-2,963) \\
(464-552) \\
(1,800-1,942)\end{array}$ & $\begin{array}{l}11 \\
1 \\
6\end{array}$ & $\begin{array}{l}14 \\
0 \\
7\end{array}$ \\
\hline 2005 & $\begin{array}{l}4,848 \\
(4,745-4,954)\end{array}$ & $\begin{array}{l}\mathrm{T}_{0} \\
\mathrm{C}_{0} \\
\mathrm{C}_{1}\end{array}$ & $\begin{array}{r}2,495 \\
276 \\
1,971\end{array}$ & $\begin{array}{l}(2,417-2,574) \\
(247-307) \\
(1,903-2,043)\end{array}$ & $\begin{array}{l}11 \\
0 \\
4\end{array}$ & $\begin{array}{l}14 \\
0 \\
4\end{array}$ \\
\hline $2006^{\mathrm{A}}$ & $\begin{array}{l}6,478 \\
(6,263-6,729)\end{array}$ & $\begin{array}{l}\mathrm{T}_{0} \\
\mathrm{C}_{0} \\
\mathrm{C}\end{array}$ & $\begin{array}{l}2,918 \\
1,626 \\
1,799\end{array}$ & $\begin{array}{l}(2,801-3,045) \\
(1,507-1,745) \\
(1,705-1,889)\end{array}$ & $\begin{array}{l}12 \\
15 \\
8\end{array}$ & $\begin{array}{l}23 \\
19 \\
14\end{array}$ \\
\hline
\end{tabular}

${ }^{\mathrm{A}}$ Migr. year 2006 data is combined groups TWS \& BWS; incomplete with 2-salt adult returns as of $8 / 13 / 2008$ 
Table A-9. Estimated number of PIT-tagged summer Chinook from McCall Hatchery arriving Lower Granite Dam in each of the three study categories from 1997 to 2006 (with $90 \%$ confidence intervals), with detected adults at Lower Granite (GRA) and Bonneville (BON) adult ladders.

\begin{tabular}{|c|c|c|c|c|c|c|}
\hline $\begin{array}{l}\text { Migr. } \\
\text { Year }\end{array}$ & $\begin{array}{l}\text { Estimated smolt } \\
\text { population at LGR } \\
\text { (with } 90 \% \mathrm{CI} \text { ) }\end{array}$ & $\begin{array}{l}\text { Study } \\
\text { category }\end{array}$ & \multicolumn{2}{|c|}{$\begin{array}{l}\text { Estimate smolt numbers } \\
\text { in each study category } \\
\text { (with } 90 \% \mathrm{CI} \text { ) }\end{array}$} & \multicolumn{2}{|c|}{$\begin{array}{l}\text { Detected adults } \\
\text { (2-salt \& older) } \\
\text { GRA BON }\end{array}$} \\
\hline 1997 & $(21,588-23,224)$ & $\begin{array}{l}\mathrm{T}_{0} \\
\mathrm{C}_{0} \\
\mathrm{C}\end{array}$ & $\begin{array}{r}6,013 \\
6,761 \\
9.272 \\
\end{array}$ & $\begin{array}{l}(5,888-6,136) \\
(6,398-7,132) \\
(8.854-9.738)\end{array}$ & $\begin{array}{l}91 \\
74 \\
102\end{array}$ & \\
\hline 1998 & $\begin{array}{l}27,812 \\
(27,474-28,141)\end{array}$ & $\begin{array}{l}\mathrm{T}_{0}^{+} \\
\mathrm{C}_{0} \\
\mathrm{C}\end{array}$ & $\begin{array}{r}10,142 \\
3,849 \\
12,816\end{array}$ & $\begin{array}{l}(9,988-10,286) \\
(3,721-3,983) \\
(12,578-13,060)\end{array}$ & $\begin{array}{l}273 \\
53 \\
94\end{array}$ & \\
\hline 1999 & $\begin{array}{l}31,571 \\
(30,816-32,358)\end{array}$ & $\begin{array}{l}\mathrm{T}_{0}^{1} \\
\mathrm{C}_{0}\end{array}$ & $\begin{array}{r}10,515 \\
8,407 \\
11.391\end{array}$ & $\begin{array}{l}(10,281-10,742) \\
(8,122-8,675) \\
(11.062-11.684)\end{array}$ & $\begin{array}{l}377 \\
202 \\
231\end{array}$ & \\
\hline 2000 & $\begin{array}{l}31,825 \\
(31,170-32,466)\end{array}$ & $\begin{array}{l}\mathrm{T}_{0}^{+1} \\
\mathrm{C}_{0} \\
\mathrm{C}\end{array}$ & $\begin{array}{r}12,806 \\
13,064 \\
4,485 \\
\end{array}$ & $\begin{array}{l}(12,552-13,083) \\
(12,558-13,601) \\
(4.349-4,624)\end{array}$ & $\begin{array}{l}497 \\
269 \\
91\end{array}$ & $\begin{array}{l}584 \\
299 \\
101\end{array}$ \\
\hline 2001 & $\begin{array}{l}36,784 \\
(36,578-36,994)\end{array}$ & $\begin{array}{l}\mathrm{T}_{0}^{1} \\
\mathrm{C}_{0} \\
\mathrm{C}\end{array}$ & $\begin{array}{r}16,704 \\
1,000 \\
15,536\end{array}$ & $\begin{array}{l}(16,511-16,882) \\
(946-1,052) \\
(15.351-15.728)\end{array}$ & $\begin{array}{l}206 \\
3^{\mathrm{A}} \\
6\end{array}$ & $\begin{array}{l}246 \\
3^{\mathrm{A}} \\
7\end{array}$ \\
\hline 2002 & $\begin{array}{l}32,599 \\
(32,042-33,229)\end{array}$ & $\begin{array}{l}\mathrm{T}_{0}^{1} \\
\mathrm{C}_{0} \\
\mathrm{C}\end{array}$ & $\begin{array}{r}8,842 \\
10,280 \\
12,315\end{array}$ & $\begin{array}{l}(8,666-9,027) \\
(9,987-10,578) \\
(12,029-12,631)\end{array}$ & $\begin{array}{l}131 \\
106 \\
126\end{array}$ & $\begin{array}{l}164 \\
127 \\
154\end{array}$ \\
\hline 2003 & $\begin{array}{l}43,144 \\
(42,480-43,777)\end{array}$ & $\begin{array}{l}\widetilde{\mathrm{T}}_{0}^{1} \\
\mathrm{C}_{0} \\
\mathrm{C}\end{array}$ & $\begin{array}{r}14,006 \\
19,821 \\
8,722 \\
\end{array}$ & $\begin{array}{l}(13,776-14,243) \\
(19,350-20,293) \\
(8.549-8.881)\end{array}$ & $\begin{array}{l}111 \\
107 \\
30\end{array}$ & $\begin{array}{l}124 \\
122 \\
32\end{array}$ \\
\hline 2004 & $\begin{array}{l}40,150 \\
(39,903-40,402)\end{array}$ & $\begin{array}{l}\mathrm{T}_{0}^{1} \\
\mathrm{C}_{0} \\
\mathrm{C}\end{array}$ & $\begin{array}{r}20,858 \\
2,368 \\
16,352 \\
\end{array}$ & $\begin{array}{l}(20,651-21,071) \\
(2,275-2,460) \\
(16,180-16,526)\end{array}$ & $\begin{array}{l}84 \\
6 \\
19\end{array}$ & $\begin{array}{l}113 \\
7 \\
34\end{array}$ \\
\hline 2005 & $\begin{array}{l}43,229 \\
(42,951-43,487)\end{array}$ & $\begin{array}{l}T_{0}^{1} \\
\mathrm{C}_{0}^{+} \\
\mathrm{C}\end{array}$ & $\begin{array}{r}22,567 \\
2,501 \\
17,325\end{array}$ & $\begin{array}{l}(22,359-22,784) \\
(2,415-2,590) \\
(17,132-17,522)\end{array}$ & $\begin{array}{l}141 \\
10 \\
31\end{array}$ & $\begin{array}{l}168 \\
11 \\
38 \\
\end{array}$ \\
\hline $2006^{\mathrm{B}}$ & $\begin{array}{l}32,854 \\
(32,330-33,401)\end{array}$ & $\begin{array}{l}\mathrm{T}_{0}^{+} \\
\mathrm{C}_{0} \\
\mathrm{C}\end{array}$ & $\begin{array}{r}14,142 \\
8,912 \\
9,102 \\
\end{array}$ & $\begin{array}{l}(13,893-14,408) \\
(8,630-9,195) \\
(8,888-9,298)\end{array}$ & $\begin{array}{l}150 \\
85 \\
58 \\
\end{array}$ & $\begin{array}{l}174 \\
111 \\
64 \\
\end{array}$ \\
\hline
\end{tabular}

A Three returning adults with no detections may have inadvertently been transported (in-river SARs based solely on Category $\mathrm{C}_{1}$ fish in 2001).

${ }^{\text {B }}$ Migr. year 2006 data is combined groups TWS \& BWS; incomplete with 2-salt adult returns as of 8/13/2008. 
Table A-10. Estimated number of PIT-tagged summer Chinook from Imnaha River Acclimation Pond arriving Lower Granite Dam in each of the three study categories from 1997 to 2006 (with 90\% confidence intervals), with detected adults at Lower Granite (GRA) and Bonneville (BON) adult ladders.

\begin{tabular}{|c|c|c|c|c|c|c|}
\hline $\begin{array}{l}\text { Migr. } \\
\text { Year }\end{array}$ & $\begin{array}{l}\text { Estimated smolt } \\
\text { population at LGR } \\
\text { (with } 90 \% \mathrm{CI} \text { ) }\end{array}$ & $\begin{array}{l}\text { Study } \\
\text { category }\end{array}$ & \multicolumn{2}{|c|}{$\begin{array}{l}\text { Estimated smolt numbers } \\
\text { in each study category }\end{array}$} & \multicolumn{2}{|c|}{$\begin{array}{l}\text { Detected adults } \\
\text { (2-salt \& older) } \\
\text { GRA } \\
\text { BON }\end{array}$} \\
\hline 1997 & $\begin{array}{l}8,254 \\
(7,814-8,740)\end{array}$ & $\begin{array}{l}\mathrm{T}_{0} \\
\mathrm{C}_{0} \\
\mathrm{C}_{1}\end{array}$ & $\begin{array}{r}2,147 \\
2,219 \\
3,785\end{array}$ & $\begin{array}{l}(2.079-2,212) \\
(2,032-2,433) \\
(3,535-4,040)\end{array}$ & $\begin{array}{l}25 \\
19 \\
26\end{array}$ & \\
\hline 1998 & $\begin{array}{l}13,577 \\
(13,327-13,833)\end{array}$ & $\begin{array}{l}\mathrm{T}_{0} \\
\mathrm{C}_{0} \\
\mathrm{C}_{1}\end{array}$ & $\begin{array}{l}4,809 \\
1,995 \\
6,335\end{array}$ & $\begin{array}{l}(4,709-4,910) \\
(1,900-2,085) \\
(6,194-6,483)\end{array}$ & $\begin{array}{l}41 \\
11 \\
19\end{array}$ & \\
\hline 1999 & $\begin{array}{l}13,244 \\
(12,829-13,687)\end{array}$ & $\begin{array}{l}\mathrm{T}_{0} \\
\mathrm{C}_{0} \\
\mathrm{C}_{1}\end{array}$ & $\begin{array}{l}4,827 \\
2,869 \\
5,084\end{array}$ & $\begin{array}{l}(4,688-4,963) \\
(2,733-3,008) \\
(4,884-5,268)\end{array}$ & $\begin{array}{l}130 \\
41 \\
62\end{array}$ & \\
\hline 2000 & $\begin{array}{l}14,267 \\
(13,926-14,650)\end{array}$ & $\begin{array}{l}\mathrm{T}_{0} \\
\mathrm{C}_{0} \\
\mathrm{C}_{1}\end{array}$ & $\begin{array}{l}6,789 \\
4,396 \\
2,254\end{array}$ & $\begin{array}{l}(6,597-6,991) \\
(4,159-4,672) \\
(2,166-2,353)\end{array}$ & $\begin{array}{l}211 \\
106 \\
37\end{array}$ & $\begin{array}{l}262 \\
114 \\
41\end{array}$ \\
\hline 2001 & $\begin{array}{l}15,650 \\
(15,531-15,763)\end{array}$ & $\begin{array}{l}\mathrm{T}_{0} \\
\mathrm{C}_{0} \\
\mathrm{C}_{1}\end{array}$ & $\begin{array}{r}7,730 \\
336 \\
6,939\end{array}$ & $\begin{array}{l}(7,609-7,855) \\
(336-396) \\
(6,819-7,055)\end{array}$ & $\begin{array}{l}48 \\
1^{\mathrm{A}} \\
4\end{array}$ & $\begin{array}{l}61 \\
4^{\mathrm{A}} \\
4\end{array}$ \\
\hline 2002 & $\begin{array}{l}13,962 \\
(13,560-14,380)\end{array}$ & $\begin{array}{l}\mathrm{T}_{0} \\
\mathrm{C}_{0} \\
\mathrm{C}_{1}\end{array}$ & $\begin{array}{l}3,912 \\
4,637 \\
5,135\end{array}$ & $\begin{array}{l}(3,777-4,041) \\
(4,429-4,853) \\
(4,952-5,333)\end{array}$ & $\begin{array}{l}31 \\
21 \\
28\end{array}$ & $\begin{array}{l}41 \\
27 \\
33\end{array}$ \\
\hline 2003 & $\begin{array}{l}14,948 \\
(14,553-15,372)\end{array}$ & $\begin{array}{l}\mathrm{T}_{0} \\
\mathrm{C}_{0} \\
\mathrm{C}_{1}\end{array}$ & $\begin{array}{l}5,189 \\
6,707 \\
2,917\end{array}$ & $\begin{array}{l}(5,039-5,338) \\
(6,426-7,024) \\
(2,818-3,012)\end{array}$ & $\begin{array}{l}30 \\
32 \\
11\end{array}$ & $\begin{array}{l}39 \\
38 \\
13\end{array}$ \\
\hline 2004 & $\begin{array}{l}12,867 \\
(12,705-13,015)\end{array}$ & $\begin{array}{l}\mathrm{T}_{0} \\
\mathrm{C}_{0} \\
\mathrm{C}_{1}\end{array}$ & $\begin{array}{l}6,927 \\
1,307 \\
4,471\end{array}$ & $\begin{array}{l}(6,802-7,052) \\
(1,228-1,384) \\
(4,367-4,580)\end{array}$ & $\begin{array}{l}26 \\
3 \\
5\end{array}$ & $\begin{array}{l}41 \\
5 \\
7\end{array}$ \\
\hline 2005 & $\begin{array}{l}11,172 \\
(11,035-11,316)\end{array}$ & $\begin{array}{l}\mathrm{T}_{0} \\
\mathrm{C}_{0} \\
\mathrm{C}_{1}\end{array}$ & $\begin{array}{r}6,012 \\
615 \\
4,384\end{array}$ & $\begin{array}{l}(5,898-6,134) \\
(570-665) \\
(4,280-4,478)\end{array}$ & $\begin{array}{l}17 \\
1 \\
7\end{array}$ & $\begin{array}{l}23 \\
1 \\
7\end{array}$ \\
\hline $2006^{\mathrm{B}}$ & $\begin{array}{l}13,095 \\
(12,783-13,436)\end{array}$ & $\begin{array}{l}\mathrm{T}_{0} \\
\mathrm{C}_{0} \\
\mathrm{C}_{1}\end{array}$ & $\begin{array}{l}5,722 \\
2,805 \\
4,201\end{array}$ & $\begin{array}{l}(5,558-5,896) \\
(2,660-2,949) \\
(4,060-4,346)\end{array}$ & $\begin{array}{l}39 \\
30 \\
18\end{array}$ & $\begin{array}{l}53 \\
33 \\
24\end{array}$ \\
\hline
\end{tabular}

${ }^{\mathrm{A}}$ One returning adult with no detections may have inadvertently been transported (in-river SARs based solely on Category $\mathrm{C}_{1}$ fish in 2001).

${ }^{\text {B }}$ Migr. year 2006 data is combined groups TWS \& BWS; incomplete with 2-salt adult returns as of $8 / 13 / 2008$. 
Table A-11. Estimated number of PIT-tagged wild steelhead (aggregate of tagged fish $>130 \mathrm{~mm}$ released in 12-month period between July 1 and June 30) arriving Lower Granite Dam in each of the three study categories from 1997 to 2005 (with $90 \%$ confidence intervals), with detected adults at Lower Granite (GRA) adult ladders.

\begin{tabular}{|c|c|c|c|c|}
\hline $\begin{array}{l}\text { Migr. } \\
\text { Year }\end{array}$ & $\begin{array}{l}\text { Estimated smolt } \\
\text { population at LGR }\end{array}$ & $\begin{array}{l}\text { Study } \\
\text { category }\end{array}$ & $\begin{array}{l}\text { Estimated smolt numbers } \\
\text { in each study category }\end{array}$ & $\begin{array}{l}\text { LGR detected } \\
\text { returning adults }\end{array}$ \\
\hline 1997 & $\begin{array}{l}3,830 \\
(3,744-3,920)\end{array}$ & $\begin{array}{l}\mathrm{T}_{0} \\
\mathrm{C}_{0}\end{array}$ & $\begin{aligned} 275 & (248-301) \\
454 & (415-492) \\
2984 & (2905-3066)\end{aligned}$ & $\begin{array}{l}4 \\
3 \\
7\end{array}$ \\
\hline 1998 & $\begin{array}{l}7,109 \\
(7,010-7,208)\end{array}$ & $\begin{array}{l}\mathrm{T}_{1}^{1} \\
\mathrm{C}_{0} \\
\mathrm{C}\end{array}$ & $\begin{aligned} 2,984 & (2,905-5.006) \\
480 & (443-518) \\
750 & (700-800) \\
5.150 & (5.053-5.242)\end{aligned}$ & $\begin{array}{l}\frac{7}{1} \\
8\end{array}$ \\
\hline 1999 & $\begin{array}{l}8,820 \\
(8,695-8,960)\end{array}$ & $\begin{array}{l}\mathrm{T}_{0}^{1} \\
\mathrm{C}_{0}\end{array}$ & $\begin{array}{ll}391 & (358-424) \\
1,113 & (1,052-1,178) \\
6992 & (6,878-7114)\end{array}$ & $\begin{array}{l}12 \\
15 \\
53\end{array}$ \\
\hline 2000 & $\begin{array}{l}13,609 \\
(13,418-13,818)\end{array}$ & $\begin{array}{l}\breve{T}_{0}^{1} \\
\mathrm{C}_{0}\end{array}$ & $\begin{aligned} 0,766 & (426-505) \\
1,871 & (1,780-1,961)\end{aligned}$ & 36 \\
\hline $2001^{\mathrm{A}}$ & $\begin{array}{l}12,929 \\
(12,810-13,066)\end{array}$ & $\begin{array}{l}\mathrm{T}_{0}^{1} \\
\mathrm{C}_{0}\end{array}$ & $\begin{aligned} 201 & (179-226) \\
103 & (87-120) \\
11892 & (11748-12014)\end{aligned}$ & $\begin{array}{l}5 \\
3^{\mathrm{B}} \\
8\end{array}$ \\
\hline 2002 & $\begin{array}{l}13,378 \\
(13,148-13,598)\end{array}$ & $\begin{array}{l}\mathrm{T}_{0}^{1} \\
\mathrm{C}_{0} \\
\mathrm{C}\end{array}$ & $\begin{aligned} 317 & (289-346) \\
4,045 & (3,908-4,197) \\
8.726 & (8.552-8,891)\end{aligned}$ & $\begin{array}{l}9 \\
27 \\
82\end{array}$ \\
\hline 2003 & $\begin{array}{l}12,926 \\
(12,707-13,143)\end{array}$ & $\begin{array}{l}\mathrm{T}_{0}^{1} \\
\mathrm{C}_{0}\end{array}$ & $\begin{array}{ll}0,210 & (2,123-2,295) \\
3,324 & (3,194-3,458)\end{array}$ & $\begin{array}{l}\frac{02}{44} \\
15 \\
37\end{array}$ \\
\hline 2004 & $\begin{array}{l}13,263 \\
(13,118-13,398)\end{array}$ & $\begin{array}{l}\mathrm{T}_{0}^{1} \\
\mathrm{C}_{0}\end{array}$ & $\begin{array}{l}(6,980-7,285) \\
(2,369-4,566) \\
(284-374)\end{array}$ & $\begin{array}{l}37 \\
39 \\
0\end{array}$ \\
\hline $2005^{\mathrm{C}}$ & $\begin{array}{l}15,124 \\
(14,993-15,274)\end{array}$ & $\begin{array}{l}\mathrm{T}_{0}^{1} \\
\mathrm{C}_{0}\end{array}$ & $\begin{aligned} 1,805 & (4,752-4,958) \\
205 & (181-228) \\
0177 & (0,050-0210)\end{aligned}$ & $\begin{array}{l}\frac{5}{40} \\
3 \\
14\end{array}$ \\
\hline
\end{tabular}

${ }^{\mathrm{A}}$ Estimates of number of smolts in study categories in 2001 are approximate due to potentially high holdover rate in lower Snake River affecting reach survival estimates and ultimately the smolt estimates in LGR-equivalents for each study category.

${ }^{B}$ Three returning adults with no detections may have inadvertently been transported or held-over to the following year (in-river SARs based solely on Category $\mathrm{C}_{1}$ fish in 2001).

${ }^{\mathrm{C}}$ Migration year 2005 is incomplete until 3-salt returns (if any) occur after 7/1/2008 at GRA. 
Table A-12. Estimated number of PIT-tagged hatchery steelhead (aggregate of tagged fish released in 3-month period between April 1 and June 30) arriving Lower Granite Dam in each of the three study categories from 1997 to 2005 (with 90\% confidence intervals), with detected adults at Lower Granite (GRA) adult ladders.

\begin{tabular}{|c|c|c|c|c|}
\hline $\begin{array}{l}\text { Migr. } \\
\text { Year }\end{array}$ & $\begin{array}{l}\text { Estimated smolt } \\
\text { population at LGR } \\
\text { (with } 90 \% \mathrm{CI} \text { ) }\end{array}$ & $\begin{array}{l}\text { Study } \\
\text { category }\end{array}$ & $\begin{array}{l}\text { Estimated smolt numbers } \\
\text { in each study category } \\
\text { (with } 90 \% \mathrm{CI} \text { ) }\end{array}$ & $\begin{array}{l}\text { LGR detected } \\
\text { returning adults }\end{array}$ \\
\hline 1997 & $\begin{array}{l}24,710 \\
(24,477-24,933)\end{array}$ & $\begin{array}{l}\mathrm{T}_{0} \\
\mathrm{C}_{0} \\
\mathrm{C}\end{array}$ & $\begin{aligned} 1,729 & (1,665-1,798) \\
3,390 & (3,266-3,526) \\
19.095 & (18.895-19.307)\end{aligned}$ & $\begin{array}{l}9 \\
8 \\
32\end{array}$ \\
\hline 1998 & $\begin{array}{l}23,507 \\
(23,325-23,685)\end{array}$ & $\begin{array}{l}\mathrm{T}_{0}^{1} \\
\mathrm{C}_{0} \\
\mathrm{C}\end{array}$ & $\begin{aligned} 1,365 & (1,304-1,425) \\
2,926 & (2,826-3,023) \\
17,958 & (17.778-18.129)\end{aligned}$ & $\begin{array}{l}7 \\
26 \\
40\end{array}$ \\
\hline 1999 & $\begin{array}{l}27,193 \\
(26,959-27,426)\end{array}$ & $\begin{array}{l}\mathrm{T}_{0}^{1} \\
\mathrm{C}_{0} \\
\mathrm{C}\end{array}$ & $\begin{aligned} 1,336 & (1,274-1,395) \\
3,952 & (3,839-4,055) \\
20.975 & (20.767-21.192)\end{aligned}$ & $\begin{array}{l}12 \\
41 \\
124\end{array}$ \\
\hline 2000 & $\begin{array}{l}24,565 \\
(24,280-24,847)\end{array}$ & $\begin{array}{l}\mathrm{T}_{0}^{+} \\
\mathrm{C}_{0} \\
\mathrm{C}\end{array}$ & $\begin{aligned} 668 & (621-717) \\
4,408 & (4,237-4,589) \\
18.804 & (18.598-19.013)\end{aligned}$ & $\begin{array}{l}14 \\
42 \\
197\end{array}$ \\
\hline $2001^{A}$ & $\begin{array}{l}20,877 \\
(20,739-21,031)\end{array}$ & $\begin{array}{l}\mathrm{T}_{0}^{1} \\
\mathrm{C}_{0} \\
\mathrm{C}\end{array}$ & $\begin{aligned} 427 & (389-464) \\
372 & (334-414) \\
19.132 & (18.985-19.294)\end{aligned}$ & $\begin{array}{l}4 \\
2^{\mathrm{B}} \\
3\end{array}$ \\
\hline 2002 & $\begin{array}{l}20,681 \\
(20,328-21,037)\end{array}$ & $\begin{array}{l}\widehat{T}_{0}^{1} \\
\mathrm{C}_{0} \\
\mathrm{C}\end{array}$ & $\begin{array}{l}(256-313) \\
(5,917-6,338) \\
(13.764-14.322)\end{array}$ & $\begin{array}{l}3 \\
43 \\
102\end{array}$ \\
\hline 2003 & $\begin{array}{l}21,400 \\
(21,051-21,734)\end{array}$ & $\begin{array}{l}\mathrm{T}_{0}^{+} \\
\mathrm{C}_{0} \\
\mathrm{C}\end{array}$ & $\begin{array}{l}(4,472-4,715) \\
(6,247-6,687) \\
(9912-10.309)\end{array}$ & $\begin{array}{l}83 \\
44 \\
37\end{array}$ \\
\hline 2004 & $\begin{array}{l}17,082 \\
(16,985-17,176)\end{array}$ & $\begin{array}{l}\mathrm{T}_{0}^{+} \\
\mathrm{C}_{0} \\
\mathrm{C}\end{array}$ & $\begin{array}{l}(432-508) \\
(351-417) \\
(15.504-15.712)\end{array}$ & $\begin{array}{l}10 \\
3 \\
30\end{array}$ \\
\hline $2005^{C}$ & $\begin{array}{l}19,640 \\
(19,527-19,750)\end{array}$ & $\begin{array}{l}\mathrm{T}_{0}^{1} \\
\mathrm{C}_{0} \\
\mathrm{C}\end{array}$ & $\begin{array}{l}(839-941) \\
(324-375)\end{array}$ & $\begin{array}{l}18 \\
2 \\
41\end{array}$ \\
\hline
\end{tabular}

${ }^{\mathrm{A}}$ Estimates of number of smolts in study categories in 2001 are approximate due to potentially high holdover rate in lower Snake River affecting reach survival estimates and ultimately the smolt estimates in LGR-equivalents for each study category.

B Two returning adults with no detections may have inadvertently been transported or held-over to the following year so in-river SARs based solely on Category $\mathrm{C}_{1}$ fish in 2001

${ }^{\mathrm{C}}$ Migration year 2005 is incomplete until 3-salt returns (if any) occur after 7/1/2008 at GRA. 
Tables A-13 to A-20 present estimated $S_{\mathrm{R}}$ (in-river survival LGR to BON denoted as $\underline{V}_{\mathrm{C}}$ in prior CSS reports), TIR (ratio of $\mathrm{SAR}_{2}\left(\mathrm{~T}_{0}\right) / \mathrm{SAR}\left(\mathrm{C}_{0}\right)$, and $D$ parameters with associated $90 \%$ confidence interval for wild and hatchery $\mathrm{Chinook}$ and steelhead.

Table A-13. Estimated in-river survival LGR to BON $\left(S_{\mathrm{R}}\right)$, TIR, and $D$ of PIT-tagged wild Chinook for migration years 1994 to 2006 (with 90\% confidence intervals).

\begin{tabular}{|l|ll|ll|ll|}
\hline Mig. Year & \multicolumn{2}{|c|}{$\boldsymbol{S}_{\mathrm{R}}$} & \multicolumn{2}{c|}{ TIR } & \multicolumn{2}{c|}{$\boldsymbol{D}$} \\
\hline 1994 & $0.20^{\mathrm{A}}$ & $(0.17-0.22)$ & 1.62 & $(0.62-5.05)$ & 0.36 & $(0.13-1.09)$ \\
\hline 1995 & $0.41^{\mathrm{B}}$ & $(0.32-0.56)$ & 0.95 & $(0.39-2.14)$ & 0.42 & $(0.17-1.09)$ \\
\hline 1996 & $0.44^{\mathrm{A}}$ & $(0.35-0.55)$ & 1.92 & $(0.00-6.80)$ & 0.92 & $(0.00-3.24)$ \\
\hline 1997 & $0.51^{\mathrm{A}}$ & $(0.33-0.82)$ & 0.74 & $(0.17-1.58)$ & 0.40 & $(0.08-0.95)$ \\
\hline 1998 & $0.61^{\mathrm{C}}$ & $(0.54-0.69)$ & 0.87 & $(0.50-1.35)$ & 0.55 & $(0.31-0.87)$ \\
\hline 1999 & 0.59 & $(0.53-0.68)$ & 1.14 & $(0.82-1.51)$ & 0.72 & $(0.52-0.98)$ \\
\hline 2000 & 0.48 & $(0.41-0.58)$ & 0.60 & $(0.32-0.92)$ & 0.32 & $(0.17-0.51)$ \\
\hline 2002 & 0.61 & $(0.52-0.76)$ & 0.65 & $(0.45-0.94)$ & 0.44 & $(0.29-0.68)$ \\
\hline 2003 & 0.60 & $(0.52-0.69)$ & 1.05 & $(0.68-1.68)$ & 0.68 & $(0.43-1.12)$ \\
\hline 2004 & 0.40 & $(0.33-0.51)$ & 1.09 & $(0.68-2.19)$ & 0.45 & $(0.27-0.95)$ \\
\hline $2005^{\mathrm{D}}$ & 0.48 & $(0.39-0.61)$ & 2.14 & $(1.40-3.45)$ & 1.07 & $(0.65-1.85)$ \\
\hline $2006^{\mathrm{E}}$ & 0.57 & $(0.43-0.77)$ & 0.88 & $(0.60-1.35)$ & 0.54 & $(0.34-0.93)$ \\
\hline Geomean $^{\mathbf{0}}$ & $\mathbf{0 . 4 6}$ & & $\mathbf{1 . 0 7}$ & & $\mathbf{0 . 5 3}$ & \\
\hline $2001^{\mathrm{F}}$ & 0.23 & $(0.20-0.27)$ & 8.96 & $(3.61-16.8)$ & 2.16 & $(0.87-4.16)$ \\
\hline
\end{tabular}

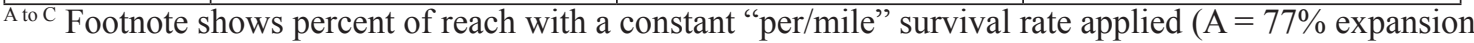
$\mathrm{LMN}$ to $\mathrm{BON}$; $\mathrm{B}=51 \%$ expansion $\mathrm{MCN}$ to $\mathrm{BON}$; $\mathrm{C}=25 \%$ expansion JDA to $\mathrm{BON}$ ).

${ }^{\mathrm{D}}$ In-river SAR is combination of groups $\mathrm{C}_{0}$ and $\mathrm{C}_{1}$ in derivation of TIR and D.

${ }^{\mathrm{E}}$ Migr. year 2006 data is combined groups TWS \& BWS; incomplete with 2-salt adult returns as of $8 / 13 / 2008$

${ }^{\mathrm{F}}$ For migration year 2001, the $\mathrm{SAR}\left(\mathrm{C}_{1}\right)$ value is used in the derivation of TIR and D.

Table A-14. Estimated in-river survival LGR to BON $\left(S_{\mathrm{R}}\right)$, TIR, and $D$ of PIT-tagged Rapid River Hatchery spring Chinook for 1997 to 2006 (with 90\% confidence intervals).

\begin{tabular}{|l|ll|ll|ll|}
\hline Mig. Year & \multicolumn{2}{|c|}{$\boldsymbol{S}_{\mathbf{R}}$} & \multicolumn{2}{c|}{ TIR } & \multicolumn{2}{c|}{$\boldsymbol{D}$} \\
\hline 1997 & $0.33^{\mathrm{A}}$ & $(0.24-0.45)$ & 1.73 & $(1.08-2.85)$ & 0.61 & $(0.37-1.09)$ \\
\hline 1998 & $0.59^{\mathrm{C}}$ & $(0.52-0.66)$ & 1.66 & $(1.32-2.16)$ & 1.01 & $(0.80-1.36)$ \\
\hline 1999 & 0.57 & $(0.49-0.67)$ & 1.28 & $(1.11-1.51)$ & 0.79 & $(0.65-0.99)$ \\
\hline 2000 & 0.58 & $(0.48-0.83)$ & 1.32 & $(1.13-1.55)$ & 0.82 & $(0.66-1.25)$ \\
\hline 2002 & 0.71 & $(0.60-0.84)$ & 1.5 & $(1.20-1.91)$ & 1.14 & $(0.87-1.52)$ \\
\hline 2003 & 0.66 & $(0.57-0.78)$ & 1.07 & $(0.73-1.58)$ & 0.75 & $(0.50-1.15)$ \\
\hline 2004 & 0.35 & $(0.27-0.51)$ & 1.57 & $(0.88-3.67)$ & 0.57 & $(0.31-1.46)$ \\
\hline $2005^{\mathrm{D}}$ & 0.54 & $(0.42-0.69)$ & 2.36 & $(1.59-3.79)$ & 1.31 & $(0.83-2.30)$ \\
\hline $2006^{\mathrm{E}}$ & $0.59^{\mathrm{C}}$ & $(0.56-0.63)$ & 1.25 & $(0.96-1.62)$ & 0.84 & $(0.63-1.08)$ \\
\hline Geomean $_{2001^{\mathrm{F}}}$ & $\mathbf{0 . 5 3}$ & & $\mathbf{1 . 4 9}$ & & $\mathbf{0 . 8 4}$ & \\
\hline
\end{tabular}

${ }_{\text {A to C }}$ Footnote shows percent of reach with a constant "per/mile" survival rate applied (A $=77 \%$ expansion $\mathrm{LMN}$ to $\mathrm{BON}$; $\mathrm{B}=51 \%$ expansion $\mathrm{MCN}$ to $\mathrm{BON}$; $\mathrm{C}=25 \%$ expansion JDA to $\mathrm{BON}$ ).

${ }^{D}$ In-river SAR is combination of groups $\mathrm{C}_{0}$ and $\mathrm{C}_{1}$ in derivation of TIR and D.

${ }^{\mathrm{E}}$ Migr. year 2006 data is combined groups TWS \& BWS; incomplete with 2-salt adult returns as of $8 / 13 / 2008$.

${ }^{\mathrm{F}}$ For migration year 2001, the $\mathrm{SAR}\left(\mathrm{C}_{1}\right)$ value is used in the derivation of TIR and D. 
Table A-15. Estimated in-river survival LGR to BON $\left(S_{\mathrm{R}}\right)$, TIR, and $D$ of PIT-tagged Dworshak Hatchery spr+ing Chinook for 1997 to 2006 (with 90\% confidence intervals).

\begin{tabular}{|c|c|c|c|c|c|c|}
\hline Mig. Year & \multicolumn{2}{|r|}{$S_{\mathrm{R}}$} & \multicolumn{2}{|r|}{ TIR } & \multicolumn{2}{|r|}{$D$} \\
\hline 1997 & $0.49^{\prime}$ & $(0.31-0.80)$ & 1.75 & $(0.92-3.46)$ & 0.88 & $(0.40-2.01)$ \\
\hline 1998 & 0.51 & $(0.44-0.58)$ & 0.72 & $(0.59-0.88)$ & 0.37 & $(0.30-0.47)$ \\
\hline 1999 & 0.54 & $(0.47-0.65)$ & 0.99 & $(0.81-1.24)$ & 0.60 & $(0.47-0.81)$ \\
\hline 2000 & 0.48 & $(0.40-0.65)$ & 0.99 & $(0.82-1.19)$ & 0.53 & $(0.42-0.75)$ \\
\hline 2002 & 0.62 & $(0.54-0.72)$ & 1.24 & $(0.93-1.61)$ & 0.84 & $(0.61-1.12)$ \\
\hline 2003 & 0.68 & $(0.58-0.81)$ & 1.21 & $(0.81-1.75)$ & 0.88 & $(0.58-1.37)$ \\
\hline 2004 & 0.50 & $(0.40-0.66)$ & 0.89 & $(0.59-1.43)$ & 0.46 & $(0.28-0.77)$ \\
\hline $2005^{D}$ & 0.51 & $(0.42-0.63)$ & 1.43 & $(0.97-2.17)$ & 0.77 & $(0.51-1.22)$ \\
\hline $2006^{\mathrm{E}}$ & 0.51 & $(0.48-0.54)$ & 0.87 & $(0.65-1.56)$ & 0.54 & $(0.40-0.72)$ \\
\hline Geomean & 0.53 & & 1.08 & & 0.63 & \\
\hline $2001^{\mathrm{F}}$ & 0.24 & $(0.20-0.30)$ & 8.76 & $(5.04-20.4)$ & 2.21 & $(1.23-5.30)$ \\
\hline
\end{tabular}

$\overline{\mathrm{A} \text { to } \mathrm{C}}$ Footnote shows percent of reach with a constant "per/mile" survival rate applied $(\mathrm{A}=77 \%$ expansion $\mathrm{LMN}$ to $\mathrm{BON}$; $\mathrm{B}=51 \%$ expansion $\mathrm{MCN}$ to $\mathrm{BON} ; \mathrm{C}=25 \%$ expansion JDA to $\mathrm{BON}$ ).

${ }^{D}$ In-river SAR is combination of groups $\mathrm{C}_{0}$ and $\mathrm{C}_{1}$ in derivation of TIR and D.

${ }^{\mathrm{E}}$ Migr. year 2006 data is combined groups TWS \& BWS; incomplete with 2-salt adult returns as of $8 / 13 / 2008$

${ }^{\mathrm{F}}$ For migration year 2001, the $\mathrm{SAR}\left(\mathrm{C}_{1}\right)$ value is used in the derivation of TIR and D.

Table A-16. Estimated in-river survival LGR to BON $\left(S_{\mathrm{R}}\right)$, TIR, and $D$ of PIT-tagged Catherine Creek AP spring Chinook for 2001 to 2006 (with 90\% confidence intervals).

\begin{tabular}{|l|ll|ll|ll|}
\hline Mig. Year & \multicolumn{2}{|c|}{$\boldsymbol{S}_{\mathrm{R}}$} & \multicolumn{2}{c|}{ TIR } & \multicolumn{2}{c|}{$\boldsymbol{D}$} \\
\hline 2002 & 0.65 & $(0.44-1.06)$ & 1.81 & $(1.02-3.43)$ & 1.23 & $(0.59-2.79)$ \\
\hline 2003 & $0.62^{\mathrm{C}}$ & $(0.51-0.74)$ & 1.45 & $(0.65-3.79)$ & 0.94 & $(0.41-2.53)$ \\
\hline 2004 & $0.48^{\mathrm{C}}$ & $(0.34-0.72)$ & 1.94 & $(0.0-2.57)$ & 0.95 & $(0.0-1.33)$ \\
\hline $2005^{\mathrm{D}}$ & $0.51^{\mathrm{C}}$ & $(0.27-0.73)$ & 2.48 & $(1.02-10.6)$ & 1.32 & $(0.50-5.9)$ \\
\hline $2006^{\mathrm{E}}$ & $0.48^{\mathrm{C}}$ & $(0.38-0.61)$ & 0.45 & $(0.21-0.84)$ & 0.23 & $(0.11-0.47)$ \\
\hline Geomean & $\mathbf{0 . 5 4}$ & & $\mathbf{1 . 4 2}$ & & $\mathbf{0 . 8 0}$ & \\
\hline $2001^{\mathrm{F}}$ & 0.25 & $(0.18-0.37)$ & 5.33 & $(0.0-13.6)$ & 1.38 & $(0.03-3.79)$ \\
\hline
\end{tabular}

$\overline{\mathrm{A} \text { to } \mathrm{C}}$ Footnote shows percent of reach with a constant "per/mile" survival rate applied $(\mathrm{A}=77 \%$ expansion

$\mathrm{LMN}$ to $\mathrm{BON}$; $\mathrm{B}=51 \%$ expansion $\mathrm{MCN}$ to $\mathrm{BON}$; $\mathrm{C}=25 \%$ expansion JDA to $\mathrm{BON}$ ).

${ }^{D}$ In-river SAR is combination of groups $\mathrm{C}_{0}$ and $\mathrm{C}_{1}$ in derivation of TIR and D.

${ }^{\mathrm{E}}$ Migr. year 2006 data is combined groups TWS \& BWS; incomplete with 2-salt adult returns as of $8 / 13 / 2008$.

${ }^{\mathrm{F}}$ For migration year 2001, the $\mathrm{SAR}\left(\mathrm{C}_{1}\right)$ value is used in the derivation of TIR and D.

Table A-17. Estimated in-river survival LGR to BON $\left(S_{\mathrm{R}}\right)$, TIR, and $D$ of PIT-tagged McCall Hatchery summer Chinook for 1997 to 2006 (with 90\% confidence intervals).

\begin{tabular}{|l|ll|ll|ll|}
\hline Mig. Year & \multicolumn{3}{|c|}{$\boldsymbol{S}_{\mathbf{R}}$} & \multicolumn{2}{c|}{ TIR } & \multicolumn{2}{c|}{$\boldsymbol{D}$} \\
\hline 1997 & $0.43^{\mathrm{A}}$ & $(0.32-0.59)$ & 1.38 & $(1.06-1.80)$ & 0.64 & $(0.43-0.93)$ \\
\hline 1998 & $0.56^{\mathrm{C}}$ & $(0.50-0.64)$ & 1.96 & $(1.54-2.56)$ & 1.16 & $(0.89-1.54)$ \\
\hline 1999 & 0.52 & $(0.46-0.61)$ & 1.49 & $(1.29-1.73)$ & 0.87 & $(0.72-1.07)$ \\
\hline 2000 & 0.61 & $(0.51-0.83)$ & 1.89 & $(1.67-2.15)$ & 1.24 & $(0.98-1.81)$ \\
\hline 2002 & 0.58 & $(0.51-0.68)$ & 1.44 & $(1.18-1.79)$ & 0.87 & $(0.68-1.14)$ \\
\hline 2003 & 0.70 & $(0.62-0.77)$ & 1.47 & $(1.18-1.83)$ & 1.09 & $(0.85-1.37)$ \\
\hline 2004 & 0.44 & $(0.35-0.59)$ & 1.59 & $(0.87-4.37)$ & 0.72 & $(0.37-1.95)$ \\
\hline $2005^{\mathrm{D}}$ & 0.53 & $(0.45-0.65)$ & 3.02 & $(2.32-4.12)$ & 1.66 & $(1.23-2.36)$ \\
\hline $2006^{\mathrm{E}}$ & $0.60^{\mathrm{C}}$ & $(0.53-0.67)$ & 1.11 & $(0.89-1.41)$ & 0.74 & $(0.59-0.96)$ \\
\hline Geomean & $\mathbf{0 . 5 5}$ & & $\mathbf{1 . 6 4}$ & & $\mathbf{0 . 9 6}$ & \\
\hline $2001^{\mathrm{F}}$ & 0.27 & $(0.22-0.34)$ & 31.9 & $(17.9-88.4)$ & 8.95 & $(4.87-24.1)$ \\
\hline
\end{tabular}

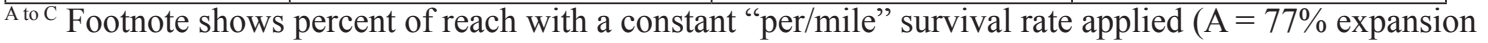
$\mathrm{LMN}$ to $\mathrm{BON}$; $\mathrm{B}=51 \%$ expansion $\mathrm{MCN}$ to $\mathrm{BON}$; $\mathrm{C}=25 \%$ expansion JDA to $\mathrm{BON}$ ).

${ }^{\mathrm{D}}$ In-river SAR is combination of groups $\mathrm{C}_{0}$ and $\mathrm{C}_{1}$ in derivation of TIR and D.

${ }^{\mathrm{E}}$ Migr. year 2006 data is combined groups TWS \& BWS; incomplete with 2-salt adult returns as of $8 / 13 / 2008$

${ }^{\mathrm{F}}$ For migration year 2001, the $\operatorname{SAR}\left(\mathrm{C}_{1}\right)$ value is used in the derivation of TIR and D. 
Table A-18. Estimated in-river survival LGR to BON $\left(S_{R}\right)$, TIR, and $D$ of of PIT-tagged Imnaha AP summer Chinook for 1997 to 2006 (with $90 \%$ confidence intervals).

\begin{tabular}{|c|c|c|c|c|c|c|}
\hline Mig. Year & 031 & $S_{\text {B }}$ & & TIR & & D \\
\hline 1998 & 0.53 & $\frac{(0.20-0.49)}{(0.46-0.62)}$ & $\frac{1.50}{1.55}$ & $\frac{(0.03-2.5)}{(0.93-3.15)}$ & $\begin{array}{l}0.45 \\
0.87\end{array}$ & $\frac{(0.24-0.92)}{(0.51-1.72)}$ \\
\hline 1999 & 0.54 & $(0.42-0.75)$ & 1.89 & $(1.40-2.51)$ & 1.11 & $(0.75-1.72)$ \\
\hline 2000 & 0.57 & $(0.43-0.83)$ & 1.29 & $(1.06-1.58)$ & 0.82 & $(0.56-1.25)$ \\
\hline 2002 & 0.50 & $(0.41-0.66)$ & 1.75 & $(1.07-3.03)$ & 0.95 & $(0.54-1.78)$ \\
\hline 2003 & 0.70 & $(0.62-0.80)$ & 1.21 & $(0.80-1.86)$ & 0.91 & $(0.57-1.41)$ \\
\hline 2004 & 0.56 & $(0.44-0.73)$ & 1.64 & $(0.54-5.32)$ & 0.94 & $(0.27-3.14)$ \\
\hline $2005^{D}$ & 0.58 & $(0.47-0.78)$ & 1.77 & $(0.91-3.93)$ & 1.11 & $(0.54-2.69)$ \\
\hline $2006^{\mathrm{E}}$ & 0.50 & $(0.43-0.59)$ & 0.64 & $(0.43-0.98)$ & 0.37 & $(0.25-0.59)$ \\
\hline Geomean & 0.52 & & 1.40 & & 0.79 & \\
\hline $2001^{\mathrm{F}}$ & 0.37 & $(0.27-0.61)$ & 10.8 & $(4.94-39.8)$ & 4.15 & $(1.83-15.3)$ \\
\hline
\end{tabular}

${ }_{\text {A to C }}$ Footnote shows percent of reach with a constant "per/mile" survival rate applied (A $=77 \%$ expansion $\mathrm{LMN}$ to $\mathrm{BON}$; $\mathrm{B}=51 \%$ expansion $\mathrm{MCN}$ to $\mathrm{BON}$; $\mathrm{C}=25 \%$ expansion JDA to $\mathrm{BON}$ ).

${ }^{D}$ In-river SAR is combination of groups $\mathrm{C}_{0}$ and $\mathrm{C}_{1}$ in derivation of TIR and D.

${ }^{\mathrm{E}}$ Migr. year 2006 data is combined groups TWS \& BWS; incomplete with 2-salt adult returns as of $8 / 13 / 2008$.

${ }^{\mathrm{F}}$ For migration year 2001, the $\mathrm{SAR}\left(\mathrm{C}_{1}\right)$ value is used in the derivation of TIR and D.

Table A-19. Estimated in-river survival LGR to BON $\left(S_{\mathrm{R}}\right)$, TIR, and $D$ of PIT-tagged wild steelhead for migration years 1997 to 2005 (with $90 \%$ confidence intervals).

\begin{tabular}{|c|c|c|c|c|c|c|}
\hline Mig. Year & \multicolumn{2}{|r|}{$S_{\mathrm{R}}$} & \multicolumn{2}{|r|}{ TIR } & \multicolumn{2}{|r|}{$D$} \\
\hline 1997 & 0.52 & $(0.28-1)$ & 2.20 & $(0.0-8.16)$ & 1.18 & $(0.0-5.74)$ \\
\hline 1998 & 0.54 & $(0.48-0.62)$ & 0.20 & $(0.0-0.70)$ & 0.11 & $(0.0-0.41)$ \\
\hline 1999 & 0.45 & $(0.38-0.54)$ & 2.28 & $(1.15-4.38)$ & 1.07 & $(0.53-2.09)$ \\
\hline 2000 & $0.30^{\mathrm{c}}$ & $(0.28-0.33)$ & 1.45 & $(0.77-2.40)$ & 0.50 & $(0.27-0.82)$ \\
\hline 2002 & 0.52 & $(0.41-0.69)$ & 4.25 & $(2.12-7.67)$ & 2.24 & $(1.09-4.25)$ \\
\hline 2003 & 0.37 & $(0.31-0.44)$ & 4.41 & $(2.74-7.73)$ & 1.75 & $(1.04-3.16)$ \\
\hline $2004^{\mathrm{D}}$ & 0.18 & $(0.13-0.26)$ & 14.3 & $(7.2-42.1)$ & 2.69 & $(1.29-8.78)$ \\
\hline $2005^{\mathrm{DE}}$ & $0.27^{\mathrm{c}}$ & $(0.21-0.35)$ & 4.55 & $(2.89-7.61)$ & 1.26 & $(0.77-2.30)$ \\
\hline Geomean & 0.37 & & 2.55 & & 0.99 & \\
\hline $2001^{\mathrm{F}}$ & 0.038 & $(0.027-0.059$ & 37.0 & $(10.6-94.6)$ & 1.46 & $(0.40-4.40)$ \\
\hline
\end{tabular}

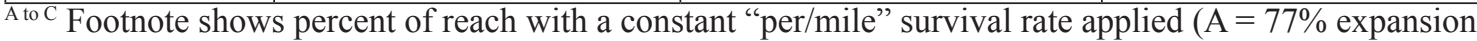
$\mathrm{LMN}$ to $\mathrm{BON} ; \mathrm{B}=51 \%$ expansion $\mathrm{MCN}$ to $\mathrm{BON}$; $\mathrm{C}=25 \%$ expansion JDA to $\mathrm{BON}$ ).

${ }^{D}$ In-river SAR is combination of groups $\mathrm{C}_{0}$ and $\mathrm{C}_{1}$ in derivation of TIR and D.

${ }^{\mathrm{E}}$ Migration year 2005 is incomplete until 3-salt returns (if any) occur after 7/1/2008 at GRA.

${ }^{\mathrm{F}}$ For migration year 2001, the $\mathrm{SAR}\left(\mathrm{C}_{1}\right)$ value is used in the derivation of TIR and D.

Table A-20. Estimated in-river survival LGR to BON $\left(S_{\mathrm{R}}\right)$, TIR, and $D$ of PIT-tagged hatchery steelhead for migration years 1997 to 2005 (with $90 \%$ confidence intervals).

\begin{tabular}{|l|ll|ll|ll|}
\hline Mig. Year & \multicolumn{2}{|c|}{$\boldsymbol{S}_{\mathbf{R}}$} & \multicolumn{2}{c|}{ TIR } & \multicolumn{2}{c|}{ D } \\
\hline 1997 & $0.40^{\mathrm{C}}$ & $(0.26-0.71)$ & 2.21 & $(0.99-5.66)$ & 0.92 & $(0.36-2.67)$ \\
\hline 1998 & 0.64 & $(0.47-1)$ & 0.58 & $(0.23-1.05)$ & 0.39 & $(0.16-0.85)$ \\
\hline 1999 & 0.45 & $(0.39-0.53)$ & 0.87 & $(0.48-1.41)$ & 0.41 & $(0.22-0.70)$ \\
\hline 2000 & $0.22^{\mathrm{C}}$ & $(0.19-0.25)$ & 2.20 & $(1.22-3.58)$ & 0.55 & $(0.30-0.93)$ \\
\hline 2002 & 0.37 & $(0.29-0.49)$ & 1.51 & $(0.38-3.33)$ & 0.60 & $(0.14-1.38)$ \\
\hline 2003 & 0.51 & $(0.42-0.61)$ & 2.65 & $(1.93-3.71)$ & 1.43 & $(0.99-2.10)$ \\
\hline $2004^{\mathrm{D}}$ & $0.17^{\mathrm{B}}$ & $(0.13-0.23)$ & 10.3 & $(5.4-17.9)$ & 1.85 & $(0.91-3.46)$ \\
\hline $2005^{\mathrm{DE}}$ & $0.36^{\mathrm{C}}$ & $(0.30-0.46)$ & 8.44 & $(5.04-13.41)$ & 3.19 & $(1.86-5.37)$ \\
\hline Geomean $_{2001^{\mathrm{F}}}$ & $\mathbf{0 . 3 6}$ & & $\mathbf{2 . 3 2}$ & & $\mathbf{0 . 8 9}$ & \\
\hline
\end{tabular}

A to C Footnote shows percent of reach with a constant "per/mile" survival rate applied $(\mathrm{A}=77 \%$ expansion $\mathrm{LMN}$ to $\mathrm{BON} ; \mathrm{B}=51 \%$ expansion $\mathrm{MCN}$ to $\mathrm{BON}$; $\mathrm{C}=25 \%$ expansion JDA to $\mathrm{BON}$ ).

${ }^{D}$ In-river SAR is combination of groups $\mathrm{C}_{0}$ and $\mathrm{C}_{1}$ in derivation of TIR and $\mathrm{D}$.

${ }^{\mathrm{E}}$ Migration year 2005 is incomplete until 3-salt returns (if any) occur after 7/1/2008 at GRA.

${ }^{\mathrm{F}}$ For migration year 2001, the $\mathrm{SAR}\left(\mathrm{C}_{1}\right)$ value is used in the derivation of TIR and D. 
Tables A-21 to A-28 present annual reach survival rates estimated with CJS method for PIT-tagged wild and hatchery Chinook and steelhead

Table A-21. In-river smolt survival rate estimates through hydrosystem for the PIT-tag aggregate of wild spring/summer Chinook in migration years 1994 to 2006.

\begin{tabular}{|c|c|c|c|c|}
\hline $\begin{array}{l}\text { Migr } \\
\text { Year }\end{array}$ & $\begin{array}{l}\text { Reach of } \\
\text { Survival }\end{array}$ & $\begin{array}{l}\text { Survival } \\
\text { Estimate }\end{array}$ & $\begin{array}{l}95 \% \text { CI } \\
\text { Lower Limit }\end{array}$ & $\begin{array}{l}95 \% \text { CI } \\
\text { Upper Limit }\end{array}$ \\
\hline 1994 & $\begin{array}{l}\text { S2 (lgr-lgs) } \\
\text { S3 (lgs-lmn) }\end{array}$ & $\begin{array}{l}0.822 \\
0.836\end{array}$ & $\begin{array}{l}0.796 \\
0.807\end{array}$ & $\begin{array}{l}0.846 \\
0.866\end{array}$ \\
\hline 1995 & $\begin{array}{l}\text { S2 (lgr-lgs) } \\
\text { S3 (lgs-lmn) } \\
\text { S4 (lmn-men) }\end{array}$ & $\begin{array}{l}0.895 \\
0.951 \\
0.764 \\
\end{array}$ & $\begin{array}{l}0.880 \\
0.924 \\
0.659\end{array}$ & $\begin{array}{l}0.800 \\
0.911 \\
0.978 \\
0.923\end{array}$ \\
\hline 1996 & $\begin{array}{l}\text { S2 (lgr-lgs) } \\
\text { S3 (lgs-lmn) }\end{array}$ & $\begin{array}{l}0.908 \\
0.911\end{array}$ & $\begin{array}{l}0.069 \\
0.850\end{array}$ & $\begin{array}{l}0.923 \\
0.946 \\
0.977\end{array}$ \\
\hline 1997 & $\begin{array}{l}\text { S2 (lgr-lgs) } \\
\text { S3 (lgs-lmn) }\end{array}$ & $\begin{array}{l}0.922 \\
0.931 \\
\end{array}$ & $\begin{array}{l}0.859 \\
0.822 \\
\end{array}$ & $\begin{array}{l}0.990 \\
1.057\end{array}$ \\
\hline 1998 & $\begin{array}{l}\text { S2 (lgr-lgs) } \\
\text { S3 (lgs-lmn) } \\
\text { S4 (lmn-mcn) } \\
\text { S5 (mcn-ida) }\end{array}$ & $\begin{array}{l}1.003 \\
0.850 \\
0.940 \\
0.854\end{array}$ & $\begin{array}{l}0.986 \\
0.824 \\
0.889 \\
0.763\end{array}$ & $\begin{array}{l}1.021 \\
0.874 \\
0.993 \\
0.965\end{array}$ \\
\hline 1999 & $\begin{array}{l}\text { S2 (lgr-lgs) } \\
\text { S3 (lgs-lmn) } \\
\text { S4 (lmn-mcn) } \\
\text { S5 (mcn-jda) } \\
\text { S6 (ida-bon) }\end{array}$ & $\begin{array}{l}0.958 \\
0.924 \\
0.889 \\
0.889 \\
0.845\end{array}$ & $\begin{array}{l}0.948 \\
0.914 \\
0.869 \\
0.854 \\
0.734\end{array}$ & $\begin{array}{l}0.967 \\
0.934 \\
0.908 \\
0.927 \\
1.000\end{array}$ \\
\hline 2000 & $\begin{array}{l}\text { S2 (lgr-lgs) } \\
\text { S3 (lgs-lmn) } \\
\text { S4 (lmn-mcn) } \\
\text { S5 (mcn-jda) } \\
\text { S6 (ida-bon) }\end{array}$ & $\begin{array}{l}0.897 \\
0.868 \\
0.977 \\
0.734 \\
0.866 \\
\end{array}$ & $\begin{array}{l}0.880 \\
0.842 \\
0.934 \\
0.674 \\
0.708 \\
\end{array}$ & $\begin{array}{l}0.915 \\
0.893 \\
1.022 \\
0.804 \\
1.097 \\
\end{array}$ \\
\hline 2001 & $\begin{array}{l}\text { S2 (lgr-lgs) } \\
\text { S3 (lgs-lmn) } \\
\text { S4 (lmn-mcn) } \\
\text { S5 (mcn-jda) } \\
\text { S6 (ida-hon) }\end{array}$ & $\begin{array}{l}0.930 \\
0.772 \\
0.684 \\
0.714 \\
0.663\end{array}$ & $\begin{array}{l}0.925 \\
0.762 \\
0.670 \\
0.669 \\
0.553\end{array}$ & $\begin{array}{l}0.936 \\
0.782 \\
0.698 \\
0.763 \\
0.827\end{array}$ \\
\hline 2002 & $\begin{array}{l}\text { S2 (lgr-lgs) } \\
\text { S3 (lgs-lmn) } \\
\text { S4 (lmn-mcn) } \\
\text { S5 (mcn-jda) } \\
\text { S6 (ida-bon) }\end{array}$ & $\begin{array}{l}0.901 \\
0.996 \\
0.810 \\
0.873 \\
0.967\end{array}$ & $\begin{array}{l}0.883 \\
0.975 \\
0.785 \\
0.826 \\
0.780\end{array}$ & $\begin{array}{l}0.920 \\
1.016 \\
0.837 \\
0.927 \\
1.268\end{array}$ \\
\hline 2003 & $\begin{array}{l}\text { S2 (lgr-lgs) } \\
\text { S3 (lgs-lmn) } \\
\text { S4 (lmn-mcn) } \\
\text { S5 (mcn-jda) } \\
\text { S6 (ida-bon) }\end{array}$ & $\begin{array}{l}0.893 \\
0.878 \\
0.990 \\
0.798 \\
0.962\end{array}$ & $\begin{array}{l}0.877 \\
0.850 \\
0.954 \\
0.754 \\
0.822 \\
\end{array}$ & $\begin{array}{l}0.911 \\
0.908 \\
1.023 \\
0.841 \\
1.159\end{array}$ \\
\hline
\end{tabular}

Table continued on next page. 
Table A-21. Continued (Spring/Summer Wild Chinook).

\begin{tabular}{|l|l|l|l|l|}
\hline $\begin{array}{c}\text { Migr } \\
\text { Year }\end{array}$ & Reach of Survival & $\begin{array}{l}\text { Survival } \\
\text { Estimate }\end{array}$ & $\begin{array}{l}\text { 95\% CI } \\
\text { Lower Limit }\end{array}$ & $\begin{array}{l}\text { 95\% CI } \\
\text { Upper Limit }\end{array}$ \\
\hline 2004 & S2 (lgr-lgs) & 0.970 & 0.961 & 0.980 \\
& S3 (lgs-lmn) & 0.830 & 0.810 & 0.850 \\
& S4 (lmn-mcn) & 0.878 & 0.838 & 0.921 \\
& S5 (mcn-jda) & 0.744 & 0.667 & 0.848 \\
& S6 (jda-bon) & 0.756 & 0.579 & 1.006 \\
\hline 2005 & S2 (lgr-lgs) & 0.905 & 0.898 & 0.913 \\
& S3 (lgs-lmn) & 0.890 & 0.873 & 0.931 \\
& S4 (lmn-mcn) & 0.895 & 0.859 & 0.854 \\
& S5 (mcn-jda) & 0.766 & 0.696 & 1.192 \\
\hline 2006 & S6 (jda-bon) & 0.862 & 0.660 & 0.955 \\
& S2 (lgr-lgs) & 0.938 & 0.920 & 0.922 \\
& S3 (lgs-lmn) & 0.933 & 0.909 & 1.024 \\
& S4 (lmn-mcn) & 0.880 & 0.840 & 1.153 \\
\hline
\end{tabular}

Table A-22. In-river smolt survival rate estimates from hatchery to LGR and through reaches in the hydrosystem for PIT-tagged Rapid River Hatchery spring Chinook in migration years 1997 to 2006.

\begin{tabular}{|c|c|c|c|c|}
\hline $\begin{array}{l}\text { Migr } \\
\text { Year }\end{array}$ & $\begin{array}{l}\text { Reach of } \\
\text { Survival }\end{array}$ & $\begin{array}{l}\text { Survival } \\
\text { Estimate }\end{array}$ & $\begin{array}{l}95 \% \mathrm{CI} \\
\text { Lower Limit }\end{array}$ & $\begin{array}{l}95 \% \text { CI } \\
\text { Upper Limit }\end{array}$ \\
\hline \multirow{3}{*}{1997} & S1 (rel-lgr) & 0.390 & 0.376 & 0.406 \\
\hline & S2 (lgr-lgs) & 0.964 & 0.903 & 1.027 \\
\hline & S3 (lgs-lmn) & 0.803 & 0.746 & 0.867 \\
\hline \multirow[t]{5}{*}{1998} & S1 (rel-lgr) & 0.665 & 0.658 & 0.672 \\
\hline & S2 (lgr-lgs) & 1.005 & 0.986 & 1.024 \\
\hline & S3 (lgs-lmn) & 0.847 & 0.826 & 0.869 \\
\hline & S4 (lmn-mcn) & 0.982 & 0.924 & 1.045 \\
\hline & S5 (mcn-jda) & 0.798 & 0.713 & 0.897 \\
\hline \multirow[t]{6}{*}{1999} & S1 (rel-lgr) & 0.751 & 0.738 & 0.765 \\
\hline & S2 (lgr-lgs) & 0.923 & 0.901 & 0.943 \\
\hline & S3 (lgs-lmn) & 0.957 & 0.937 & 0.977 \\
\hline & S4 (lmn-mcn) & 0.906 & 0.875 & 0.939 \\
\hline & S5 (mcn-jda) & 0.945 & 0.882 & 1.022 \\
\hline & S6 (jda-bon) & 0.750 & 0.622 & 0.923 \\
\hline \multirow[t]{6}{*}{2000} & SI (rel-lgr) & 0.737 & 0.724 & 0.752 \\
\hline & S2 (lgr-lgs) & 0.846 & 0.813 & 0.882 \\
\hline & S3 (lgs-lmn) & 1.127 & 1.016 & 1.255 \\
\hline & S4 (lmn-men) & 0.823 & 0.721 & 0.937 \\
\hline & S5 (mcn-jda) & 0.945 & 0.760 & 1.250 \\
\hline & S6 (jda-bon) & 0.782 & 0.546 & 1.171 \\
\hline \multirow[t]{6}{*}{2001} & S1 (rel-lgr) & 0.690 & 0.686 & 0.694 \\
\hline & S2 (lgr-lgs) & 0.958 & 0.951 & 0.965 \\
\hline & S3 (lgs-lmn) & 0.856 & 0.843 & 0.867 \\
\hline & S4 (lmn-men) & 0.698 & 0.683 & 0.715 \\
\hline & S5 (mcn-jda) & 0.924 & 0.854 & 1.013 \\
\hline & S6 (jda-bon) & 0.618 & 0.497 & 0.802 \\
\hline \multirow[t]{6}{*}{2002} & S1 (rel-lgr) & 0.755 & 0.741 & 0.769 \\
\hline & S2 (lgr-lgs) & 0.947 & 0.923 & 0.972 \\
\hline & S3 (lgs-lmn) & 0.981 & 0.959 & 1.004 \\
\hline & S4 (lmn-men) & 0.841 & 0.819 & 0.863 \\
\hline & S5 (mcn-jda) & 0.953 & 0.895 & 1.018 \\
\hline & $\frac{\text { S6 (jda-bon) }}{\text { S1 (rel-lgr) }}$ & $\frac{0.951}{0.692}$ & $\frac{0.770}{0.679}$ & $\frac{1.191}{0.705}$ \\
\hline \multirow{5}{*}{2003} & S2 $(\lg -\operatorname{lgs})$ & 0.916 & 0.883 & 0.952 \\
\hline & S3 (lgs-lmn) & 0.875 & 0.808 & 0.945 \\
\hline & S4 (lmn-mcn) & 0.964 & 0.890 & 1.045 \\
\hline & S5 (mcn-jda) & 0.902 & 0.833 & 0.977 \\
\hline & S6 (jda-bon) & 0.947 & 0.779 & 1.207 \\
\hline
\end{tabular}

Table continued next page. 
Table A-22. Continued (Rapid River Hatchery Spring Chinook).

\begin{tabular}{|l|l|l|l|l|}
\hline $\begin{array}{l}\text { Migr } \\
\text { Year }\end{array}$ & Reach of Survival & $\begin{array}{l}\text { Survival } \\
\text { Estimate }\end{array}$ & $\begin{array}{l}\text { 95\% CI } \\
\text { Lower Limit }\end{array}$ & $\begin{array}{l}\text { 95\% CI } \\
\text { Upper Limit }\end{array}$ \\
\hline 2004 & S1 (rel-lgr) & 0.696 & 0.691 & 0.701 \\
& S2 (lgr-lgs) & 0.999 & 0.985 & 1.014 \\
& S3 (lgs-lmn) & 0.754 & 0.708 & 0.802 \\
& S4 (lmn-mcn) & 0.880 & 0.810 & 0.950 \\
& S5 (mcn-jda) & 0.766 & 0.659 & 0.893 \\
& S6 (ja-bon) & 0.696 & 0.477 & 1.113 \\
\hline 2005 & S1 (rel-lgr) & 0.736 & 0.731 & 0.740 \\
& S2 (lgr-lgs) & 0.947 & 0.937 & 0.955 \\
& S3 (lgs-lmn) & 0.907 & 0.883 & 0.935 \\
& S4 (lmn-mcn) & 0.896 & 0.845 & 0.941 \\
& S5 (mcn-jda) & 0.887 & 0.779 & 1.021 \\
& S6 (jda-bon) & 0.784 & 0.583 & 1.106 \\
\hline 2006 & S1 (rel-lgr) & 0.774 & 0.767 & 0.781 \\
& S2 (lgr-lgs) & 0.857 & 0.846 & 0.869 \\
& S3 (lgs-lmn) & 0.934 & 0.918 & 0.949 \\
& S4 (lmn-mcn) & 0.940 & 0.910 & 0.969 \\
& S5 (mcn-jda) & 0.896 & 0.841 & 0.953 \\
\hline
\end{tabular}

Table A-23. In-river smolt survival rate estimates from hatchery to LGR and through reaches in the hydrosystem for PIT-tagged Dworshak Hatchery spring Chinook in migration years 1997 to 2006.

\begin{tabular}{|c|c|c|c|c|}
\hline Migr & Reach of & Survival & $95 \% \mathrm{CI}$ & $95 \% \mathrm{CI}$ \\
\hline \multirow{4}{*}{$\frac{\text { Year }}{1997}$} & Survival & Estimate & Lower Limit & Upper Limit \\
\hline & S1 (rel-lgr) & 0.581 & 0.547 & 0.613 \\
\hline & S2 (lgr-lgs) & 1.047 & 0.959 & 1.148 \\
\hline & S3 (lgs-lmn) & 0.810 & 0.725 & 0.908 \\
\hline \multirow{5}{*}{1998} & S1 (rèl-lgr) & 0.843 & 0.832 & 0.855 \\
\hline & S2 (lgr-lgs) & 1.071 & 1.043 & 1.098 \\
\hline & S3 (lgs-lmn) & 0.765 & 0.740 & 0.790 \\
\hline & S4 (lmn-men) & 0.931 & 0.891 & 0.976 \\
\hline & S5 (mcn-jda) & 0.782 & 0.696 & 0.891 \\
\hline \multirow[t]{6}{*}{1999} & S1 (rel-lgr) & 0.853 & 0.832 & 0.873 \\
\hline & S2 $(\lg r-\lg s)$ & 0.887 & 0.862 & 0.914 \\
\hline & S3 (lgs-lmn) & 0.952 & 0.935 & 0.968 \\
\hline & S4 (lmn-men) & 0.875 & 0.848 & 0.901 \\
\hline & S5 (mcn-jda) & 0.899 & 0.849 & 0.959 \\
\hline & S6 (jda-bon) & 0.816 & 0.684 & 1.010 \\
\hline \multirow[t]{6}{*}{2000} & S1 (rel-lgr) & 0.825 & 0.809 & 0.843 \\
\hline & S2 (lgr-lgs) & 0.807 & 0.777 & 0.839 \\
\hline & S3 (lgs-lmn) & 1.036 & 0.955 & 1.124 \\
\hline & S4 (lmn-men) & 0.834 & 0.754 & 0.920 \\
\hline & S5 (mcn-jda) & 0.944 & 0.804 & 1.145 \\
\hline & S6 (jda-bon) & 0.730 & 0.543 & 1.007 \\
\hline \multirow[t]{6}{*}{2001} & S1 (rel-lgr) & 0.748 & 0.744 & 0.752 \\
\hline & S2 (lgr-lgs) & 0.941 & 0.934 & 0.947 \\
\hline & S3 (lgs-lmn) & 0.839 & 0.828 & 0.849 \\
\hline & S4 (lmn-mcn) & 0.694 & 0.681 & 0.707 \\
\hline & S5 (mcn-jda) & 0.693 & 0.654 & 0.739 \\
\hline & S6 (ida-bon) & 0.636 & 0.510 & 0.839 \\
\hline \multirow[t]{6}{*}{2002} & S1 (rel-lgr) & 0.827 & 0.803 & 0.849 \\
\hline & S2 $(\operatorname{lgr}-\lg s)$ & 0.917 & 0.884 & 0.953 \\
\hline & S3 (lgs-lmn) & 0.978 & 0.950 & 1.007 \\
\hline & S4 (lmn-men) & 0.810 & 0.787 & 0.834 \\
\hline & S5 (mcn-jda) & 0.931 & 0.877 & 0.995 \\
\hline & $\begin{array}{l}\text { S6 (ida-bon) } \\
\text { S1 (rel-|lor) }\end{array}$ & $\frac{0.910}{0.706}$ & $\frac{0.758}{0.692}$ & 1.086 \\
\hline \multirow{5}{*}{2003} & S2 $(\lg r-\operatorname{lgs})$ & 0.905 & 0.875 & 0.937 \\
\hline & S3 (lgs-lmn) & 0.897 & 0.855 & 0.946 \\
\hline & S4 (lmn-mcn) & 0.983 & 0.931 & 1.031 \\
\hline & S5 (mcn-jda) & 0.856 & 0.807 & 0.910 \\
\hline & S6 (jda-bon) & 0.990 & 0.825 & 1.235 \\
\hline
\end{tabular}

Table continued on next page. 
Table A-23. Continued (Dworshak Hatchery Spring Chinook).

\begin{tabular}{|l|l|l|l|l|}
\hline $\begin{array}{l}\text { Migr } \\
\text { Year }\end{array}$ & Reach of Survival & $\begin{array}{l}\text { Survival } \\
\text { Estimate }\end{array}$ & $\begin{array}{l}\text { 95\% CI } \\
\text { Lower Limit }\end{array}$ & $\begin{array}{l}\text { 95\% CI } \\
\text { Upper Limit }\end{array}$ \\
\hline 2004 & S1 (rel-lgr) & 0.823 & 0.817 & 0.830 \\
& S2 (lgr-lgs) & 0.977 & 0.964 & 0.991 \\
& S3 (lgs-lmn) & 0.969 & 0.911 & 1.024 \\
& S4 (lmn-mcn) & 0.779 & 0.726 & 0.839 \\
& S5 (mcn-jda) & 0.790 & 0.699 & 0.917 \\
& S6 (jda-bon) & 0.858 & 0.642 & 1.217 \\
\hline 2005 & S1 (rel-lgr) & 0.831 & 0.826 & 0.836 \\
& S2 (lgr-lgs) & 0.927 & 0.917 & 0.936 \\
& S3 (lgs-lmn) & 0.893 & 0.870 & 0.918 \\
& S4 (lmn-mcn) & 0.967 & 0.920 & 1.012 \\
& S5 (mcn-jda) & 0.837 & 0.728 & 0.962 \\
& S6 (jda-bon) & 0.759 & 0.587 & 1.032 \\
\hline 2006 & S1 (rel-lgr) & 0.844 & 0.832 & 0.857 \\
& S2 (lgr-lgs) & 0.825 & 0.809 & 0.840 \\
& S3 (lgs-lmn) & 0.923 & 0.905 & 0.940 \\
& S4 (lmn-mcn) & 0.869 & 0.841 & 0.897 \\
& S5 (mcn-jda) & 0.914 & 0.862 & 0.968 \\
\hline
\end{tabular}

Table A-24. In-river smolt survival rate estimates from hatchery to LGR and through reaches in the hydrosystem for PIT-tagged Catherine Creek Acclimation Pond spring Chinook in migration years 2001 to 2006.

\begin{tabular}{|l|l|l|l|l|}
\hline Migr & Reach of & Survival & $\mathbf{9 5 \%}$ CI & $\mathbf{9 5 \% ~ C I ~}$ \\
Year & Survival & Estimate & Lower Limit & Upper Limit \\
\hline 2001 & S1 (rel-lgr) & 0.520 & 0.513 & 0.528 \\
& S2 (lgr-lgs) & 0.945 & 0.931 & 0.961 \\
& S3 (lgs-lmn) & 0.814 & 0.787 & 0.840 \\
& S4 (lmn-mcn) & 0.659 & 0.624 & 0.699 \\
& S5 (mcn-jda) & 0.768 & 0.654 & 0.901 \\
& S6 (jda-bon) & 0.639 & 0.419 & 1.101 \\
\hline 2002 & S1 (rel-lgr) & 0.406 & 0.391 & 0.421 \\
& S2 (lgr-lgs) & 0.949 & 0.899 & 0.998 \\
& S3 (lgs-lmn) & 1.013 & 0.954 & 1.073 \\
& S4 (lmn-mcn) & 0.808 & 0.743 & 0.887 \\
& S5 (mcn-jda) & 0.928 & 0.779 & 1.125 \\
& S6 (jda-bon) & 0.896 & 0.562 & 1.726 \\
\hline 2003 & S1 (rel-lgr) & 0.349 & 0.334 & 0.366 \\
& S2 (lgr-lgs) & 0.972 & 0.892 & 1.061 \\
& S3 (lgs-lmn) & 0.855 & 0.747 & 1.004 \\
& S4 (lmn-mcn) & 1.093 & 0.925 & 1.273 \\
& S5 (mcn-jda) & 0.764 & 0.643 & 0.919 \\
\hline 2004 & S1 (rel-lgr) & 0.255 & 0.248 & 0.262 \\
& S2 (lgr-lgs) & 0.976 & 0.943 & 1.009 \\
& S3 (lgs-lmn) & 0.921 & 0.823 & 1.050 \\
& S4 (lmn-mcn) & 0.900 & 0.749 & 1.086 \\
& S5 (mcn-jda) & 0.704 & 0.503 & 1.036 \\
& S6 (jda-bon) & 0.579 & 0.273 & 2.172 \\
\hline 2005 & S1 (rel-lgr) & 0.233 & 0.227 & 0.239 \\
& S2 (lgr-lgs) & 0.936 & 0.909 & 0.960 \\
& S3 (lgs-lmn) & 0.889 & 0.831 & 0.954 \\
& S4 (lmn-mcn) & 0.997 & 0.881 & 1.156 \\
& S5 (mcn-jda) & 0.728 & 0.525 & 1.090 \\
\hline 2006 & S1 (rel-lgr) & 0.309 & 0.296 & 0.323 \\
& S2 (lgr-lgs) & 0.904 & 0.851 & 0.965 \\
& S3 (lgs-lmn) & 0.934 & 0.855 & 1.028 \\
& S4 (lmn-mcn) & 0.937 & 0.811 & 1.096 \\
& S5 (mcn-jda) & 0.728 & 0.580 & 0.934 \\
\hline
\end{tabular}


Table A-25. In-river smolt survival rate estimates from hatchery to LGR and through reaches in the hydrosystem for PIT-tagged McCall Hatchery summer Chinook in migration years 1997 to 2006.

\begin{tabular}{|c|c|c|c|c|}
\hline Migr & Reach of & Survival & $95 \% \mathrm{Cl}$ & $95 \%$ CI \\
\hline \multirow[t]{3}{*}{$\begin{array}{l}\text { Year } \\
1997\end{array}$} & $\begin{array}{l}\text { Survival } \\
\text { S1 (rel-lgr) }\end{array}$ & $\frac{\text { Estimate }}{0.425}$ & $\begin{array}{l}\text { Lower Limit } \\
0.411\end{array}$ & $\begin{array}{l}\text { Upper Limit } \\
0.441\end{array}$ \\
\hline & S2 $(\lg r-\lg s)$ & 0.935 & 0.889 & 0.987 \\
\hline & S3 (lgs-lmn) & 0.882 & 0.820 & 0.954 \\
\hline \multirow[t]{5}{*}{1998} & S1 (rel-lgr) & 0.588 & 0.580 & 0.595 \\
\hline & S2 $(\operatorname{lgr} r-\operatorname{lgs})$ & 0.991 & 0.971 & 1.012 \\
\hline & S3 (lgs-lmn) & 0.843 & 0.820 & 0.867 \\
\hline & $\mathrm{S} 4$ (lmn-men) & 0.942 & 0.884 & 1.007 \\
\hline & S5 (mcn-jda) & 0.824 & 0.738 & 0.930 \\
\hline \multirow[t]{6}{*}{1999} & S1 (rel-lgr) & 0.658 & 0.642 & 0.675 \\
\hline & S2 (lgr-lgs) & 0.908 & 0.880 & 0.939 \\
\hline & S3 (lgs-lmn) & 0.936 & 0.908 & 0.961 \\
\hline & S4 (lmn-men) & 0.913 & 0.872 & 0.957 \\
\hline & S5 (mcn-jda) & 1.086 & 0.989 & 1.206 \\
\hline & S6 (ida-bon) & 0.622 & 0.514 & 0.766 \\
\hline \multirow[t]{6}{*}{2000} & S1 (rel-lgr) & 0.667 & 0.650 & 0.685 \\
\hline & S2 (lgr-lgs) & 0.867 & 0.813 & 0.932 \\
\hline & S3 (lgs-lmn) & 0.917 & 0.807 & 1.036 \\
\hline & S4 (lmn-men) & 1.034 & 0.911 & 1.181 \\
\hline & S5 (mcn-jda) & 1.307 & 0.904 & 2.258 \\
\hline & S6 (ida-bon) & 0.570 & 0.323 & 0.887 \\
\hline \multirow{5}{*}{2001} & S1 (rel-lgr) & 0.667 & 0.663 & 0.672 \\
\hline & S2 $(\operatorname{lgr}-\lg s)$ & 0.928 & 0.920 & 0.937 \\
\hline & S3 (lgs-lmn) & 0.771 & 0.756 & 0.786 \\
\hline & $\mathrm{S} 4$ (lmn-men) & 0.647 & 0.628 & 0.666 \\
\hline & S5 (mcn-jda) & 0.862 & 0.784 & 0.954 \\
\hline \multirow{6}{*}{2002} & $\begin{array}{l}\text { S6 (jda-bon) } \\
\text { S1 (rel-lor) }\end{array}$ & $\begin{array}{l}0.674 \\
0.596\end{array}$ & 0.531 & $\frac{0.924}{0.609}$ \\
\hline & S2 $(\operatorname{lgr}-\lg s)$ & 0.964 & 0.936 & 0.992 \\
\hline & S3 (lgs-lmn) & 0.990 & 0.964 & 1.016 \\
\hline & S4 (lmn-men) & 0.837 & 0.809 & 0.869 \\
\hline & S5 (mcn-jda) & 1.051 & 0.969 & 1.144 \\
\hline & S6 (jda-bon) & 0.688 & 0.583 & 0.840 \\
\hline \multirow[t]{6}{*}{2003} & S1 (rel-lgr) & 0.581 & 0.570 & 0.591 \\
\hline & S2 (lgr-lgs) & 0.921 & 0.893 & 0.951 \\
\hline & S3 (lgs-lmn) & 0.884 & 0.844 & 0.932 \\
\hline & S4 (lmn-men) & 1.014 & 0.962 & 1.068 \\
\hline & S5 (mcn-jda) & 0.907 & 0.854 & 0.962 \\
\hline & S6 (jda-bon) & 0.929 & 0.803 & 1.068 \\
\hline
\end{tabular}

\begin{tabular}{|l|l|l|l|l|}
\hline $\begin{array}{l}\text { Migr } \\
\text { Year }\end{array}$ & $\begin{array}{l}\text { Reach of } \\
\text { Survival }\end{array}$ & $\begin{array}{l}\text { Survival } \\
\text { Estimate }\end{array}$ & $\begin{array}{l}\text { 95\% CI } \\
\text { Lower Limit }\end{array}$ & $\begin{array}{l}\text { 95\% CI } \\
\text { Upper Limit }\end{array}$ \\
\hline 2004 & S1 (rel-lgr) & 0.563 & 0.559 & 0.567 \\
& S2 (lgr-lgs) & 0.938 & 0.927 & 0.949 \\
& S3 (lgs-lmn) & 0.993 & 0.938 & 1.055 \\
& S4 (lmn-mcn) & 0.754 & 0.698 & 0.814 \\
& S5 (mcn-jda) & 0.893 & 0.786 & 1.030 \\
& S6 (jda-bon) & 0.696 & 0.517 & 1.014 \\
\hline 2005 & S1 (rel-lgr) & 0.603 & 0.598 & 0.607 \\
& S2 (lgr-lgs) & 0.935 & 0.926 & 0.945 \\
& S3 (lgs-lmn) & 0.919 & 0.895 & 0.944 \\
& S4 (lmn-mcn) & 0.913 & 0.870 & 0.960 \\
& S5 (mcn-jda) & 0.864 & 0.756 & 1.011 \\
& S6 (jda-bon) & 0.782 & 0.612 & 1.042 \\
\hline 2006 & S1 (rel-lgr) & 0.633 & 0.622 & 0.646 \\
& S2 (lgr-lgs) & 0.871 & 0.846 & 0.896 \\
& S3 (lgs-lmn) & 0.932 & 0.899 & 0.968 \\
& S4 (lmn-mcn) & 0.965 & 0.905 & 1.028 \\
& S5 (mcn-jda) & 0.862 & 0.773 & 0.967 \\
\hline
\end{tabular}


Table A-26. In-river smolt survival rate estimates from hatchery to LGR and through reaches in the hydrosystem for PIT-tagged Imnaha Acclimation Pond summer Chinook in migration years 1997 to 2006.

\begin{tabular}{|c|c|c|c|c|}
\hline $\begin{array}{l}\text { Migr } \\
\text { Year }\end{array}$ & Reach of Survival & $\begin{array}{l}\text { Survival } \\
\text { Estimate }\end{array}$ & $95 \%$ CI & $95 \%$ CI \\
\hline \multirow[t]{3}{*}{1997} & S1 (rel-lgr) & $\begin{array}{l}\text { Lstumate } \\
0.617\end{array}$ & Lower limit & $\begin{array}{l}\text { Upper Limit } \\
0.654\end{array}$ \\
\hline & S2 $(\operatorname{lgr}-\operatorname{lgs})$ & 0.994 & 0.909 & 1.082 \\
\hline & S3 (lgs-lmn) & 0.768 & 0.693 & 0.856 \\
\hline \multirow[t]{5}{*}{1998} & S1 (rel-lgr) & 0.685 & 0.673 & 0.697 \\
\hline & S2 $(\lg r-\lg s)$ & 0.978 & 0.951 & 1.006 \\
\hline & S3 (lgs-lmn) & 0.843 & 0.812 & 0.872 \\
\hline & S4 (lmn-mcn) & 0.956 & 0.894 & 1.035 \\
\hline & S5 (mcn-jda) & 0.784 & 0.685 & 0.907 \\
\hline \multirow[t]{6}{*}{1999} & S1 (rel-lgr) & 0.664 & 0.645 & 0.686 \\
\hline & S2 (lgr-lgs) & 0.921 & 0.885 & 0.957 \\
\hline & S3 (lgs-lmn) & 0.954 & 0.920 & 0.989 \\
\hline & S4 (lmn-mcn) & 0.876 & 0.825 & 0.931 \\
\hline & S5 (mcn-jda) & 0.944 & 0.840 & 1.075 \\
\hline & S6 (jda-bon) & 0.740 & 0.548 & 1.103 \\
\hline \multirow{6}{*}{2000} & SI (rel-lgr) & 0.685 & 0.665 & 0.707 \\
\hline & S2 (lgr-lgs) & 0.822 & 0.774 & 0.877 \\
\hline & S3 (lgs-lmn) & 1.008 & 0.869 & 1.201 \\
\hline & S4 (lmn-mcn) & 0.885 & 0.717 & 1.081 \\
\hline & S5 (mcn-jda) & 0.893 & 0.677 & 1.293 \\
\hline & S6 (jda-bon) & 1.013 & 0.570 & 2.469 \\
\hline \multirow{6}{*}{2001} & S1 (rel-lgr) & 0.748 & 0.742 & 0.755 \\
\hline & S2 (lgr-lgs) & 0.958 & 0.950 & 0.968 \\
\hline & S3 (lgs-lmn) & 0.892 & 0.877 & 0.908 \\
\hline & S4 (lmn-men) & 0.751 & 0.729 & 0.776 \\
\hline & S5 (mcn-jda) & 0.853 & 0.763 & 0.958 \\
\hline & S6 (jda-bon) & 0.678 & 0.462 & 1.226 \\
\hline \multirow[t]{6}{*}{2002} & S1 (rel-lgr) & 0.667 & 0.645 & 0.691 \\
\hline & S2 $(\operatorname{lgr}-\lg s)$ & 0.951 & 0.910 & 0.994 \\
\hline & S3 (lgs-lmn) & 0.947 & 0.911 & 0.984 \\
\hline & S4 (lmn-mcn) & 0.858 & 0.817 & 0.904 \\
\hline & S5 (mcn-jda) & 0.828 & 0.753 & 0.914 \\
\hline & S6 (ida-bon) & 0.788 & 0.603 & 1.120 \\
\hline \multirow[t]{5}{*}{2003} & S1 (rel-lgr) & 0.715 & 0.694 & 0.739 \\
\hline & S2 (lgr-lgs) & 0.901 & 0.853 & 0.953 \\
\hline & S3 (lgs-lmn) & 0.905 & 0.813 & 1.014 \\
\hline & S4 (lmn-mcn) & 0.914 & 0.816 & 1.029 \\
\hline & S5 (mcn-jda) & 1.027 & 0.909 & 1.153 \\
\hline \multirow{7}{*}{$\begin{array}{l}\text { Migr } \\
\text { Year } \\
2004\end{array}$} & Reach of Survival & Survival & $95 \%$ CI & $95 \% \mathrm{CI}$ \\
\hline & S1 (rol-1or) & Estimate & Lower Limit & Upper Limit \\
\hline & $\begin{array}{l}\text { S1 (rel-1gr) } \\
\text { S2 (lor-lgs) }\end{array}$ & $\begin{array}{l}0.615 \\
0.964\end{array}$ & $\begin{array}{l}0.606 \\
0.940\end{array}$ & 0.624 \\
\hline & S3 (lgs-lmn) & 0.910 & 0.828 & 1.002 \\
\hline & S4 (lmn-mcn) & 0.834 & 0.731 & 0.954 \\
\hline & S5 (mcn-jda) & 0.878 & 0.686 & 1.153 \\
\hline & S6 (jda-bon) & 0.576 & 0.315 & 1.429 \\
\hline \multirow{5}{*}{2005} & S1 (rel-lgr) & 0.534 & 0.526 & 0.542 \\
\hline & S2 (lgr-lgs) & 0.920 & 0.902 & 0.938 \\
\hline & S3 (lgs-lmn) & 0.871 & 0.832 & 0.915 \\
\hline & S4 (lmn-mcn) & 1.029 & 0.938 & 1.144 \\
\hline & $\frac{\text { S5 (mcn-jda) }}{\text { S1(rel-gr) }}$ & $\frac{0.822}{0.635}$ & $\frac{0.665}{0.617}$ & $\frac{1.051}{0.655}$ \\
\hline \multirow{4}{*}{2006} & S2 (lgr-lgs) & 0.833 & 0.799 & 0.864 \\
\hline & S3 (lgs-lmn) & 0.927 & 0.885 & 0.971 \\
\hline & S4 (lmn-mcn) & 0.870 & 0.804 & 0.945 \\
\hline & S5 (mcn-ida) & 0.877 & 0.755 & 1.039 \\
\hline
\end{tabular}


Table A-27. In-river smolt survival rate estimates through reaches in the hydrosystem for the PITtag aggregate of wild summer steelhead in migration years 1997 to 2005.

\begin{tabular}{|c|c|c|c|c|}
\hline Migr & Reach of & Survival & $95 \%$ CI & $95 \%$ CI \\
\hline \multirow[t]{4}{*}{$\begin{array}{l}\text { Year } \\
1997\end{array}$} & $\begin{array}{l}\text { Survival } \\
\text { S2 (lgr-lgs) }\end{array}$ & $\frac{\text { Estimate }}{0.984}$ & $\begin{array}{l}\text { Lower Limit } \\
0.948\end{array}$ & $\begin{array}{l}\text { Upper Limit } \\
1.017\end{array}$ \\
\hline & S3 (lgs-lmn) & 0.975 & 0.902 & 1.060 \\
\hline & S4 (lmn-men) & 0.886 & 0.685 & 1.233 \\
\hline & S5 (mcn-jda) & 0.721 & 0.368 & 2.096 \\
\hline \multirow[t]{4}{*}{1998} & S2 (gr-lgs) & 0.969 & 0.945 & 0.995 \\
\hline & S3 (lgs-lmn) & 0.843 & 0.807 & 0.879 \\
\hline & S4 (lmn-men) & 0.889 & 0.805 & 1.000 \\
\hline & S5 (mcn-jda) & 0.868 & 0.746 & 1.009 \\
\hline \multirow[t]{5}{*}{1999} & S2 (gr-lgs) & 0.974 & 0.956 & 0.991 \\
\hline & S3 (lgs-lmn) & 0.910 & 0.888 & 0.934 \\
\hline & $\mathrm{S} 4$ (lmn-men) & 0.835 & 0.785 & 0.890 \\
\hline & S5 (mcn-jda) & 1.040 & 0.937 & 1.148 \\
\hline & S6 (jda-bon) & 0.580 & 0.473 & 0.761 \\
\hline \multirow[t]{4}{*}{2000} & S2 $2(\operatorname{lgr}-\operatorname{lgg})$ & 0.790 & 0.771 & 0.807 \\
\hline & S3 (lgs-lmn) & 0.910 & 0.878 & 0.943 \\
\hline & S4 (lmn-men) & 0.860 & 0.800 & 0.931 \\
\hline & S5 (mcn-jda) & 0.659 & 0.594 & 0.729 \\
\hline \multirow{5}{*}{2001} & S2 (lgr-lgs) & 0.834 & 0.823 & 0.845 \\
\hline & S3 (lgs-lmn) & 0.716 & 0.694 & 0.741 \\
\hline & S4 (lmn-men) & 0.288 & 0.267 & 0.312 \\
\hline & S5 (mcn-jda) & 0.230 & 0.191 & 0.281 \\
\hline & S6 (jda-bon) & $\frac{0.958}{0.043}$ & $\frac{0.618}{0.921}$ & $\frac{1.714}{0.065}$ \\
\hline \multirow{5}{*}{2002} & & & ר? & \\
\hline & S3 (lgs-lmn) & 1.164 & 1.122 & 1.215 \\
\hline & S4 (lmn-men) & 0.522 & 0.493 & 0.553 \\
\hline & S5 (mcn-jda) & 0.960 & 0.886 & 1.083 \\
\hline & S6 (jda-bon) & 0.939 & $\begin{array}{l}0.720 \\
0.879\end{array}$ & $\begin{array}{l}1.269 \\
0.937\end{array}$ \\
\hline \multirow{5}{*}{2003} & $52(\lg 1-190)$ & 0.300 & & 0.901 \\
\hline & S3 (lgs-lmn) & 0.914 & 0.867 & 0.967 \\
\hline & S4 (lmn-men) & 0.729 & 0.669 & 0.791 \\
\hline & S5 (mcn-jda) & 0.913 & 0.807 & 1.044 \\
\hline & S6 (jda-bon) & 0.664 & 0.527 & 0.866 \\
\hline \multirow[t]{2}{*}{2004} & S2 (Igr-lgs) & 0.955 & 0.940 & 0.968 \\
\hline & S3 (lgs-lmn) & 0.752 & 0.704 & 0.805 \\
\hline \multirow{5}{*}{2005} & S4 (lmn-men) & $\frac{0.603}{0.916}$ & $\frac{0.496}{0.908}$ & $\frac{0.756}{0.925}$ \\
\hline & SL (Igr-lgs) & 0.916 & & 0.925 \\
\hline & S3 (lgs-lmn) & 0.836 & 0.801 & 0.866 \\
\hline & S4 (lmn-mcn) & 0.726 & 0.657 & 0.816 \\
\hline & S5 (mcn-jda) & 0.659 & 0.522 & 0.877 \\
\hline
\end{tabular}


Table A-28. In-river smolt survival rate estimates through reaches in the hydrosystem for the PITtag aggregate of hatchery summer steelhead in migration years 1997 to 2005.

\begin{tabular}{|c|c|c|c|c|}
\hline Migr & Reach of & Survival & $95 \% \mathrm{CI}$ & $95 \%$ CI \\
\hline \multirow[t]{4}{*}{$\begin{array}{l}\text { Year } \\
1997\end{array}$} & $\frac{\text { Survival }}{\text { S2 (lgr-lgs) }}$ & $\frac{\text { Estimate }}{0.954}$ & $\frac{\text { Lower Limit }}{0.937}$ & Upper Limit \\
\hline & S3 (lgs-lmn) & 0.853 & 0.823 & 0.888 \\
\hline & S4 (lmn-mcn) & 0.938 & 0.814 & 1.104 \\
\hline & S5 (mcn-ida) & 0.656 & 0.440 & 1.187 \\
\hline \multirow[t]{5}{*}{1998} & S2 (gr-lgs) & 0.950 & 0.936 & 0.963 \\
\hline & S3 (lgs-lmn) & 0.854 & 0.834 & 0.875 \\
\hline & S4 (lmn-men) & 0.820 & 0.775 & 0.868 \\
\hline & S5 (mcn-jda) & 1.058 & 0.970 & 1.148 \\
\hline & S6 (jda-bon) & 0.915 & 0.642 & 1.543 \\
\hline \multirow[t]{5}{*}{1999} & S2 (lgr-lgs) & 0.966 & 0.955 & 0.978 \\
\hline & S3 (lgs-lmn) & 0.895 & 0.880 & 0.909 \\
\hline & S4 (lmn-men) & 0.801 & 0.769 & 0.837 \\
\hline & S5 (mcn-jda) & 1.044 & 0.985 & 1.111 \\
\hline & S6 (ida-bon) & 0.622 & 0.519 & 0.772 \\
\hline \multirow[t]{4}{*}{2000} & S2 (lgr-lgs) & 0.693 & 0.673 & 0.717 \\
\hline & S3 (lgs-lmn) & 0.812 & 0.778 & 0.854 \\
\hline & S4 (lmn-men) & 0.803 & 0.735 & 0.877 \\
\hline & S5 (mcn-jda) & 0.705 & 0.614 & 0.820 \\
\hline \multirow[t]{5}{*}{2001} & S2 (lgr-lgs) & 0.693 & 0.682 & 0.705 \\
\hline & S3 (lgs-lmn) & 0.678 & 0.650 & 0.707 \\
\hline & S4 (lmn-men) & 0.284 & 0.262 & 0.311 \\
\hline & S5 (mcn-jda) & 0.353 & 0.286 & 0.463 \\
\hline & S6 (jda-bon) & 0.805 & 0.418 & 2.455 \\
\hline \multirow[t]{5}{*}{2002} & S2 (lgr-lgs) & 0.908 & 0.887 & 0.930 \\
\hline & S3 (lgs-lmn) & 0.970 & 0.943 & 1.001 \\
\hline & S4 (lmn-men) & 0.570 & 0.536 & 0.610 \\
\hline & S5 (mcn-jda) & 0.937 & 0.830 & 1.051 \\
\hline & S6 (jda-bon) & 0.777 & 0.604 & 1.067 \\
\hline \multirow{5}{*}{2003} & S2 (1gr-lgs) & 0.949 & 0.920 & 0.977 \\
\hline & S3 (lgs-lmn) & 0.935 & 0.893 & 0.977 \\
\hline & S4 (lmn-men) & 0.709 & 0.655 & 0.768 \\
\hline & S5 (mcn-jda) & 0.954 & 0.850 & 1.081 \\
\hline & S6 (jda-bon) & 0.842 & 0.672 & 1.076 \\
\hline \multirow{3}{*}{2004} & S2 (lgr-lgs) & 0.871 & 0.861 & 0.880 \\
\hline & S3 (lgs-lmn) & 0.892 & 0.850 & 0.940 \\
\hline & S4 (lmn-men) & 0.541 & 0.459 & 0.644 \\
\hline \multirow{4}{*}{2005} & S2 (lgr-lgs) & 0.924 & 0.918 & 0.931 \\
\hline & S3 (lgs-lmn) & 0.861 & 0.840 & 0.883 \\
\hline & S4 (lmn-men) & 0.787 & 0.722 & 0.858 \\
\hline & S5 (mcn-jda) & 0.739 & 0.610 & 0.912 \\
\hline
\end{tabular}


Tables A-29 to A-33 present age distribution of returning adult Chinook and steelhead detected at LGR for upriver populations and BON for downriver populations

Table A-29. Age composition of returning PIT-tagged wild Chinook jacks and adults detected at Lower Granite Dam that were PIT-tagged during the 10-month period from July 25 to May 20 for each migration year between 1994 and 2006.

\begin{tabular}{|l|l|l|l|l|l|l|}
\hline $\begin{array}{l}\text { Migration } \\
\text { Year }\end{array}$ & $\begin{array}{l}\text { Jacks } \\
\text { 1-salt }\end{array}$ & $\begin{array}{l}\text { Adults } \\
\text { 2-salt }\end{array}$ & $\begin{array}{l}\text { Adults } \\
\text { 3-salt }\end{array}$ & $\begin{array}{l}\text { Percent } \\
\text {-salt }\end{array}$ & $\begin{array}{l}\text { Percent } \\
\text { 2-salt }\end{array}$ & $\begin{array}{l}\text { Percent } \\
\text { 3-salt }\end{array}$ \\
\hline 1994 & 1 & 11 & 11 & 4.3 & 47.8 & 47.8 \\
\hline 1995 & 1 & 38 & 20 & 1.7 & 64.4 & 33.9 \\
\hline 1996 & 0 & 11 & 5 & 0.0 & 68.8 & 31.3 \\
\hline 1997 & 2 & 33 & 5 & 5.0 & 82.5 & 12.5 \\
\hline 1998 & 17 & 148 & 47 & 8.0 & 69.8 & 22.2 \\
\hline 1999 & 25 & 517 & 144 & 3.6 & 75.4 & 21.0 \\
\hline 2000 & 9 & 259 & $312\left(1^{\mathrm{A}}\right)$ & 1.5 & 44.6 & $53.7\left(0.2^{\mathrm{A}}\right)$ \\
\hline 2001 & 2 & 30 & 15 & 4.3 & 63.8 & 31.9 \\
\hline 2002 & 26 & 197 & 38 & 10.0 & 75.5 & 14.6 \\
\hline 2003 & 3 & 61 & 24 & 3.4 & 69.3 & 27.3 \\
\hline 2004 & 3 & 83 & $42\left(1^{\mathrm{A}}\right)$ & 2.3 & 64.8 & 32.8 \\
\hline 2005 & 4 & 38 & 24 & 6.1 & 57.6 & 36.4 \\
\hline $20066^{\mathrm{B}}$ & 12 & 120 & n/a & 9.1 & 90.9 & n.a \\
\hline Average & & & $\mathbf{4 . 6}$ & $\mathbf{6 7 . 3}$ & $\mathbf{3 0 . 5}$ \\
\hline
\end{tabular}

${ }^{\mathrm{A}}$ One 4-salt adult shown in parenthesis in 3-salt column.

B Migration year 2006 is incomplete until 3-salt returns occur at GRA; not included in average.

Table A-30. Age composition of returning PIT-tagged wild steelhead adults detected at Lower Granite Dam that were PIT-tagged during the 12-month period from July 1 to June 30 for each migration year between 1997 and 2005.

\begin{tabular}{|l|l|l|l|l|l|l|}
\hline $\begin{array}{l}\text { Migration } \\
\text { Year }\end{array}$ & $\begin{array}{l}\text { Age } \\
\text { 1-salt }\end{array}$ & $\begin{array}{l}\text { Age } \\
\text { 2-salt }\end{array}$ & $\begin{array}{l}\text { Age } \\
\text { 3-salt }\end{array}$ & $\begin{array}{l}\text { Percent } \\
\text { 1-salt }\end{array}$ & $\begin{array}{l}\text { Percent } \\
\text { 2-salt }\end{array}$ & $\begin{array}{l}\text { Percent } \\
\text { 3-salt }\end{array}$ \\
\hline 1997 & 4 & 10 & 0 & 28.6 & 71.4 & 0 \\
\hline 1998 & 16 & 8 & 0 & 66.7 & 33.3 & 0 \\
\hline 1999 & 33 & 51 & 2 & 38.4 & 59.3 & 2.3 \\
\hline 2000 & 132 & 131 & 3 & 49.6 & 49.3 & 1.1 \\
\hline 2001 & 5 & 14 & 2 & 23.8 & 66.7 & 9.5 \\
\hline 2002 & 59 & 60 & 1 & 49.2 & 50.0 & 0.8 \\
\hline 2003 & 38 & 63 & 0 & 37.6 & 62.4 & 0 \\
\hline 2004 & 26 & 21 & 0 & 57.8 & 43.7 & 0 \\
\hline 2005 & 17 & 42 & 0 & 28.8 & 71.2 & 0 \\
\hline Average & \multicolumn{7}{|l}{} & & & $\mathbf{4 1 . 6}$ & $\mathbf{5 5 . 6}$ & $\mathbf{1 . 6 9}$ \\
\hline
\end{tabular}

Table A-31. Age composition of returning PIT-tagged hatchery steelhead adults detected at Lower Granite Dam that migrated as smolts in 1997 to 2005.

\begin{tabular}{|l|l|l|l|l|l|l|}
\hline $\begin{array}{l}\text { Migration } \\
\text { Year }\end{array}$ & $\begin{array}{l}\text { Age } \\
\text { 1-salt }\end{array}$ & $\begin{array}{l}\text { Age } \\
\text { 2-salt }\end{array}$ & $\begin{array}{l}\text { Age } \\
\text { 3-salt }\end{array}$ & $\begin{array}{l}\text { Percent } \\
\text { 1-salt }\end{array}$ & $\begin{array}{l}\text { Percent } \\
\text { 2-salt }\end{array}$ & $\begin{array}{l}\text { Percent } \\
\text { 3-salt }\end{array}$ \\
\hline 1997 & 34 & 15 & 0 & 69.4 & 30.6 & 0 \\
1998 & 45 & 32 & 0 & 58.4 & 41.6 & 0 \\
1999 & 85 & 96 & 1 & 46.7 & 52.7 & 0.5 \\
2000 & 178 & 89 & 1 & 66.4 & 33.2 & 0.4 \\
2001 & 3 & 8 & 0 & 27.3 & 72.7 & 0 \\
2002 & 99 & 49 & 1 & 66.4 & 32.9 & 0.7 \\
2003 & 90 & 77 & 0 & 53.9 & 46.1 & 0 \\
2004 & 21 & 24 & 0 & 46.7 & 53.3 & 0 \\
2005 & 41 & 26 & 0 & 61.2 & 38.8 & 0 \\
\hline Average & \multicolumn{5}{|l}{} \\
\hline
\end{tabular}


Table A-32. Age composition of returning PIT-tagged hatchery Summer Chinook adults and jacks detected at Lower Granite Dam that migrated as smolts in 1997 to 2006.

\begin{tabular}{|c|c|c|c|c|c|c|c|}
\hline Hatchery & $\begin{array}{l}\text { Smolt Migr } \\
\text { Year }\end{array}$ & $\begin{array}{l}\text { Jacks } \\
\text { 1-salt }\end{array}$ & $\begin{array}{l}\text { Adults } \\
\text { 2-salt }\end{array}$ & $\begin{array}{l}\text { Adults } \\
\text { 3-salt }\end{array}$ & $\begin{array}{l}\text { Percent } \\
\text { 1-salt }\end{array}$ & $\begin{array}{l}\text { Percent } \\
\text { 2-salt }\end{array}$ & $\begin{array}{l}\text { Percent } \\
\text { 3-salt }\end{array}$ \\
\hline \multirow[t]{10}{*}{ MCCA } & 1997 & $\frac{1-5 a n t}{21}$ & $\frac{2-3514}{263}$ & 11 & 7.1 & 89.2 & 3.7 \\
\hline & 1998 & 108 & 394 & 37 & 20.0 & 73.1 & 6.9 \\
\hline & 1999 & 119 & 722 & 113 & 12.5 & 75.7 & 11.8 \\
\hline & 2000 & 144 & 635 & $239\left(1^{\mathrm{B}}\right)$ & 14.1 & 62.3 & $1.5\left(0.1^{\mathrm{B}}\right)$ \\
\hline & 2001 & 62 & 200 & 23 & 21.8 & 70.2 & 8.1 \\
\hline & 2002 & 116 & 347 & 18 & 24.1 & 72.1 & 3.7 \\
\hline & 2003 & 129 & 222 & 27 & 34.1 & 58.7 & 7.1 \\
\hline & 2004 & 25 & 91 & 20 & 18.4 & 66.9 & 14.7 \\
\hline & 2005 & 16 & 155 & 29 & 8.0 & 77.5 & 14.5 \\
\hline & $2006^{\mathrm{A}}$ & 67 & 301 & $\mathrm{n} / \mathrm{a}$ & 18.2 & 81.8 & $\mathrm{n} / \mathrm{a}$ \\
\hline \multirow[t]{11}{*}{ IMNA } & $\begin{array}{l}\text { Average } \\
1997\end{array}$ & 24 & 63 & 7 & $\frac{17.8}{25.5}$ & $\frac{72.8}{67.0}$ & $\frac{8.8}{7.4}$ \\
\hline & 1998 & 54 & 69 & 2 & 43.2 & 55.2 & 1.6 \\
\hline & 1999 & 81 & 226 & 12 & 25.4 & 70.8 & 3.8 \\
\hline & 2000 & 149 & 289 & 79 & 28.8 & 55.9 & 15.3 \\
\hline & 2001 & 30 & 49 & 4 & 36.1 & 59.0 & 4.8 \\
\hline & 2002 & 46 & 81 & 2 & 35.7 & 63.8 & 1.6 \\
\hline & 2003 & 93 & 71 & 2 & 56.0 & 42.8 & 1.2 \\
\hline & 2004 & 9 & 33 & 2 & 20.5 & 75.0 & 4.5 \\
\hline & 2005 & 5 & 24 & 1 & 16.7 & 80.0 & 3.3 \\
\hline & $2006^{\mathrm{A}}$ & 39 & 89 & $\mathrm{n} / \mathrm{a}$ & 30.5 & 69.5 & $\mathrm{n} / \mathrm{a}$ \\
\hline & Average & & & & 31.8 & 63.9 & 4.8 \\
\hline
\end{tabular}

${ }^{\mathrm{A}}$ Migration year 2006 is incomplete until 3-salt returns occur at GRA; not included in average.

${ }^{\text {B }}$ One 4-salt adult shown in parenthesis in 3-salt column.

Table A-33. Age composition of returning PIT-tagged hatchery Spring Chinook adults and jacks detected at Lower Granite Dam that migrated as smolts in 1997 to 2006.

\begin{tabular}{|c|c|c|c|c|c|c|c|}
\hline Hatchery & $\begin{array}{l}\text { Smolt } \\
\text { Migr Year }\end{array}$ & $\begin{array}{l}\text { Jacks } \\
\text { 1-salt }\end{array}$ & $\begin{array}{l}\text { Adults } \\
\text { 2-salt }\end{array}$ & $\begin{array}{l}\text { Adults } \\
\text { 3-salt }\end{array}$ & $\begin{array}{l}\text { Percent } \\
\text { 1-salt }\end{array}$ & $\begin{array}{l}\text { Percent } \\
2 \text {-salt }\end{array}$ & $\begin{array}{l}\text { Percent } \\
\text { 3-salt }\end{array}$ \\
\hline \multirow[t]{11}{*}{ RAPH } & 1997 & 2 & 86 & 7 & 2.1 & 90.5 & 7.4 \\
\hline & 1998 & 32 & 390 & 23 & 7.2 & 87.6 & 5.2 \\
\hline & 1999 & 43 & 787 & 31 & 5.0 & 91.4 & 3.6 \\
\hline & 2000 & 8 & 371 & 256 & 1.3 & 58.4 & 40.3 \\
\hline & 2001 & 21 & 206 & 13 & 8.8 & 85.8 & 5.4 \\
\hline & 2002 & 60 & 298 & 5 & 16.5 & 82.1 & 1.4 \\
\hline & 2003 & 20 & 75 & 8 & 19.4 & 72.8 & 7.8 \\
\hline & 2004 & 4 & 67 & 27 & 4.1 & 68.4 & 27.6 \\
\hline & 2005 & 6 & 61 & 16 & 7.2 & 73.5 & 19.3 \\
\hline & $2006^{\mathrm{A}}$ & 79 & 273 & $\mathrm{n} / \mathrm{a}$ & 22.4 & 77.6 & $\mathrm{n} / \mathrm{a}$ \\
\hline & \multicolumn{4}{|l|}{ Average } & 9.4 & 78.8 & 13.1 \\
\hline \multirow[t]{11}{*}{ DWOR } & 1997 & 1 & 36 & 6 & 2.3 & 83.7 & 14.0 \\
\hline & 1998 & 51 & 372 & 23 & 11.4 & 83.4 & 5.2 \\
\hline & 1999 & 14 & 393 & 44 & 3.1 & 87.1 & 9.8 \\
\hline & 2000 & 3 & 180 & 197 & 0.8 & 47.4 & 51.8 \\
\hline & 2001 & 14 & 79 & 10 & 13.6 & 76.7 & 9.7 \\
\hline & 2002 & 52 & 222 & 8 & 18.4 & 78.7 & 2.8 \\
\hline & 2003 & 5 & 73 & 12 & 5.6 & 81.1 & 13.3 \\
\hline & 2004 & 1 & 84 & 26 & 0.9 & 75.7 & 23.4 \\
\hline & 2005 & 2 & 53 & 20 & 2.7 & 70.7 & 26.7 \\
\hline & $2006^{\mathrm{A}}$ & 73 & 228 & $\mathrm{n} / \mathrm{a}$ & 24.3 & 75.5 & $\mathrm{n} / \mathrm{a}$ \\
\hline & \multicolumn{4}{|l|}{ Average } & 8.3 & 76.0 & 17.4 \\
\hline \multirow[t]{7}{*}{ СATH } & 2001 & 2 & 13 & 0 & 13.3 & 86.7 & 0.0 \\
\hline & 2002 & 11 & 45 & 1 & 19.3 & 79.0 & 1.8 \\
\hline & 2003 & 5 & 22 & 0 & 18.5 & 81.5 & 0.0 \\
\hline & 2004 & 2 & 17 & 1 & 10.0 & 85.0 & 5.0 \\
\hline & 2005 & 3 & 15 & 0 & 16.7 & 83.3 & 0.0 \\
\hline & $2006^{\mathrm{A}}$ & 10 & 36 & $\mathrm{n} / \mathrm{a}$ & 21.7 & 78.3 & $\mathrm{n} / \mathrm{a}$ \\
\hline & \multicolumn{4}{|l|}{ Average } & 13.6 & 79.2 & 10.6 \\
\hline
\end{tabular}

${ }^{\mathrm{A}}$ Migration year 2006 is incomplete until 3-salt returns occur at GRA; not included in average. 
Tables A-34 to A-42 cover numbers of PIT-tagged smolts transported at each collector dam

(plus estimated number if tagged fish had been transported in same proportion as the untagged population) and site-specific SAR estimates

Table A-34. Number of PIT-tagged wild Chinook actually transported from each dam and estimate $\left(t_{i}\right)$ of total PIT-tagged wild Chinook that would have been transported if all tagged fish were transported at same rate as the untagged run-at-large, 1994 to 2006.

\begin{tabular}{|c|c|c|c|c|c|c|}
\hline Migr & Lower & anite Dam & Little $G$ & e Dam & Lower & umental Dam \\
\hline Year & Actual & & Actual & & Actual & \\
\hline 1994 & 1,051 & 6,851 & 387 & 2,094 & 330 & 1,308 \\
\hline 1995 & 1,702 & 9,657 & 356 & 3,626 & 156 & 1,490 \\
\hline 1996 & 268 & 2,269 & 85 & 1,749 & 32 & 927 \\
\hline 1997 & 185 & 1,064 & 30 & 335 & 11 & 171 \\
\hline 1998 & 820 & 7,669 & 359 & 4,002 & 79 & 1,632 \\
\hline 1999 & 1,107 & 8,183 & 319 & 14,213 & 287 & 4,594 \\
\hline 2000 & 327 & 7,095 & 244 & 6,603 & 187 & 2,095 \\
\hline 2001 & 452 & 18,062 & 72 & 2,904 & 13 & 278 \\
\hline 2002 & 1,640 & 4,813 & 1,856 & 6,505 & 167 & 3,705 \\
\hline 2003 & 5,098 & 11,694 & 2,548 & 6,634 & 599 & 1,495 \\
\hline 2004 & 8,951 & 20,367 & 2,812 & 6,552 & 834 & 1,849 \\
\hline 2005 & 12,063 & 24,029 & 3,222 & 6,507 & 231 & 457 \\
\hline 2006 & 3,974 & 5,321 & 4,122 & 6,029 & 1,140 & 2,459 \\
\hline \multicolumn{2}{|c|}{ Average Percent ${ }^{\mathrm{A}}$} & $57 \%$ & & $31 \%$ & & $12 \%$ \\
\hline
\end{tabular}

${ }^{\mathrm{A}}$ Average percentage of total transported population occurring at each Snake River dam.

Table A-35. Estimated dam-specific transportation SARs (\%) of the PIT-tagged wild Chinook aggregate for migration years 1994 to 2006 (with 90\% confidence intervals).

\begin{tabular}{|c|c|c|c|c|c|c|}
\hline $\begin{array}{l}\text { Migr } \\
\text { Year }\end{array}$ & $\begin{array}{l}\left.\text { SAR(T }{ }_{\text {LGR }}\right) \\
\% \quad(C I \%)\end{array}$ & $\begin{array}{l}\text { Adult } \\
\#\end{array}$ & $\begin{array}{l}\text { SAR(T } \\
\% \quad(\text { LGS }) \\
0\end{array}$ & $\begin{array}{l}\text { Adult } \\
\#\end{array}$ & $\begin{array}{l}\left.\text { SAR(T }{ }_{\text {LMN }}\right) \\
\%\end{array}$ & $\begin{array}{l}\text { Adult } \\
\#\end{array}$ \\
\hline 1994 & $0.67(0.28-1.12)$ & 7 & $0.52(0.0-1.11)$ & 2 & $\mathrm{NA}$ & None \\
\hline 1995 & $0.41 \quad(0.18-0.68)$ & 7 & $0.28(0.0-0.84)$ & 1 & $\mathrm{NA}$ & None \\
\hline 1996 & $0.37(0.0-1.10)$ & 1 & $1.18(0.0-3.41)$ & 1 & NA & None \\
\hline 1997 & $1.08(0.0-2.37)$ & 2 & $6.67(0.0-14.8)$ & 2 & $\mathrm{NA}$ & None \\
\hline 1998 & $1.34 \quad(0.72-2.01)$ & 11 & $0.84(0.0-1.66)$ & 3 & $1.27(0.0-3.53)$ & 1 \\
\hline 1999 & $2.53(1.82-3.28)$ & 28 & $2.82(1.49-4.47)$ & 9 & $2.09 \quad(0.72-3.58)$ & 6 \\
\hline 2000 & $1.22(0.31-2.27)$ & 4 & $2.46 \quad(0.87-4.29)$ & 6 & $1.07(0.0-2.38)$ & 2 \\
\hline 2001 & $1.33(0.46-2.23)$ & 6 & $1.39(0.0-4.11)$ & 1 & NA & None \\
\hline 2002 & $0.61 \quad(0.30-0.95)$ & 10 & $1.08(0.70-1.53)$ & 20 & $0.60(0.0-1.79)$ & 1 \\
\hline 2003 & $0.31 \quad(0.19-0.45)$ & 16 & $0.51 \quad(0.28-0.75)$ & 13 & $0.17(0.0-0.50)$ & $T$ \\
\hline 2004 & $0.55(0.42-0.67)$ & 49 & $0.46 \quad(0.25-0.68)$ & 13 & $0.72(0.25-1.24)$ & 6 \\
\hline 2005 & $0.22(0.16-0.29)$ & 27 & $0.31 \quad(0.16-0.48)$ & 10 & $\mathrm{NA}$ & None \\
\hline $2006^{\mathrm{A}}$ & $0.60 \quad(0.41-0.81)$ & 24 & $0.46 \quad(0.29-0.64)$ & 19 & $1.40(0.89-2.01)$ & 16 \\
\hline
\end{tabular}

${ }^{\mathrm{A}}$ Migration year 2006 is incomplete until 3-salt returns at GRA. 
Table A-36. Number of PIT-tagged hatchery Chinook actually transported from each dam and estimate $\left(t_{i}\right)$ of total PIT-tagged hatchery Chinook that would have been transported if all PIT-tagged fish had been transported at same rate as the untagged run-at-large.

\begin{tabular}{|c|c|c|c|c|c|c|c|}
\hline \multirow[t]{2}{*}{$\begin{array}{l}\text { Migr } \\
\text { Year }\end{array}$} & \multirow[t]{2}{*}{$\begin{array}{l}\text { Hat. } \\
\text { Code }^{\text {A }}\end{array}$} & \multicolumn{2}{|c|}{$\begin{array}{l}\text { Lower Granite } \\
\text { Dam }\end{array}$} & \multicolumn{2}{|c|}{$\begin{array}{l}\text { Little Goose } \\
\text { Dam }\end{array}$} & \multicolumn{2}{|c|}{$\begin{array}{l}\text { Lower Monumental } \\
\text { Dam }\end{array}$} \\
\hline & & Actual & $t_{2}$ & Actual & $\mathbf{t}_{3}$ & Actual & $\mathbf{t}_{4}$ \\
\hline \multirow{4}{*}{1997} & $\overline{\mathrm{RAPH}}$ & 4,135 & 5,365 & 132 & 1,618 & 38 & 949 \\
\hline & MCCA & 5,851 & 7,428 & 105 & 2,241 & 31 & 1,153 \\
\hline & DWOR & 1,864 & 2,351 & 52 & 970 & 15 & 517 \\
\hline & IMNA & 2,074 & 2.603 & 45 & 954 & 12 & 487 \\
\hline \multirow{4}{*}{1998} & RAPH & 11,279 & 15,274 & 1,359 & 7,578 & 197 & 3,100 \\
\hline & MCCA & 8,988 & 12,178 & 896 & 6,970 & 157 & 3,073 \\
\hline & DWOR & 11,096 & 14,350 & 3,574 & 9,326 & 225 & 3,887 \\
\hline & IMNA & 4.036 & 5.621 & 606 & 3.749 & 97 & 1.354 \\
\hline \multirow{4}{*}{1999} & RAPH & 7,385 & 9,488 & 4,724 & 12,750 & 290 & 3,818 \\
\hline & MCCA & 4,730 & 6,374 & 4,986 & 10,584 & 203 & 3,515 \\
\hline & DWOR & 4,930 & 6,346 & 3,798 & 14,602 & 484 & 5,304 \\
\hline & IMNA & 2.160 & 2.785 & 2.293 & 5.129 & 114 & 1.428 \\
\hline & RAPH & 10,367 & 14,386 & 4,181 & 6,123 & 1,213 & 1,625 \\
\hline \multirow[t]{4}{*}{2000} & MCCA & 8,496 & 11,734 & 2,821 & 4,086 & 776 & 1,279 \\
\hline & DWOR & 9,805 & 13,399 & 4,911 & 7,206 & 2,030 & 2,539 \\
\hline & IMNA & 3,862 & 5,447 & 1,812 & 2,705 & 530 & 713 \\
\hline & RAPH & 15,385 & 28,122 & 2,846 & 5,874 & 582 & 1,076 \\
\hline \multirow[t]{5}{*}{2001} & MCCA & 13,093 & 27,575 & 2,643 & 5,119 & 500 & 892 \\
\hline & DWOR & 16,567 & 28,345 & 4,091 & 8,490 & 639 & 1,177 \\
\hline & IMNA & 5,734 & 10,629 & 1,604 & 3,380 & 246 & 483 \\
\hline & $\mathrm{CATH}$ & 3.375 & 7.356 & 1.096 & 2.143 & 195 & 373 \\
\hline & RAPH & 5,339 & 8,475 & 5,312 & 8,852 & 572 & 8,534 \\
\hline \multirow[t]{5}{*}{2002} & MCCA & 4,284 & 6,729 & 4,140 & 6,951 & 200 & 7,305 \\
\hline & DWOR & 4,088 & 6,417 & 4,348 & 7,274 & 734 & 9,673 \\
\hline & IMNA & 1,616 & 2,531 & 1,953 & 3,271 & 194 & 2,814 \\
\hline & CATH & 1,464 & 2,286 & 1,112 & 1,826 & 50 & 1,586 \\
\hline & RAPH & 8,391 & 12,925 & 3,887 & 6,115 & 574 & 874 \\
\hline \multirow[t]{4}{*}{2003} & MCCA & 8,334 & 13,604 & 4,242 & 7,094 & 866 & 1,391 \\
\hline & DWOR & 7,031 & 10,747 & 4,345 & 6,926 & 1,113 & 1,695 \\
\hline & IMNA & 3,094 & 4,764 & 1,557 & 2,547 & 299 & 464 \\
\hline & $\mathrm{CATH}$ & 1,564 & 2,416 & 698 & 1,141 & 176 & 291 \\
\hline \multirow{2}{*}{$\begin{array}{l}\text { Migr } \\
\text { Year }\end{array}$} & Hat. & \multirow{2}{*}{\multicolumn{2}{|c|}{ Lower Granite }} & \multirow{2}{*}{\multicolumn{2}{|c|}{$\begin{array}{l}\text { Little Goose } \\
\text { Dam }\end{array}$}} & \multirow{2}{*}{\multicolumn{2}{|c|}{ Lower Monumental }} \\
\hline & Code $^{A}$ & & & & & & \\
\hline \multirow{5}{*}{2004} & RAPH & 13,511 & 21,806 & $\frac{\text { Actual }}{5,271}$ & $\frac{t}{8,775}$ & $\frac{\text { Actual }}{550}$ & $\frac{t}{946}$ \\
\hline & MCCA & 16,455 & 28,896 & 3,877 & 6,879 & 251 & 439 \\
\hline & DWOR & 12,725 & 20,489 & 8,154 & 13,623 & 552 & 888 \\
\hline & IMNA & 4,754 & 7,583 & 1,916 & 3,230 & 162 & 292 \\
\hline & CATH & 2,078 & 3,292 & 700 & 1,181 & 73 & 188 \\
\hline \multirow{5}{*}{2005} & RAPH & 15,736 & 24,756 & 3,990 & 6,876 & 205 & 538 \\
\hline & MCCA & 17,268 & 27,350 & 4,510 & 7,685 & 411 & 780 \\
\hline & DWOR & 14,606 & 23,686 & 5,447 & 9,503 & 431 & 1,010 \\
\hline & IMNA & 4,452 & 6,831 & 1,361 & 2,130 & 65 & 220 \\
\hline & CATH & 1,903 & 2.998 & 526 & 903 & 25 & 103 \\
\hline \multirow{5}{*}{$2006^{\mathrm{B}}$} & RAPH & 8,355 & 20,371 & 6,993 & 18,741 & 2,567 & 8,106 \\
\hline & MCCA & 6,017 & 8,102 & 4,756 & 7,462 & 2,165 & 3,808 \\
\hline & DWOR & 4,363 & 12,799 & 6,323 & 19,870 & 2,765 & 9,998 \\
\hline & IMNA & 1,975 & 2,839 & 2,342 & 3,861 & 722 & 1,350 \\
\hline \multirow{2}{*}{\multicolumn{2}{|c|}{ Average percent }} & 1,186 & 1.583 & 1,129 & 1.727 & 408 & 704 \\
\hline & & & $57 \%$ & & $31 \%$ & & $12 \%$ \\
\hline
\end{tabular}

${ }^{\mathrm{A}}$ Abbreviations: RAPH = Rapid River H; MCCA = McCall H; DWOR = Dworshak NFH;

$\mathrm{IMNA}=$ Imnaha AP; CATH $=$ Catherine Ck AP.

B Migration year 2006 is incomplete until 3-salt returns at GRA.

${ }^{\mathrm{C}}$ Average percentage of total transported population occurring at each Snake River dam. 
Table A-37. Estimated dam-specific transportation SAR percentages of PIT-tagged hatchery Spring Chinook that outmigrated in 1997 to 2006 (with 90\% confidence intervals).

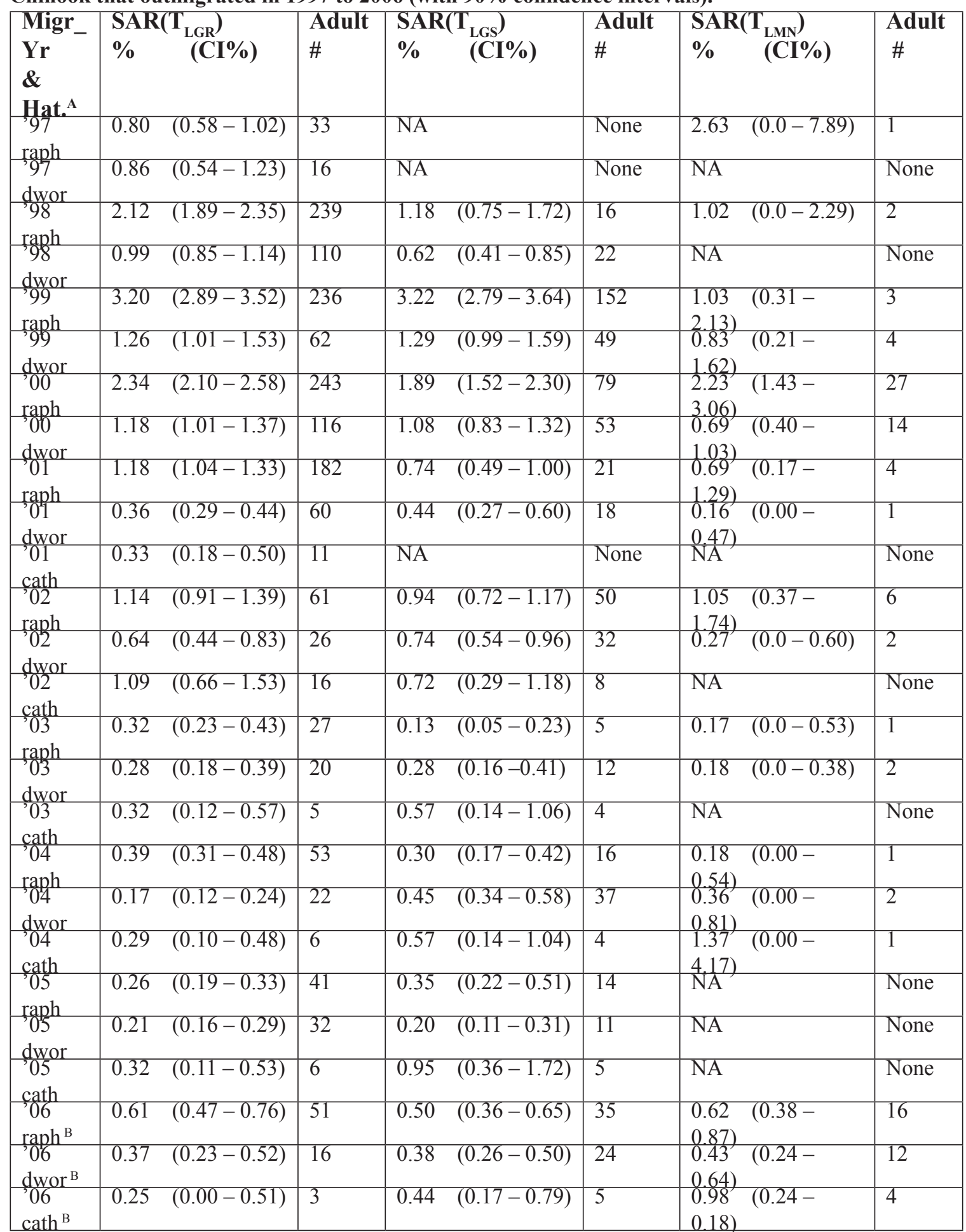

${ }^{\text {A }}$ Abbreviations: $r a p h=$ Rapid River H; dwor=Dworshak NFH; cath=Catherine Ck AP.

B Migration year 2006 is incomplete until 3-salt returns at GRA. 
Table A-38. Estimated dam-specific transportation SAR percentages of PIT-tagged hatchery Summer Chinook that outmigrated in 1997 to 2006 (with 90\% confidence intervals).

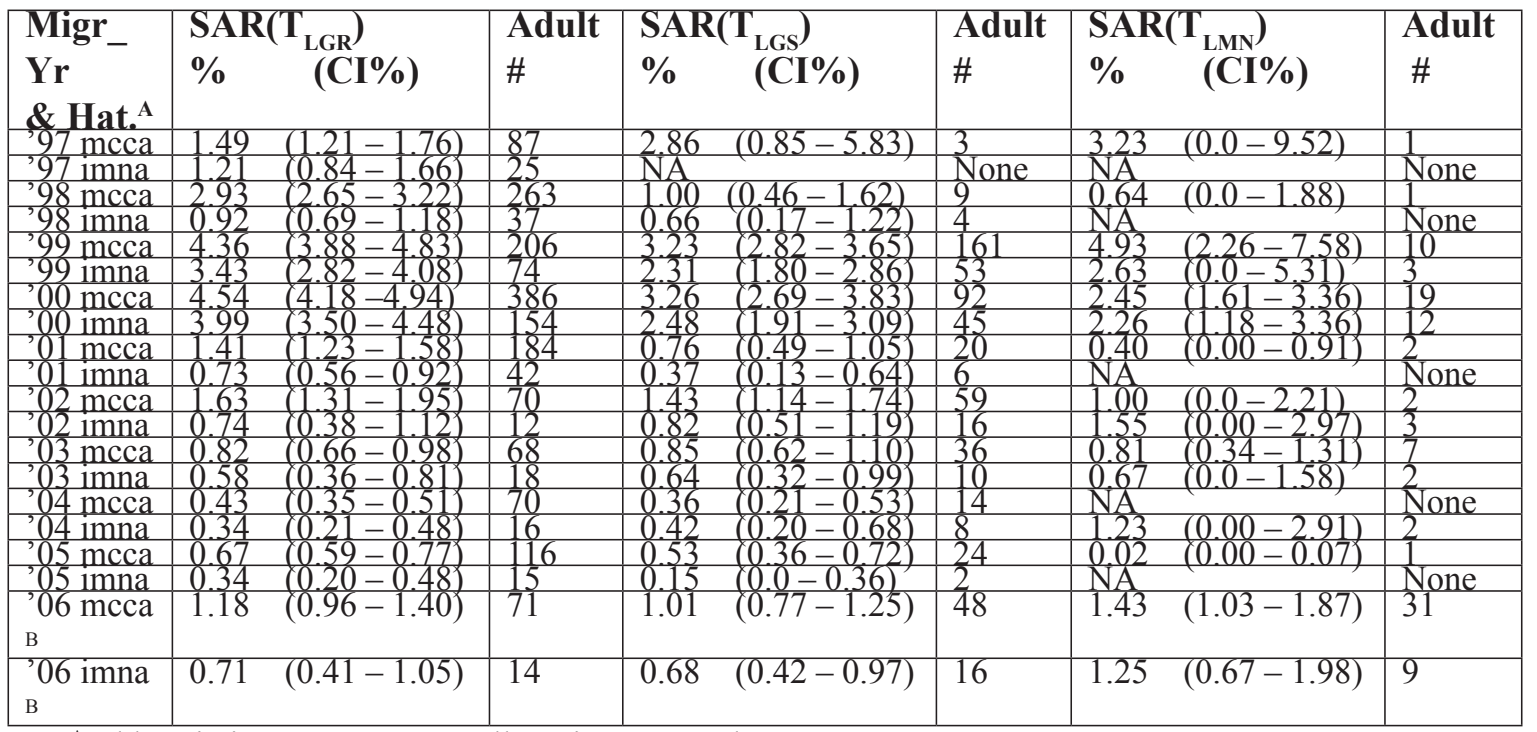

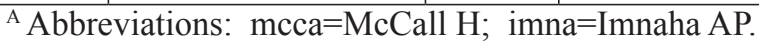

${ }^{\text {B }}$ Migration year 2006 is incomplete until 3-salt returns at GRA.

Table A-39. Number of PIT-tagged wild steelhead actually transported from each dam and estimate $\left(t_{i}\right)$ of total PIT-tagged wild steelhead that would have been transported if all PIT- tagged fish had been transported at same rate as the untagged run-at-large.

\begin{tabular}{|c|c|c|c|c|c|c|}
\hline \multirow{2}{*}{$\begin{array}{l}\text { Migr } \\
\text { Year }\end{array}$} & \multicolumn{2}{|c|}{ Lower Granite Dam } & \multicolumn{2}{|c|}{ Little Goose Dam } & \multicolumn{2}{|c|}{$\begin{array}{l}\text { Lower Monumenta } \\
\text { Dam }\end{array}$} \\
\hline & Actual & $t$ & Actual & & Actual & \\
\hline 1997 & & & 2 & & 26 & 184 \\
\hline 1998 & 294 & 4,246 & 100 & 64 & 68 & 595 \\
\hline 1999 & 223 & 2,910 & 90 & 3.134 & 67 & 1.129 \\
\hline 2000 & 200 & 6,264 & 89 & 2.643 & 110 & 971 \\
\hline 2001 & 162 & 11.126 & 23 & 833 & & 139 \\
\hline 2002 & $\frac{128}{1215}$ & 3,804 & 62 & 2,896 & 135 & 2.154 \\
\hline$\frac{2003}{2004}$ & $\frac{1}{3,215}$ & $\frac{4,705}{0,500}$ & $\frac{655}{807}$ & $\frac{2,958}{2,168}$ & $\frac{227}{158}$ & $\frac{991}{438}$ \\
\hline 2005 & 3,516 & 9.811 & $\frac{0.133}{1,133}$ & 2944 & $\frac{100}{76}$ & $\frac{438}{166}$ \\
\hline Avera & ent ${ }^{A}$ & $67.8 \%$ & & $23.8 \%$ & & $8.4 \%$ \\
\hline
\end{tabular}

A Average percentage of total transported population occurring at each Snake River dam.

Table A-40. Estimated dam-specific transportation SAR percentages of PIT-tagged wild steelhead in the annual aggregate groups for 1997 to 2005 (with $90 \%$ confidence intervals).

\begin{tabular}{|c|c|c|c|c|c|c|}
\hline $\begin{array}{l}\text { Migr } \\
\text { Year }\end{array}$ & $\begin{array}{l}\text { SAR(T } \\
\text { LGR }\end{array}$ & Adult & $\begin{array}{l}\text { SAR(T } \\
\text { LGS }\end{array}$ & Adult & $\begin{array}{l}\text { SAR(T } \\
\text { LMN }\end{array}$ & $\begin{array}{l}\text { Adults } \\
\#\end{array}$ \\
\hline 1997 & $(0.47-3.59)$ & $\pi$ & $\mathrm{NA}$ & None & NA & None \\
\hline 998 & $(0.0-1.00)$ & & $\mathrm{NA}$ & None & & None \\
\hline 1999 & $(0.98-4.65)$ & 6 & $(1.12-8.43)$ & 4 & $(0.0-7.04)$ & \\
\hline 2000 & $(1.51-5.64)$ & $\frac{1}{5}$ & $(0.0-6.86)$ & 3 & $(0.74-5.36)$ & \\
\hline$\frac{2001}{2002}$ & $\frac{(.16-5.59)}{(.55-6.82)}$ & $\frac{5}{5}$ & $(0.0-4.92)$ & None & $(0.65-4.41)$ & $\frac{\text { None }}{3}$ \\
\hline 2003 & $15-2.40$ & 21 & -3.85 & 18 & $(0.84-4.07)$ & 5 \\
\hline$\frac{2004}{2005 \mathrm{~A}}$ & $(0.66-1.19)$ & 31 & $(0.37-1.40)$ & 1 & $(0.0-1.90)$ & \\
\hline $2005^{\mathrm{A}}$ & $0.94(0.67-1.22)$ & 33 & $(0.26-1.04)$ & 7 & ) & None \\
\hline
\end{tabular}

${ }^{A}$ Migration year 2005 is incomplete until 3-salt returns (if any) occur at GRA after 7/1/2008. 
Table A-41. Number of PIT-tagged hatchery steelhead actually transported from each dam and estimate $\left(t_{i}\right)$ of total PIT-tagged hatchery steelhead that would have been transported if all PITtagged fish had been transported at same rate as the untagged run-at-large.

\begin{tabular}{|c|c|c|c|c|c|c|}
\hline $\begin{array}{l}\text { Migr } \\
\text { Year }\end{array}$ & \multicolumn{2}{|c|}{$\begin{array}{l}\text { Lower Granite } \\
\text { Dam }\end{array}$} & \multicolumn{2}{|c|}{$\begin{array}{l}\text { Little Goose } \\
\text { Dam }\end{array}$} & \multicolumn{2}{|c|}{$\begin{array}{l}\text { Lower Monumental } \\
\text { Dam }\end{array}$} \\
\hline & Actua & & Actual & & Actual & \\
\hline 1997 & & 122,445 & 104 & $1^{3}, 128$ & & \\
\hline 1998 & 795 & $\frac{13.080}{9.69}$ & $\frac{358}{291}$ & $\frac{4.264}{8.845}$ & 157 & 27 \\
\hline 2000 & $\begin{array}{l}179 \\
399 \\
\end{array}$ & 14.023 & $\frac{291}{73}$ & $\begin{array}{l}0,045 \\
2.091\end{array}$ & 921 &, 402 \\
\hline 2001 & 331 & 17.696 & 43 & 950 & 16 & 205 \\
\hline 2002 & 124 & 4,951 & 64 & 4.101 & 79 & 4.278 \\
\hline 2003 & 2,068 & 6.459 & 1.510 & 4.817 & 829 & 2,730 \\
\hline$\frac{2004}{2005}$ & & 12,430 & $\frac{87}{105}$ & 2,828 & 13 & 259 \\
\hline$\frac{2005}{\text { Averas }}$ & $\frac{632}{\text { cent }}$ & 11,906 & 195 & 4,096 & 35 & 296 \\
\hline Avera & $\operatorname{cent}^{\mathrm{A}}$ & $67.7 \%$ & & $21.9 \%$ & & $10.4 \%$ \\
\hline
\end{tabular}

${ }^{\mathrm{A}}$ Average percentage of total transported population occurring at each Snake River dam.

Table A-42. Estimated dam-specific transportation SAR percentages of PIT-tagged hatchery steelhead in the annual aggregate groups for 1997 to 2005 (with $90 \%$ confidence intervals).

\begin{tabular}{|c|c|c|c|c|c|c|}
\hline $\begin{array}{l}\text { Migr } \\
\text { Year }\end{array}$ & $\begin{array}{l}\left.\text { SAR(T } \text { TGR }_{\text {L }}\right) \\
\%\end{array}$ & Adult & $\begin{array}{l}\operatorname{SAR}\left(\mathrm{T}_{\text {LGS }}\right) \\
\%\end{array}$ & Adult & $\begin{array}{l}\text { SAR(T } \\
\% \%\end{array}$ & Adult \\
\hline & 0.59 & $\frac{\pi}{9}$ & & None & & None \\
\hline 1998 & $(0.24-1.13)$ & 5 & $(0.0-0.84)$ & & $(0.0-1.91)$ & \\
\hline 1999 & $(0.50-1.69)$ & 8 & $(0.34-2.57)$ & 4 & & Vone \\
\hline 2000 & $(1.74-4.56)$ & 14 & $(0.0-3.90)$ & & $(0.0-3.09)$ & \\
\hline$\frac{2001}{2002}$ & $(0.30-2.32)$ & $\frac{4}{3}$ & NA & None & NI & None \\
\hline 2002 & $\frac{(0.70-4.93)}{(1.49-2.49)}$ & 3 & NA & None & $(059-186)$ & None \\
\hline 004 & $(0.58-2.83)$ & $\frac{41}{6}$ & $(1.31-2.10)$ & $\frac{32}{4}$ & $(0.59-1.80)$ & None \\
\hline $2005^{\mathrm{A}}$ & $(1.43-3.43)$ & $\frac{15}{15}$ & $(0.0-2.29)$ & 2 & $2.86(0.0-8.82)$ & \\
\hline
\end{tabular}

${ }^{\mathrm{A}}$ Migration year 2005 is incomplete until 3-salt returns (if any) occur at GRA after 7/1/2008. 


\section{Appendix B}

\section{CSS Planned PIT-tagging Activity for 2009 and Assessment of Sample Size Requirements}

\section{A. Goals and Objectives}

The Comparative Survival Rate Study (CSS) is a multi-year research project (entering its $14^{\text {th }}$ year of operation) conducted by the fishery agencies and tribes to measure the smolt-to-adult survival rates (SARs) of hatchery and wild spring/summer Chinook and steelhead from representative sites in the Snake River basin. An interagency CSS Oversight Committee oversees the design, execution, and analysis of this study.

A foundational goal of the CSS is obtaining annual estimates of SARs for Snake River hatchery and wild spring/summer Chinook (hereafter, Chinook) and steelhead through the two primary migration pathways: transportation and in-river migration. Estimation of the SARs of fish that are transported and those that migrate entirely inriver is essential for evaluating the avoidance of jeopardy as well as progress towards recovery goals. Through the consistent monitoring of SARs across years, the overall magnitude and the inter-annual variation of SARs can be estimated, forming key inputs for population viability analyses as well as allowing for comparison to management targets. Another goal of the CSS has been to develop long-term indices of SAR ratios between transported and in-river fish. A common comparison, termed the "Transport:Inriver" ratio, or TIR, is the SAR of transported fish divided by the SAR of in-river fish, with SARs being estimated for smolts passing Lower Granite Dam (LGR) and returning as adults back to LGR (LGR-LGR SARs). Estimates of TIR address the management question of whether transportation is beneficial or detrimental to smolt-to-adult survival, compared to leaving smolts to migrate in-river, under the hydrosystem as currently configured. Finally, the groups tagged by the CSS also are used to monitor juvenile passage metrics such as travel time, survival, and passage timing distributions as well as adult passage metrics such as upstream migration success and straying rates. Both the estimates of SARs and in-river survival rates for reaches between monitored dams provide data useful for evaluating smolt mitigation measures such as flow augmentation, spill, and transportation for the recovery of listed salmon stocks.

To satisfy these broad goals, the CSS is designed to address the following objectives: (i) estimate smolt-to-adult survival rates (SAR) for transported wild and hatchery yearling Chinook and steelhead; (ii) determine if SAR rates are significantly different from the interim SAR hydro goal established by the Northwest Power and Conservation Council; and (iii) estimate transport/control ratios and in-river survival rates for wild and hatchery yearling Chinook and steelhead concurrently over a number of years in order to assess biological responses over a wide range of environmental conditions.

The CSS accomplishes objectives (i) and (ii) by estimating SARs for Snake River basin wild and hatchery Chinook and steelhead that are transported and those that 
migrated in-river to below Bonneville Dam (BON). The CSS accomplishes objective (iii) by estimating TIRs and estimating in-river survival rates, which are then used to evaluate smolt mitigation measures such as flow augmentation and spill.

In addition to the CSS study objectives described above, the current experimental design for hatchery steelhead will allow the region to meet three additional objectives important to the Lower Snake River Compensation Program (LSRCP), the U.S. Fish and Wildlife Service (USFWS), and the National Marine Fisheries Service (NMFS): 1) it will allow estimation of the total number of LSRCP (and Idaho Power Company and Dworshak) hatchery steelhead returns to the Columbia River (in conjunction with CWT's) for the first time; 2) it will allow the evaluation of return success (adult return per smolt) to the LSRCP project area (above Ice Harbor/LGR) of various stocks and release location for the first time; and 3) it will provide timing and survival data for B run (and A run) steelhead from Bonneville to McNary for use in evaluating fishing impacts, which is a critical element in managing the Zone 6 fishery under the ESA (previous analysis indicates little difference between survival of wild and hatchery B run steelhead through this area). These are very important aspects of the LSRCP, Federal ESA, and Tribal trust responsibilities and are the reason why the LSRCP program is urging participation by all the parties and is willing to contribute to the CSS effort.

\section{B. Sample size determination}

This section addresses the determination of study group sample sizes for the CSS. The sample sizes used in the CSS reflect tradeoffs between the tagging levels desired for statistical precision, and several practical constraints that often limit the sample sizes that can be achieved. There are limitations of availability and trap collection efficiency that affect the sample sizes for both wild steelhead and wild Chinook. The numbers of fish that can be physically captured via traps, safely handled, and are allowable for capture with permits are all factors that are difficult to control and sample sizes are near the maximum possible at some locations. Hatchery steelhead have been, in past years due to a lack of funding, a group that was marked only to a minimal extent. Only recently have sample sizes increased for hatchery steelhead. Other factors that can affect sample sizes for hatchery Chinook include hatchery constraints on marking and coordinating with other marked groups. A goal of the CSS has been to work within these constraints to maximize statistical precision to the greatest degree possible. Tools for accomplishing this include increasing the number of tagged fish through coordination efforts and altering the number of collected fish diverted to transportation or back to the river.

For a given sample size, several factors affect the level of statistical precision that is achieved. Variation in survival rates, hydrosystem operations, and detection probabilities all affect the precision of the juvenile survival, SAR, and TIR estimates calculated within the CSS. Due to these factors, the precision achieved can vary substantially across years, even if similar numbers of tagged fish are released across years.

To assess the levels of precision achieved within the CSS, we present and summarize estimates of the coefficient of variation (CV, a measure of statistical precision) for the three major metrics calculated in the CSS: in-river survival from LGR-BON $\left(\mathrm{S}_{\mathrm{R}}\right)$, SARs for the $\mathrm{T}_{0}$ and $\mathrm{C}_{0}$ passage groups, and the TIR. Detailed descriptions of the methods used to calculate these metrics are provided in the CSS 10-year Retrospective Summary Report (Schaller et al. 2007).

Over the 1994-2004 migration years analyzed within the Schaller et al. (2007), release group sample sizes have ranged from 7,700 to 103,000 tagged fish, with an 
average release group sample size of 40,500. Figures B-1, B-2, and B-3 present the estimated CVs across release group sample sizes for $\mathrm{S}_{\mathrm{R}}$, the $\mathrm{T}_{0}$ and $\mathrm{C}_{0} \mathrm{SARs}$, and the TIR.

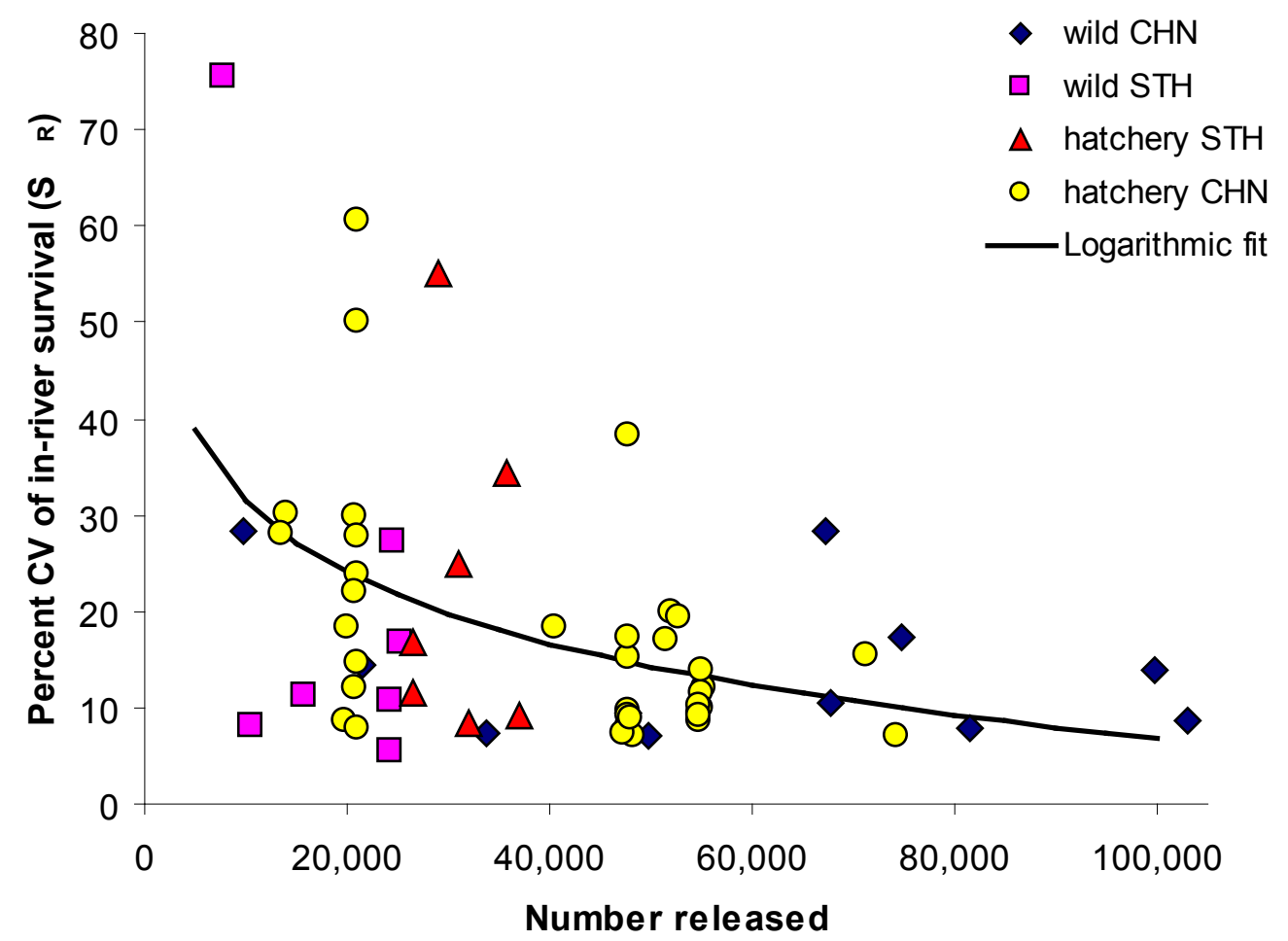

Figure B-1. Percent coefficient of variation $(C V)$ in LGR-BON survival $\left(S_{R}\right)$ for wild and hatchery steelhead and Chinook over migration years 1994-2004 analyzed in the CSS. The solid line depicts a logarithmic fit to the data, $\mathrm{CV}\left(\mathrm{S}_{\mathrm{R}}\right)=129.7-10.7 \log _{\mathrm{e}}($ Release $)$.

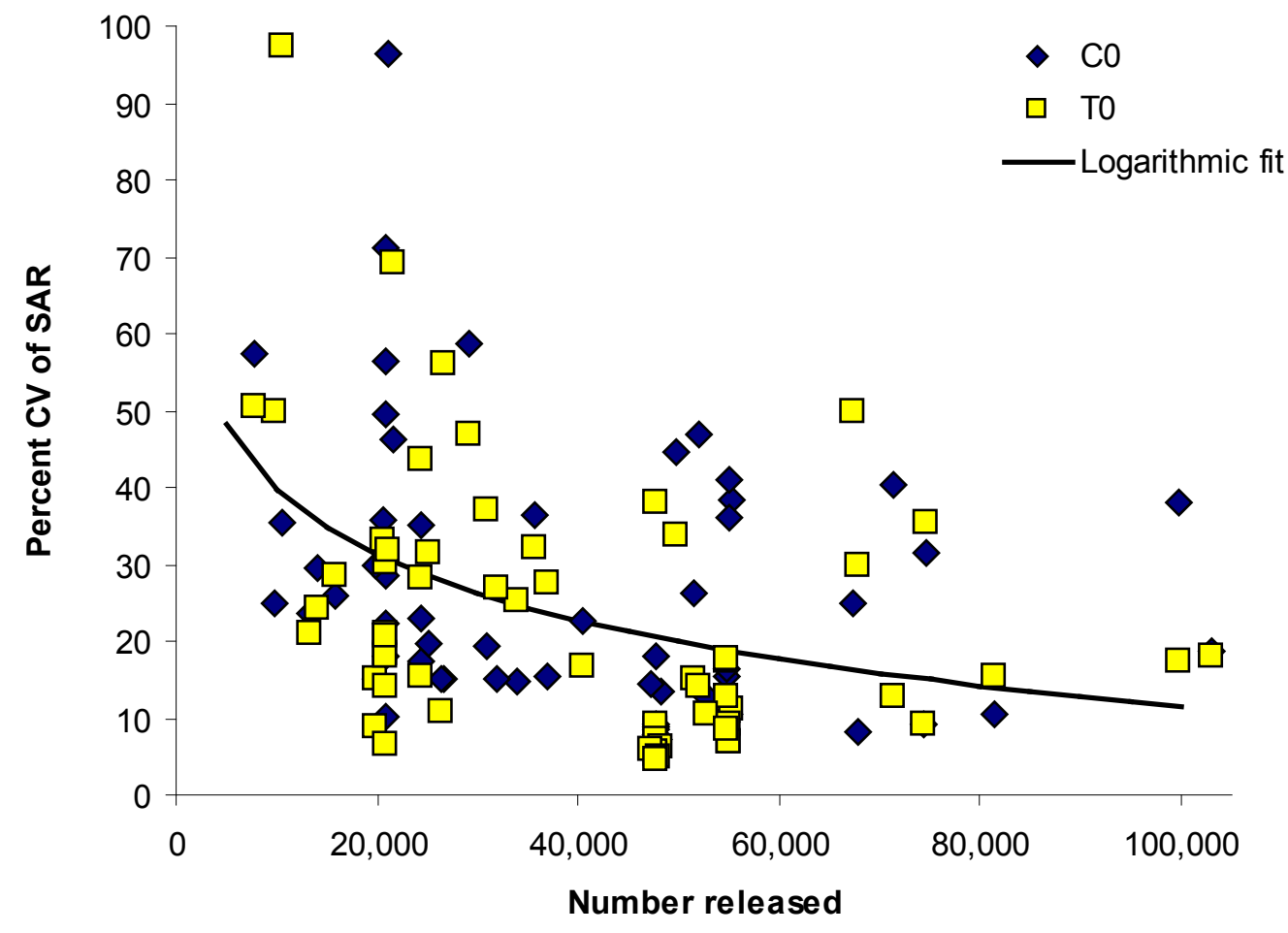

Figure B-2. Percent coefficient of variation (CV) for SARs of C0 and T0 migration groups for wild and hatchery steelhead and Chinook over migration years 1994-2004 analyzed in the CSS. The solid line depicts a logarithmic fit to the data, $\mathrm{CV}(\mathrm{SAR})=152.8-12.3 \log _{\mathrm{e}}$ (Release). 


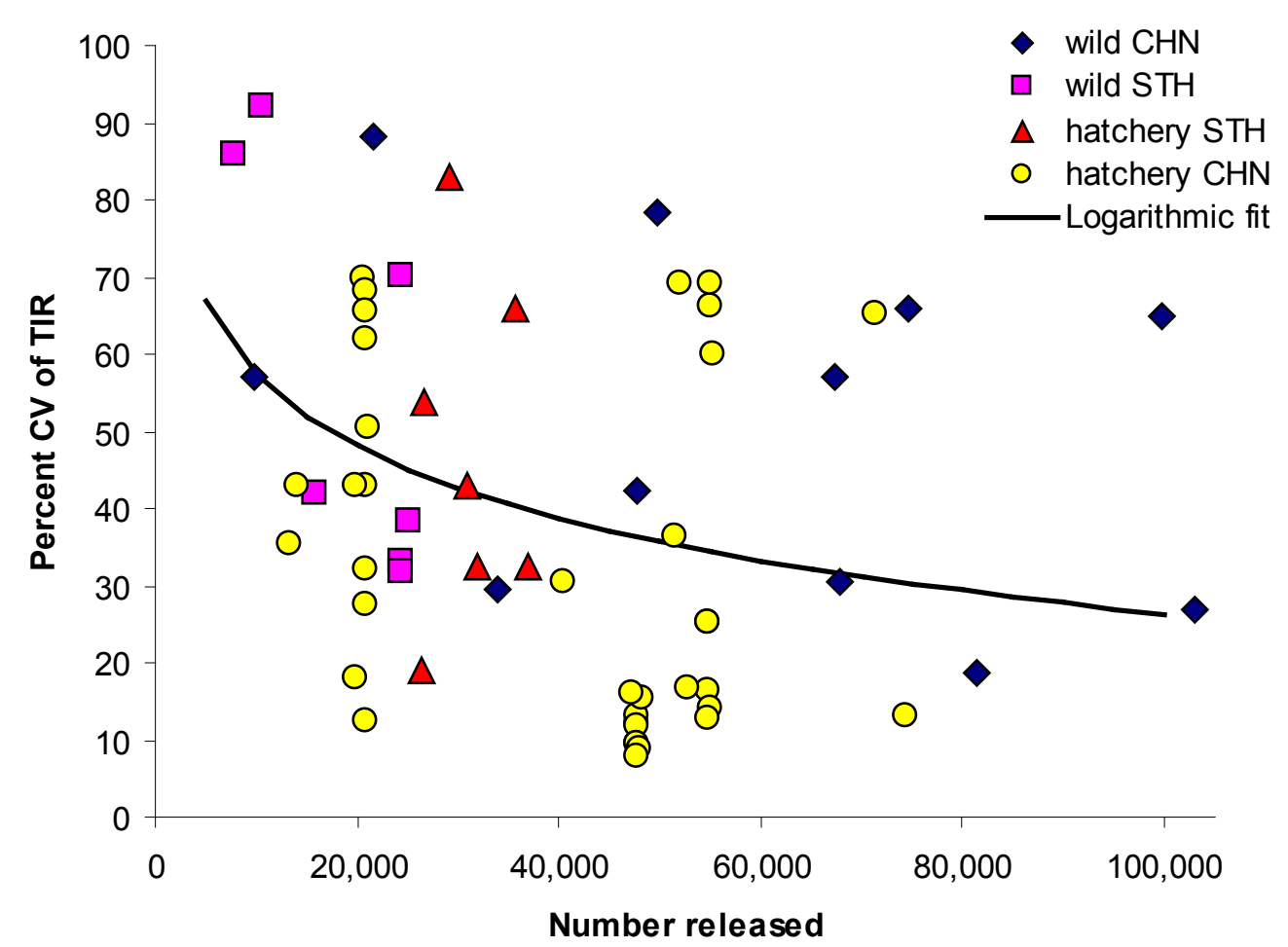

Figure B-3. Percent coefficient of variation (CV) for the TIR of wild and hatchery steelhead (STH) and Chinook (CHN) over migration years 1994-2004 analyzed in the CSS. The solid line depicts a logarithmic fit to the data, CV(TIR) $=181.8-13.5 \log _{\mathrm{e}}($ Release $)$.

Table B-1. Average percent coefficient of variation (CV) in the $S_{R}$, SARs, and TIR based on logarithmic fits of $C V$ versus the number released over migration years 1994-2004 analyzed in the CSS.

\begin{tabular}{rccc} 
Release & $S_{R}$ & SAR & TIR \\
\hline 10,000 & 31 & 40 & 57 \\
20,000 & 24 & 31 & 48 \\
30,000 & 20 & 26 & 43 \\
40,000 & 17 & 23 & 39 \\
50,000 & 14 & 20 & 36 \\
60,000 & 12 & 18 & 33 \\
70,000 & 11 & 16 & 31 \\
80,000 & 9 & 14 & 29 \\
90,000 & 8 & 13 & 28 \\
100,000 & 7 & 11 & 26
\end{tabular}

As expected, CVs for all three metrics declined with increasing sample size (Figures B-1-3, Table B-1). Within sample sizes, there was substantial variability in the $\mathrm{CVs}$, reflecting the large amount of variation in survival rates, hydrosystem operations, and detection probabilities that occurred over migration years 1994-2004. Of the three metrics, TIRs had the least precision with high variability in $\mathrm{CVs}$, even at the largest sample sizes. Based on visual inspection, CVs for the SARs were similar within sample sizes for the $\mathrm{T}_{0}$ and $\mathrm{C}_{0}$ migration routes (Figure B-2). Similarly, no patterns were apparent in the CVs for $\mathrm{S}_{\mathrm{R}}$ and TIR within samples sizes for hatchery versus wild and steelhead versus Chinook comparisons (Figures B-1, B-3). For a sample size of 20,000 
fish, average CVs were $24 \%, 31 \%$, and $48 \%$ for $\mathrm{S}_{\mathrm{R}}, \mathrm{SARs}$, and TIR (Table B-1). For a sample size of 50,000 fish, average CVs declined to $14 \%, 20 \%$, and $36 \%$. At the largest sample sizes of 100,000 fish, average CVs declined further to $7 \%, 11 \%$, and $26 \%$.

\section{Sample sizes for testing the TIR parameter}

As described above, the CSS provides a long-term data series of transport $\left(\mathrm{T}_{0}\right)$ and in-river $\left(\mathrm{C}_{0}\right)$ SARs, from which the TIR is calculated. This parameter is commonly used to addresses the question of whether transportation provides an overall benefit or detriment to transported smolts as compared to smolts that migrated in-river. When this value is greater than one, then transportation did provide an overall benefit and when less than one it did not.

We are interested in reliable estimates of the TIR and the ability to statistically detect when the TIR is truly greater than one at individual hatcheries. The desired estimate, in probabilistic terms, will be able to detect a true case of a TIR greater than one $90 \%$ of the time (statistical power or $1-\beta$ ) with a $5 \%$ risk of falsely accepting a TIR greater than one (the $\alpha$ ). A statistically significant TIR $>1$ occurs when the lower limit of the non-parametric 90\% confidence interval is above 1 (denoted in Tables 3.8 and 3.9 of Chapter 3 for hatchery Chinook).

The ideal sample size for marked groups are often based on requiring $\sim 8500$ smolts at LGR or 85 returning adults to LGR (assuming a 1\% SAR for 8500 smolts). This was based on using a sample size needed to test for a $50 \%$ difference between two binomial proportions when the smaller of the two equaled 1\%. Assuming independence between samples and binomially distributed SARs, the equation for minimum smolt sample size, $\mathrm{N}$, in each study group to be compared is:

$$
N=\left(Z_{\alpha}+Z_{\beta}\right)^{2} \times\left(p_{1} q_{1}+p_{2} q_{2}\right) \div\left(p_{2}-p_{1}\right)^{2}
$$

Here, the quantity $\left(Z_{\alpha}+Z_{\beta}\right)^{2}=8.6$ under a one-tail test with Power $=1-\beta=0.90$ and $\alpha=0.05$ (Snedecor and Cochran, 1989, Statistical Methods, $8^{\text {th }}$ edition). With the smaller of the two SARs generally occurring with Group $\mathrm{C}_{0}$ rather than $\mathrm{T}_{0}$, the goal of achieving a minimum of 85 returning adults in $\mathrm{C}_{0}$ was realized in 8 cases in Table 2; in each case a statistically significant TIR was obtained. Other cases with statistically significant TIRs occurred had either TIR point estimates greater than 1.5, or lower than 1.5 but with higher $\operatorname{SAR}\left(\mathrm{C}_{0}\right)>1 \%$.

The sample size required to detect a statistically significant TIR can be affected by both the number of adults that return in the lower valued SAR and the magnitude of the difference between the TIR and one. Using formula B.1, the required sample size for various situations can be calculated. The sample size needed to detect a statistical difference in a higher and lower valued SAR in four different cases is shown in Figure B-4. In the figure, each line represents a different magnitude in the difference between SARs. The red data point is the case where the TIR ratio is 1.5, and the in-river SAR is $1 \%$. The number of smolts needed for the in-river SAR would be 8488 (and therefore $\sim 85$ adults). Note that this sample size represents the number of smolts at LGR or the number of adults returning to LGR (the CSS measures LGR-LGR SARs); all of the smolts marked at each hatchery do not survive to LGR (Table B-3). Also, as either the difference between two SARs or the value of the lower SAR decrease, then the required sample size increases at a nonlinear rate. So in general, very large sample sizes are required to detect very small differences between SARs or when the lower valued SAR is 
small.

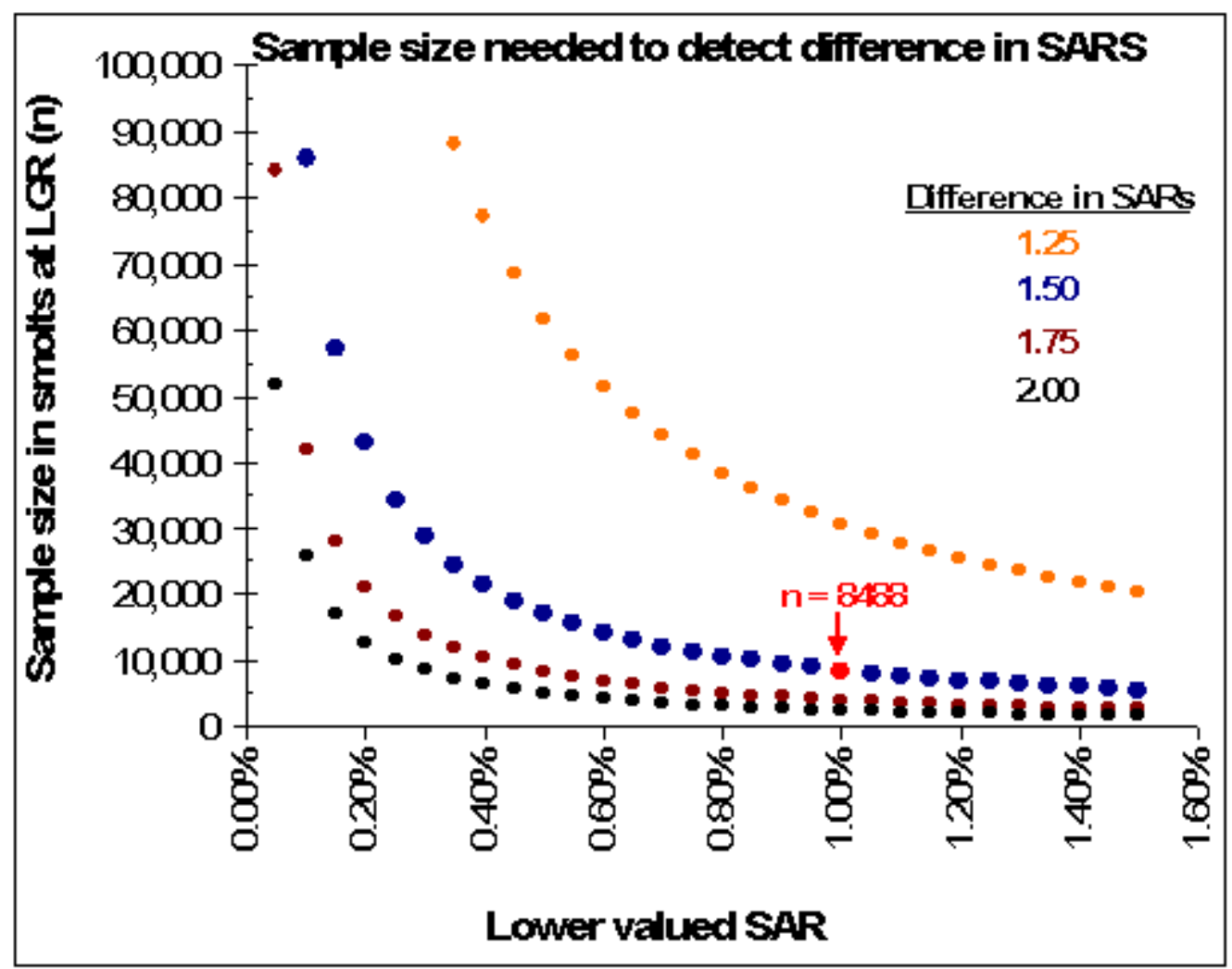

Figure B-4. Sample size needed to detect a statistical difference in SARs (a one tailed test where $\alpha=$ $0.05)$. The $x$ axis is the value of the lower of the two SARs tested. The number of smolts required at $L G R$ is shown on the $\mathbf{y}$ axis. Each colored line displays a different magnitude in difference between two SARs.

\section{Study Design with Fish Sources and PIT-Tag Quotas}

In the CSS study, the wild and hatchery fish are implanted with a PIT (Passive Integrated Transponder) tag, which allows unique identification of each fish. The tagged fish are assigned to transportation and bypass groups using the protocol developed by Nez Perce Tribe for sub-basin evaluations. With this protocol a fixed proportion of the tagged fish will be placed in a group to reflect the current transportation operations at collector dams (Group TWS - transport with spill provided) and the remaining fish will be placed in a group to reflect a bypass operation at collector dams (Group BWS - bypassed with spill provided). Group TWS fish will directly reflect what happens to the untagged runat-large, while Group BWS fish will reflect what would happen if all collected fish were bypassed back to the river instead of being transported. For most wild and hatchery Chinook and steelhead stocks, $70 \%$ of the tagged fish will be randomly assigned to the TWS group. The BWS group will allow the estimation of in-river juvenile survival rates from release to LGR and within reaches of the hydrosystem between LGR and BON, using the CJS methodology. The returning PIT-tagged adults will be detected at BON, MCN, ICH, and LGR. Returns to the hatchery rack of the CSS PIT-tagged hatchery Chinook will be adjusted for any terminal sport and tribal harvest to provide an estimate of total return to the hatchery.

For the 2009 migration year, the CSS plan is to PIT tag 52,000 Chinook at each of Rapid River, Dworshak, and McCall hatcheries. In the fall of 2009, the CSS plan is to PIT tag 21,000 tags each at the Imnaha River and Catherine Creek acclimation facilities 
for the 2010 migration year (Table B-2).

Table B-2. Wild Chinook/steelhead and hatchery Chinook smolts to tag for CSS 2009 program.

\begin{tabular}{|l|l|l|c|}
\hline Organization & \multicolumn{1}{|c|}{ Tagging Site } & $\begin{array}{c}\text { Species and } \\
\text { rearing type }\end{array}$ & \# PIT tags \\
\hline IDFG & Rapid R Hatchery & H Ch & 52,000 \\
& McCall Hatchery & H Ch & 52,000 \\
& Salmon R. Trap & W Ch & 5,000 \\
& Snake R. Trap & W Ch & 2,000 \\
& Clearwater R. Trap & W Ch; W St & 5,200 \\
& Other IDFG tributary traps & W Ch & $14,500^{\mathrm{A}}$ \\
\hline ODFW & Lookingglass Hatchery & & \\
& • Imnaha R. release & H Ch & $21,000^{\mathrm{B}}$ \\
& • Catherine Ck. release & H Ch & $21,000^{\mathrm{B}}$ \\
& Grande Ronde R. Trap & W Ch & 1,400 \\
\hline USFWS & Dworshak NFH & H Ch & 52,000 \\
\hline
\end{tabular}

${ }^{\mathrm{A}}$ Cost for PIT tags only to complement on-going wild Chinook PIT tagging efforts in Idaho.

${ }^{\text {B }}$ Fish to be PIT tagged in September 2009 for the 2010 migration.

In 2009, the CSS plan is to continue PIT tagging upwards of 11,600 wild Chinook at the Salmon, Snake, Clearwater, and Grande Ronde River traps, plus 2,000 wild steelhead at the Clearwater River (Table B-2). It will also provide 14,500 PIT tags for IDFG researchers to augment ongoing wild Chinook tagging in the upper tributaries of the Clearwater and Salmon Rivers. In addition, the CSS will utilize wild Chinook and steelhead tagged by organizations participating in the pre-assignment of tagged fish to transport and bypass routes of passage at the collector dams, including Idaho Department of Fish and Game (IDFG), Oregon Department of Fish and Wildlife (ODFW), Nez Perce Tribe, Confederated Tribes of the Umatilla Reservation, and Shoshone-Bannock Tribes.

In 2009, the CSS plan is to PIT tag 77,000 hatchery steelhead to complement the LSRCP's tagging of steelhead at LSRCP hatcheries making release above Lower Granite Dam (i.e., Irrigon, Lyons Ferry, Clearwater, Magic Valley, and Hagerman hatcheries), plus USFWS' tagging of steelhead at Dworshak Hatchery (which also is being done in cooperation with the LSRCP study), and to improve the tagging effort at Niagara Springs Hatchery (a non-LSRCP hatchery owned by Idaho Power Company [IPC], and operated by IDFG).

In 2008, the CSS received only enough funding to cover the PIT-tagging of a total of 34,000 hatchery steelhead at Clearwater, Magic Valley, Hagerman, and Dworshak hatcheries to complement the tagging efforts underway at those hatcheries. The allocation of CSS tags across these hatcheries was in direct proportion to the numbers being tagged by the LSRCP/USFWS programs. In 2008, the CSS provided approximately $30 \%$ of the total tags released from the above four hatcheries. Production fish tagged for the LSRCP/USFWS programs were routed at the collector dams in a manner identical to the untagged hatchery steelhead collected at these dams. Therefore, $100 \%$ of their PIT-tagged fish were routed to the raceways for transportation whenever transportation was occurring (forming the TWS group). The CSS tagging complemented the other PIT-tagging activities by providing a group of tagged fish that would be returned-to-river at each collector dam throughout the season (forming the BWS group) in order to provide estimates of in-river survival rates and the population of PIT-tagged hatchery steelhead arriving LGR, which is used in the LGR-to-LGR smolt-to-adult survival rate (SAR) estimation. The CSS tagged steelhead provides the opportunity to make comparative analyses between transported and bypassed fish, as well as fish not detected at the transportation sites.

In coordination with LSRCP, USFWS, and IPC, the 2009 CSS plan is to PIT- 
tag 35,000 steelhead at the same hatcheries it covered in 2008, plus add 42,000 tags to steelhead at those hatcheries where CSS tagging did not take place in 2008 due to budgetary shortfalls (Table B-3). The goal is to make the allocation of CSS tags across these hatcheries directly proportional to the numbers being tagged by the LSRCP/ USFWS programs. The CSS tagged fish would augment the existing tagging programs to allow formation of the BWS groups, with 9,000 tags for Dworshak Hatchery, 26,000 tags for the Clearwater, Magic Valley, and Hagerman hatcheries, 14,000 tags for Irrigon Hatchery releases in the Grande Ronde and Imnaha Rivers, and 4,000 tags for Lyons Ferry Hatchery release in the Grange Ronde River (latter covering both the 2009 and 2010 outmigrants). For IPC's Niagara Springs Hatchery, the CSS proposes to PIT-tag 24,000 steelhead with 70\% (16,800 fish) forming the TWS group and 30\% (7,200 fish) forming the BWS group (Table B-3).

Table B-3. Hatchery steelhead smolts to tag for CSS 2009 program.

\begin{tabular}{|c|c|c|}
\hline Organization & $\begin{array}{c}\text { Tagging Site } \\
\end{array}$ & \#PT tags \\
\hline $\mathrm{IDFG}$ & Magic Valley, Hagerman, Clearwater Hatchery & $26,000^{\circ}$ \\
\hline & Niagara Snrings Hatcherv & 24.000 \\
\hline ODFW & Irrigon Hatchery & \\
\hline & - Imnaha River release & 7,000 \\
\hline & - Grande River release & 7.000 \\
\hline USFWS & Dworshak NFH & 9,000 \\
\hline WDFW & Lyons Ferry Hatchery ${ }^{1}$ & \\
\hline & - Cottonwood AP 2009 release & 2,000 \\
\hline & - Cottonwood AP 2010 release & 2.000 \\
\hline
\end{tabular}

${ }^{1}$ Fish to be PIT-tagged in September 2008 for 2009 release and September 2009 for 2010 release.

Historical data for hatchery Chinook (pre-2006)

Here, we will present historical estimates of the TIR parameter and whether they had required precision to detect a TIR greater than one. The estimated TIRs for hatchery Chinook (1997 to 2004) are shown in Tables 3-8 and 3-9 from Chapter 3. Migration years 2001 and 2005 had little to no spill and therefore would not be representative of what is reasonably expected for future years. The TIRs from 1997-2000, and 20022004 provide 7 years with estimates that will be useful for future PIT-tag sample size determinations. These historic years characterize conditions of spill similar to what may be anticipated. It should be noted that transportation operations in these examples spanned the entire spring season, whereas future years may delay transportation until as late as May (this occurred in 2007 \& 2008). However, the differential in SARs between transported and those in-river migrants not detected at a Snake River collector dams (i.e., the TIR) remains useful for planning purposes.

During 1997-2007 and 2002-2004, when the TIR point estimate was 1.25 or less, the estimate was not statistically greater than one. When TIR point estimates was greater than 1.25 (which occur only for the hatchery stocks), there were 23 cases (i.e., yearhatchery datasets) with either a statistically significant or non-significant TIRs depending on the magnitude of $\mathrm{SAR}\left(\mathrm{C}_{0}\right)$ and number of returning adults of Group $\mathrm{C}_{0}$. These 23 
cases are presented in Table B-4 for ease of further investigation.

Table B-4. Hatchery Chinook with TIR point estimates greater than 1.25 sorted by ascending $\operatorname{SAR}\left(\mathrm{C}_{0}\right)$. Statistically significant values greater than 1 are highlighted in red. Blue text denotes the study group $\left(\mathrm{T}_{0}\right.$ or $\left.\mathrm{C}_{0}\right)$ with fewer smolts at $\mathrm{LGR}$.

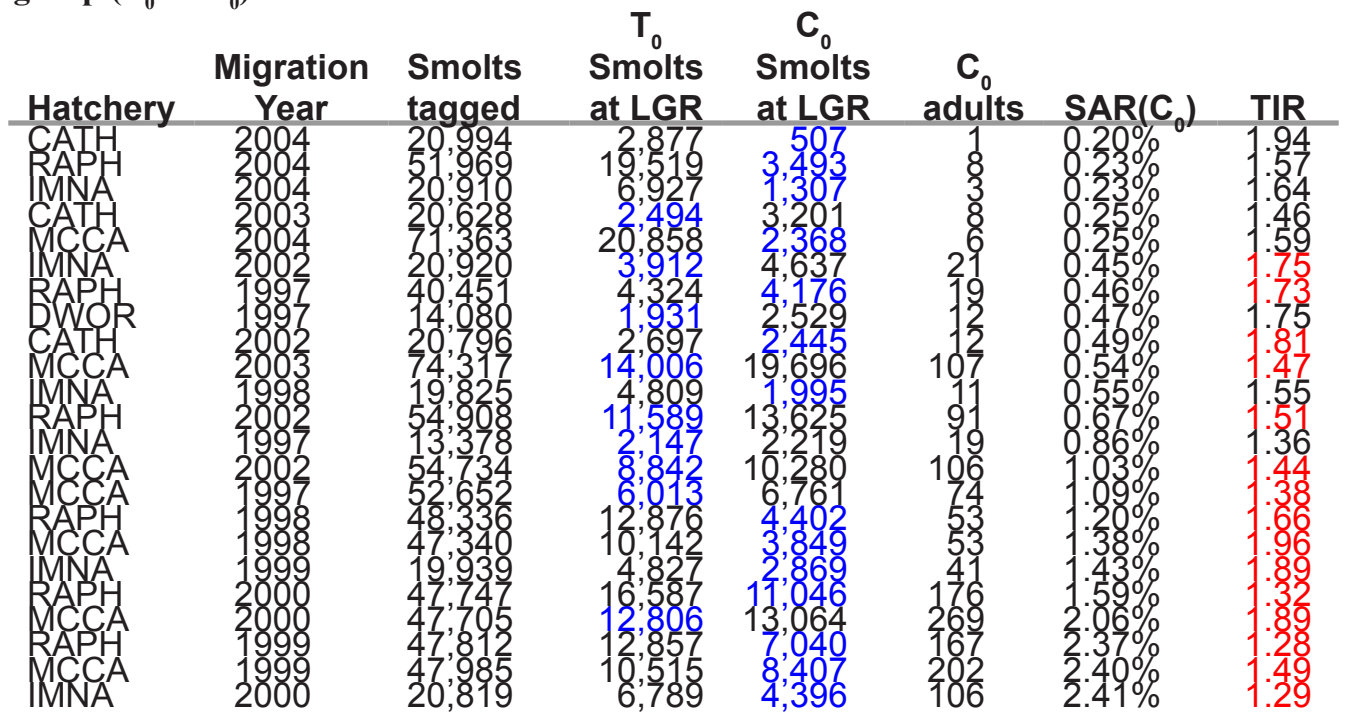

During pre-2006 migration years, the fewest numbers of smolts were often in the $\mathrm{C}_{0}$ category. The historic data summarized in Table B-4 reveals that with $\mathrm{SAR}\left(\mathrm{C}_{0}\right)$ as low as $0.45-0.49 \%$, and high TIR point estimates $(>1.7)$, it was possible to obtain some statistically significant TIRs. As $\mathrm{SAR}\left(\mathrm{C}_{0}\right)$ values rose to $0.54-0.67 \%$, it was possible to obtain statistically significant TIRs when the TIR point estimate was at a more moderate level of around 1.5. When the $\operatorname{SAR}\left(\mathrm{C}_{0}\right)$ values were above $1 \%$ (in 10 cases), all of the TIRs were statistically significant and ranged in point values from 1.28 to 1.96.

The number of smolts to PIT tag for the CSS program at RAPH, DWOR, and MCCA was established between 45,000 (early years) to 52,000 (later years) to achieve a minimum of 85 returning adults (or $\sim 8500$ smolts at LGR with a $1 \% \mathrm{SAR}$ ) for the $\mathrm{T}_{0}$ and $\mathrm{C}_{0}$ study groups that formed the TIR parameter.

The number of PIT tagged smolts at IMNA and CATH has been set at 21,000 because the overall production is much lower than RAPH, DWOR, and MCCA and these two stocks contribute less to the run at large. IMNA and CATH had statistically significant TIRs in 4 cases where either the TIR was relatively high or the number of adults was over 85 .

\section{Hatchery Chinook with pre-assignment (2006-2008)}

As mentioned in the previous section, prior to 2006, transportation occurred over the entire spring season. Transportation was delayed until April in 2006 and until May in 2007 and 2008. It is reasonable to assume this will be the case in years to come. So, fewer fish are expected to be transported than occurred in the historic years. Whereas, Group $\mathrm{C}_{0}$ tended to have fewer smolt numbers at LGR as compared to Group $\mathrm{T}_{0}$ in the historic years, the opposite could be the case when transportation is delayed.

The approach used after the 2005 migration year entails randomly assigning a fixed percentage of fish into two categories. Before migration begins, individuals are selected for the TWS or BWS category, where the TWS fish follow the run-at-large and the BWS fish are default returned to river at the collector dams (i.e. LGR, LGS, LMN). So, the smolts in the "T" study group are primary a subset of the TWS pre-assignment (although some spuriously transported fish may come from BWS). Also because of a 
modification in transport protocol, fish that were previously detected are now transported. This increases the " $T$ " study group by a small amount of fish; we will refer to this as $T_{1}$ instead of the previous protocol's $\mathrm{T}_{0}$ naming.

The current study design measures parameters under a different transport regime than pre-2006 but should retain some continuity with previous migration years. The comparison of SARs for the $\mathrm{T}_{1}$ and $\mathrm{C}_{0}$ should be analogous with old TIR parameter. However, new elements influencing the number of smolts in the $\mathrm{T}_{1}$ include smolt outmigration timing, spill levels, and the percent of marked fish pre-assigned to TWS and BWS categories. Table B-5 summarizes several of these aspects for hatchery Chinook during 2006-2008.

Table B-5. Hatchery Chinook PIT tagged smolts summarized from 2006 to 2008. Total smolts tagged, smolts in study categories, and the $25^{\text {th }}$ and $50^{\text {th }}$ percentile of LGR juvenile detects are shown. Blue text denotes the study group $\left(T_{1}\right.$ or $\left.C_{0}\right)$ with fewer smolts at $L G R$.

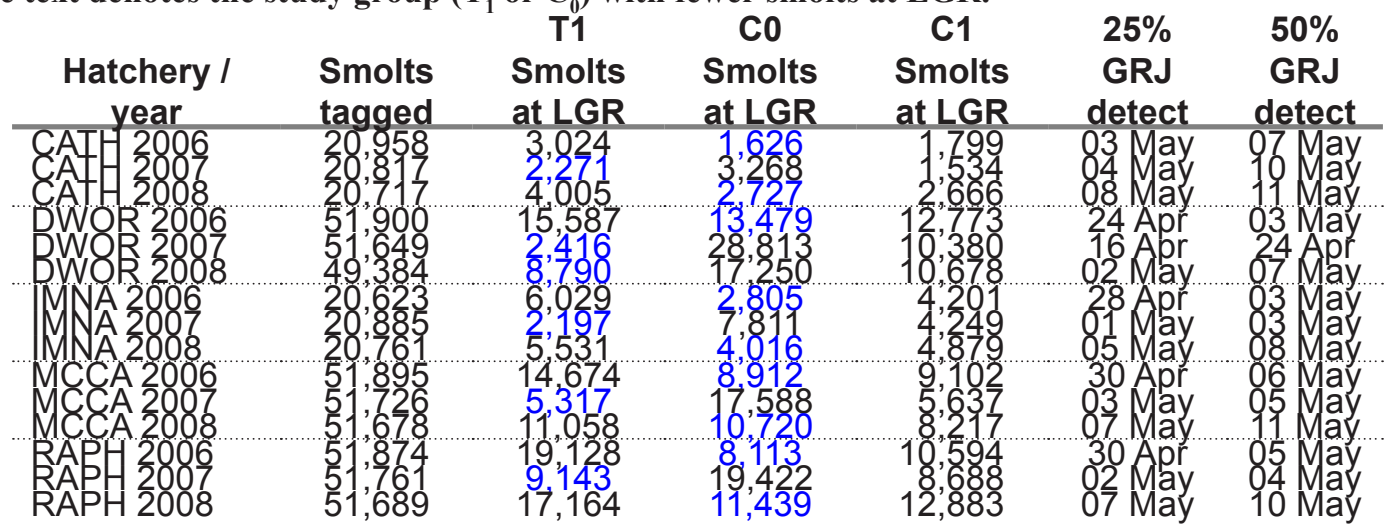

The number of smolts in the $\mathrm{C}_{0}$ group is less often the limiting sample size for TIR type comparisons as compared to pre-2006 years (Table B-4, Table B-5). Although shown here, the number of smolts in each category during 2006 may not be typical of what is expected in coming years as transportation was only delayed until April.

The percentage assigned to TWS changed from $66.6 \%$ to $70 \%$ in migration year 2008 (Table B-6). Concurrent with this change in pre-assignment, the juvenile out-migration was later than in 2007 (Table B-5; $25^{\text {th }}$ and $50^{\text {th }}$ percentile LGR juvenile detection dates). So, the numbers in the $\mathrm{T}_{1}$ and $\mathrm{C}_{0}$ are more evenly distributed in 2008 than in 2007. The exception to this is the more disparate smolt numbers in 2008 at Dworshak; this may be due to the apparent earlier smolt out-migration for Dworshak. However, the change in pre-assignment percentage in 2008 seems to provide the best possible smolt sample size at LGR in most cases.

Balanced with concerns over providing a proper number of smolts at LGR in the $\mathrm{T}_{1}$ group is ensuring that enough smolts are in-river to estimate a precise in-river smolt survival $\left(\mathrm{S}_{\mathrm{R}}\right)$. Figure B-5 summarizes the precision around the $\mathrm{S}_{\mathrm{R}}$ parameter for all years available where $S_{R}$ could be estimated to BON without any expansion. Typically, to estimate CV's below 20\% around the $\mathrm{S}_{\mathrm{R}}$ parameter, 10,000 smolts at LGR are needed in the $\mathrm{C}_{1}$ and $\mathrm{C}_{0}$ categories; for a CV less than $10 \%$, about 20,000 smolts at LGR are needed. Note that in 2007 for Rapid River and Dworshak (the two points to the far right in Figure B-2), in-river Corps of Engineer marked fish were added to test the effects of increasing the in-river sample sizes. Although only two points, greatly increasing the sample size did not markedly affect the precision of the $S_{R}$ estimate. 


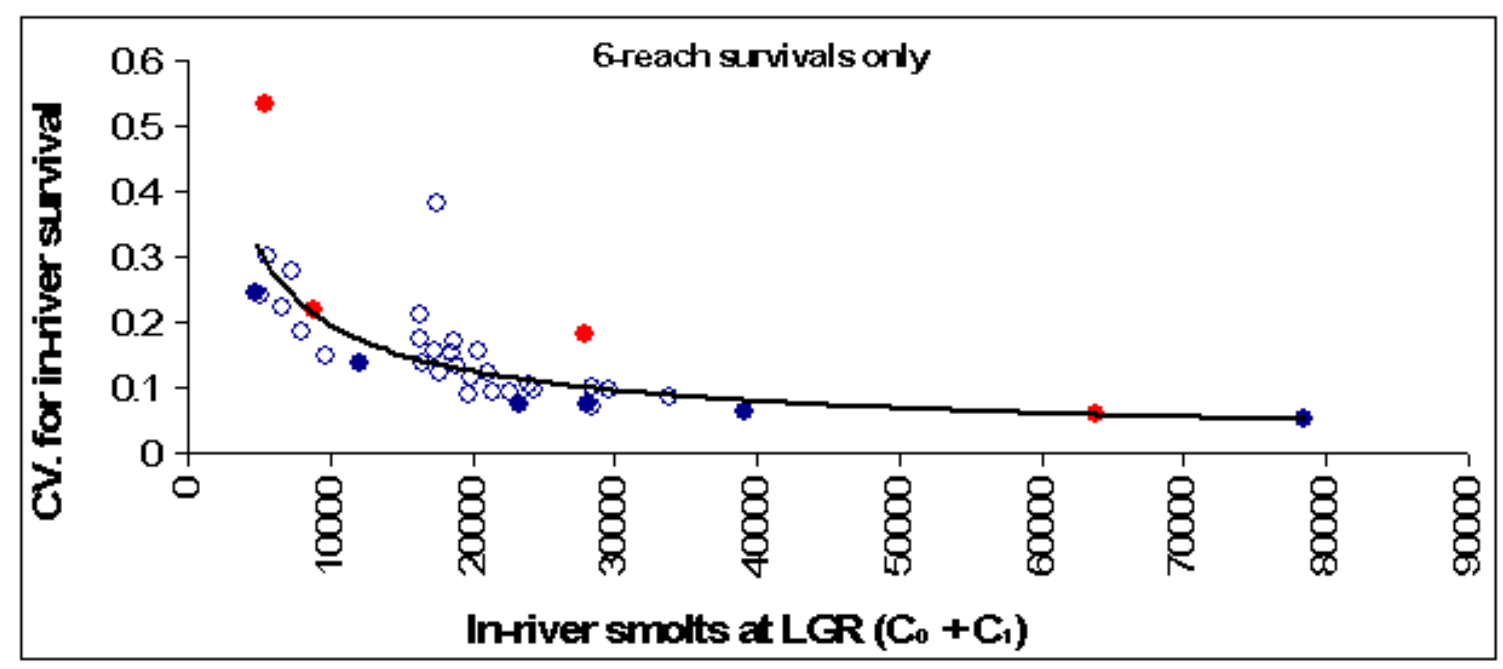

Figure B-5. Coefficient of variation around $S_{R}$ plotted vs. in-river smolt numbers at LGR. All points are for years when $S_{R}$ was estimated from LGR to BON without expansion. Estimates for 2007 (filled blue circles) and 2008 (filled red circles) are preliminary.

The sample size needed for precise estimates of in-river survival and good statistical inference with the TIR parameter can be inferred using the above statistical and observational data. More than 10,000 smolts are needed in the $\mathrm{C}_{1}$ and $\mathrm{C}_{0}$ categories (Figure B-5) for useable in-river survival estimates and a pre-assignment of $70 \%$ to transportation should give an adequate split of smolts between $\mathrm{T}_{1}$ and $\mathrm{C}_{0}$ categories (Table B-5). For TIR inference at CATH and IMNA, the current sample sizes are too low to detect a 1.5 TIR (with a lower SAR of 1\%) but they are adequate for TIRs of 1.75 or 2.00 (or higher values for the lower SAR).

For comparison of SARs for Group TWS (reflecting the current years transport strategy) versus Group BWS (reflecting a non-transportation strategy), Table B-6 shows that a minimum of 8,500 smolts in each group starting at LGR occurs for each hatchery where tagging quotas were set at 52,000 fish (actual release numbers are lower due to pre-release mortalities and tag loss). With release quotas of 21,000 fish for the Imnaha River and Catherine Creek stocks in Oregon, the minimum of 8,500 smolts in each study group at LGR will be more difficult to achieve. Since production levels are much lower at these two hatcheries, increasing release quotas is not an option. The percent of hatchery production of Imnaha stock Chinook being PIT tagged has been close to $5 \%$, which is similar to the level of PIT tagging at Dworshak and McCall hatcheries in 2006 to 2008 for the CSS. Given the very lower production releases of Catherine Creek stock Chinook, the percent of fish being PIT tagged is very high (approximately 18\% in 2008 to $30 \%$ in 2006-2007). Catherine Creek Chinook had the lowest survival rates to LGR in 2006-2008 compared to the other hatchery release group; however, given the distance the Catherine Creek Chinook migrate to LGR, its overall survival rate, when scale on a per $100 \mathrm{~km}$ basis was fairly close to that of the Dworshak and Imnaha releases. So, numbers of Catherine Creek and Imnaha stock Chinook at LGR in the two study groups are seldom likely to achieve the 8,500 smolts minimum goal.

Table B-6. Numbers of PIT tagged smolts released and estimated at Lower Granite Dam in Groups TWS and BWS for hatchery Chinook (2006-2008), wild Chinook (2006-2007), and wild steelhead (2006). BLUE denotes numbers at LGR $<8,500$ fish. 


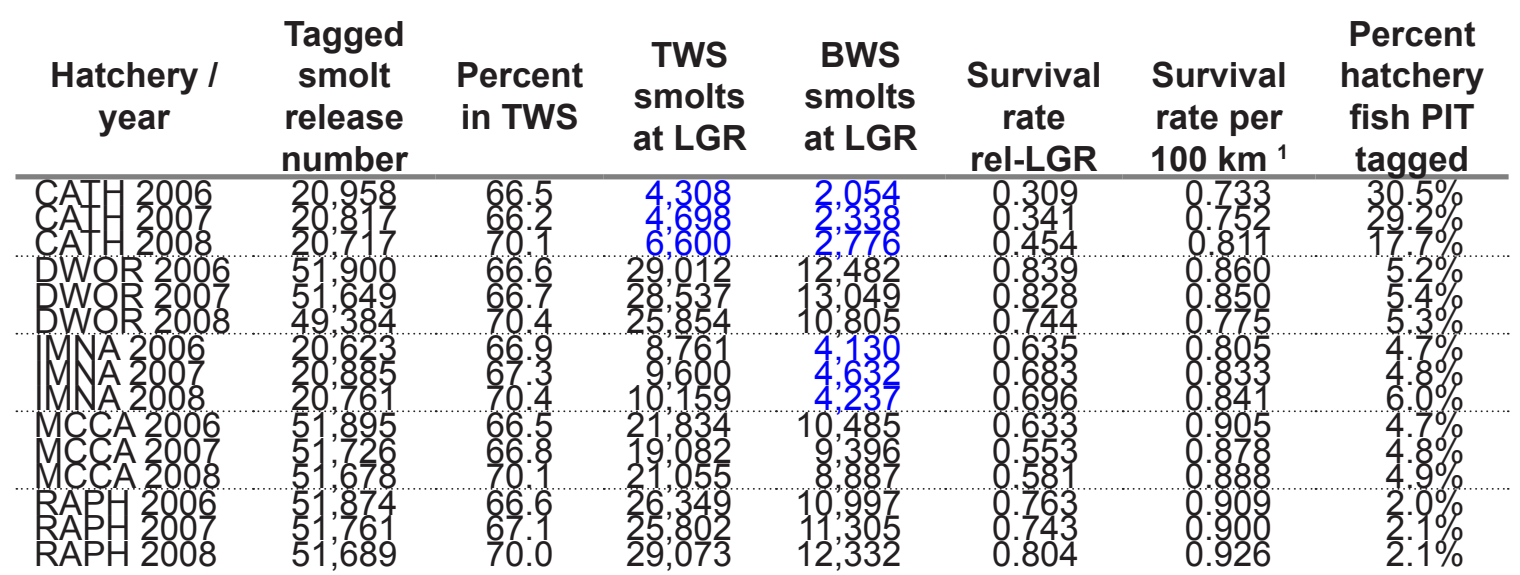

${ }^{1}$ Survival per km is computed as (Survival rate release-LGR)^ $(100 / \mathrm{km}$ release-LGR), where $\mathrm{km}$ are 116 to Dworshak NFH, 209 to Imnaha AP, 283 to Rapid River H, 378 to Catherine Ck AP, and 457 to McCall H.

\section{Hatchery steelhead with pre-assignment (2008)}

Beginning with the 2008 migration year, hatchery steelhead groups are now under the pre-assignment protocol. The CSS coordinated an additional release of 34,000 tags at IDFG and USFWS facilities (Dworshak, Clearwater, Magic Valley, and Hagerman) to create a BWS group to complement the 2008 production releases of PIT-tagged smolts to reflect the untagged smolts experience through the hydrosystem (i.e., TWS-type fish). Table B-7 presents a preliminary result of this coordinated PIT-tagging activity by showing the number of smolts estimated at LGR in the various CSS study categories by drainage and run type for 2008. Because of the differences in outmigration timing between Clearwater River B-run steelhead (earliest), Salmon River A-run steelhead (next), and Salmon River B-run steelhead (latest) as shown in Figure B-6, the desire is to maintain large enough PIT-tag releases by drainage and run type to estimate all parameters uniquely for each of these groups of hatchery steelhead. The planning goal of 8,500 smolts minimum in each study category is not always being met at the level of drainage and run type for 2008, but the overall aggregate has over 25,000 PIT-tagged smolts in each study category. These larger aggregate sample sizes should improve our ability to detect differences in SARs between study categories if "true" differences occur in the population.

Table B-7. Coordinated 2008 PIT-tagging of hatchery steelhead by IDFG, USFWS, and CSS to create TWS and BWS groups of production fish released from Dworshak, Clearwater, Magic Valley, and Hagerman hatcheries. Sample sizes less than 8,500 smolts are highlighted in blue.

\begin{tabular}{|c|c|c|c|c|c|c|c|}
\hline Drainage-run type ${ }^{1}$ & $\begin{array}{c}\text { Tagged } \\
\text { smolt } \\
\text { release }\end{array}$ & $\begin{array}{c}\text { T1 } \\
\text { smolts } \\
\text { at LGR }\end{array}$ & $\begin{array}{c}\text { CO } \\
\text { smolts } \\
\text { at LGR }\end{array}$ & $\begin{array}{c}\text { C1 } \\
\text { smolts } \\
\text { at LGR }\end{array}$ & $\begin{array}{c}\% \text { of } \\
\text { release } \\
\text { in TWS }\end{array}$ & $\begin{array}{c}\text { TWS } \\
\text { smolts } \\
\text { at LGR }\end{array}$ & $\begin{array}{c}\text { BWS } \\
\text { smolts } \\
\text { at LGR }\end{array}$ \\
\hline Clearwater R. & 47,304 & 7,649 & 13,533 & 14,191 & & & \\
\hline B-Run & & & & & 69.9 & 24.767 & 512 \\
\hline Salmon R. B-run & 35,773 & 10,486 & 7,767 & 7,876 & 70.3 & & \\
\hline Salmon R. A-run & 28,146 & 8,339 & 8,629 & & 70.3 & 17,455 & \\
\hline AGGREGATE & 111,223 & 26,474 & 29,929 & 29,879 & 70.1 & 60,608 & 377 \\
\hline \multicolumn{8}{|c|}{ Run type determined based on release location as follows: } \\
\hline \multirow{2}{*}{\multicolumn{8}{|c|}{$\begin{array}{l}\text { All PIT-tag releases in Clearwater River from Dworshak and Clearwater hatcheries are B-run steelhead } \\
\text { PIT-tag releases in Little Salmon River are mixture of A- and B-run steelhead }\end{array}$}} \\
\hline & & & & & & & \\
\hline \multirow{2}{*}{\multicolumn{8}{|c|}{$\begin{array}{l}\text { PIT-tag releases in mainstem Salmon River, Pahsimeroi and Yankee Fork rivers, and Valley Creek are } \\
\text { A-run steelhead, plus the A-run portion of releases in Little Salmon River }\end{array}$}} \\
\hline & & & & & & & \\
\hline \multicolumn{8}{|c|}{ PIT-tag releases in East Fork Salmon River, Slate Creek, and Squaw Creek and Pond are B-run } \\
\hline
\end{tabular}




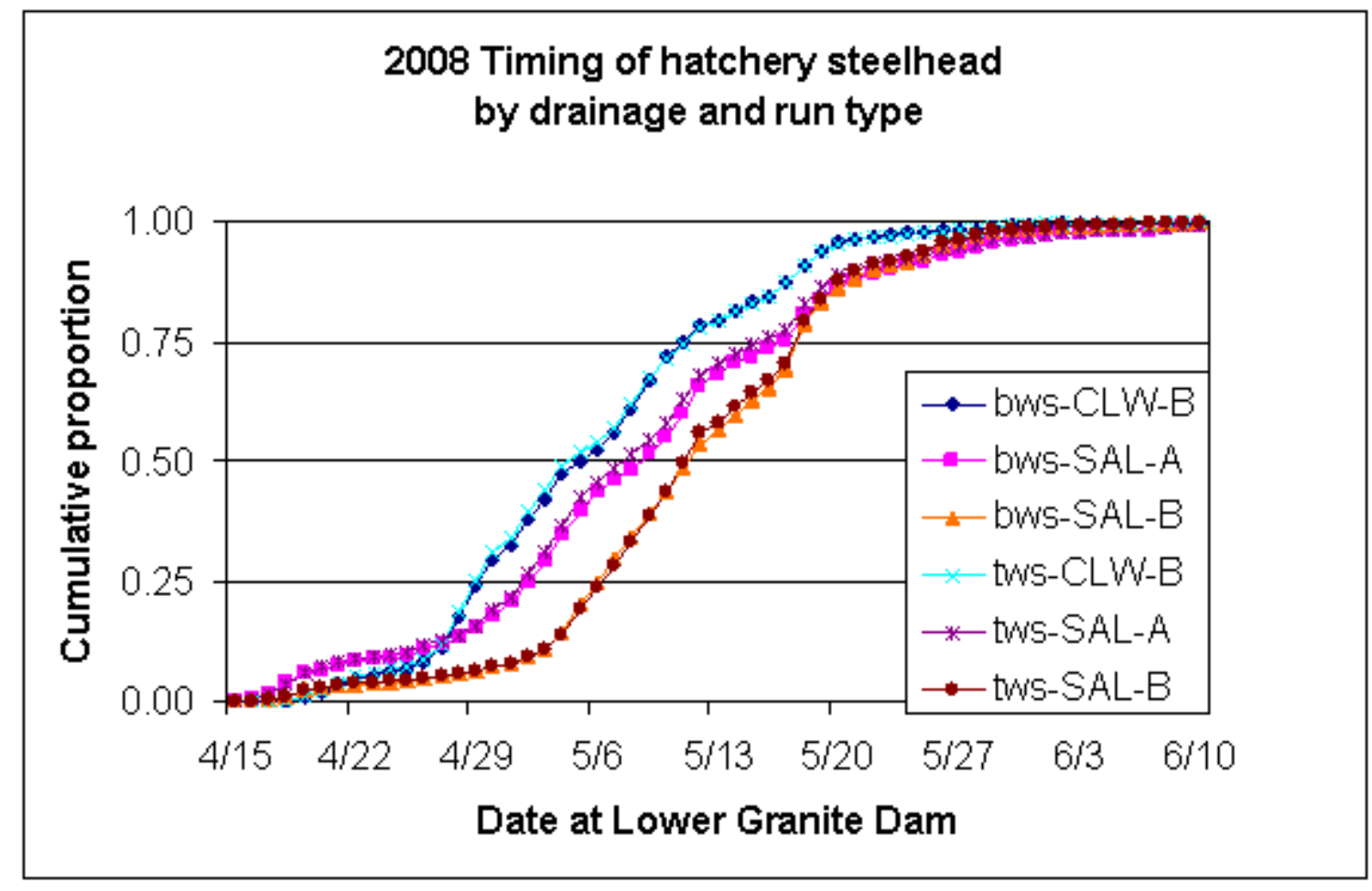

Figure B-6. Timing of PIT-tagged hatchery steelhead at Lower Granite Dam in 2008 that originated in the Clearwater (CLW) and Salmon (SAL) rivers based on run type (A- or B-run). Fish preassigned to study categories TWS and BWS prior to hatchery release, so timing at Lower Granite Dam (first dam encountered) should be nearly identical with only slight random variation, as demonstrated in this plot.

Wild Chinook and steelhead with pre-assignment (2006 - 2007)

The CSS provides PIT-tags to wild Chinook tagging activities that are (i) on-going at Smolt Monitoring Program traps on the Salmon and mainstem Snake rivers operated by IDFG and on the Grande Ronde River operated by ODFW, (ii) on-going at upper tributary traps in the Clearwater and Salmon rivers operated by IDFG, and (iii) specific for the CSS program at a lower Clearwater River trap operated by IDFG. Coordinated with the CSS, but conducted separately, the Nez Perce Tribal researchers pre-assign their own PIT-tagged wild Chinook from the Imnaha River. Having these additional PIT tags to augment the tagging levels of the on-going tagging activities has allowed more smolts to be routed to transportation, whenever the untagged population was being transported at Snake River collector dams, since 2002. Concurrent with the CSS shifting to the preassignment approach in 2006, the timing of transportation was changing at the Snake River collector dams. Table B-8 shows the a large drop in the number of smolts in Group $\mathrm{T}_{1}$ between 2006 and 2007 due largely to the much later start of transportation in 2007 (e.g., 2006 transportation commenced April 20 at LGR, April 24 at LGS, and April 28 at LMN, while 2007 transportation commenced May 1 at LGR, May 8 at LGS, and May 11 at LMN). With a delaying of the transportation season to May, the likelihood of reaching a minimum of 8,500 wild Chinook in the aggregate $\mathrm{T}_{1}$ group will be reduced from that of prior years (e.g., smolts in $\mathrm{T}_{0}>8,500$ in 2003 to 2006, see Table A-5 in this report). However, increasing the number of smolts in $\mathrm{T}_{1}$ by increasing the proportion of fish routed to Group TWS would be counter productive, since the numbers of smolts in Group BWS in 2006 and 2007 were below 8,500 fish. In 2008, the CSS did make some modifications to the proportion being routed to Groups TWS and BWS. It increased the B-13 
proportion to a 70/30 split for IDFG tagging to match the hatchery Chinook and steelhead allocation, but dropped the proportion to 50/50 for ODFW tagging due to their need for more in-river migrates when estimating reach survival rates at the individual stream level.

Table B-8. Numbers of PIT tagged smolts released estimated $T_{1}$ and $\mathrm{C}_{0}$ smolts at Lower Granite Dam, percent of release in Group TWS, and estimate number of smolts at Lower Granite Dam in Groups TWS and BWS for wild Chinook (2006-2007) and wild steelhead (2006) by drainage and overall aggregate. Sample sizes less than 8,500 smolts in aggregates are highlighted in blue.

\begin{tabular}{|c|c|c|c|c|c|c|c|}
\hline Drainage & $\begin{array}{l}\text { Tagged } \\
\text { Smolts } \\
\text { released }\end{array}$ & $\begin{array}{c}T_{1} \\
\text { Smolts } \\
\text { at LGR }\end{array}$ & $\begin{array}{l}C_{0} \\
\text { Smolts } \\
\text { at LGR }\end{array}$ & $\begin{array}{c}C_{1} \\
\text { Smolts } \\
\text { at LGR }\end{array}$ & $\begin{array}{c}\% \text { of } \\
\text { release } \\
\text { in TWS }\end{array}$ & $\begin{array}{c}\text { TWS } \\
\text { Smolts } \\
\text { at LGR }\end{array}$ & $\begin{array}{c}\text { BWS } \\
\text { Smolts } \\
\text { at LGR }\end{array}$ \\
\hline $\begin{array}{l}\text { Çlearwater R } \\
\text { Grande Ronde R. } \\
\text { Imnaha R. } \\
\text { Şalmon R. } \\
\text { Snake R. at }\end{array}$ & $\begin{array}{r}8,678 \\
10,463 \\
1,127 \\
28,998\end{array}$ & $\begin{array}{l}1,146 \\
2,337 \\
4,134 \\
5,134\end{array}$ & $\begin{array}{r}505 \\
900 \\
137 \\
1,652\end{array}$ & $\begin{array}{l}9960 \\
1,959 \\
301 \\
4,543\end{array}$ & $\begin{array}{l}67.1 \\
66.1 \\
83.8 \\
66.5\end{array}$ & $\begin{array}{l}1,783 \\
3,464 \\
7,593\end{array}$ & $\begin{array}{r}0 \\
1,691 \\
121 \\
3,671\end{array}$ \\
\hline $\begin{array}{l}\text { Lewiston Idaho } \\
\text { AGGREGATE } \\
\text { Wid Chinoo }\end{array}$ & $\begin{array}{r}2,639 \\
51,905\end{array}$ & $\begin{array}{r}1,228 \\
10,253\end{array}$ & $\begin{array}{r}299 \\
3,493\end{array}$ & $\begin{array}{r}903 \\
8,692\end{array}$ & $\begin{array}{l}67.6 \\
66.9 \\
\end{array}$ & $\begin{array}{r}1,653 \\
15,208 \\
\end{array}$ & $\begin{array}{r}751 \\
7,091 \\
\end{array}$ \\
\hline $\begin{array}{l}\text { Wild Chinoo } \\
\text { Ǵlearwater Ŕ } \\
\text { Grande Ronde R. } \\
\text { Imnahaha R. } \\
\text { Salmon R. } \\
\text { Snake R. at }\end{array}$ & $\begin{array}{r}2007,07320 \\
3,, 733 \\
11,310 \\
33,228\end{array}$ & $\begin{array}{r}107 \\
461 \\
927 \\
1,423\end{array}$ & $\begin{array}{r}381 \\
3,86 \\
5,901\end{array}$ & $\begin{array}{r}374 \\
557 \\
2,719 \\
4,278\end{array}$ & $\begin{array}{l}66.0 \\
65.8 \\
56.5 \\
66.8\end{array}$ & $\begin{array}{l}\text { 1,78 } \\
4,110 \\
4,763\end{array}$ & $\begin{array}{r}293 \\
6,86 \\
3,814\end{array}$ \\
\hline $\begin{array}{l}\text { Lewiston Idaho } \\
\text { AGGREGATE } \\
\text { Wild Steelhea }\end{array}$ & $\begin{array}{r}54,680 \\
2006\end{array}$ & $\begin{array}{r}102 \\
3,020\end{array}$ & $\begin{array}{r}147 \\
10,598\end{array}$ & $\begin{array}{r}91 \\
8,019\end{array}$ & $\begin{array}{l}67.9 \\
64.9\end{array}$ & $\begin{array}{r}232 \\
13,872\end{array}$ & $\begin{array}{r}107 \\
7,686 \\
\end{array}$ \\
\hline $\begin{array}{l}\text { Ćlearyater Ra } \\
\text { Grande Ronde R. } \\
\text { Imnaha Ra } \\
\text { Salmon Ra } \\
\text { AGGREGATE }\end{array}$ & $\begin{array}{r}08,275 \\
2,053 \\
2,268 \\
3,847 \\
16,443\end{array}$ & $\begin{array}{l}1,512 \\
461 \\
1,396 \\
372 \\
3,741\end{array}$ & $\begin{array}{l}2644 \\
710 \\
70 \\
620\end{array}$ & $\begin{array}{r}2,3633 \\
317 \\
464 \\
442 \\
3,586\end{array}$ & $\begin{array}{l}636.1 \\
62.1 \\
82.2 \\
68.8 \\
68.8\end{array}$ & $\begin{array}{l}2,744 \\
5,716 \\
1,597 \\
5,639\end{array}$ & $\begin{array}{r}1,3334 \\
251 \\
318 \\
2,176 \\
\end{array}$ \\
\hline
\end{tabular}

The CSS conducts PIT-tagging of wild steelhead only at the lower Clearwater River trap in conjunction with its own wild Chinook tagging activity at that trap. All other wild steelhead are provided from on-going tagging activities of other researchers, who allow the CSS to pre-assign a proportion of their tags to Groups TWS and BWS (e.g., Clearwater, Grande Ronde, and Salmon River drainages), or who pre-assign themselves a proportion of their tags to these groups (e.g., Imnaha River drainage). Because of the already low numbers of wild steelhead available for PIT-tagging under existing programs (Table B-8), there are few options for the CSS to provide more tags to increase the numbers of PIT-tagged wild steelhead for use in creating Groups TWS and BWS at this time. 
B-15 